\title{
Phytoplankton Growth and Diel Variations in Beam Attenuation through Individual Cell Analysis
}

by

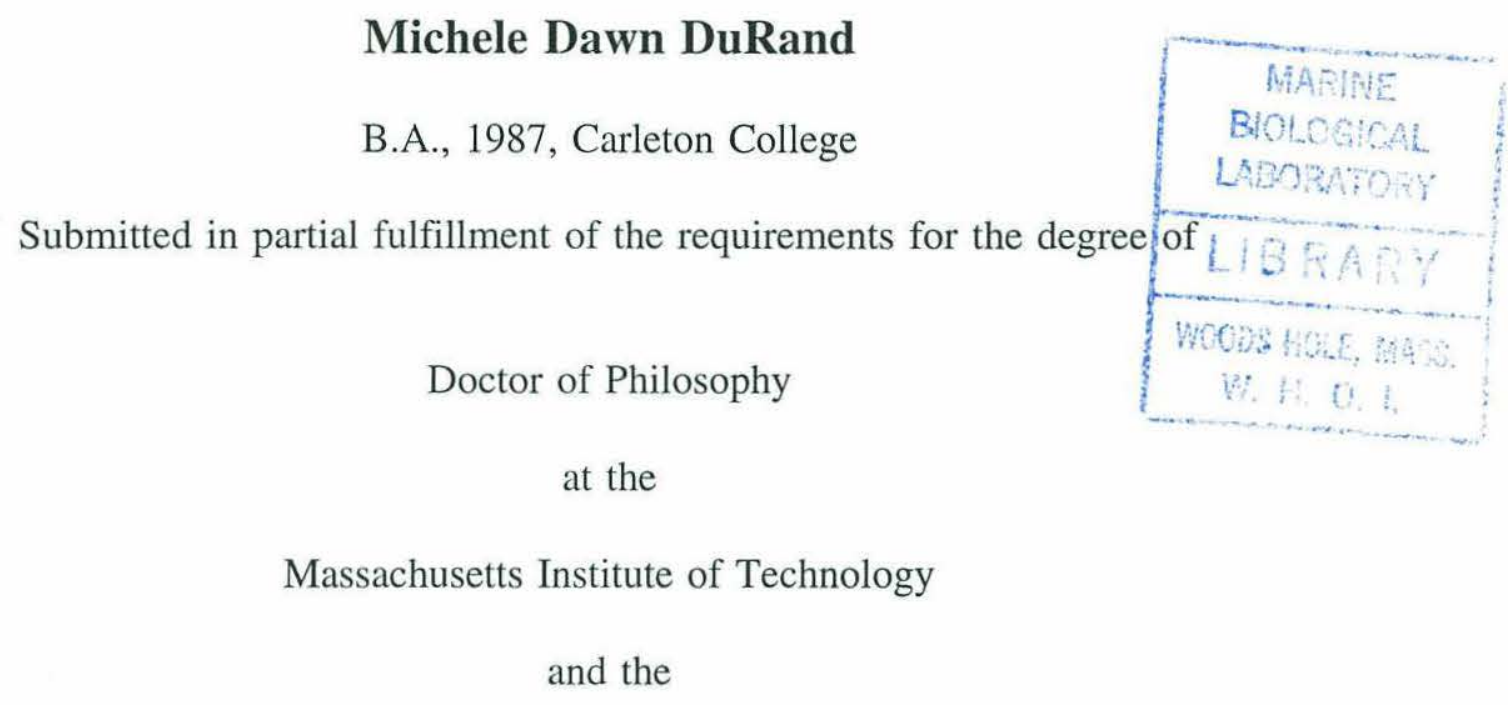

Woods Hole Oceanographic Institution

September 1995

(C) 1995 Michele D. DuRand. All rights reserved.

The author hereby grants to MIT and WHOI permission to reproduce and distribute publicly paper and electronic copies of this thesis document in whole or in part.

Signature of Author

Joint Program in Biological Oceanography Massachusetts Institute of Technology and

Woods Hole Oceanographic Institution

Certified by

Robert J. Olson

Thesis Supervisor

Accepted by

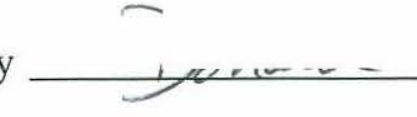

Donald M. Anderson, Chairman

Joint Committee for Biological Oceanography

Massachusetts Institute of Technology and

Woods Hole Oceanographic Institution 


\title{
Phytoplankton Growth and Diel Variations in Beam Attenuation through Individual Cell Analysis
}

by

\section{Michele Dawn DuRand}

Submitted to the Department of Biology in July 1995 in partial fulfillment of the requirements for the Degree of Doctor of Philosophy.

\begin{abstract}
A number of investigators have observed diel variations in the bulk water inherent optical property beam attenuation, with a minimum near dawn and a maximum near dusk, and have assumed them to be caused by the phytoplankton. In an attempt to understand these patterns, mean forward light scatter of different populations of phytoplankton, from flow cytometric analysis of individual cells, was determined and found to show similar diel patterns for populations of pico- and nanophytoplankton measured in the equatorial Pacific and the Sargasso Sea. The cell concentration patterns do not generally correspond to those of beam attenuation. Laboratory experiments, combined with theoretical calculations, were undertaken to attempt to account for the diel variations in beam attenuation observed at sea and to estimate in situ phytoplankton group-specific growth and loss rates.

To investigate how cell growth and division affect the optical properties of phytoplankton, cultures of the chlorophyte Nannochloris sp. were sampled over a diel cycle to measure cell size and concentration, light attenuation and absorption, flow cytometric light scattering (in forward and side directions), and carbon content. In addition, the refractive index was calculated using the anomalous diffraction approximation of Mie theory. At six different light levels ranging from $60-1500$ $\mu$ mol photons $\mathrm{m}^{-2} \mathrm{~s}^{-1}$ (specific growth rates from $\sim 0.2$ to $\sim 0.7 \mathrm{~d}^{-1}$ ), cell division was tightly phased to the light:dark cycle, occurring soon after dark. There were pronounced diel patterns, with a minimum near dawn and a maximum near dusk, in cell size and in cell-specific beam attenuation, absorption, flow cytometric light scatter and carbon. The diel variations in the attenuation cross section were primarily influenced by the changes in cell size due to growth and division, while changes in refractive index had only a small effect. Because eukaryotic cells in the size range of Nannochloris are major constituents of many phytoplankton communities, these results have important consequences for the interpretation of diel variations in optical properties observed in the ocean.

To interpret field data of diel variations in red beam attenuation, the relationships between cell optical properties determined in the laboratory were applied to three diel sampling experiments in the equatorial Pacific and four in the Sargasso Sea. In the equatorial Pacific in April and October 1992, the phytoplankton biomass was dominated by picophytoplankton (Prochlorococcus and Synechococcus), and by mixed populations of ultraphytoplankton (1-2 $\mu \mathrm{m}$ diameter) and nanophytoplankton $(2-20 \mu \mathrm{m}$, mostly $2-3 \mu \mathrm{m})$. Flow cytometric measurements of
\end{abstract}


mean forward light scatter of each of these populations showed typical diel patterns which were similar to those of bulk beam attenuation due to particles, whereas cell concentration changes were not. Using a combination of empirical calibrations relating beam attenuation to flow cytometric measurements of pure cultures of phytoplankton in the laboratory, and Mie theory, the contributions of different groups of phytoplankton to the diel variations in beam attenuation were estimated. The results indicate that the phytoplankton assemblage measured by flow cytometry can account for essentially all of the diel variation in the beam attenuation signal. In most instances the nanophytoplankton were the largest contributor to total beam attenuation due to phytoplankton, but the ultraphytoplankton usually were more important in determining the diel variations in this property. Prochlorococcus were a smaller but appreciable contributor to beam attenuation changes, and Synechococcus were much less important.

A similar analysis was performed for diel sampling experiments in the Sargasso Sea in January 1992, July 1993, and May 1994. The bulk beam attenuation due to particles was strongly correlated with calculated beam attenuation due to phytoplankton. During the July 1993 diel sampling, when pico- and nanophytoplankton populations were analyzed, in most instances the nanophytoplankton were the largest contributor to total beam attenuation due to phytoplankton, but Prochlorococcus were equally important at $70 \mathrm{~m}$ for some time points over the diel cycle. In the upper $40 \mathrm{~m}$, Prochlorococcus were a smaller contributor to beam attenuation changes than the nanophytoplankton, and Synechococcus were even less important. These findings emphasize the need to characterize the composition of the phytoplankton community in order to use beam attenuation to monitor productivity.

Flow cytometric measurements of phytoplankton light scattering and cell concentration over the diel light cycle were used to estimate in situ phytoplankton group-specific growth and loss rates in the equatorial Pacific and the Sargasso Sea. Measurements of forward light scatter were converted to cell volume and carbon using laboratory and theoretically derived calibration factors for specific groups of phytoplankton, including Prochlorococcus, Synechococcus, ultraphytoplankton, nanophytoplankton, and coccolithophores. Assuming that division was phased, specific growth rates were estimated based on volume and carbon changes between minimum and maximum values over the day. Phytoplankton group-specific loss rates, and also separate day and night loss rates, were estimated from the calculated growth rates and measured cell concentrations over time. The method used to estimate growth rates works well for Prochlorococcus and appears to work for small eukaryotic phytoplankton, but leads to underestimates for Synechococcus and larger eukaryotes. Estimated growth rates for Prochlorococcus reached one division per day in the upper waters of the equatorial Pacific, but were about half that in the Sargasso Sea. For the eukaryotic phytoplankton, growth rates in the equatorial Pacific were near one division per day in the upper waters; in the Sargasso Sea, the growth rates approached that, but were more often lower. In general, phytoplankton growth rates were closely matched by in situ loss rates over the course of a day.

Thesis Supervisor: Dr. Robert J. Olson, Associate Scientist Woods Hole Oceanographic Institution 


\section{Acknowledgements}

Any project which spans six years and two oceans cannot be accomplished by one person alone. There are many people to whom I am greatly indebted. Rob Olson, my advisor, has been a tremendous source of support, assistance, and advice throughout my time here. I realize that there are very few advisors who would stay up all night in the lab helping with a student's experiment, and Rob did that many times with me. His enthusiasm and "hands on" approach to science, both in the lab and during cruises, have been an inspiration to me. I have been lucky that, besides having an advisor, I have also had a friend, and I have many memories of sailing Buzzard's Bay in the Lightning with Rob and enjoying meals with his family.

I would also like to thank the other members of my committee for their enthusiasm and advice: Penny Chisholm, Dave Siegel, Andy Solow, John Waterbury, Sandy Williams, and Judy McDowell (Chairperson). Penny Chisholm has been a source of encouragement throughout the years and helpful in key aspects of my professional development. Dave Siegel has provided useful advice and suggestions especially during the crucial final stages of the thesis preparation.

For the first five years, my officemate, labmate, and cruisemate was Erik Zettler. His assistance in the lab and on cruises has been invaluable, and he was always willing to help out and answer any and all of my questions. For the last year and a half that Heidi Sosik has been at WHOI, she has provided valuable advice and assistance in several aspects of my work during the critical "finishing up" time. I would like to thank the others, besides Rob and Erik, who stayed up all night working in the lab with me: Jessica Bohonowych, Tanya Churilova, Elisabeth Jaffe, Catherine Preston, and Elizabeth Riemer. There have been a number of people in the Biology Department who have helped me out over the years, I would particularly like to thank Freddy Valois, Diana Franks, and Mark Dennett. At sea, of course, there have been people too numerous to mention who have helped with the diel sampling experiments. In addition to Rob and Erik, I am especially grateful to Jeff Dusenberry and Brian Binder for their contributions.

I would like to thank my fellow students and friends for their support, particularly Carla Curran, John Kokinos, David Mann, Paul Snelgrove, and Erik Zettler. My family, especially my mother Betty, has always been supportive of me and I thank them for that over the many years. Finally, I'd like to thank my closest friend for nearly six years, Paul Snelgrove. His support and caring, whether from nearby or from 315 miles away, has made a great difference to me. It's been a lot better having gone through it all with Paul by my side. And a well-deserved ear-rub goes to Casey, the best dog in the world, whose unbounded joy every time he sees me never fails to boost my spirits.

This work has been supported in part by: NSF (OCE-9012147 and OCE9024380), DOE (DE-FG02-93ER61693), ONR (N00014-83-K-0661 and 89-1-1110), the Vetlesen Foundation, a WHOI Ocean Ventures Award, and the Education Office. 


\section{Table of Contents}

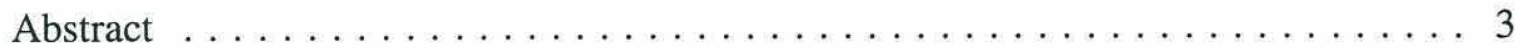

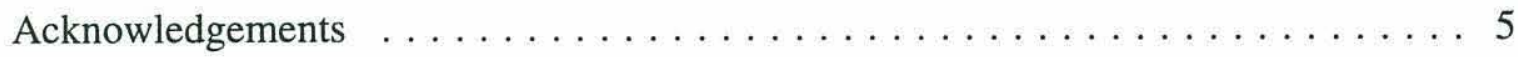

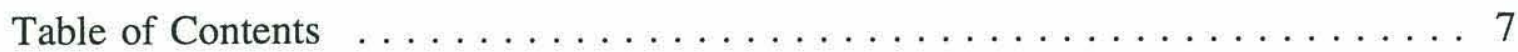

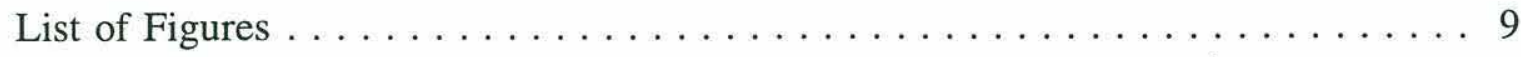

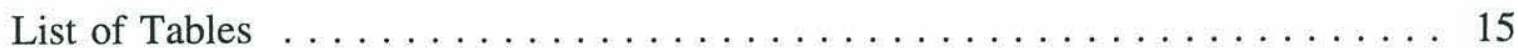

Chapter 1: Introduction $\ldots \ldots \ldots \ldots \ldots \ldots \ldots \ldots \ldots \ldots \ldots \ldots \ldots \ldots \ldots \ldots \ldots$

References ................... 22

Chapter 2: Diel patterns in optical properties of the chlorophyte Nannochloris sp. grown on light:dark cycles . . . . . . . . . . . . . 23

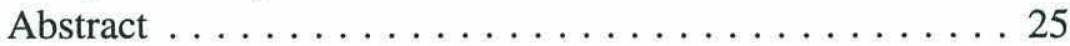

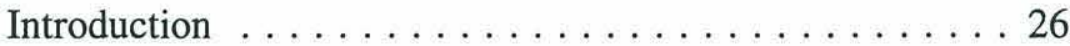

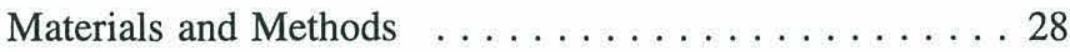

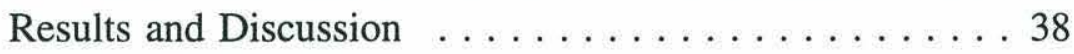

Measurements of cell properties ......... 38

Estimation of cell volume and specific growth rate 60

Carbon-specific beam attenuation .........67 67

Contributions of diameter and refr. index to $\sigma_{c} \ldots 72$

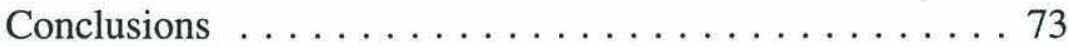

Acknowledgements . . . . . . . . . . . . . 74

References .................... 75

Chapter 3: Contributions of phytoplankton light scattering and cell concentration changes to diel variations in beam attenuation in the equatorial Pacific from flow cytometric measurements of pico-, ultra-, and nanoplankton . . . . . . . . . . . . . . 79

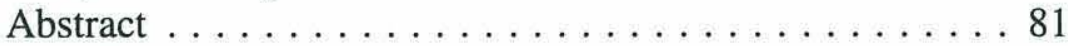

Introduction $\ldots \ldots \ldots \ldots \ldots \ldots \ldots \ldots \ldots \ldots \ldots$.

Materials and Methods ................ 84

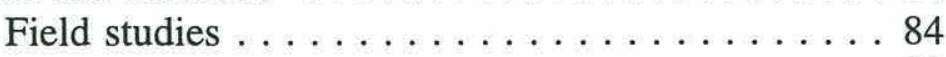

Laboratory studies . . . . . . . . . . . 88

Conversion of FLS to scattering cross section . . 89

Results and Discussion $\ldots \ldots \ldots \ldots \ldots \ldots \ldots$

Diel patterns in phytoplankton and beam c . . . 91

Calculation of beam $\mathrm{c}$ due to phytoplankton .... .98

Comparison of $\mathrm{c}_{\text {particles }}$ and $\mathrm{c}_{\text {phytoplankton }} \ldots \ldots \ldots 107$

Non-phytoplankton beam attenuation . . . . . . . 107

Interpretation of diel patterns in $\mathrm{c}$ as production .115

Conclusions ................... 117 
Acknowledgements $\ldots \ldots \ldots \ldots \ldots \ldots \ldots \ldots \ldots 118$

References ........................ 119

Chapter 4: Contributions of phytoplankton light scattering and cell concentration changes to diel variations in beam attenuation in the Sargasso Sea 123

Abstract . . . . . . . . . . . . . . . . 125

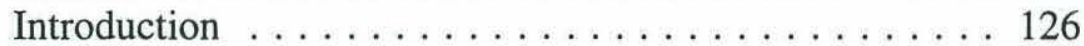

Materials and Methods . . . . . . . . . . . . . 127

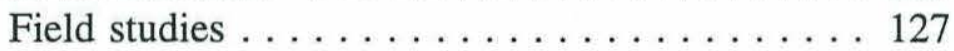

Laboratory studies . . . . . . . . . . . 128

Conversion of FLS to scattering cross section . . 129

Results and Discussion . . . . . . . . . . . . . 129

Diel patterns in phytoplankton and beam c . . . 129

Calculation of beam c due to phytoplankton .... 139

Comparison of $\mathrm{c}_{\text {particles }}$ and $\mathrm{c}_{\text {phytoplankton }} \ldots \ldots \ldots \ldots 148$

Conclusions ...................... 161

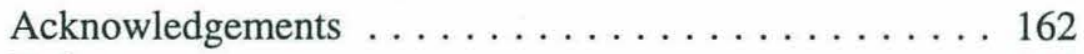

References ...................... 163

Chapter 5: Analysis of phytoplankton growth in the equatorial Pacific and the Sargasso Sea by flow cytometric measurements of light scatter over diel cycles . . . . . . . . . . . . . . . . . . . . 165

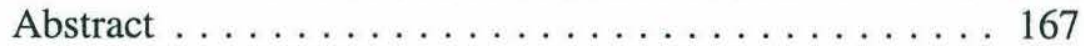

Introduction $\ldots \ldots \ldots \ldots \ldots \ldots \ldots \ldots \ldots \ldots$

Materials and Methods $\ldots \ldots \ldots \ldots \ldots \ldots \ldots 170$

Field studies . . . . . . . . . . . . 170

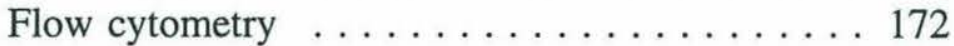

Laboratory experiments .......... 173

Calculation of growth and loss rate . . . . . 173

Results and Discussion ............... 175

Diel variations in light scatter and concentration . 175

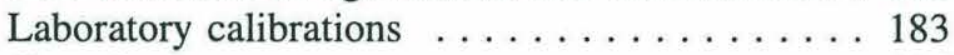

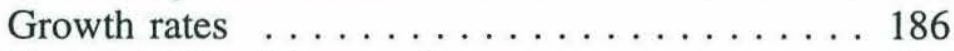

Equatorial Pacific growth rates . . . . . . . 187

Sargasso Sea growth rates . . . . . . . . . . 198

Loss rates . . . . . . . . . . . . 207

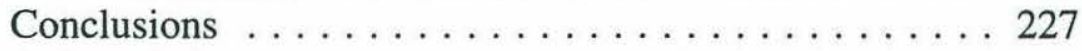

Acknowledgements . . . . . . . . . . . . 227

References ..................... 228

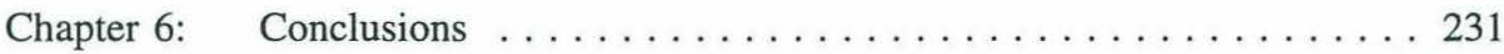

References ................... 237

Appendix A. Calibration of forward light scatter and cell volume . . . . . . . 239

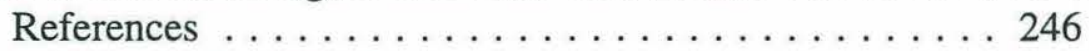

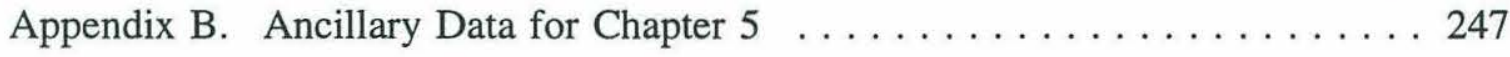




\section{List of Figures}

Chapter 2: Diel patterns in optical properties of the chlorophyte Nannochloris sp. grown on light:dark cycles

Figure 1. Light intensity during outdoor experiment $\ldots \ldots \ldots \ldots \ldots \ldots 31$

Figure 2. Comparison between live and preserved samples ......... 35

Figure 3. Time series of cell concentrations during laboratory experiments . . 41

Figure 4. Specific growth rates at different light levels $\ldots \ldots \ldots \ldots \ldots 43$

Figure 5. Time series of cell volume $\ldots \ldots \ldots \ldots \ldots \ldots \ldots \ldots \ldots 45$

Figure 6. Time series of forward and side light scatter . . . . . . . 47

Figure 7. Time series of carbon per cell $\ldots \ldots \ldots \ldots \ldots \ldots \ldots \ldots .49$

Figure 8. Time series of real refractive index, intracellular carbon concentration, and imaginary refractive index $\ldots \ldots \ldots \ldots \ldots \ldots \ldots \ldots$

Figure 9. Time series of attenuation, scattering, and absorption cross sections 55

Figure 10. Time series of chlorophyll fluorescence per cell $\ldots \ldots \ldots \ldots 57$

Figure 11. Relationship between refractive index and intracellular carbon

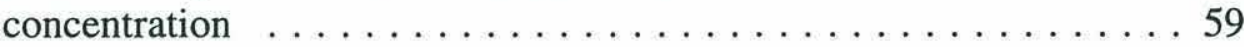

Figure 12. Relationship between flow cytometric forward light scatter and total

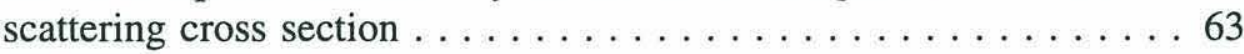

Figure 13. Relationship between forward light scatter and cell volume $\ldots \ldots 65$

Figure 14. Time series of carbon-specific beam attenuation $\ldots \ldots \ldots \ldots 69$

Figure 15. Results of sensitivity analysis of the attenuation cross section to changes in diameter and refractive index $\ldots \ldots \ldots \ldots \ldots \ldots 71$

Chapter 3: Contributions of phytoplankton light scattering and cell concentration changes to diel variations in beam attenuation in the equatorial Pacific from flow cytometric measurements of pico-, ultra-, and nanoplankton 
Figure 1. Typical flow cytometric signatures of picoplankton and eukaryotic phytoplankton in the equatorial Pacific . . . . . . . . . 87

Figure 2. Time series of beam attenuation due to particles and forward light scattering cross section and cell concentration for nanophytoplankton, ultraphytoplankton, Synechococcus, and Prochlorococcus . . . . . . 93

Figure 3. Relationship between carbon per cell and forward scattering cross section from laboratory experiments on Nannochloris and Synechococcus cultures ..................... 97

Figure 4. Relationship between attenuation cross section and forward scattering cross section from laboratory experiments on Nannochloris and Synechococcus cultures ..................... 101

Figure 5. Comparison between empirical and theoretical relationships between the attenuation and scattering cross sections $\ldots \ldots \ldots \ldots \ldots 103$

Figure 6. Time series of beam attenuation due to particles and calculated beam attenuation due to nanophytoplankton, ultraphytoplankton, Synechococcus, and Prochlorococcus . . . . . . . . . . . . 105

Figure 7. Time series of calculated beam attenuation to show relative contributions of each group of phytoplankton . . . . . . . . 109

Figure 8. Relationship between the change in beam attenuation due to particles and the change in beam attenuation due to phytoplankton $\ldots \ldots 111$

Figure 9. Depth profile of beam attenuation due to particles and beam attenuation

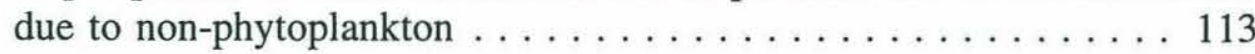

\section{Chapter 4: Contributions of phytoplankton light scattering and cell concentration changes to diel variations in beam attenuation in the Sargasso Sea}

Figure 1. Time series of $c_{p}$ and forward light scattering cross section and cell concentration for nanophytoplankton in January 1992 during diel sampling $1 \ldots \ldots \ldots \ldots \ldots \ldots \ldots \ldots \ldots \ldots \ldots \ldots \ldots \ldots \ldots$

Figure 2. Time series of $c_{p}$ and forward light scattering cross section and cell concentration for nanophytoplankton in January 1992 during diel sampling $2 \ldots \ldots \ldots \ldots \ldots \ldots \ldots \ldots \ldots \ldots \ldots \ldots \ldots \ldots \ldots$ 
Figure 3. Time series of $c_{p}$ and forward light scattering cross section and cell concentration for nanophytoplankton in May 1994 ... . . . . . 135

Figure 4. Time series of $c_{p}$ and forward light scattering cross section and cell concentration for nanophytoplankton, Synechococcus, and Prochlorococcus in July 1993 . . . . . . . . . . . . . . . . . 137

Figure 5. Time series of $c_{p}$ and calculated beam attenuation due to nanophytoplankton in January 1992 during diel sampling 1 . . . 141

Figure 6. Time series of $c_{p}$ and calculated beam attenuation due to nanophytoplankton in January 1992 during diel sampling 2 . . . 143

Figure 7. Time series of $c_{p}$ and calculated beam attenuation due to nanophytoplankton in May 1994 . . . . . . . . . . . . . . . 145

Figure 8. Time series of $\mathrm{c}_{\mathrm{p}}$ and calculated beam $\mathrm{c}$ due to nanophytoplankton, Synechococcus, and Prochlorococcus in July 1993 . . . . . . . 147

Figure 9. Time series of calculated beam attenuation to show relative contributions of each group of phytoplankton in July $1993 \ldots \ldots 151$

Figure 10. Relationship between the change in $c_{p}$ and the change in $c_{\text {phyto }}$ in January 1992 during diel sampling $2 \ldots \ldots \ldots \ldots \ldots \ldots \ldots$

Figure 11. Time series of $c_{p}$ and $c_{\text {phyto }}$ for a selected depth $\ldots \ldots \ldots \ldots 155$

Figure 12. Relationship between $c_{p}$ and $c_{\text {phyto }} \ldots \ldots \ldots \ldots \ldots \ldots \ldots \ldots$

Chapter 5: Analysis of phytoplankton growth in the equatorial Pacific and the Sargasso Sea by flow cytometric measurements of light scatter over diel cycles

Figure 1. Time series of Prochlorococcus and Synechococcus forward light scatter and cell concentration in the Pacific in April 1992 . . . . 177

Figure 2. Time series of ultraphytoplankton and nanophytoplankton forward light scatter and cell concentration in the Pacific in April 1992 . . . . 179

Figure 3. Time series of Prochlorococcus, Synechococcus, and nanophytoplankton forward light scatter and cell concentration in the Sargasso Sea in July 1993 
Figure 4. Relationship between forward light scatter and cell diameter for Nannochloris cultures . . . . . . . . . . . . . . . . 185

Figure 5. Relationship between forward light scatter and cell carbon for Nannochloris cultures . . . . . . . . . . . . . . . . . . . 189

Figure 6. Depth profiles of growth rates for Prochlorococcus and Synechococcus in the equatorial Pacific in April and October 1992 . . . . . . . 191

Figure 7. Comparison of growth rates estimated from forward light scatter and from DNA distributions . . . . . . . . . . . . . . 193

Figure 8. Depth profiles of growth rates for ultraphytoplankton and nanophytoplankton in the Pacific in April and October 1992 . . . 197

Figure 9. Depth profiles of growth rates for nanophytoplankton in the Sargasso Sea in January 1992 . . . . . . . . . . . . . . . . . . 201

Figure 10. Depth profiles of growth rates for Prochlorococcus, Synechococcus, and nanophytoplankton in the Sargasso Sea in July 1993 . . . . . 203

Figure 11. Depth profiles of growth rates for nanophytoplankton in the Sargasso Sea in May $1994 \ldots \ldots \ldots \ldots \ldots$. . . . . . . . . . . . 205

Figure 12. Depth profiles of growth rates and loss rates for Prochlorococcus, ultraphytoplankton, and nanophytoplankton in the equatorial Pacific in April and October 1992 . . . . . . . . . . . . . . . . . . 209

Figure 13. Depth profiles of growth rates and loss rates for nanophytoplankton and coccolithophores in the Sargasso Sea in January 1992 . . . . . . 211

Figure 14. Depth profiles of growth rates and loss rates for Synechococcus and nanophytoplankton in the Sargasso Sea in July 1993 . . . . . . . 213

Figure 15. Depth profiles of growth rates and loss rates for nanophytoplankton in the Sargasso Sea in May $1994 \ldots \ldots \ldots \ldots \ldots \ldots . \ldots \ldots$

Figure 16. Depth profiles of day or night loss rates for Prochlorococcus, ultraphytoplankton, and nanophytoplankton in the equatorial Pacific in April and October $1992 \ldots \ldots \ldots \ldots \ldots \ldots \ldots \ldots \ldots$

Figure 17. Depth profiles of day or night loss rates for nanophytoplankton and coccolithophores in the Sargasso Sea in January 1992 . . . . . . . 219 
Figure 18. Depth profiles of day or night loss rates for Synechococcus and nanophytoplankton in the Sargasso Sea in July 1993 . . . . . . . 221

Figure 19. Depth profiles of day or night loss rates for nanophytoplankton in the Sargasso Sea in May 1994 . . . . . . . . . . . . . . . . . 223

Figure 20. Depth profile of density over the day during a diel sampling experiment in the Sargasso Sea in January $1992 \ldots \ldots \ldots . \ldots 225$

\section{Appendix A. Calibration of forward light scatter and cell volume}

Figure 1. Relationship between flow cytometric forward light scatter and cell volume over a range of eukaryotic phytoplankton sizes . . . . . 245

\section{Appendix B. Ancillary Data for Chapter 5}

Figure 1. Time series of Prochlorococcus and Synechococcus forward light scatter and cell concentration in the equatorial Pacific in October 1992 during diel sampling $1 \ldots \ldots \ldots \ldots \ldots \ldots \ldots \ldots \ldots \ldots \ldots$

Figure 2. Time series of ultraphytoplankton and nanophytoplankton forward light scatter and cell concentration in the equatorial Pacific in October 1992 during diel sampling $1 \ldots \ldots \ldots \ldots \ldots \ldots \ldots \ldots \ldots \ldots \ldots$

Figure 3. Time series of Prochlorococcus and Synechococcus forward light scatter and cell concentration in the equatorial Pacific in October 1992

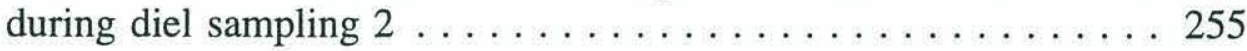

Figure 4. Time series of ultraphytoplankton and nanophytoplankton forward light scatter and cell concentration in the equatorial Pacific in October 1992 during diel sampling $2 \ldots \ldots \ldots \ldots \ldots \ldots \ldots \ldots \ldots \ldots \ldots \ldots$

Figure 5. Time series of nanophytoplankton forward light scatter and cell concentration over two days in the Sargasso Sea in January 1992 during diel sampling $1 \ldots \ldots \ldots \ldots \ldots \ldots \ldots \ldots \ldots$

Figure 6. Time series of nanophytoplankton and coccolithophore forward light scatter and cell concentration in the Sargasso Sea in January 1992

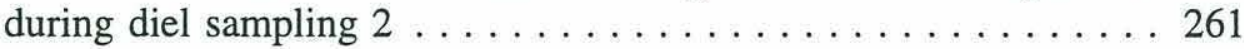

Figure 7. Time series of nanophytoplankton forward light scatter and cell concentration in the Sargasso Sea in May 1994 . . . . . . . . . 263 


\section{List of Tables}

Chapter 2: Diel patterns in optical properties of the chlorophyte Nannochloris sp. grown on light:dark cycles

Table 1. Summary of laboratory experiments on Nannochloris . . . . . . 29

Table 2. Results of linear regression on volume and forward or side light scatter

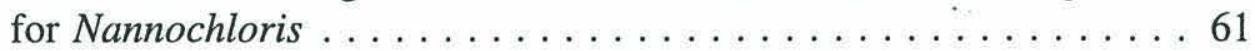

Table 3. Results of regressions on estimated growth rates for Nannochloris . 67

Chapter 4: Contributions of phytoplankton light scattering and cell concentration changes to diel variations in beam attenuation in the Sargasso Sea

Table 1. Results of regressions of beam attenuation due to particles on the calculated beam attenuation due to phytoplankton . . . . . . . 160

Chapter 5: Analysis of phytoplankton growth in the equatorial Pacific and the Sargasso Sea by flow cytometric measurements of light scatter over diel cycles

Table 1. Summary of diel sampling experiments in the equatorial Pacific and Sargasso Sea . . . . . . . . . . . . . . . . . . 171

Appendix A. Calibration of forward light scatter and cell volume

Table 1. Phytoplankton culture information, forward light scatter, and cell volume from calibration . . . . . . . . . . . . . . . 242 
Chapter 1

Introduction 
There is a wide spectrum of approaches in studying phytoplankton growth and productivity in the ocean, including cell cycle markers, biochemical rate measurements, and cage and bottle incubations (reviewed by Furnas 1990). Currently, there is increasing interest in using optical measurements such as ocean color and beam attenuation, which can be made remotely or from a mooring, to provide convenient and efficient estimates of ocean biomass and primary productivity on large scales. The use of ocean color to estimate primary production, with biooptical algorithms to interpret the remote measurements in terms of biogeochemical processes, is based on the fact that the color of the ocean is determined by the optical properties of the suspended particles, particularly the phytoplankton and their products (Lewis and Cullen 1991). Beam attenuation, which measures the combined effects of scattering and absorption when a beam of light travels through the water, can be partitioned into the contributions of pure seawater (which is known), dissolved organic material (which is negligible at the red wavelength of the SeaTech beam transmissometer), and particles. Thus an understanding of the variability in optical properties among the particles in the ocean can help us to better interpret these bulk measurements.

The absolute dependence of phytoplankton growth on light has a consequence that one of the most important scales of variation is over the daily cycle of light and 
dark. Many researchers have observed diel variations in bio-optical properties in the ocean (Dickey et al. 1990; Hamilton et al. 1990; Stramska and Dickey 1992), and diel variations in beam attenuation have been used to estimate primary production (Siegel et al. 1989; Cullen et al. 1992) by assuming a constant carbon-specific beam attenuation and applying it to the diel measurements of beam attenuation. In order to more completely understand beam attenuation and relate it to productivity, it is necessary to understand the particles and processes that cause the observed patterns. In this thesis, I will use individual cell analysis from flow cytometry to interpret measurements of beam attenuation in terms of the contribution of different phytoplankton groups to the overall signal and to the diel variations.

A second aspect of this thesis is the interpretation of diel variations in flow cytometric light scatter of phytoplankton as in situ growth rates. From flow cytometric measurements of phytoplankton cells sampled at different times of the day (Olson et al. 1990) or over a diel cycle (Olson et al. 1991), it has been seen that the mean forward light scatter of a population of cells increases during the day and decreases at night. These observations have been made for populations of the picoplankton Prochlorococcus and Synechococcus and also for eukaryotic nanophytoplankton. It appears that these diel patterns in forward light scatter reflect cell growth during the day followed by division at night. In this thesis, I will use diel variations in flow cytometric measurements of cell light scatter for specific types of phytoplankton to estimate in situ phytoplankton group-specific growth rates and, with the concomitant cell concentration measurements, loss rates in the ocean. 
The organization of the thesis is as follows. I first present the results of laboratory experiments on optical properties of cultures of the chlorophyte Nannochloris sp., which has a size and shape similar to open ocean nanophytoplankton (Chapter 2). In these diel sampling experiments, I determine cell size and concentration, light attenuation and absorption, flow cytometric light scattering, and carbon content of Nannochloris grown on a light:dark cycle at a range of light levels. I then present in Chapter 3 field observations from diel sampling experiments in the equatorial Pacific, where flow cytometric measurements of light scattering and cell concentration for different phytoplankton groups were made. Calibrations, both laboratory and theoretically derived, are applied to the field data in order to account for the diel variations in beam attenuation. Chapter 4 continues with a similar analysis for diel sampling experiments in the Sargasso Sea during three different months. In Chapter 5, I estimate in situ phytoplankton group-specific growth and loss rates in the equatorial Pacific and the Sargasso Sea, using a combination of field observations and laboratory calibrations. In Chapter 6, I present general conclusions of the thesis. In Appendix A, I describe an experiment to calibrate flow cytometric forward light scatter and cell volume over a range of cell sizes. Appendix B contains ancillary data from the field diel sampling experiments in Chapter 5. 


\section{REFERENCES}

Cullen, J.J., M.R. Lewis, C.O. Davis and R.T. Barber. 1992. Photosynthetic characteristics and estimated growth rates indicate grazing is the proximate control of primary production in the equatorial Pacific. J. Geophys. Res. 97: 639-654.

Dickey, T., T. Granata, M. Hamilton, J. Wiggert, J. Marra, C. Langdon and D.A. Siegel. 1990. Time series observations of bio-optical properties in the upper layer of the Sargasso Sea. SPIE: Ocean Optics X 1302: 202-213.

Furnas, M.J. 1990. In situ growth rates of marine phytoplankton: approaches to measurement, community and species growth rates. J. Plankton Res. 12: $1117-1151$.

Hamilton, M., T.C. Granata, T.D. Dickey, J.D. Wiggert, D.A. Siegel, J. Marra and C. Langdon. 1990. Diel variations of bio-optical properties in the Sargasso Sea. SPIE: Ocean Optics X 1302: 214-224.

Lewis, M.R. and J.J. Cullen. 1991. From cells to the ocean: Satellite ocean color, pp. 325-337. In S. Demers [ed.], Particle Analysis in Oceanography. NATO ASI Series G 27. Springer-Verlag.

Olson, R.J., S.W. Chisholm, E.R. Zettler and E.V. Armbrust. 1990. Pigments, size, and distribution of Synechococcus in the North Atlantic and Pacific Oceans. Limnol. Oceanogr. 35: 45-58.

Olson, R.J., E.R. Zettler, S.W. Chisholm and J.A. Dusenberry. 1991. Advances in oceanography through flow cytometry, pp. 351-399. In S. Demers [ed.], Particle Analysis in Oceanography. NATO ASI Series G 27. Springer-Verlag.

Siegel, D.A., T.D. Dickey, L. Washburn, M.K. Hamilton and B.G. Mitchell. 1989. Optical determination of particulate abundance and production variations in the oligotrophic ocean. Deep-Sea Res. 36: 211-222.

Stramska, M. and T.D. Dickey. 1992. Variability of bio-optical properties of the upper ocean associated with diel cycles in phytoplankton populations. J. Geophys. Res. 97: 17,873-17,887. 
Chapter 2

Diel patterns in optical properties of the chlorophyte Nannochloris sp. grown on light:dark cycles 


\begin{abstract}
To investigate how cell growth and division affect the optical properties of phytoplankton, cultures of the chlorophyte Nannochloris sp. were sampled over a diel cycle to measure cell size and concentration, light beam attenuation and absorption, flow cytometric light scattering (in forward and side directions), and carbon content. In addition, the refractive index was calculated using the anomalous diffraction approximation of Mie theory. At six different light levels ranging from $60-1500$ $\mu \mathrm{mol}$ photons $\mathrm{m}^{-2} \mathrm{~s}^{-1}$ (specific growth rates from $\sim 0.2$ to $\sim 0.7 \mathrm{~d}^{-1}$ ), cell division was tightly phased to the light:dark cycle, occurring soon after dark. There were pronounced diel patterns, with a minimum near dawn and a maximum near dusk, in cell size and in cell-specific attenuation, absorption, flow cytometric light scatter and carbon. The diel variations in the attenuation cross section were primarily influenced by the changes in cell size due to growth and division, while changes in refractive index had only a small effect. Because eukaryotic cells in the size range of Nannochloris are major constituents of many phytoplankton communities, the results presented here have important consequences for the interpretation of diel variations in optical properties observed in the ocean.
\end{abstract}




\section{INTRODUCTION}

There is increasing interest in using optical measurements such as ocean color and beam attenuation to provide convenient and efficient estimates of ocean biomass and primary productivity on large scales. The use of ocean color to estimate primary production, with bio-optical algorithms to interpret the remote measurements in terms of biogeochemical processes, is based on the fact that the color of the ocean is determined by the optical properties of the suspended particles, particularly the phytoplankton and their products (Lewis and Cullen 1991). Thus, an understanding of the variability in optical properties among the particles in the ocean can lead to a better interpretation of these bulk measurements, and thus better estimates of larger scale production.

Since phytoplankton growth is dependent on light, one of the most important scales of variation is over the daily cycle of light and dark. Many researchers have observed diel variations in bio-optical properties in the ocean (Dickey et al. 1990, Hamilton et al. 1990, Stramska and Dickey 1992), and diel variations in beam attenuation have been used to estimate primary production by utilizing a carbonspecific beam attenuation derived from the literature (Siegel et al. 1989, Cullen et al. 1992). In order to fully interpret such bulk measurements made at sea, the diel variations in optical properties of phytoplankton cells must be better understood. Stramski and Reynolds (1993) investigated the diel variations in optical properties of the diatom Thalassiosira pseudonana and found that variations in refractive index 
were equal to or more important than variations in cell size in affecting changes in optical cross sections. The measured carbon-specific beam attenuation varied over the diel cycle (up to almost 30\%). A recent study of Synechococcus indicated that, for a slowly growing culture, optical cross sections were minimum near dawn or mid-morning and maximum near dusk (Stramski et al. 1995). The carbon-specific beam attenuation showed substantial diel variability, changing by up to two-fold over the cycle and was different for Synechococcus $\left(2.48 \mathrm{~m}^{2}(\mathrm{~g} \mathrm{C})^{-1}\right)$ than for $T$. pseudonana $\left(3.81 \mathrm{~m}^{2}\left(\mathrm{~g} \mathrm{C}^{-1}\right)\right.$. Stramski et al. (1995) suggested that there may be considerable variability in the carbon-specific beam attenuation which should be considered when estimating productivity from diel variations in beam attenuation.

In the experiments reported here on diel variations in phytoplankton optical properties, we chose the chlorophyte Nannochloris because it is of a size and shape similar to open ocean ultraphytoplankton (coccoid, 2-3 $\mu \mathrm{m}$ diameter) and it has division patterns typical of eukaryotic phytoplankton (non-diatoms): cell division occurs during the night (Chisholm 1981). We measured cell concentration, attenuation and absorption, cell volume, and carbon, and calculated optical cross sections and refractive index. We also measured forward and side light scatter of these cells using flow cytometry, a method which is used in the field to distinguish phytoplankton populations on the basis of their optical properties. Thus the results of this study can be readily applied to flow cytometric measurements of phytoplankton populations in the field (DuRand and Olson in press, Chapter 4). 


\section{MATERIALS AND METHODS}

Batch cultures - Three experiments were performed in which the chlorophyte Nannochloris sp. (2.5-3 $\mu \mathrm{m}$ diameter) was grown in $\mathrm{f} / 2$ medium in replicate cultures at $22^{\circ} \mathrm{C}$ (Table 1). The $\mathrm{f} / 2$ medium was autoclaved, then sterile filtered through a $0.22 \mu \mathrm{m}$ Millipore filter (142 $\mathrm{mm}$ diameter). For two of the experiments the cultures were grown in 10-1 carboys in an incubator on a 14:10 L:D cycle at 250 (Nan250) and $500 \mu \mathrm{mol}$ photons $\mathrm{m}^{-2} \mathrm{~s}^{-1}$ (Nan500) (Cool-White fluorescent lights, measured with a Biospherical Instruments Inc. QSL-100 $4 \pi$ sensor). The carboys were mixed with a magnetic stir bar and also bubbled with moisturized, filtered air. Samples were obtained through a sterile sampling port (forced out by air pressure). A third experiment (Nan1500) was performed outdoors under natural sunlight with an average integrated light level of about $1500 \mu \mathrm{mol}$ photons $\mathrm{m}^{-2} \mathrm{~s}^{-1}$ and a maximum of 2200 (14 h daylight on a mostly sunny day in August, Fig. 1). The light level was measured with a Biospherical Instruments Inc. QSR-240 $4 \pi$ sensor in the air. The cultures were in the shadow of the building from dawn $(\sim 0600 \mathrm{~h})$ until $\sim 0800 \mathrm{~h}$, after which they were in full sunlight. The cells were grown in Fernbach flasks set in a clear plexiglass water bath with the temperature controlled by a recirculating water bath. The flasks were stirred throughout the experiment and samples were taken by transporting the flasks to a laminar flow hood and then pouring out an aliquot. The cultures were first grown in an incubator at $500 \mu \mathrm{mol}$ photons $\mathrm{m}^{-2} \mathrm{~s}^{-1}$ and then outdoors for one day before sampling began. 
Table 1. Summary of laboratory experiments on Nannochloris.

\begin{tabular}{|c|c|c|c|}
\hline Experiment & Light level & Type of experiment & Measurements \\
\hline $\begin{array}{l}\text { Nan250 } \\
\text { July } 92\end{array}$ & $\begin{array}{l}250 \mu \mathrm{mol} \\
\text { photons } \mathrm{m}^{-2} \mathrm{~s}^{-1}\end{array}$ & $\begin{array}{l}\text { Replicate carboys } \\
\text { in incubator }\end{array}$ & $\begin{array}{l}\text { Cell size } \\
\text { Concentration } \\
\text { Attenuation } \\
\text { Absorption } \\
\text { Carbon } \\
\text { Forward light scatter }\end{array}$ \\
\hline $\begin{array}{l}\text { Nan500 } \\
\text { Aug. } 92\end{array}$ & $\begin{array}{l}500 \mu \mathrm{mol} \\
\text { photons } \mathrm{m}^{-2} \mathrm{~s}^{-1}\end{array}$ & $\begin{array}{l}\text { Replicate carboys } \\
\text { in incubator }\end{array}$ & $\begin{array}{l}\text { Cell size } \\
\text { Concentration } \\
\text { Attenuation } \\
\text { Absorption } \\
\text { Carbon } \\
\text { Forward light scatter } \\
\text { Side light scatter }\end{array}$ \\
\hline $\begin{array}{l}\text { Nan } 1500 \\
\text { Aug. } 94\end{array}$ & $\begin{array}{l}1500 \mu \mathrm{mol} \\
\text { photons } \mathrm{m}^{-2} \mathrm{~s}^{-1}\end{array}$ & $\begin{array}{l}\text { Replicate flasks in } \\
\text { natural light }\end{array}$ & $\begin{array}{l}\text { Cell size } \\
\text { Concentration } \\
\text { Attenuation } \\
\text { Absorption } \\
\text { Carbon } \\
\text { Forward light scatter } \\
\text { Side light scatter }\end{array}$ \\
\hline $\begin{array}{l}\text { Nan60 } \\
\text { May } 93\end{array}$ & $\begin{array}{l}60 \mu \mathrm{mol} \\
\text { photons } \mathrm{m}^{-2} \mathrm{~s}^{-1}\end{array}$ & $\begin{array}{l}\text { Cyclostat in } \\
\text { incubator }\end{array}$ & $\begin{array}{l}\text { Cell size } \\
\text { Concentration } \\
\text { Forward light scatter }\end{array}$ \\
\hline $\begin{array}{l}\text { Nan120 } \\
\text { May } 93\end{array}$ & $\begin{array}{l}120 \mu \mathrm{mol} \\
\text { photons } \mathrm{m}^{-2} \mathrm{~s}^{-1}\end{array}$ & $\begin{array}{l}\text { Cyclostat in } \\
\text { incubator }\end{array}$ & $\begin{array}{l}\text { Cell size } \\
\text { Concentration } \\
\text { Forward light scatter }\end{array}$ \\
\hline $\begin{array}{l}\text { Nan330 } \\
\text { May } 93\end{array}$ & $\begin{array}{l}330 \mu \mathrm{mol} \\
\text { photons } \mathrm{m}^{-2} \mathrm{~s}^{-1} \\
\text { (up from } 120 \\
\text { previous day) }\end{array}$ & $\begin{array}{l}\text { Cyclostat in } \\
\text { incubator }\end{array}$ & $\begin{array}{l}\text { Cell size } \\
\text { Concentration } \\
\text { Forward light scatter }\end{array}$ \\
\hline
\end{tabular}


Figure 1. Light intensity ( $\mu \mathrm{mol}$ photons $\mathrm{m}^{-2} \mathrm{~s}^{-1}$ ) measured outdoors near the experimental setup for Nan 1500 for the days the cultures were in natural light. Sampling times (9 Aug - 10 Aug) are marked with asterisks. 


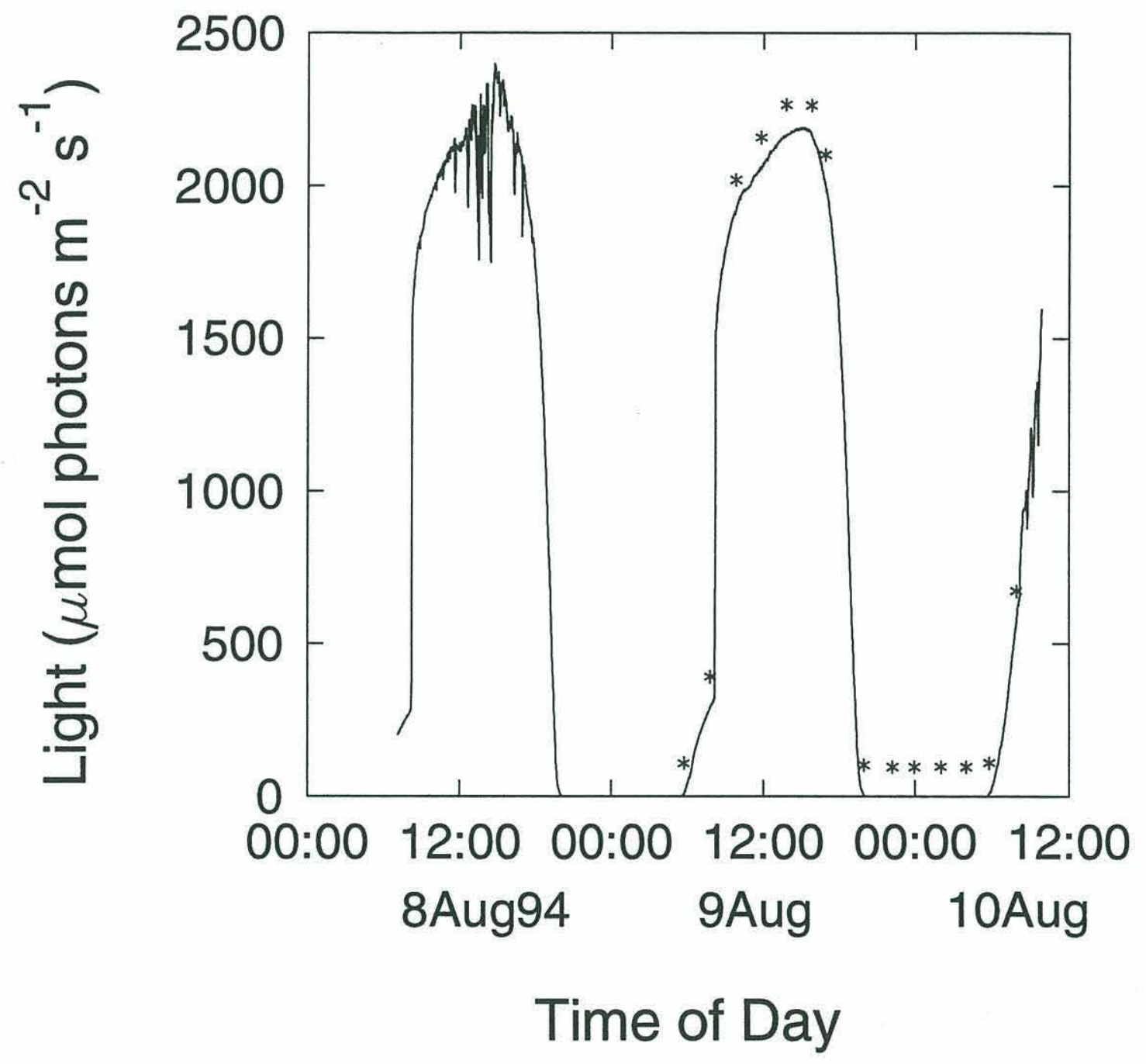


For each of the three experiments, beginning at dawn, the exponential phase cultures were sampled every two hours for 24 hours and a number of measurements were made (described below). All measurements were completed within two hours, except where noted. During the nighttime samplings, all samples were kept in dim light during analysis.

Cyclostat cultures - An additional set of experiments was performed using two cyclostats (nutrient-replete continuous cultures on a L:D cycle), in which samples were collected automatically every hour with a fraction collector (Table 1). The samples were refrigerated at $4^{\circ} \mathrm{C}$ for up to twelve hours and then analyzed on a Coulter Multisizer; 2-ml aliquots were preserved and frozen for later analysis on the flow cytometer (see below for description of analysis). Light levels for the cyclostats were 60 and $120 \mu \mathrm{mol}$ photons $\mathrm{m}^{-2} \mathrm{~s}^{-1}$ for the first 24-h sampling, then a second $24-\mathrm{h}$ sampling was started after increasing the light level to $330 \mu \mathrm{mol}$ photons $\mathrm{m}^{-2} \mathrm{~s}^{-1}$ for the cyclostat that previously had been at $120 \mu \mathrm{mol}$ photons $\mathrm{m}^{-2} \mathrm{~s}^{-1}$.

Flow cytometry - Triplicate samples were analyzed on an EPICS 753 flow cytometer modified to analyze $50 \mathrm{ml}$ seawater samples at $5-10 \mathrm{ml} \mathrm{min}^{-1}$ (Olson et al. 1991, 1993). The culture was diluted $100 \mu \mathrm{l}: 50 \mathrm{ml}$ with $0.22 \mu \mathrm{m}$ filtered seawater (FSW). Fluorescent microspheres (3.79 $\mu \mathrm{m}$, Polysciences, Inc.) were added to each sample as an internal standard. The concentration of beads was calibrated on the flow cytometer in order to calculate cell concentrations (Olson et al. 1993). For each particle, forward light scatter (FLS, $3^{\circ}-19^{\circ}$; see Appendix A), side scatter (90LS, $73^{\circ}$ $107^{\circ}$ ), red (chlorophyll, 660-700 $\mathrm{nm}$ ) fluorescence, and orange (phycoerythrin, 530- 
630) fluorescence were collected. The resulting "listmode" files were analyzed using CytoPC software (D. Vaulot, Station Biologique, Roscoff, France) to obtain numbers of cells and beads analyzed and the mean values for each parameter collected. For Nan500 and Nan1500 the samples were analyzed live, for Nan250 and the cyclostat experiments (Nan60, Nan120, and Nan330) the samples were fixed with $0.1 \%$ glutaraldehyde and stored in liquid nitrogen until analysis (Vaulot et al. 1989, Olson et al. 1993). A comparison of live and frozen samples for Nan500 showed very little difference in forward light scatter, though side light scatter did change significantly and thus was not used for preserved samples (Fig. 2).

Beam attenuation - Beam attenuation was measured with a SeaTech transmissometer (665 $\mathrm{nm}$ light source, $25-\mathrm{cm}$ pathlength) enclosed by a PVC sleeve with a sampling port. First, 1.6 liters FSW was added to the sleeve and a voltage reading was made. Then, culture was added, progressively, to total 8,12 , and $16 \mathrm{ml}$ and a reading was made after each addition. For each measurement, the culture was added to the FSW, the mixture was stirred, and any bubbles were cleared from the transmissometer windows before taking the reading. The procedure was repeated twice for each culture. To analyze the data, voltages were converted to beam attenuation $\left(\mathrm{c}, \mathrm{m}^{-1}\right)$, the preceding FSW blank reading was subtracted from each culture measurement, and the value was normalized to the concentration of cells in the transmissometer sleeve (the measured volume of the culture addition and the calculated concentration from flow cytometric measurements). The samples in the transmissometer sleeve were determined to be optically thin (since the sequential 
Figure 2. Flow cytometric light scatter for Nannochloris grown at $500 \mu \mathrm{mol}$ photons $\mathrm{m}^{-2} \mathrm{~s}^{-1}$ (Nan500) analyzed live and after being preserved with glutaraldehyde and stored in liquid nitrogen. Forward light scatter (FLS) changed little, but side light scatter (90LS) showed significant changes and was thus the 90LS data were not used for preserved samples. Both FLS and 90LS are expressed relative to $3.79 \mu \mathrm{m}$ beads. 


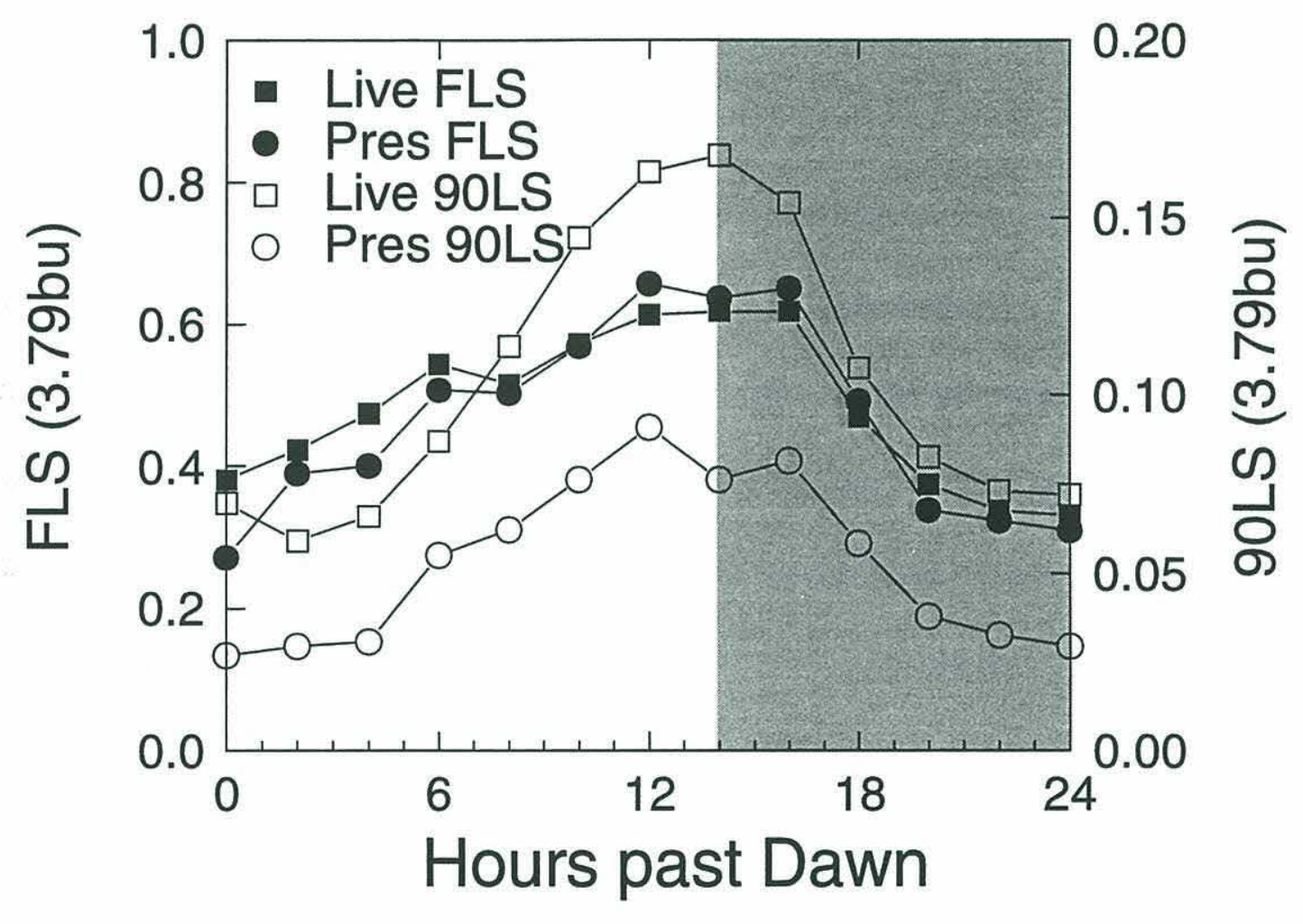


addition series did not depart from linearity), thus multiple interactions were negligible (Bricaud et al. 1983).

Volume - Cell volume was measured using a Coulter Multisizer equipped with a 30 or $50 \mu \mathrm{m}$ orifice. Samples were diluted in filtered seawater to keep the coincidence rate $<5 \%$. At each sampling point, duplicate or triplicate samples were mixed and measured. The samples were analyzed immediately after sampling, except for the cyclostat experiments (Nan60, Nan120, Nan330) when they were refrigerated for up to 12 hours before analysis. There was little difference between replicate test samples run on the Multisizer immediately after collection or after eleven hours of refrigeration (diameter was identical and cell concentration was only $1 \%$ different). For all samples the 256-channel data was saved and analyzed on a computer using software by $\mathrm{M}$. Brzezinski.

Carbon - Replicate samples $(25 \mathrm{ml})$ were filtered onto pre-combusted GF/F filters, frozen, and later dried overnight at $60^{\circ} \mathrm{C}$ and analyzed on a Perkin-Elmer 2400 CHN Analyzer. Replicate blanks consisting of a wet filter were made at each sampling point. Acetanilide was used as the standard. The blanks were subtracted from the samples to obtain the carbon content of the known volume (and number) of cells.

Absorption - Absorption was measured using the opal glass method (Shibata 1958) in a spectrophotometer. A piece of opal glass was attached as close to the detector as possible, and a 1-cm cuvette was place directly against the opal glass. For Nan250 and Nan500, a Bausch and Lomb Spectronic spectrophotometer was 
used (Model 88 for Nan250, Model 100 for Nan500) and a reading was made at two wavelengths, $488 \mathrm{~nm}$ to correspond to the flow cytometer laser light and $665 \mathrm{~nm}$ to correspond to the LED light source in the transmissometer. For Nan1500, a Shimadzu UV-260 spectrophotometer was used and each sample was scanned from 400-750 nm. For each experiment, sterile-filtered $\mathrm{f} / 2$ medium was used in the reference cuvette and subtracted as the blank.

Calculations of optical properties - The scattering coefficient (b) was calculated from the measured attenuation (c) and absorption (a) coefficients (b $=\mathrm{c}$ a). The cross sections for attenuation $\left(\sigma_{\mathrm{c}}\right)$, absorption $\left(\sigma_{\mathrm{a}}\right)$, and scattering $\left(\sigma_{\mathrm{b}}\right)$ are the relevant coefficients normalized to the cell concentration (for example, $\sigma_{\mathrm{c}}=\mathrm{c} /(\mathrm{N} / \mathrm{V})$, where N/V is the number of cells per volume). Cross sections are in units of length ${ }^{2}$ per cell. The dimensionless efficiency factor for attenuation $\left(\mathrm{Q}_{c}\right.$, and similarly for absorption and scattering) was calculated: $\mathrm{Q}_{\mathrm{c}}=\sigma_{\mathrm{c}} /\left(\pi \mathrm{r}^{2}\right)$. Using the anomalous diffraction approximation of Mie theory (Van de Hulst 1957, as described in Morel and Bricaud 1986), the imaginary part of the refractive index $n^{\prime}$ (where $n^{\prime}=$ $\rho^{\prime} / 4\left[2 \pi r /\left(\lambda / n_{w}\right)\right], \rho^{\prime}$ is the optical thickness due to absorption, $\lambda=$ wavelength of light, and $\mathrm{n}_{\mathrm{w}}=1.34$, the refractive index of seawater) was then calculated through iterations from

$$
Q_{a}\left(\rho^{\prime}\right)=1+2 \frac{\exp \left(-\rho^{\prime}\right)}{\rho^{\prime}}+2 \frac{\exp \left(-\rho^{\prime}\right)-1}{\rho^{\prime 2}}
$$

Once n' (and thus $\rho^{\prime}$ ) was determined, the real part of the refractive index was 
calculated through iterations from

$$
Q_{c}(\rho)=2-4 \exp (-\rho \tan \xi)\left[\frac{\cos \xi}{\rho} \sin (\rho-\xi)+\left(\frac{\cos \xi}{\rho}\right)^{2} \cos (\rho-2 \xi)\right]+4\left(\frac{\cos \xi}{\rho}\right)^{2} \cos 2 \xi
$$

where $\tan \zeta=(1 / 2) \rho^{\prime} / \rho$ and $\rho$ is the phase lag of a ray which crosses the particle along its diameter (Morel and Bricaud 1986). Since there are multiple solutions for $\mathrm{Q}_{\mathrm{c}}$, the results were restricted to those reasonable for phytoplankton cells (the first solution with $\mathrm{n}>1.02$ was accepted; all calculated $\mathrm{n}$ values were between 1.04 and 1.07).

\section{RESULTS AND DISCUSSION}

\section{Measurements of cell properties}

For Nan250, Nan500, and Nan1500, cell division was tightly phased, with division starting two hours after darkness and continuing for about six hours (Fig. 3A). Nan1500 was performed outdoors in natural light, unlike the other experiments, thus the cells were exposed to a true dawn and dusk (Fig. 1). The timing of the cell division for this experiment was very similar to that of the others. The cells in the cyclostat experiments (Nan60, Nan120, and Nan330) also divided during the night (Fig. 3B). Specific growth rates determined from flow cytometric measurements of cell concentrations ranged from $\sim 0.2$ to $\sim 0.7 \mathrm{~d}^{-1}$ (approximately one division per day; Fig. 4). 
Cell volume of Nannochloris was minimum near both dawn samplings and maximum near dusk for each experiment (Fig. 5). Flow cytometric measurements of individual cell light scatter (forward, FLS, and side, 90LS) showed similar patterns (Fig. 6). Carbon per cell also increased during the day and decreased at night (Fig. 7). Thus the individual cells are photosynthesizing to add carbon and grow in size during the day and then dividing in the dark to produce smaller cells with less carbon per cell and lower scatter per cell.

The calculated values of refractive index (n) ranged from 1.04 to 1.066 (Fig. 8A), within the range expected for phytoplankton cells (1.02 - 1.07; Aas 1981 as referred to by Morel and Bricaud 1986). There appears to be a small diel pattern in refractive index. The slope of a linear regression fitted to the values of refractive index over time was significantly less than zero for all the experiments during the night, when cell division was occurring (t-test, $\mathrm{p}<0.05$ for each of the three experiments). The refractive index increased significantly during the day for Nan500 (t-test, $\mathrm{p}<0.0025)$. The increase was not significant for Nan250 and Nan1500, perhaps because most of the increase occurred between the first two points for Nan1500 and because the first point for Nan250 was lost.

Refractive index most likely reflects the changing composition of the cells as they grow and divide, due to the different refractive indices of internal components and the cell water content (Aas 1981, as referred to by Morel and Bricaud 1986). The intracellular carbon concentration shows a pattern similar to that of refractive index (Fig. 8B). Both $\mathrm{n}$ and intracellular carbon concentration clearly decrease at 
Figure 3. Cell concentrations changes, measured by flow cytometry, over the course of the experiments for Nannochloris at A) $250 \mu \mathrm{mol}$ photons $\mathrm{m}^{-2} \mathrm{~s}^{-1}$ (Nan250), 500 $\mu \mathrm{mol}$ photons $\mathrm{m}^{-2} \mathrm{~s}^{-1}$ (Nan500), and $1500 \mu \mathrm{mol}$ photons $\mathrm{m}^{-2} \mathrm{~s}^{-1}$ (Nan1500) and B) the cyclostat experiments at $60 \mu \mathrm{mol}$ photons $\mathrm{m}^{-2} \mathrm{~s}^{-1}$ (Nan60), $120 \mu \mathrm{mol}$ photons $\mathrm{m}^{-2} \mathrm{~s}^{-1}$ (Nan120), and $330 \mu \mathrm{mol}$ photons $\mathrm{m}^{-2} \mathrm{~s}^{-1}$ (Nan330). Shading indicates the time period when the lights were out in the incubator (or nighttime for Nan1500). In A) each point represents the average value for the two carboys and error bars show standard errors. In B) the potential cell concentration is shown (measured cell concentration with the dilution rate of the cyclostat taken into account: potential cells $\mathrm{ml}^{-1}=$ measured cells $\mathrm{ml}^{-1}+$ hourly dilution rate $*$ number of hours elapsed $*$ measured cells $\mathrm{ml}^{-1}$ ). Note that Nan120 and Nan330 were the same culture, with only the light level changed for the second day. 

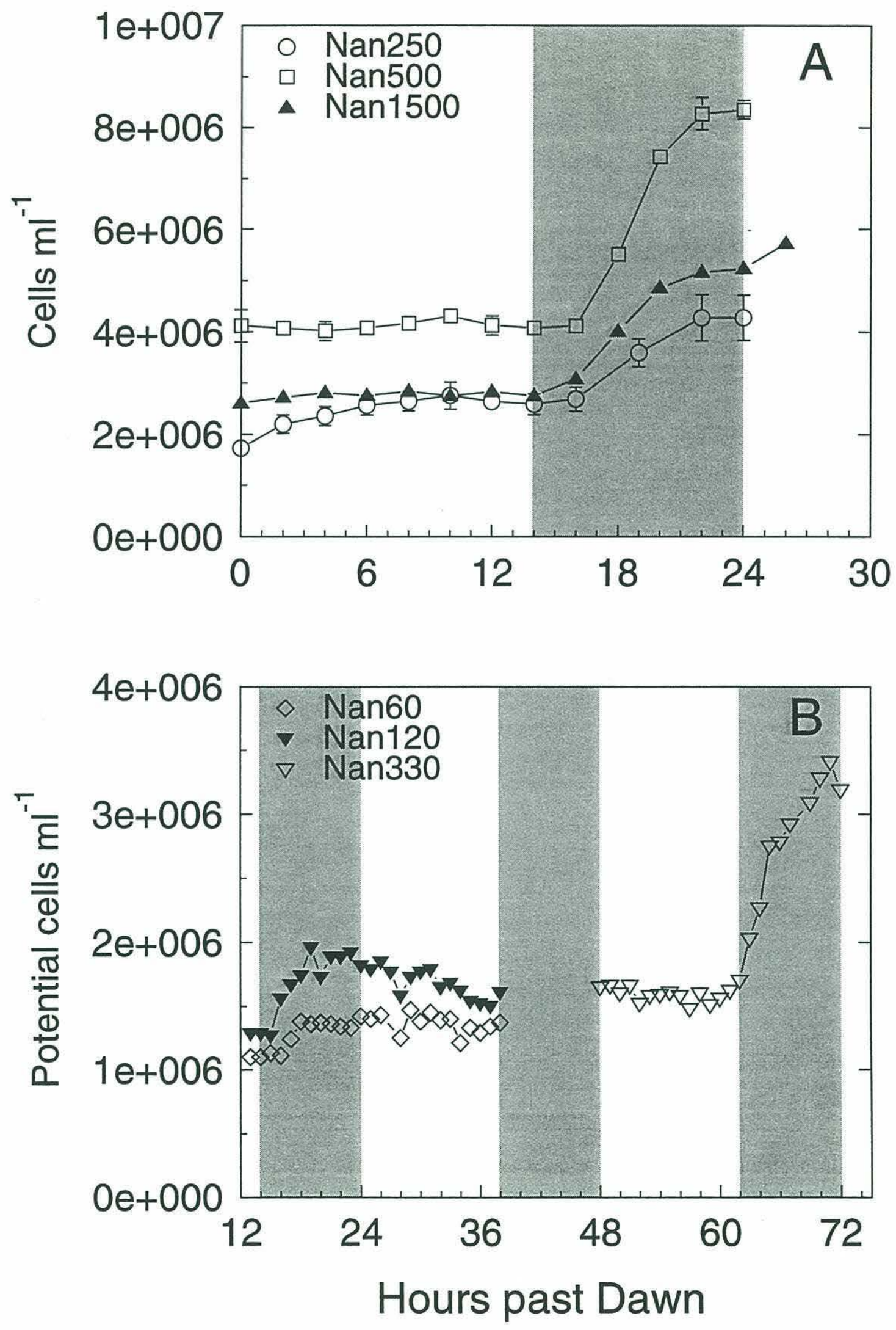
Figure 4. Specific growth rate $\left(\mathrm{d}^{-1}\right)$ determined from changes in cell concentration (see Fig. 3) at different light levels. For each experiment the cells were exposed to the light level indicated for fourteen hours out of every 24 hours. 


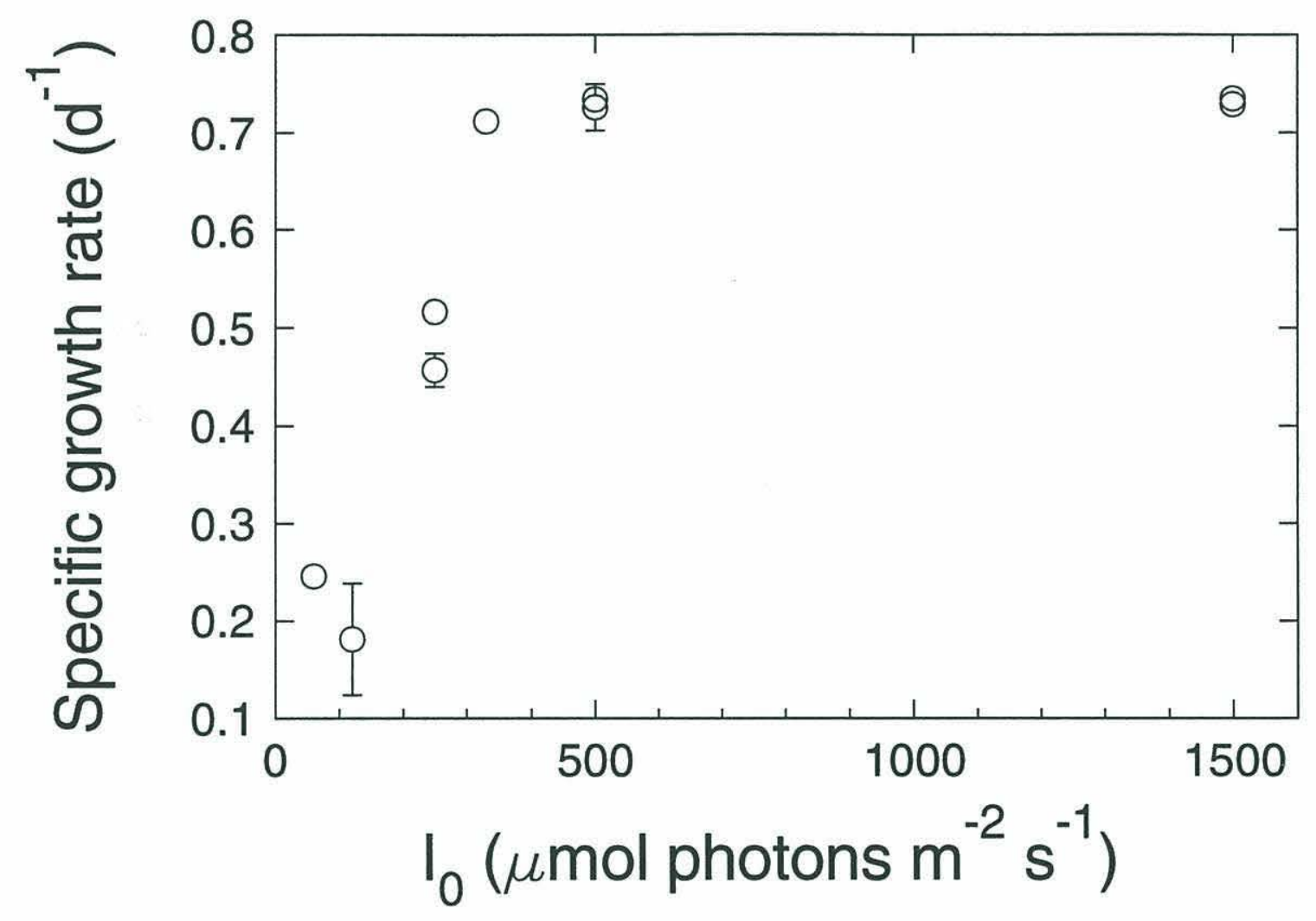


Figure 5. Time series measurements of cell volume from Coulter electronic particle sizer for A) Nan250, Nan500, and Nan1500 and B) the cyclostat experiments Nan60, Nan120, and Nan330. For A) average $(n=2)$ and standard error bars are shown. 


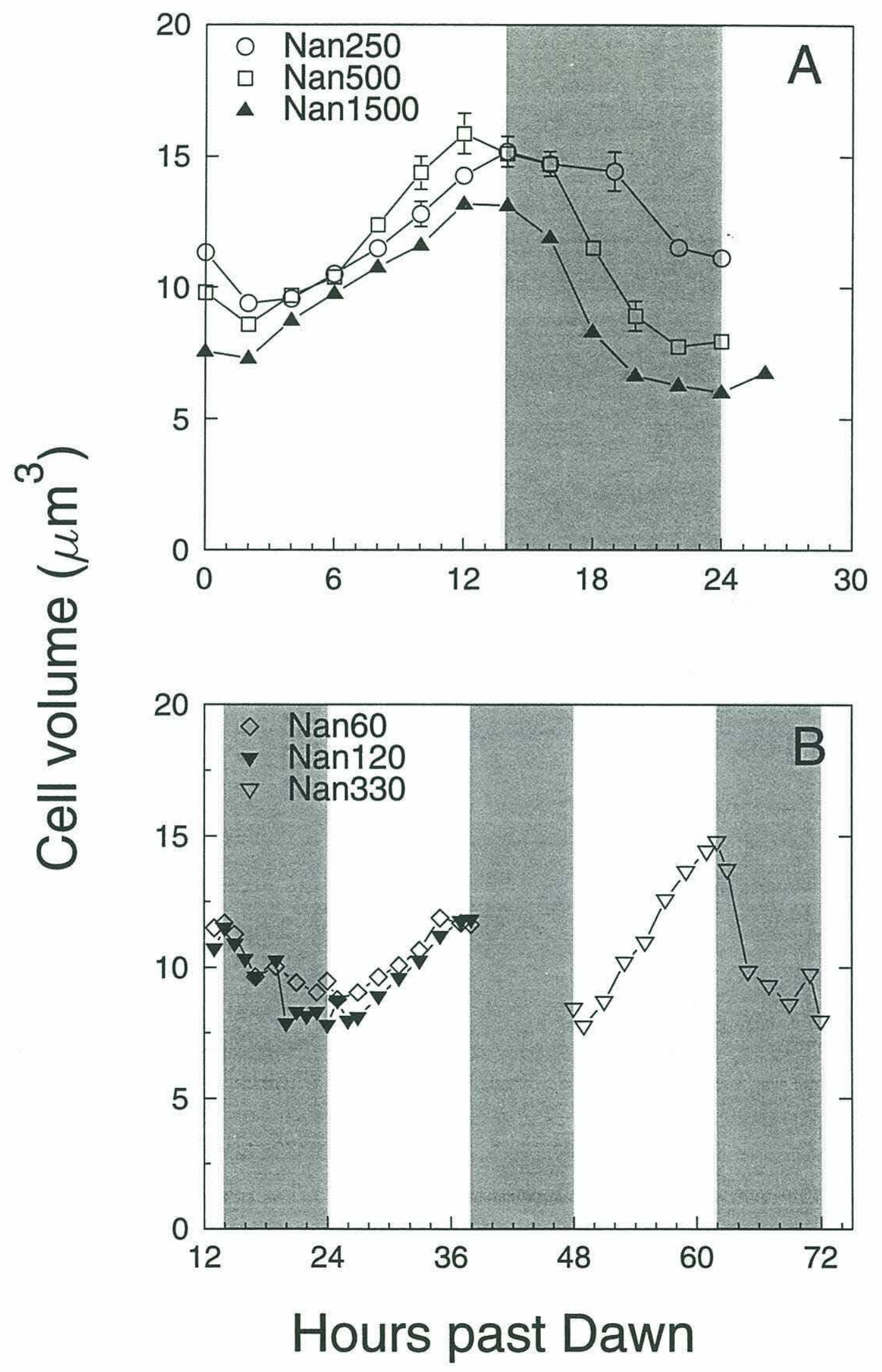


Figure 6. Time series measurements of forward light scatter $\left(3^{\circ}-19^{\circ}\right)$ for A) Nan 250 , Nan500, and Nan1500, and B) Nan60, Nan120, and Nan330. C) Side scatter $\left(73^{\circ}-\right.$ $107^{\circ}$ ) from flow cytometric measurements for the same experiments as in panel A. Values are expressed relative to $3.79 \mu \mathrm{m}$ beads. 

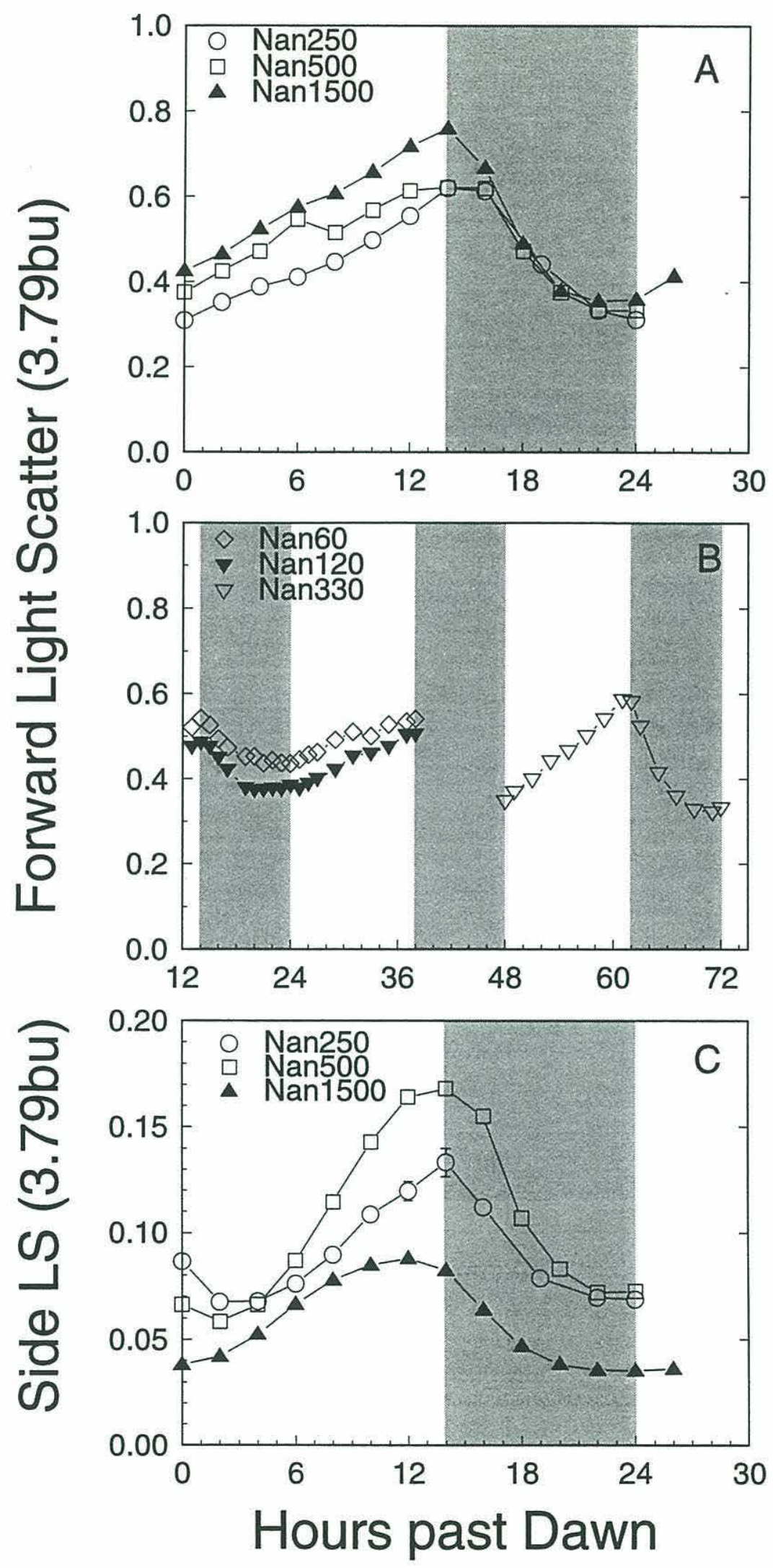
Figure 7. Time series measurements of fg carbon per cell for Nan250, Nan500, and Nan1500. Averages ( $n=2$ carboys) and standard error bars are shown. 


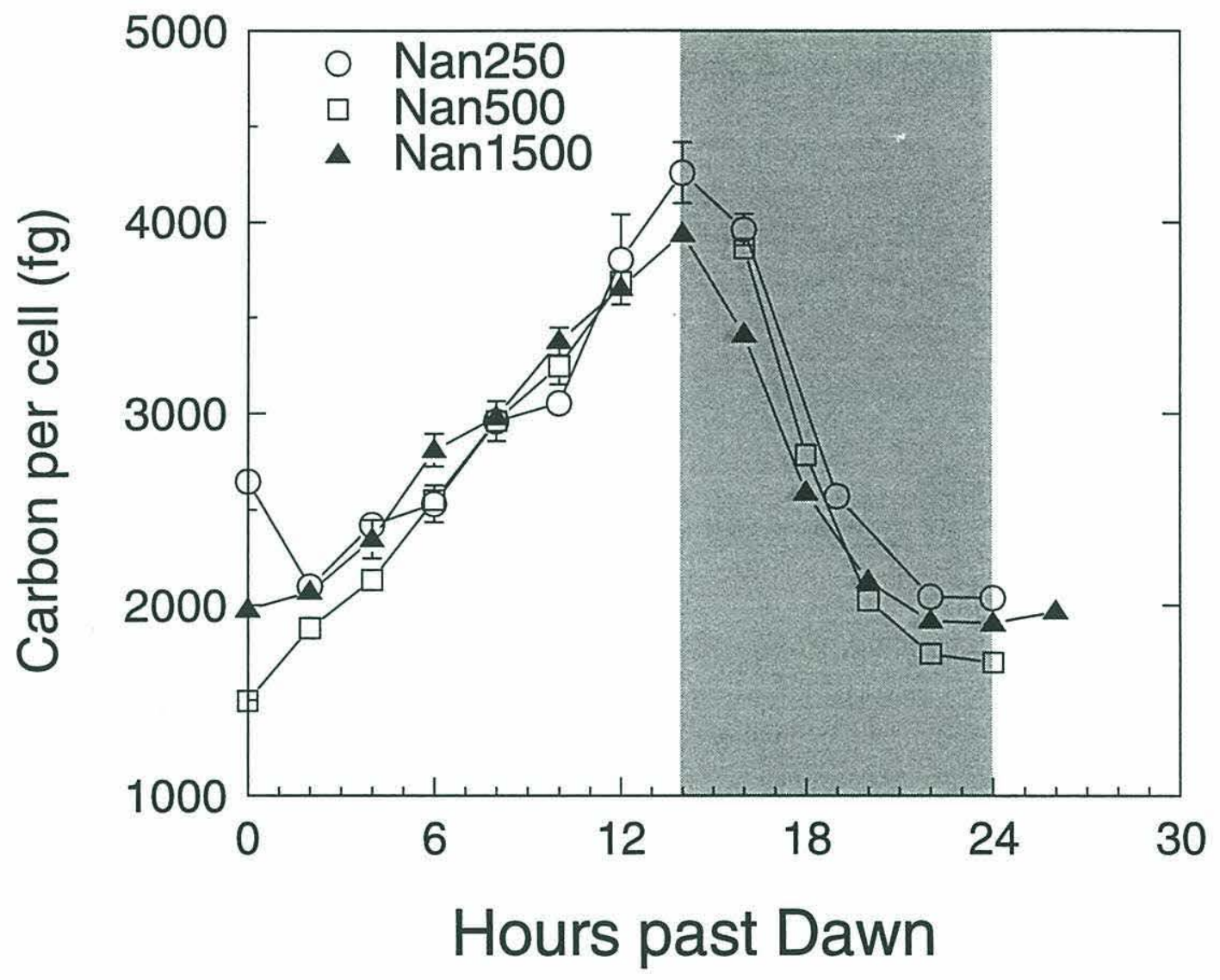


Figure 8. Time series of A) calculated real refractive index (n), B) intracellular carbon concentration $\left(\mathrm{kg} \mathrm{m}^{-3}\right)$, and C) calculated imaginary refractive index (n') of Nannochloris for Nan250, Nan500, and Nan1500. All calculations were made at a wavelength of $665 \mathrm{~nm}$. 

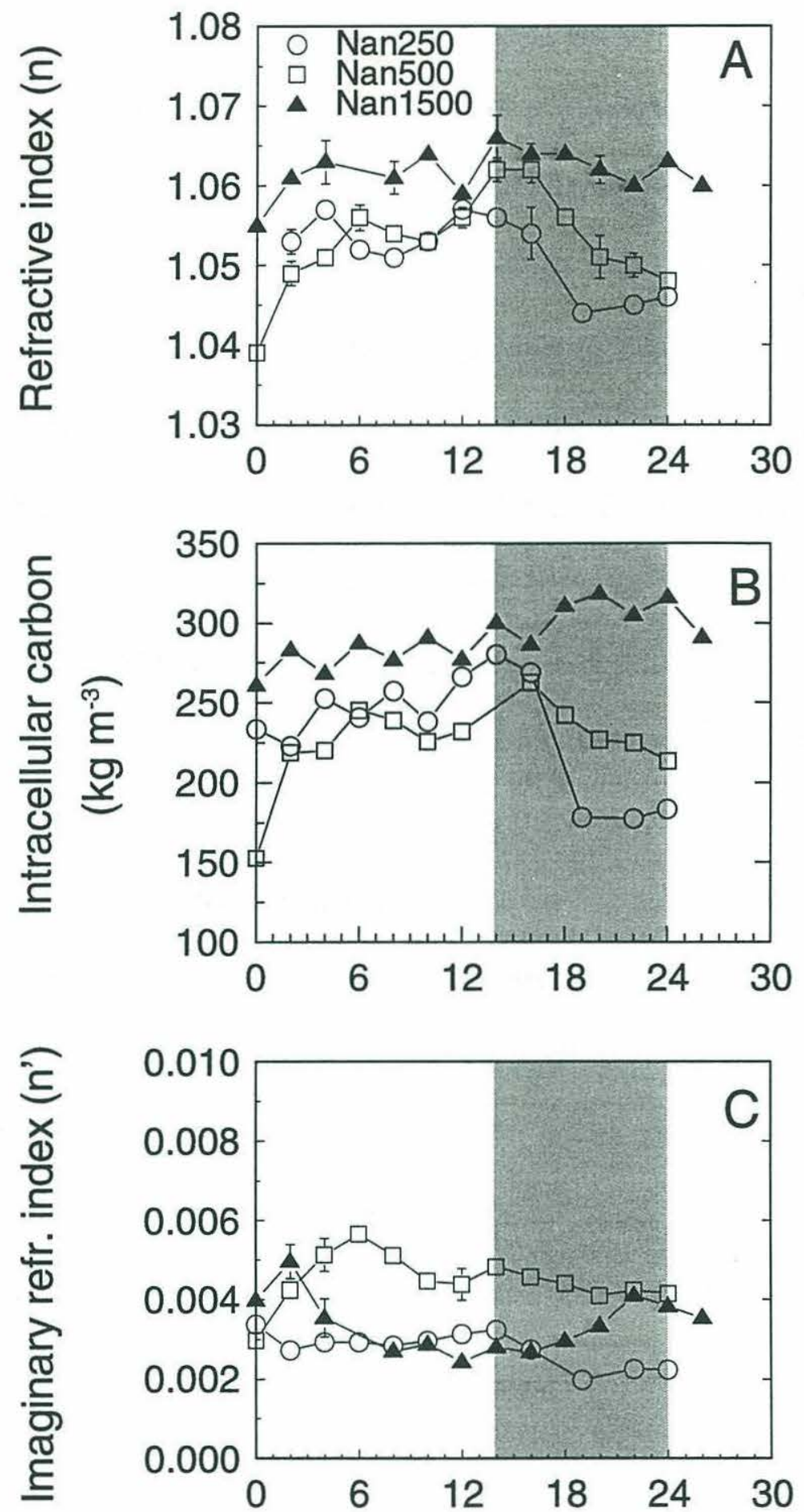

Hours past Dawn 
night when the cells are dividing for Nan250 and Nan500. One explanation is that the cell water content could be higher (causing a lower refractive index) when the cells are dividing. Another possibility is that the decrease in refractive index reflects a loss of carbon due to cell respiration when the cells are dividing. Markager et al. (1992) observed a faster rate of dark respiration for the first two hours in the dark for a community of phytoplankton in a eutrophic lake. In studies of Isochrysis galbana, Carder et al. (1972) suggested that increases in refractive index seemed to be related to increases in the surface area to volume ratio of the cells, since the cell wall was expected to be one of the most refractive parts. However, if this were the case, we would expect an increase in $\mathrm{n}$ with cell division, instead of the observed decrease, since the newly divided (smaller) cells would have a higher surface area to volume ratio. It is interesting to note that the highest $\mathrm{n}$ (close to 1.06) and intracellular carbon concentration and the smallest changes in both properties during the diel cycle are for the natural light experiment (Nan1500). This could be due to the higher light level or the fact that there was a true dawn and dusk for that experiment. Additional experiments are required to further investigate these effects. The calculated value of the imaginary part of the refractive index, generally ranging from 0.003 to 0.005 (Fig. $8 \mathrm{C}$ ), was similar to that determined by others for phytoplankton cells $\left(\mathrm{n}^{\prime} \simeq 0.004\right.$ at $660 \mathrm{~nm}$; Stramski and Reynolds 1993). For all three experiments, the changes seen are small. There was little pattern over the diel cycle for Nan250; Nan500 increased during the morning and then decreased during the afternoon, while Nan 1500 tended to decrease during the day and increase at 
night. Since the cultures for Nan 1500 were only exposed to the higher natural light conditions for one day before the sampling began, they were not expected to be at steady state. Thus we are most likely seeing effects of photoacclimation during that experiment.

The attenuation cross section $\left(\sigma_{\mathrm{c}}\right)$ and the scattering cross section $\left(\sigma_{\mathrm{b}}\right)$ both increased during the day to reach a maximum at dusk and then decreased at night (Fig. 9A, B). These patterns are similar to those seen in cell volume (Fig. 5), light scatter per cell (Fig. 6) and carbon per cell (Fig. 7). The absorption cross section $\left(\sigma_{\mathrm{a}}\right)$ was always small compared to the attenuation cross section (Fig. 9C); it tended to increase during the day and decrease at night. The chlorophyll fluorescence per cell measured with the flow cytometer showed similar patterns to $\sigma_{a}$, with higher fluorescence for Nan60 and Nan120, the lowest light levels, compared to Nan250, Nan500, and Nan1500 (Fig. 10). The second day of the cyclostat experiment (when the Nan120 culture was exposed to high light to become Nan330) shows unexpected results, reaching the highest fluorescence value of all the experiments at its maximum.

Refractive index and intracellular carbon concentration are strongly correlated $\left(n=36, r^{2}=0.85\right.$; Fig. 11). The slope of the relationship (approximately 1.5e-4) indicates that the refractive index of the Nannochloris cells increases by $1.5 \mathrm{e}-4$ for every one $\mathrm{kg} \mathrm{m}^{-3}$ increase in the intracellular carbon concentration. This value is lower than that calculated by Morel and Ahn (1990) based on the contributions of the internal components of a cell (2.3e-4). It is also lower than that measured by 
Figure 9. Time series of the attenuation cross section $\left(\sigma_{c}, \mathrm{~A}\right)$, scattering cross section $\left(\sigma_{\mathrm{b}}, \mathrm{B}\right)$, and absorption cross section $\left(\sigma_{\mathrm{a}}, \mathrm{C}\right)$ at a wavelength of $665 \mathrm{~nm}$ for Nan250, Nan500, and Nan1500. The attenuation and absorption cross sections are from bulk measurements of attenuation and absorption normalized to the cell concentration. The scattering cross sections were obtained by subtraction $\left(\sigma_{\mathrm{c}}-\sigma_{\mathrm{a}}\right)$. 

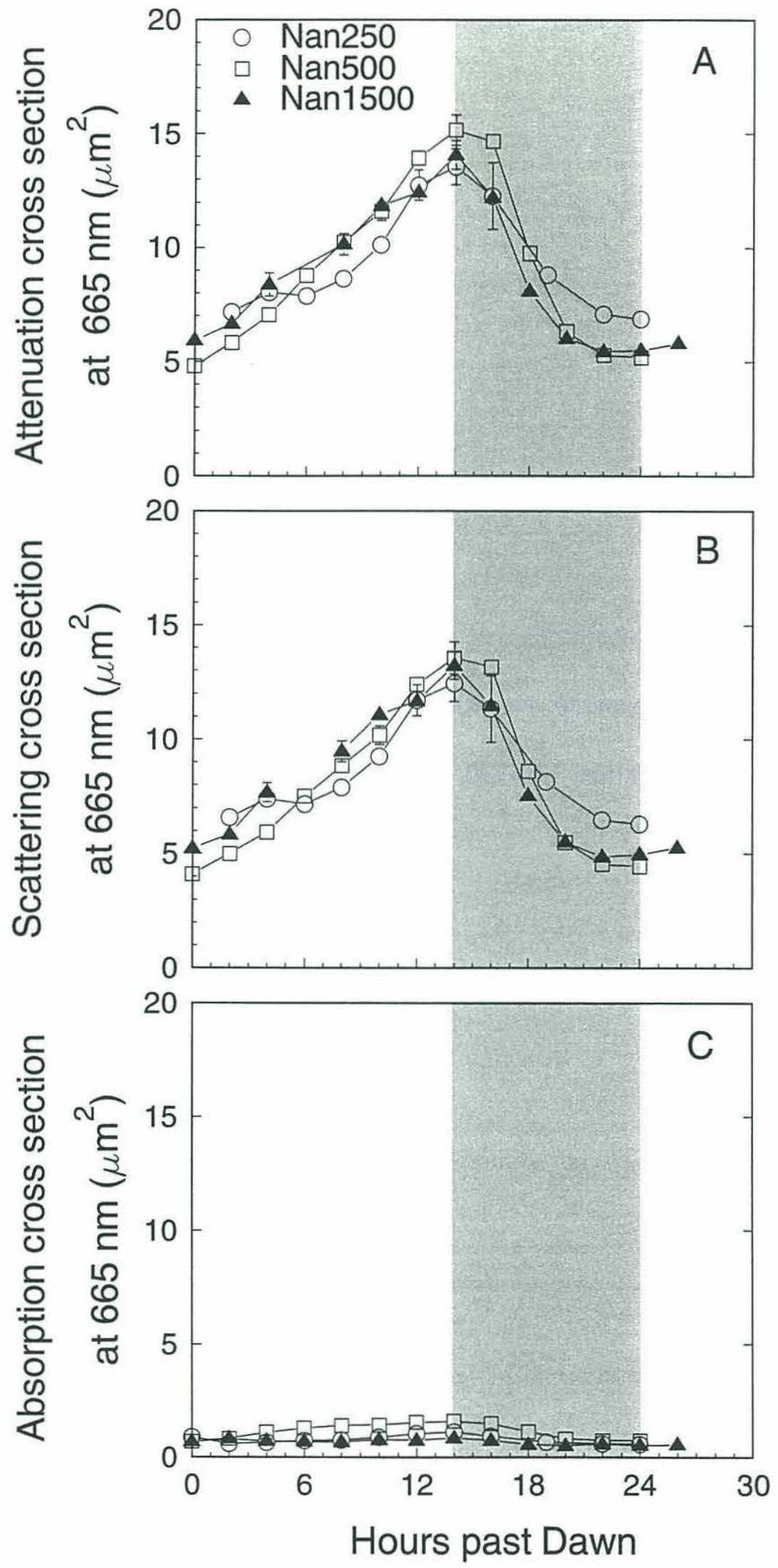
Figure 10. Time series measurements of chlorophyll fluorescence per cell from flow cytometric analysis for A) Nan250, Nan500, and Nan1500 and B) the cyclostat experiments Nan60, Nan120, and Nan330. Values are expressed relative to $3.79 \mu \mathrm{m}$ beads. 


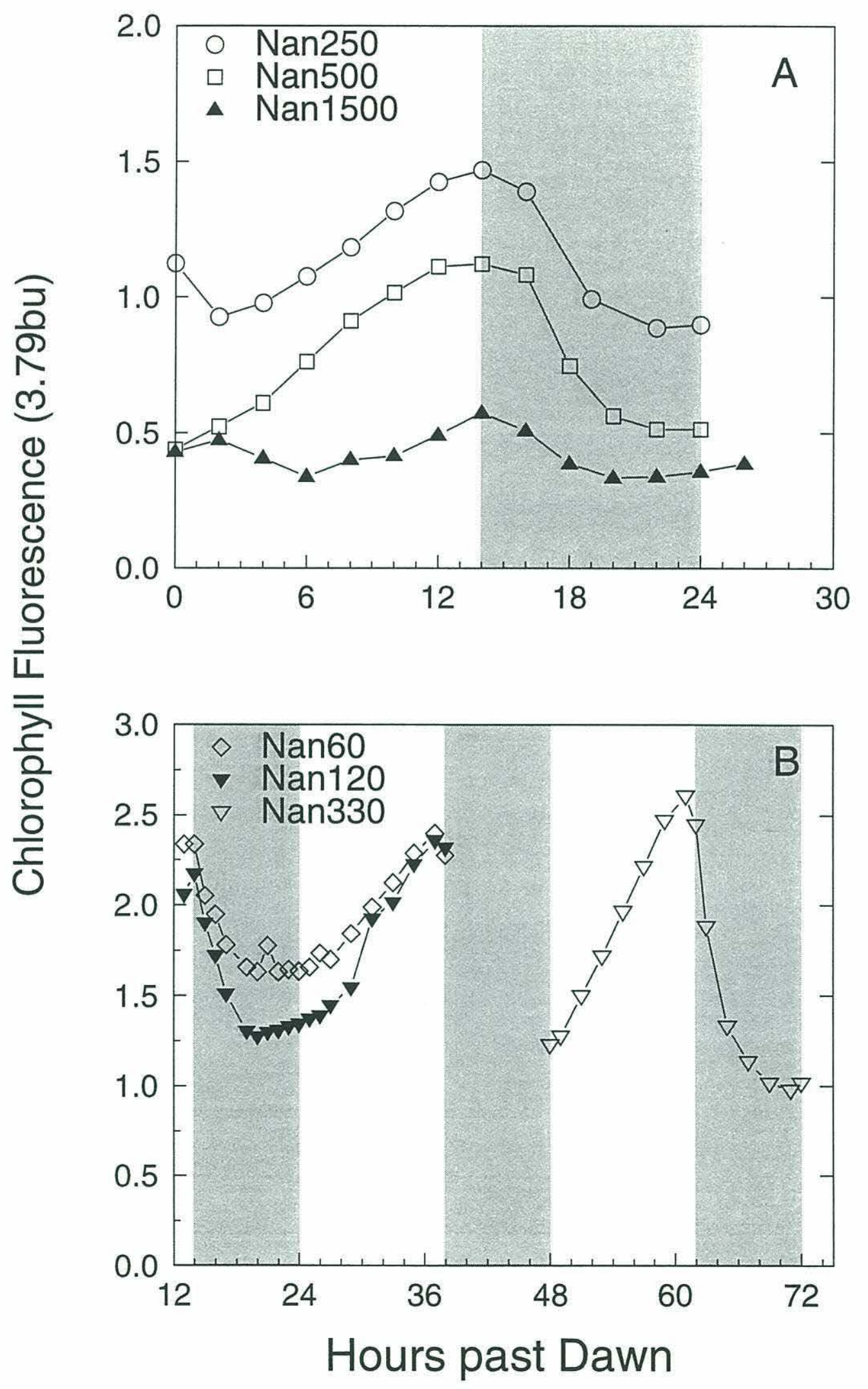


Figure 11. Relationship between refractive index (n at $665 \mathrm{~nm}$ ) and intracellular carbon concentration $\left(\mathrm{kg} \mathrm{m}^{-3}\right)$ for Nan250, Nan500, and Nan1500. The equation for the regression is $\mathrm{y}=1.47 \mathrm{e}-4(\mathrm{x})+1.02, \mathrm{r}^{2}=0.85$. 


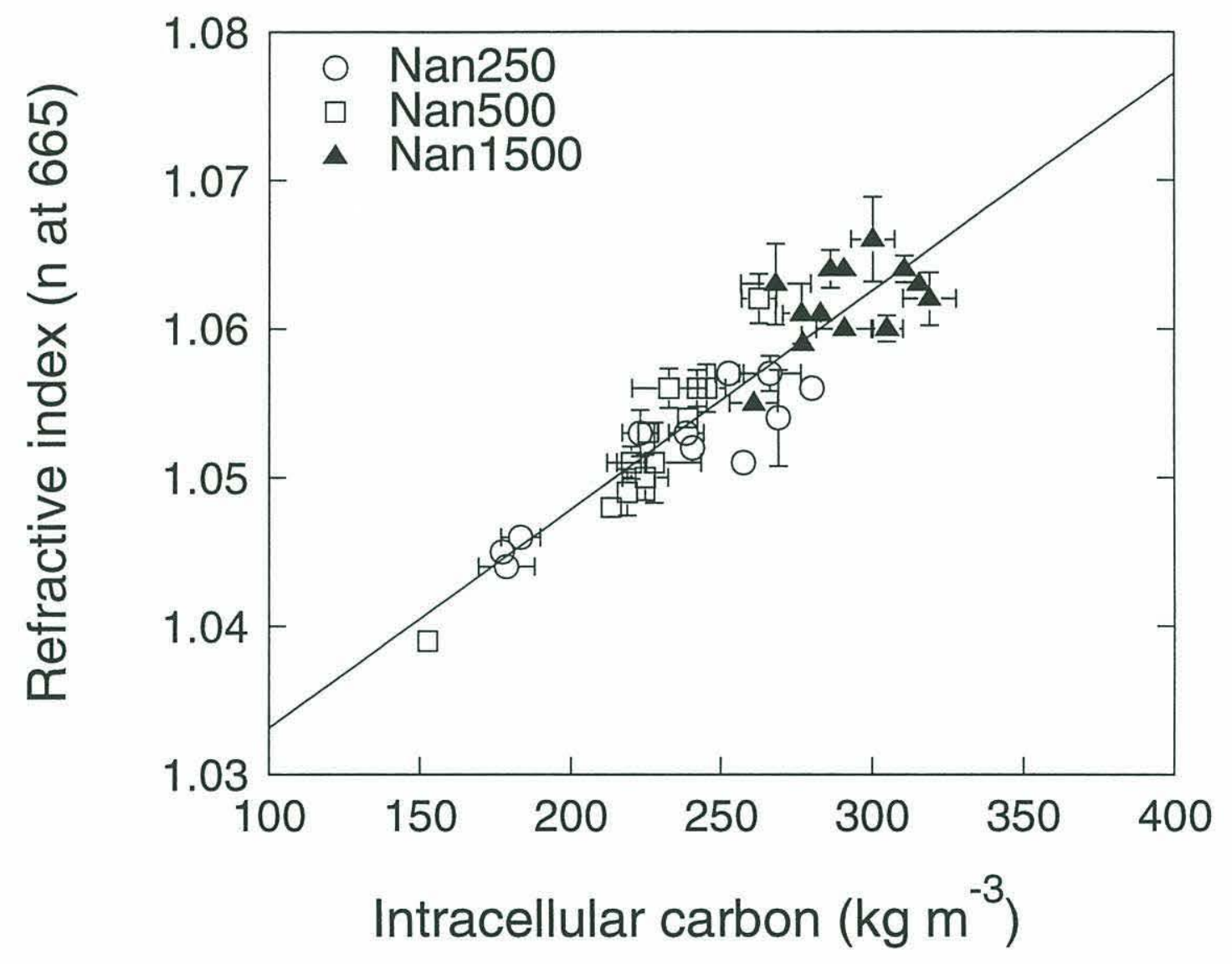


Stramski and Reynolds (1993) for Thalassiosira pseudonana (1.7e-4), Stramski et al. (1995) for Synechococcus (1.7e-4), and Stramski and Morel (1990) for Synechocystis (2.4e-4). Thus, compared to previous cells tested, Nannochloris appears to have a smaller increase in refractive index for the same change in intracellular carbon concentration.

There is a strong correlation between the flow cytometric forward light scatter (at $488 \mathrm{~nm}$ ) and the total scattering cross section $\left(\sigma_{\mathrm{b}}\right.$, at $\left.665 \mathrm{~nm}\right)$ determined by subtraction of the measured $\sigma_{\mathrm{c}}$ and $\sigma_{\mathrm{a}}\left(\mathrm{r}^{2}=0.80\right.$; Fig. 12). This is important since flow cytometric FLS can be measured on individual cells within mixed populations in natural samples. Flow cytometry provides an important link between optical properties which, though often measured in bulk, can be expressed on a per cell basis for laboratory studies, and measurements in the field which can only be made in bulk, such as beam attenuation (DuRand and Olson in press, Chapter 4).

Estimation of cell volume and specific growth rate

The relationship between cell size and forward light scatter changes depending on cell size. According to Mie theory, for picoplankton-sized cells, forward light scatter should vary with diameter to the sixth power (Morel and Bricaud 1986). For cells in the size range of Nannochloris, FLS should vary with diameter to the second or third power (i.e., with area or volume) depending on the assumed refractive index and angles of collection (results of Mie theory calculations performed using program of Ackleson and Spinrad 1988). Since we are interested in 
Table 2. Results of linear regressions on volume $\left(\mathrm{vol}\right.$, in $\left.\mu \mathrm{m}^{3}\right)$ and forward light scatter (FLS) or side light scatter (90LS), both expressed relative to $3.79 \mu \mathrm{m}$ reference beads.

\begin{tabular}{llll}
\hline \hline Experiment & Equation & $\mathrm{n}$ & $\mathrm{r}^{2}$ \\
\hline Nan1500 & Vol $=18.6 *$ FLS -0.70 & 27 & 0.98 \\
Nan1500 & Vol $=121 * 90 \mathrm{LS}+2.29$ & 27 & 0.91 \\
Nan60,120,330,500 & $\mathrm{Vol}=24.1 *$ FLS -0.54 & 77 & 0.80 \\
Nan60,120,330,500 & $\mathrm{Vol}=68.9 * 90 \mathrm{LS}+4.13$ & 26 & 0.91 \\
\hline \hline
\end{tabular}

small ranges of size (close to twofold), we can simplify the situation by assuming a linear relationship between size and FLS (given an approximately constant refractive index). For each Nannochloris experiment, a linear regression was obtained for the relationship between FLS and cell volume (Fig. 13). An analysis of covariance was performed and the hypothesis that all slopes $(\beta)$ are equal was rejected $(\mathrm{p}<0.0005)$. A multiple comparison testing of the slopes (Tukey test) revealed that they came from two separate populations, where $\beta_{120}=\beta_{60}=\beta_{500}=\beta_{330} \neq \beta_{1500}$ (we cannot conclude how $\beta_{250}$ is related to the other population slopes). The implication is that Nan1500, the natural light experiment, is different from the others and we will consider it separately.

Relationships between FLS or 90LS and cell volume were determined separately for the two distinguishable groups of data: for Nan1500 and for Nan60, $.120,500$, and 330 combined. Cell volume for both data sets was well estimated by either a linear regression on FLS or 90LS (Table 2), despite changes in refractive index seen over the day (Fig. 8A). Ackleson and co-workers used flow cytometric 
Figure 12. Relationship between flow cytometric forward light scatter (at $488 \mathrm{~nm}$, $3.79 \mu \mathrm{m}$ bead units) and total scattering cross section (calculated from measured attenuation and absorption at $665 \mathrm{~nm})$. Linear regression $\left(\mathrm{r}^{2}=0.80\right)$ and $95 \%$ confidence intervals are shown. 


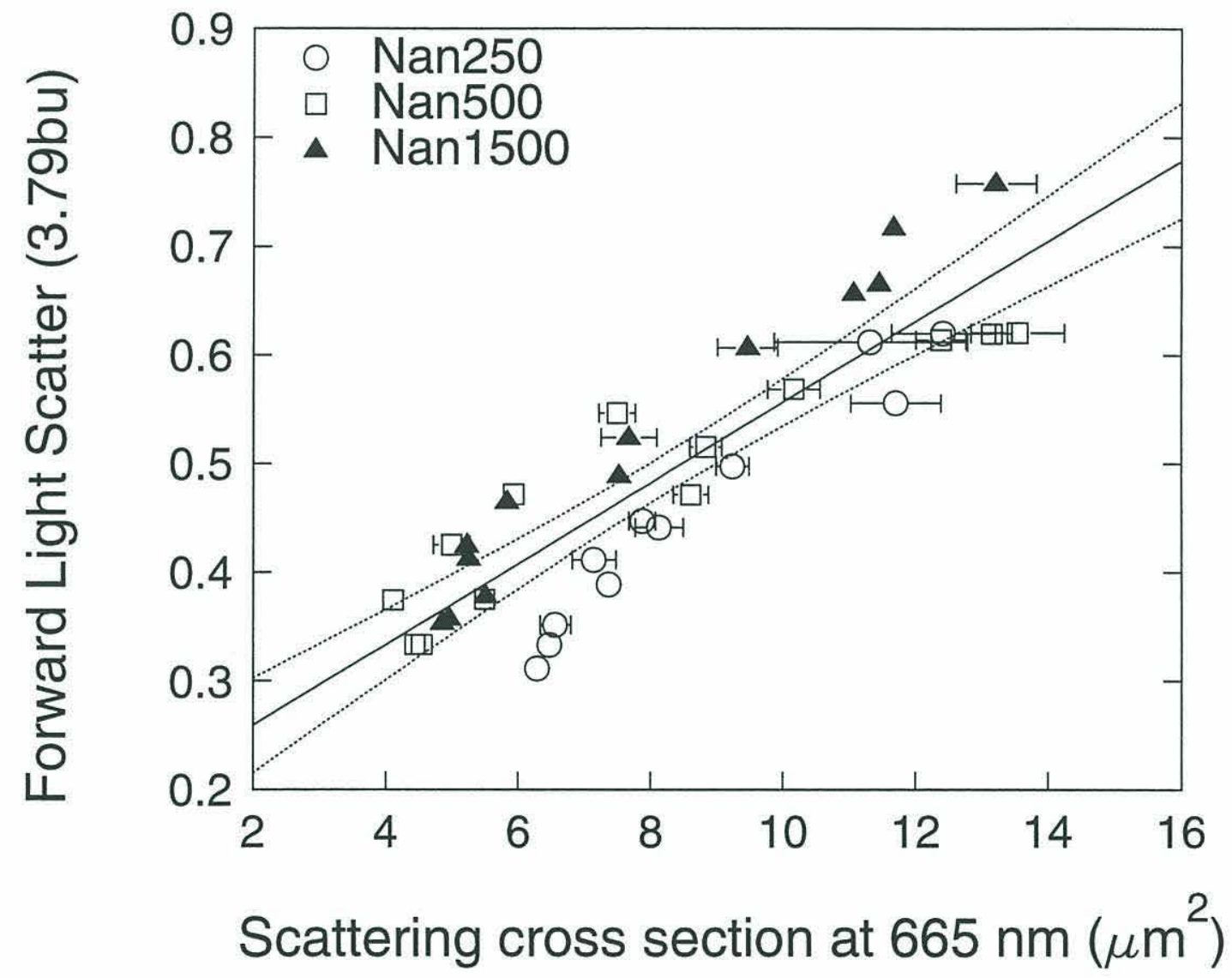


Figure 13. The relationship between forward light scatter (FLS in $3.79 \mu \mathrm{m}$ bead units) and cell volume $\left(\mu^{3}\right)$ for Nan60, Nan120, Nan250, Nan330, Nan500, and Nan1500. The dotted line is a linear regression on the Nan 1500 data only. The solid line is a linear regression on the combined data for Nan60, Nan120, Nan330, and Nan500. 


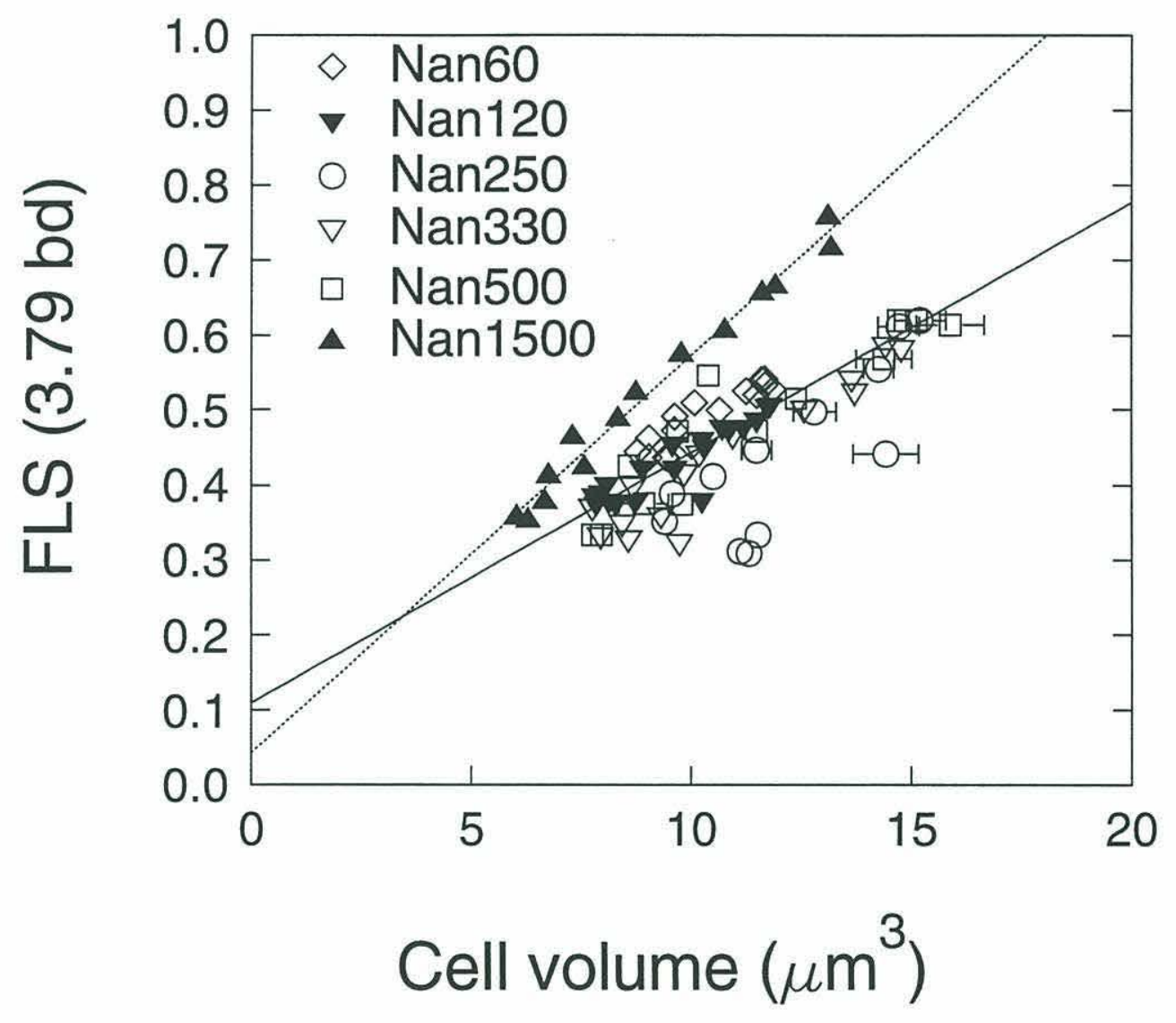


measurements of FLS and side scatter to estimate cell volume and refractive index using Mie theory for laboratory cultures (Ackleson and Spinrad 1988) and also in the field (Ackleson et al. 1988). For their laboratory culture work, the range in the estimated refractive index was up to nearly 0.01 , which is similar to the range calculated for the Nannochloris experiments reported here. Thus it appears that such a method may not be able to distinguish the small changes in refractive index which may occur over the day. This may not be an important drawback, however, if the small refractive index changes do not affect the total scattering or attenuation as much as changes in cell size do.

Specific growth rates can be estimated from the diel measurements in cell volume if cell division is phased. If, for example, the cells are dividing once per day, then the average volume would be expected to double during the day and then halve upon division at night (in general, $\mu=\ln$ (MaxVolume/MinVolume). If the refractive index is not changing significantly, then cell light scattering should also give a good estimate of the growth rate for cells of this size, for which forward light scatter is proportional to volume (near $\mathrm{d}^{3}$ ). For these experiments, the forward light scatter measurements give a better estimate of the growth rate (calculated from cell concentrations) than do cell volume or side scatter (Table 3). 
Table 3. Results of linear regressions (with zero intercept) where $X=$ specific growth rate calculated from cell concentration $\left(\mu=\ln \left(\mathrm{N}_{1} / \mathrm{N}_{0}\right) /\left(\mathrm{t}_{1}-\mathrm{t}_{0}\right)\right.$; where $\mathrm{N}$ is the cell concentration, $\mathrm{t}$ is time, and the subscripts indicate values at two times ( 1 is after division and 0 is before division; the time interval is one day)) and $\mathrm{Y}=$ specific growth rate calculated from forward light scatter, side light scatter, or cell volume ( $\mu=\ln (\mathrm{Max} / \mathrm{Min})$; with a time interval of one day). $\mathrm{N}=9, \mathrm{p}<0.001$ for all regressions except Volume Daytime increase where $\mathrm{p}<0.10$.

\begin{tabular}{lll}
\hline \hline Data for Y & Equation & $\mathrm{r}^{2}$ \\
\hline FLS (Daytime increase) & $\mathrm{y}=0.740 \mathrm{x}$ & 0.82 \\
FLS (Nighttime decrease) & $\mathrm{y}=0.934 \mathrm{x}$ & 0.88 \\
90LS (Daytime increase) & $\mathrm{y}=1.23 \mathrm{x}$ & 0.78 \\
90LS (Nighttime decrease) & $\mathrm{y}=1.186 \mathrm{x}$ & 0.72 \\
Volume (Daytime increase) & $\mathrm{y}=0.871 \mathrm{x}$ & 0.25 \\
Volume (Nighttime decrease) & $\mathrm{y}=0.947 \mathrm{x}$ & 0.82 \\
\hline \hline
\end{tabular}

\section{Carbon-specific beam attenuation}

The carbon-specific beam attenuation $\left(\mathrm{c}_{\mathrm{c}}{ }^{*}\right.$, Fig. 14$)$ varies by up to $25 \%$ over

the course of the measurements. $\mathrm{C}_{\mathrm{c}}{ }^{*}$ for both Nan500 and Nan1500 tends to increase during the day and decrease rapidly concurrent with cell division at the beginning of the night; $\mathrm{c}_{\mathrm{c}}{ }^{*}$ for Nan250 shows no distinct pattern. This may be important in relation to estimates of carbon production from diel variations in beam attenuation at sea (Siegel et al. 1989, Cullen et al. 1992, Walsh et al. in press). In these cases, a constant $\mathrm{c}_{\mathrm{c}}{ }^{*}$ was applied to represent all phytoplankton at all times of the day. If, indeed, $\mathrm{c}_{\mathrm{c}}{ }^{*}$ changes during the day then these conclusions may not be valid. The increase from dawn to dusk is up to $25 \%$ for Nannochloris (reported here), and about 30\% for slowly-growing Synechococcus (Stramski et al. 1995), but with no consistent pattern from dawn to dusk for Thalassiosira pseudonana (though up to $30 \%$ variation 
Figure 14. Time series of the carbon-specific beam attenuation $\left(\mathrm{c}_{\mathrm{c}}{ }^{*}\right.$ in $\left.\mathrm{m}^{2}(\mathrm{gC})^{-1}\right)$ for Nan250, Nan500, and Nan1500. 


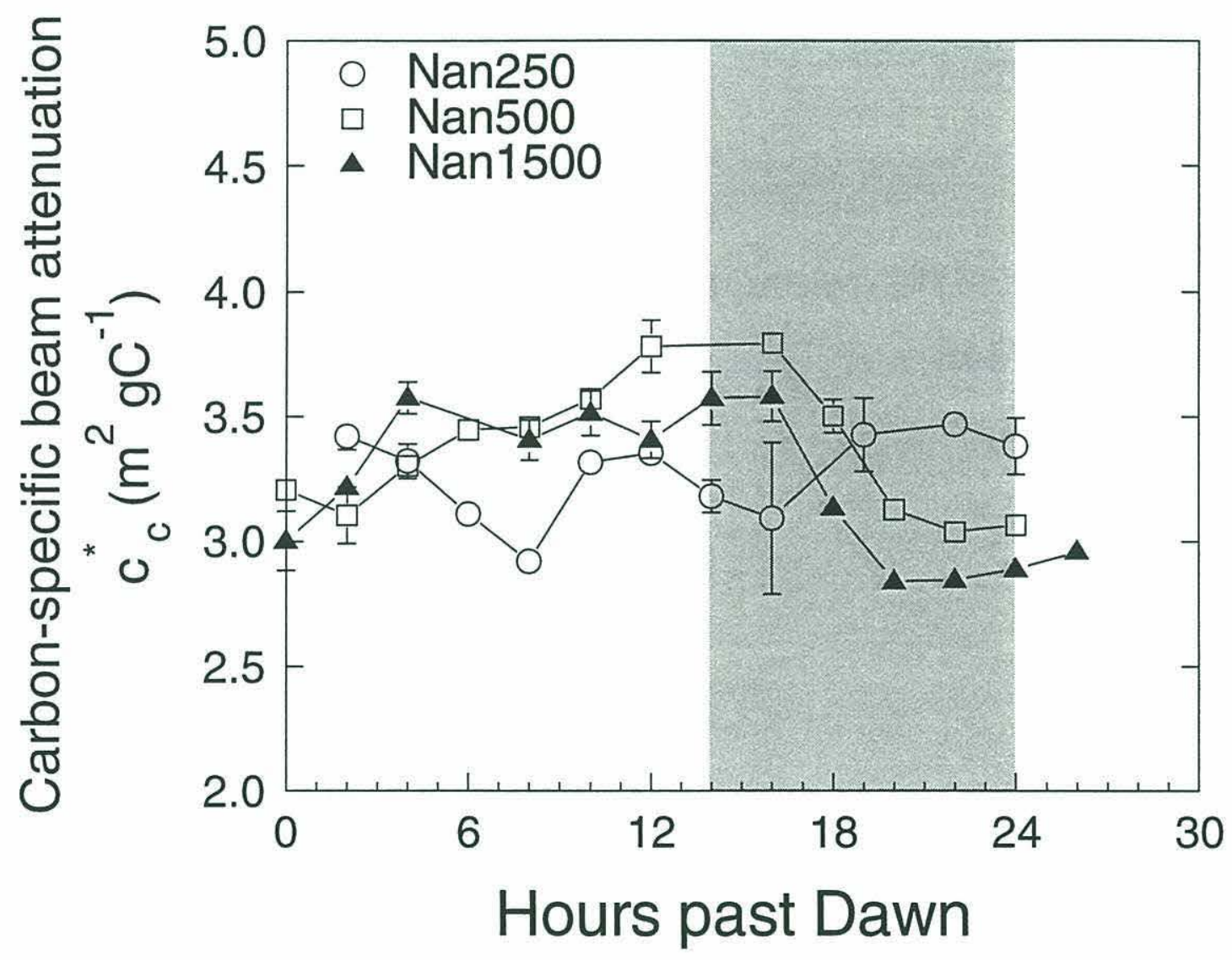


Figure 15. Results of the sensitivity analysis of the attenuation cross section $\left(\sigma_{\mathrm{c}}\right)$ to varying refractive index, $\mathrm{n}$, at a constant diameter, $\mathrm{d}$ (open symbols) and varying diameter at a constant refractive index (filled symbols). 


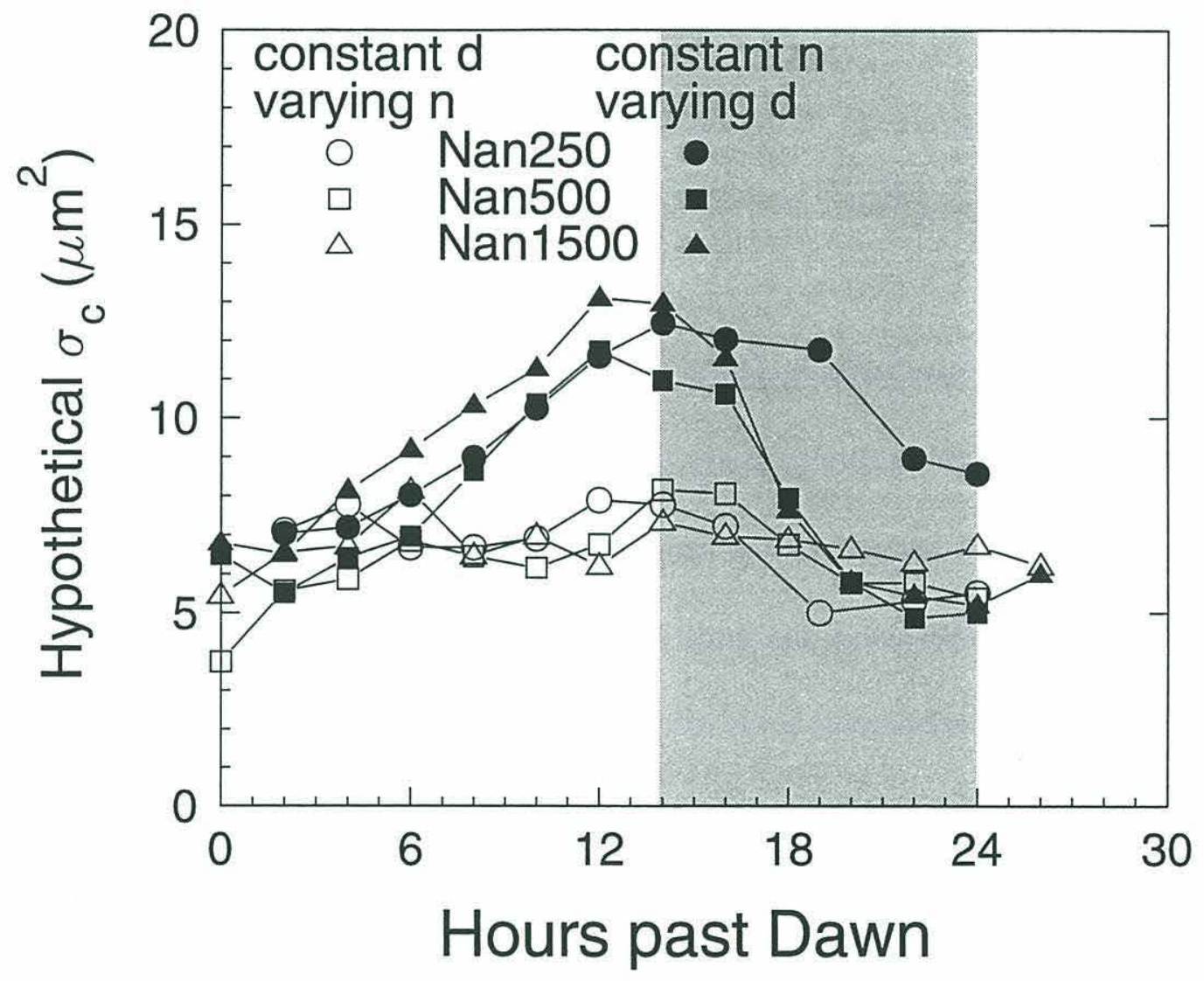


over a three-day sampling; Stramski and Reynolds 1993). Our average $\mathrm{c}_{\mathrm{c}}{ }^{*}$ for Nannochloris of $3.38 \mathrm{~m}^{2}(\mathrm{~g} \mathrm{C})^{-1}(\mathrm{n}=49, \mathrm{sd}=0.34)$ is similar to that of Stramski and Reynolds for T. pseudonana, 3.81. Stramski et al. found Synechococcus to have a lower value of $2.48 \mathrm{~m}^{2}(\mathrm{~g} \mathrm{C})^{-1}$. We also found a lower $\mathrm{c}_{\mathrm{c}}{ }^{*}$ for Synechococcus, 1.52 ( $\mathrm{n}=8, \mathrm{sd}=0.26$, for four strains, unpublished data). It therefore appears that there can be significant differences in the carbon-specific beam attenuation both with time of day and among different species. Thus it may be possible to improve estimates of production by using a different $\mathrm{c}_{\mathrm{c}}{ }^{*}$ for dawn and for dusk (the minimum and maximum of beam attenuation in the field) and for different species (if the composition of the phytoplankton community is known; DuRand and Olson in press).

\section{Contributions of diameter and refractive index to $\sigma_{c}$}

We performed a sensitivity analysis to determine the contributions of diameter and refractive index to the attenuation cross section $\left(\sigma_{c}\right)$. Using the data from each carboy in each diel experiment, the mean cell diameter was held constant at the minimum value near dawn (two hours after dawn), and $\mathrm{Q}_{\mathrm{c}}$ and $\sigma_{\mathrm{c}}$ were calculated to determine the effect of changing refractive index on $\sigma_{c}$ (n', which had only a small effect, was assumed to be zero for these calculations). Similarly, the refractive index was held constant (at its value at two hours after dawn) and $Q_{c}$ and $\sigma_{c}$ were calculated to determine the effect of changing diameter on $\sigma_{\mathrm{c}}$. The observed variations in diameter through the diel cycle had a much greater effect on $\sigma_{c}$ than did those of refractive index (Fig. 15). To quantify this effect, we performed a linear 
regression between the measured attenuation cross section (data in Fig. 9A) and the hypothetical attenuation cross section (Fig. 15). We found that $79 \%$ of the variance in measured $\sigma_{c}$ is explained by the hypothetical $\sigma_{c}$ when only diameter is allowed to vary. Thus the diel variations in $\sigma_{\mathrm{c}}$ for Nannochloris are primarily influenced by changes in cell size and not in refractive index. In contrast to this, studies on Thalassiosira pseudonana and Synechococcus, have shown that changes in cell size were equally or less important than changes in refractive index in determining $\sigma_{\mathrm{c}}$, depending on the time of day (Stramski and Reynolds 1993, Stramski et al. 1995).

\section{CONCLUSIONS}

At six different light levels ranging from $60-1500 \mu \mathrm{mol}$ photons $\mathrm{m}^{-2} \mathrm{~s}^{-1}$ (specific growth rates from $\sim 0.2$ to $\sim 0.7 \mathrm{~d}^{-1}$ ), cell division of Nannochloris was tightly phased to the light:dark cycle, occurring soon after dark. There were pronounced diel patterns, with a minimum near dawn and a maximum near dusk, in cell size and in cell-specific attenuation, absorption, flow cytometric light scatter and carbon. The diel variations in the attenuation cross section were primarily influenced by the changes in cell size due to growth and division, while changes in refractive index had only a small effect. Because eukaryotic cells in the size range of Nannochloris are major constituents of many phytoplankton communities, the results presented here have important consequences for the interpretation of diel variations in optical properties observed in the ocean. Since properties measurable by flow 
cytometry were determined, the relationships calculated in this work can be applied to field measurements made using flow cytometry to distinguish particular phytoplankton populations. It should thus be possible to account for variations in bulk optical properties such as beam attenuation (Chapters 3 and 4). In addition, since the variations observed represent growth processes of the cells, the relationships determined in this work can be used to estimate in situ growth rates of different phytoplankton groups (Chapter 5).

\section{Acknowledgements}

I thank Rob Olson and Erik Zettler for assistance during all the diel laboratory experiments. I also thank the others who worked the $24+$ hour shift with us during particular experiments: Jessica Bohonowych, Tanya Churilova, Elisabeth Jaffe, Catherine Preston, and Elizabeth Riemer. This work was supported by NSF grant OCE-9012147 (to R. Olson) and a WHOI Ocean Ventures Award (to M. DuRand). 


\section{REFERENCES}

Ackleson, S.G., D.B. Robins and J.A. Stephens. 1988. Distributions in phytoplankton refractive index and size within the North Sea. SPIE, Ocean Optics IX 925: 317-325.

Ackleson, S.G. and R.W. Spinrad. 1988. Size and refractive index of individual marine particulates: a flow cytometric approach. Appl. Opt. 27: 1270-1277.

Bricaud, A., A. Morel and L. Prieur. 1983. Optical efficiency factors of some phytoplankters. Limnol. Oceanogr. 28: 816-832.

Carder, K.L., R.D. Tomlinson and G.F. Beardsley. 1972. A technique for the estimation of indices of refraction of marine phytoplankters. Limnol. Oceanogr. 17: 833-839.

Chisholm, S.W. 1981. Temporal patterns of cell division in unicellular algae, pp. 150-181. In T. Platt [ed.], Physiological Bases of Phytoplankton Ecology. Canadian Bulletin of Fisheries and Aquatic Sciences 210.

Cullen, J.J., M.R. Lewis, C.O. Davis and R.T. Barber. 1992. Photosynthetic characteristics and estimated growth rates indicate grazing is the proximate control of primary production in the equatorial Pacific. J. Geophys. Res. 97: 639-654.

Dickey, T., T. Granata, M. Hamilton, J. Wiggert, J. Marra, C. Langdon and D.A. Siegel. 1990. Time series observations of bio-optical properties in the upper layer of the Sargasso Sea. SPIE: Ocean Optics X 1302: 202-213.

DuRand, M.D. and R.J. Olson. in press. Contributions of phytoplankton light scattering and cell concentration changes to diel variations in beam attenuation in the equatorial Pacific from flow cytometric measurements of pico-, ultra-, and nanoplankton. Deep-Sea Res.

Hamilton, M., T.C. Granata, T.D. Dickey, J.D. Wiggert, D.A. Siegel, J. Marra and C. Langdon. 1990. Diel variations of bio-optical properties in the Sargasso Sea. SPIE: Ocean Optics X 1302: 214-224.

Lewis, M.R. and J.J. Cullen. 1991. From cells to the ocean: Satellite ocean color, pp. 325-337. In S. Demers [ed.], Particle Analysis in Oceanography. NATO ASI Series G 27. Springer-Verlag. 
Markager, S., A.-M. Jespersen, T.V. Madsen, E. Berdalet and R. Weisburd. 1992.

Diel changes in dark respiration in a plankton community. Hydrobiologia 238: $119-130$.

Morel, A. and Y.-H. Ahn. 1990. Optical efficiency factors of free-living marine bacteria: Influence of bacterioplankton upon the optical properties and particulate organic carbon in oceanic waters. J. Mar. Res. 48: 145-175.

Morel, A. and A. Bricaud. 1986. Inherent optical properties of algal cells including picoplankton: Theoretical and experimental results, pp. 521-559. In T. Platt and W.K.W. Li [eds.], Photosynthetic Picoplankton. Canadian Bulletin of Fisheries and Aquatic Sciences 214.

Olson, R.J., E.R. Zettler, S.W. Chisholm and J.A. Dusenberry. 1991. Advances in oceanography through flow cytometry, pp. 351-399. In S. Demers [ed.], Particle Analysis in Oceanography. NATO ASI Series G 27. Springer-Verlag.

Olson, R.J., E.R. Zettler and M.D. DuRand. 1993. Phytoplankton analysis using flow cytometry, pp. 175-186. In P.F. Kemp, B.F. Sherr, E.B. Sherr and J.J. Cole [eds.], Handbook of Methods in Aquatic Microbial Ecology. Lewis Publishers.

Shibata, K. 1958. Spectrophotometry of intact biological materials. Journal of Biochemistry 45: 599-623.

Siegel, D.A., T.D. Dickey, L. Washburn, M.K. Hamilton and B.G. Mitchell. 1989. Optical determination of particulate abundance and production variations in the oligotrophic ocean. Deep-Sea Res. 36: 211-222.

Stramska, M. and T.D. Dickey. 1992. Variability of bio-optical properties of the upper ocean associated with diel cycles in phytoplankton populations. J. Geophys. Res. 97: 17,873-17,887.

Stramski, D. and A. Morel. 1990. Optical properties of photosynthetic picoplankton in different physiological states as affected by growth irradiance. Deep-Sea Res. 37: 245-266.

Stramski, D. and R.A. Reynolds. 1993. Diel variations in the optical properties of a marine diatom. Limnol. Oceanogr. 38: 1347-1364.

Stramski, D., A. Shalapyonok and R.A. Reynolds. 1995. Optical characterization of the oceanic unicellular cyanobacterium Synechococcus grown under a day-night cycle in natural irradiance. J. Geophys. Res. 
Van de Hulst, H.C. 1957. Light Scattering by Small Particles. John Wiley \& Sons, Inc., New York.

Vaulot, D., C. Courties and F. Partensky. 1989. A simple method to preserve oceanic phytoplankton for flow cytometric analyses. Cytometry 10: 629-635.

Walsh, I.D., S.P. Chung, M.J. Richardson and W.D. Gardner. in press. The diel cycle in the integrated particle load in the equatorial Pacific: A comparison with primary production. Deep-Sea Res. 


\section{Chapter 3}

\section{Contributions of phytoplankton light scattering and}

cell concentration changes to diel variations in beam attenuation in the equatorial Pacific from flow cytometric measurements of pico-, ultra-, and nanoplankton

This chapter has been accepted for publication in Deep-Sea Research with R. J. Olson as co-author. 


\begin{abstract}
The phytoplankton biomass in the equatorial Pacific is dominated by picophytoplankton (Prochlorococcus, $<1 \mu \mathrm{m}$, and Synechococcus, $\sim 1 \mu \mathrm{m}$ diameter), and by mixed populations of ultraphytoplankton (1-2 $\mu \mathrm{m}$ diameter) and nanophytoplankton $(2-20 \mu \mathrm{m}$, mostly $2-3 \mu \mathrm{m})$. The mean forward light scatter of each of these populations, measured on individual cells by flow cytometry, increased during the day and decreased during the night. This pattern was similar to that of bulk red beam attenuation due to particles. In contrast, cell concentration changes did not correspond to the patterns in beam attenuation.

Using a combination of empirical calibrations relating beam attenuation to flow cytometric measurements of pure cultures of phytoplankton in the laboratory, and Mie theory, we estimated the contributions of different groups of phytoplankton to the diel variations in beam attenuation observed. Our results indicate that the phytoplankton assemblage measured by flow cytometry can account for essentially all of the diel variation in the beam attenuation signal. In most instances the nanophytoplankton were the largest contributor to total beam attenuation due to phytoplankton, but the ultraphytoplankton usually were more important in determining the diel variations in this property. Prochlorococcus were a smaller but appreciable contributor to beam attenuation changes, and Synechococcus were much less important. These findings emphasize the need to characterize the composition of the phytoplankton community in order to use beam attenuation as a tool for monitoring productivity.
\end{abstract}




\section{INTRODUCTION}

Diel variations in red beam attenuation have been observed in many parts of the world's oceans (SIEGEL et al., 1989; HAMILTON et al., 1990; GARDNER et al., 1990, 1995). Since beam attenuation has been shown to be correlated with suspended particle mass, analysis of this diel pattern has been proposed as a method for estimating primary production (SIEGEL et al., 1989). However, the relationship between particle mass and beam attenuation is not a constant, but depends on the size distribution and optical properties of the constituent particles (BAKER and LAVELLE, 1984). In order to better interpret diel variations in the bulk water inherent optical property of beam attenuation, we used flow cytometry to measure the light scattering and cell concentrations of different groups within the phytoplankton, whose dynamics have been presumed to cause the variations.

The beam attenuation coefficient (c) is composed of the scattering coefficient (b) and the absorption coefficient (a), where $c(\lambda)=a(\lambda)+b(\lambda)$. Theoretical and experimental studies on a variety of phytoplankton species have indicated that attenuation is dominated by scattering, and only a small portion of the signal is due to absorption (BRICAUD et al., 1988). Beam attenuation can be partitioned into the contributions of pure seawater $\left(c_{w}\right)$, dissolved organic material (yellow substance, $c_{y}$ ), and particles $\left(c_{\text {particles }}\right): \quad c=c_{w}+c_{y}+c_{\text {particles. }} . C_{w}$ is a constant and $c_{y}$ is negligible in the open ocean at the red wavelength $(660 \mathrm{~nm})$ of the transmissometer light source

(BARTZ et al., 1978), thus $\mathrm{c}_{\text {particles }}$ determines the variations in $\mathrm{c}$. In this work, $\mathrm{c}_{\text {particles }}$ 
will be further subdivided into the contributions of phytoplankton $\left(\mathrm{c}_{\text {phyto }}\right)$ as distinguished using flow cytometry, and of non-phytoplankton $\left(\mathrm{c}_{\text {non-phyto }}\right) . \mathrm{C}_{\text {phyto }}$ consists of the contributions of different groups of phytoplankton: Prochlorococcus $\left(<1 \mu \mathrm{m}\right.$ diameter, $\left.\mathrm{c}_{\mathrm{pro}}\right)$, Synechococcus $\left(\sim 1 \mu \mathrm{m}, \mathrm{c}_{\text {syn }}\right)$, ultraphytoplankton $(1-2 \mu \mathrm{m}$ cells, $\mathrm{c}_{\mathrm{ult}}$ ), and nanophytoplankton (mostly $2-3 \mu \mathrm{m}$ cells, but including cells up to 20 $\left.\mu \mathrm{m}, \mathrm{c}_{\mathrm{nan}}\right)$.

Previous investigators observed diel variations in beam attenuation with a minimum near sunrise and a maximum near sunset. From observations in the North Pacific, SIEGEL et al. (1989) suggested that these patterns could be accounted for by a balance between photosynthetic production of ultraplankton (causing an increase in particles) and grazing by microzooplankton (causing a decrease in particles). During spring bloom conditions in the North Atlantic, diel variations in beam attenuation were measured in the mixed layer, and the daytime increases in beam attenuation were found to be primarily due to increases in particulate matter concentration (GARDNER et al., 1993). STRAMSKA and DICKEY's time series measurements of water column bio-optical properties (1992) in the North Atlantic also suggested a relationship between phytoplankton production and beam c.

In an attempt to elucidate this relationship for conditions encountered in the equatorial Pacific, we have related direct measurements of changes in the light scattered by the phytoplankton to changes in beam $\mathrm{c}$ over the diel cycle from sampling experiments in April and October 1992. Our observations reveal diel variations in mean forward light scatter for populations of eukaryotic and prokaryotic 
phytoplankton that are minimum near dawn and maximum near dusk, the same pattern as that seen for bulk beam attenuation (GARDNER et al., 1995). In contrast, phytoplankton cell concentrations in these samples do not have the same diel pattern; indeed, they usually have the opposite pattern. Using laboratory calibrations on phytoplankton combined with theoretical calculations, we estimated the contributions that each phytoplankton population made to the diel variations in beam attenuation. The implications of these findings for the use of diel variations in beam $\mathrm{c}$ for estimating productivity will be discussed.

\section{MATERIALS AND METHODS}

\section{Field Studies}

Intensive diel sampling was performed on five occasions during the two JGOFS Time Series cruises in the equatorial Pacific (cruises 8 and 12 of R.V. Thomas Thompson to $\left.0^{\circ}, 140^{\circ} \mathrm{W}\right)$. Of these, we will discuss only three: the first diel study on cruise TT8, 1 April 1992 (TT8D1), and the first two diel studies on cruise TT12, 5 and 11 October 1992 (TT12D1 and TT12D2). Portions of the data

from the other two were lost due to equipment failure. In each case, CTD casts were made every three hours for 24 hours and samples for flow cytometric analysis were taken with Niskin bottles at $0,15,30,45,60,75,90$, and $100 \mathrm{~m}$. A limited number of daily dawn and dusk casts during each cruise were also sampled for flow cytometry. 
The eukaryotic phytoplankton were analyzed immediately on board the ship using an EPICS V flow cytometer modified to analyze $50 \mathrm{ml}$ seawater samples at 5$10 \mathrm{ml} \mathrm{min}^{-1}$ (OLSON et al., 1991, 1993). Samples were kept at room temperature in the dark until analysis; the surface samples were analyzed first and all depths were completed within two hours of collection (see below for comparison of test samples). Fluorescent microspheres ( $3.79 \mu \mathrm{m}$, Polysciences) were added to each sample as an internal standard. Eukaryotic phytoplankton from 1-20 $\mu \mathrm{m}$ in diameter were counted and, for each particle, forward light scatter (FLS, $3^{\circ}-19^{\circ}$ at $488 \mathrm{~nm}$ ), side scatter, red (chlorophyll, 660-700 nm) fluorescence, and orange (phycoerythrin, 530-630)

fluorescence were collected. Phytoplankton populations were discriminated on plots of forward light scatter vs. chlorophyll fluorescence (Fig. 1) using CytoPC software (D. Vaulot, Station Biologique, Roscoff, France). During each cruise the phytoplankton groups were sorted on the flow cytometer and examined microscopically. Typically, the most abundant population of eukaryotic phytoplankton consisted of 1-2 $\mu \mathrm{m}$-diameter coccoid cells (referred to here as the ultraphytoplankton). The population referred to here as the nanophytoplankton primarily consisted of 2-3 $\mu \mathrm{m}$ diameter coccoid cells, but also included cells as large as $20 \mu \mathrm{m}$. In addition, there were a small number of phytoplankton cells which were off-scale on chlorophyll fluorescence (but not on FLS) at the flow cytometer settings we used. These were not included in the nanophytoplankton category, but were considered separately (referred to as "off-scale"). Analysis of test samples (one each from 0,15 , and $30 \mathrm{~m}$ during TT8) kept for greater than two hours in the dark at 
Figure 1. Typical flow cytometric signatures of prokaryotic picoplankton (A and B) and eukaryotic phytoplankton (C) populations (from a surface sample from TT12D2) after gating to clearly show the separate populations. Contour plots show relative chlorophyll fluorescence (red, $660-700 \mathrm{~nm})$ vs. scattering cross section $\left(3^{\circ}-19^{\circ}\right.$ in $\mu \mathrm{m}^{2}$, calculated from FLS). Each contour level represents a doubling in cell number. A) Synechococcus (Syn), were first distinguished by gating on their high phycoerythrin fluorescence. B) Prochlorococcus (Pro) population after removing Synechococcus by gating. C) Polygons outline the populations of the ultraphytoplankton (Ult) and the nanophytoplankton (Nan). A) and B) are from analysis of the sample run with a high-sensitivity configuration of the flow cytometer; the scattering cross section of $0.57 \mu \mathrm{m}$ beads is marked by a triangle. C) is from the less sensitive high flow rate configuration of the flow cytometer used to analyze the less abundant eukaryotic phytoplankton (scattering cross section of 3.79 $\mu \mathrm{m}$ beads marked by a triangle). 


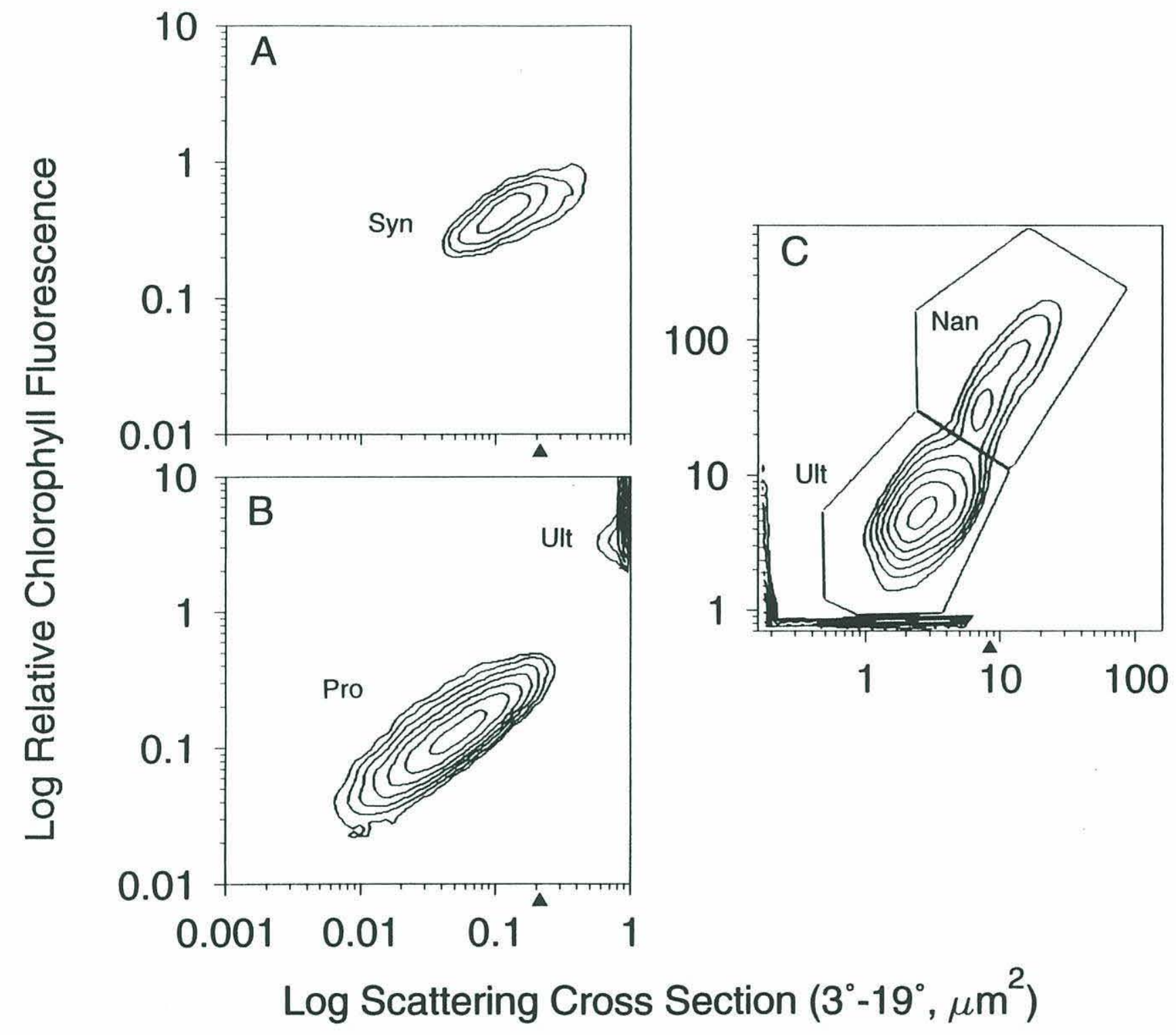


room temperature showed an average $4 \%$ decrease from initials for ultraphytoplankton FLS and a 1\% increase for nanophytoplankton FLS.

The picoplankton Synechococcus and Prochlorococcus were analyzed on shore from samples preserved with $0.125 \%$ glutaraldehyde and stored in liquid nitrogen (VAULOT et al., 1989, OLSON et al., 1993), using a high sensitivity configuration of an EPICS 753 flow cytometer (OLSON et al., 1993), and $0.57 \mu \mathrm{m}$ beads (Polysciences) as an internal standard. Synechococcus were distinguished by their high phycoerythrin fluorescence and Prochlorococcus by their low FLS and chlorophyll fluorescence (Fig. 1).

\section{Laboratory Studies}

Three laboratory experiments (shore-based) were performed in which the chlorophyte Nannochloris sp. $(2.5-3 \mu \mathrm{m}$ diameter) was grown in $\mathrm{f} / 2$ medium in replicate carboys at $22^{\circ} \mathrm{C}$. For two of the experiments the cultures were grown in an incubator on a 14:10 L:D cycle, at $250 \mu \mathrm{mol}$ photons $\mathrm{m}^{-2} \mathrm{~s}^{-1}$ for one experiment and at $500 \mu \mathrm{mol}$ photons $\mathrm{m}^{-2} \mathrm{~s}^{-1}$ for the other (Cool-White fluorescent lights). A third experiment was performed under natural sunlight with an average integrated light level of $1500 \mu \mathrm{mol}$ photons $\mathrm{m}^{-2} \mathrm{~s}^{-1}$ (14 h daylight on a mostly sunny day in August). The cultures were sampled at mid-exponential phase every two hours for 24 hours. Triplicate samples were analyzed immediately on the flow cytometer, as at sea except that the culture was diluted $100 \mu \mathrm{l}: 50 \mathrm{ml} 0.22 \mu \mathrm{m}$ filtered seawater (FSW), to obtain cell FLS and concentration. Beam attenuation was measured with a 
SeaTech transmissometer ( $25-\mathrm{cm}$ pathlength; $\lambda=665 \mathrm{~nm}$ ) enclosed by a PVC sleeve with a sampling port, by adding progressively 8,12 , and $16 \mathrm{ml}$ of culture to $1600 \mathrm{ml}$ FSW in the transmissometer. For each measurement, the culture was added to the FSW, the mixture was stirred, and any bubbles were cleared from the transmissometer windows before taking the reading. The procedure was repeated twice for each culture. Replicate samples $(25 \mathrm{ml})$ were filtered onto pre-combusted GF/F filters, frozen, and later dried and analyzed on a Perkin-Elmer $2400 \mathrm{CHN}$ Analyzer. Absorption was measured using the opal glass method (SHIBATA, 1958) in a spectrophotometer (Bausch and Lomb Spectronic 88) to confirm that absorption was small relative to scattering (see Introduction).

A similar experiment was performed on Synechococcus, with 4 strains (WH8012, 8015, 8018, and 8103; from J. Waterbury, WHOI) grown at $75 \mu \mathrm{mol}$ photons $\mathrm{m}^{-2} \mathrm{~s}^{-1}$ on a 14:10 L:D cycle and sampled at "dawn" and "dusk." For the beam attenuation measurements, $20-35 \mathrm{ml}$ of the culture was added to $1600 \mathrm{ml} \mathrm{FSW}$ and mixed in a flask and then poured into the transmissometer "sleeve." Replicate measurements were made for each strain. Measurements of carbon content were also made.

Conversion of forward light scatter to scattering cross section

Our measurements of forward light scatter $\left(3^{\circ}-19^{\circ}\right)$ are expressed relative to light scattered by standard beads. To compare our results to theory, we need to express them in more meaningful units. We therefore calculated the scattering cross 
section $\left(\mu \mathrm{m}^{2}\right)$ of the cells by reference to the calculated scattering cross section $\left(3^{\circ}\right.$ $19^{\circ}$ ) of the beads, for which the size, refractive index, and absorption are known (BOHREN and HUFFMAN, 1983; ACKLESON and SPINRAD, 1988):

$\frac{\text { FLS cells }}{\text { FLS beads }} *$ scat. cross section beads $\left(\mu \mathrm{m}^{2}\right)=$ scat. cross section of cells $\left(\mu \mathrm{m}^{2}\right)$.

Mie calculations (program of ACKLESON and SPINRAD, 1988) of scattering over the collection angles of the flow cytometer were performed using the diameter of the beads $(3.79 \mu \mathrm{m})$, the refractive index of polystyrene (1.59 relative to air), the concentration of beads (calibrated on the flow cytometer), and the absorption coefficient of the "cellular" material $\left(0.12 \mu \mathrm{m}^{-1}\right.$, measured on a suspension of beads using the opal glass technique on a Shimadzu UV-260 spectrophotometer; SHIBATA, 1958). Similar calculations were performed for the $0.57 \mu \mathrm{m}$ beads (used in the picoplankton samples), except that the absorption was assumed to be zero (absorption has a negligible effect at this size). The angles of collection of the flow cytometer FLS were estimated to be $3^{\circ}-19^{\circ}$, by measuring the angles of the light intercepted by the FLS detector, and by comparing the ratio of measured FLS of different sized beads to the ratio of theoretical determinations of scattering cross sections of the same beads. 


\section{RESULTS AND DISCUSSION}

\section{Diel Patterns in Phytoplankton and Beam Attenuation}

During each of the three diel time series we sampled, the mean scattering cross section (calculated from flow cytometric forward light scatter) of nanophytoplankton, ultraphytoplankton, and Prochlorococcus cells was consistently at a minimum near dawn and maximum near dusk (Fig. 2B-E, H, I). The Synechococcus mean scattering cross section was also at a minimum near dawn, but its maximum was near noon rather than dusk (Fig. $2 \mathrm{~F}, \mathrm{G})$. These patterns were visible down to $100 \mathrm{~m}$ for TT8D1 and TT12D1 and to $75 \mathrm{~m}$ for TT12D2; the amplitude of the diel variation tended to decrease with depth. Cell concentrations generally decreased during the day and increased at night (or increased at the beginning of the night and then leveled off or decreased before dawn) down to at least $60 \mathrm{~m}$ for all diel samplings, except for Synechococcus, for which cell concentrations increased from near noon until dusk and then decreased during the night hours. The patterns in beam attenuation due to particles ( $c_{\text {particles}}$, GARDNER et al., 1995) were similar to those of FLS, with a minimum near dawn and a maximum near dusk (Fig. 2A). This pattern was seen down to $100 \mathrm{~m}$ during TT8D1, down to $60 \mathrm{~m}$ during TT12D1, and down to $45 \mathrm{~m}$ during TT12D2. As with FLS, the amplitude of the diel change in beam attenuation was smaller at depth than in the upper water column. 
Figure 2. Time series data for the selected depths $0 \mathrm{~m}(0), 30 \mathrm{~m}(\bullet)$, and $60 \mathrm{~m} \mathrm{( \nabla )}$ from TT12D2. A) Beam attenuation due to particles $\left(\mathrm{c}_{\text {particles }}\right.$ in $\mathrm{m}^{-1}$, data from $\mathrm{W}$. Gardner). Forward light scattering cross section $\left(\mu \mathrm{m}^{2}\right)$, and cell concentration (cells $\mathrm{ml}^{-1}$ ) for nanophytoplankton (B and C), ultraphytoplankton (D and E), Synechococcus (F and G), and Prochlorococcus ( $\mathrm{H}$ and $\mathrm{I})$. Note that the $\mathrm{y}$-axis for each plot is scaled independently. Patterns for TT8D1 and TT12D1 were similar to those shown here, though the cell concentrations differed. At dawn in the near surface depths, nanophytoplankton concentrations were $1500 \mathrm{ml}^{-1}$ (TT8D1) and $1800 \mathrm{ml}^{-1}$ (TT12D1 and D2). Ultraphytoplankton concentrations were $4000 \mathrm{ml}^{-1}$ (TT8D1), $7500 \mathrm{ml}^{-1}$ (TT12D1), and $9500 \mathrm{ml}^{-1}$ (TT12D2). Synechococcus concentrations were $9000 \mathrm{ml}^{-1}$ (TT8D1), $6000 \mathrm{ml}^{-1}$ (TT12D1), and $8000 \mathrm{ml}^{-1}$ (TT12D2). Prochlorococcus concentrations were $2 \times 10^{5} \mathrm{ml}^{-1}$ (TT8D1), $1 \times 10^{5} \mathrm{ml}^{-1}$ (TT12D1), and $1.3 \times 10^{5} \mathrm{ml}^{-1}$ (TT12D2). 


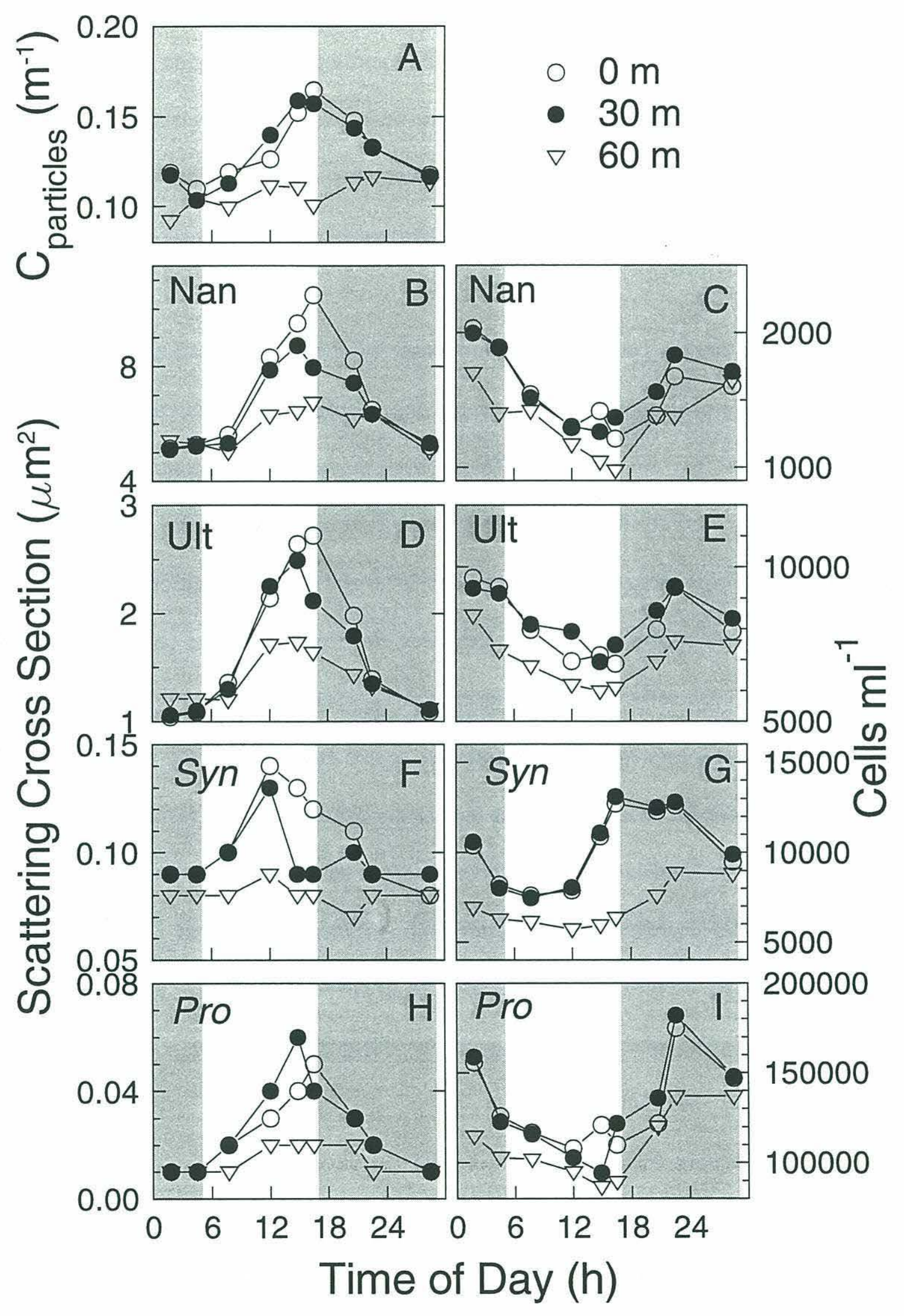


In addition to the diel sampling periods, we analyzed a few "pairs" of data from consecutive dawn/dusk profiles (two for TT8 and four for TT12; data not shown). In all of these pairs, at every depth that bulk beam c was lower at dawn than at dusk, the FLS for ultra- and nanophytoplankton showed the same pattern. The cell concentration for both ultra- and nanophytoplankton were generally higher at dawn than at dusk.

It is clear that the patterns in the bulk property of beam attenuation are similar to the patterns in mean light scatter per cell of different populations of phytoplankton, and they are generally different from those in cell concentration. The increase in light scatter during the day can be explained by growth of the phytoplankton cells as they photosynthesize and fix carbon. As a result of the increase in light scatter, the total beam c increases, despite the fact that cell concentrations are generally decreasing during the day (presumably due to grazing). The maximum in cell light scatter almost always occurs at the same time as the minimum in cell concentration, near dusk (except for Synechococcus, for which they occur at noon). The implication is that the cells begin to divide at this time, so that the average cell size decreases, with a corresponding increase in the cell concentration (newly divided cells). Diel patterns in DNA per cell for Prochlorococcus in the same samples support this interpretation (VAULOT et al., 1995; BINDER et al., submitted).

Changes in light scatter can be due to changes in refractive index or shape as well as cell size, although these have usually been considered less important than changes in size (JERLOV, 1976; GORDON et al., 1984). ACKLESON et al. (1993) 
reported variations in refractive index for phytoplankton cultures at high light intensity which were to some extent carbon independent. However, in laboratory experiments with the diatom Thalassiosira pseudonana (STRAMSKI and REYNOLDS, 1993) and with Synechococcus (STRAMSKI et al., 1995) strong correlations between refractive index and intracellular carbon concentration were found. In our laboratory experiments on Nannochloris and Synechococcus, the cell scattering cross section was strongly correlated with cell carbon, though the relationship may be different for the two species (Fig. 3). During the same cruises we discuss, GARDNER et al. (1995) found that beam c was well correlated with particle mass. Thus we interpret the daytime increases in scatter we observed as due primarily to cell growth (carbon fixation).

A number of factors can contribute to the decrease in beam $\mathrm{c}$ during the night; these include cell division, respiration, mixing, cell aggregation, and grazing. According to the anomalous diffraction approximation of Mie scattering theory (VAN DE HULST, 1957; MOREL and BRICAUD, 1986), the redistribution of cell material into smaller packages during cell division should cause a decrease in c for cells smaller than about $5 \mu \mathrm{m}$. For example, c would decrease by $12 \%$ if a $2 \mu \mathrm{m}$ diameter cell divided into two cells, each with half the original volume. Loss of cell material through respiration would be expected to reduce beam c by an amount that depends on the growth conditions but which is not easy to quantify. Nocturnal deepening of the mixed layer has been suggested as a means of removing particles from the upper, productive water; such a mechanism was clearly documented during the Time Series cruises (GARDNER et al., 1995). 
Figure 3. Relationship between carbon per cell and forward scattering cross section $\left(3^{\circ}-19^{\circ}\right.$, measured with the flow cytometer,) for laboratory cultures of Nannochloris and Synechococcus measured over the light:dark cycle. Data for Nannochloris are from diel experiments at two different light levels $\left(250\right.$ and $500 \mu \mathrm{mol}$ photons $\mathrm{m}^{-2}$ $\left.\mathrm{s}^{-1}\right)$. Data for Synechococcus are from "dawn" and "dusk" samplings of four different strains. A linear regression for each cell type is shown. 


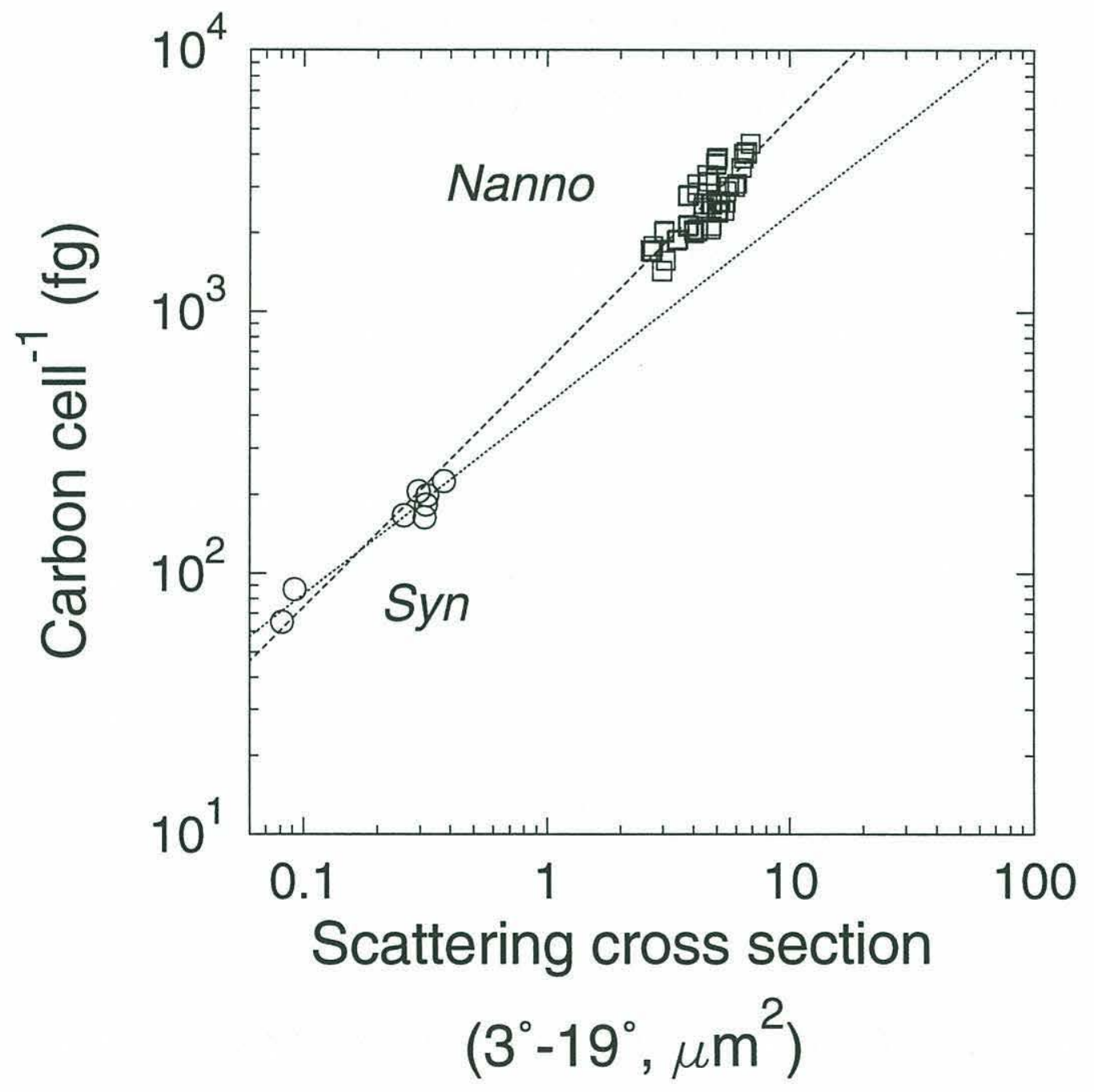


Since particles larger than about $20 \mu \mathrm{m}$ are typically too rare in the open ocean to be effectively sampled by the transmissometer (PAK et al., 1988; GARDNER et al., 1993), any process which repackages the phytoplankton biomass into large (and therefore inadequately sampled) parcels will cause beam $\mathrm{c}$ to decrease. Walsh and Gardner (pers. comm.) measured aggregates in the North Atlantic and saw a diel variation in aggregate abundance, which they suggested could be a factor in the decrease in beam $\mathrm{c}$ at night. Grazing by zooplankton that are not effectively sampled by the transmissometer would decrease beam $\mathrm{c}$ by the same mechanism.

\section{Calculation of beam attenuation due to phytoplankton}

To obtain estimates of beam c from field measurements of scattering cross sections and cell concentrations of phytoplankton populations, we began with an empirical calibration using Nannochloris and Synechococcus cultures. Attenuation cross section (beam c normalized to cell concentration) was regressed on scattering cross section (linear regression of the log transformed data, $r^{2}=0.97$; Fig. 4). This empirical relationship was compared to Mie theory (an iterative calculation using program from ACKLESON and SPINRAD, 1988) assuming a constant refractive index

of 1.05 and absorption of cellular material $\left(\mathrm{a}_{\mathrm{cm}}\right)$ of either 0.1 or $0.2 \mu \mathrm{m}^{-1}$ and using a range of cell diameters from $0.5-8 \mu \mathrm{m}$ (Fig. 5). Changing the refractive index to 1.07 changes the relationship between the attenuation and scattering cross sections only slightly (not shown). Though a linear regression of our empirical data is reasonably close to Mie theory calculations over the range of cell sizes from 
Synechococcus to Nannochloris, extending the same regression to much smaller cells (such as Prochlorococcus) is not appropriate. We do not yet have an axenic culture of Prochlorococcus, so we have not empirically confirmed the relationship between attenuation and scattering cross sections for these cells. For Prochlorococcus, we obtained a relationship analogous to that used for the other populations by using theoretically-derived attenuation cross sections $\left(\mathrm{n}=1.05, \mathrm{a}_{\mathrm{cm}}=0.2 \mathrm{um}^{-1}\right)$ obtained over the range of Prochlorococcus scattering cross sections observed in the field.

The appropriate calibration was applied to the field data of mean scattering cross section for different phytoplankton populations to obtain beam c per cell $\mathrm{ml}^{-1}$ (i.e., attenuation cross section) for each population. This was multiplied by the cell concentration to obtain an estimate of beam attenuation due to each specific group of phytoplankton. The diel patterns in beam $\mathrm{c}$ due to each of the populations are qualitatively quite similar to that of $\mathrm{c}_{\text {particles }}$ (Fig. 6) and to those of each other, indicating that all the phytoplankton groups are contributing to attenuation in a similar manner. At first glance the patterns in $\mathrm{c}$ of the groups appear to follow those of scattering cross section (see Fig. 2B, D, F, H), which was the original observation from flow cytometric FLS measurements. However, upon closer examination it is apparent that the amplitude of the diel excursions in c are damped relative to those in mean scattering. This is the result of the opposing trends in scattering and cell concentration. At $60 \mathrm{~m}$ in this diel sampling, for example, the diel pattern in $\mathrm{c}$ is no longer visible, even though both scatter and cell concentration patterns are still evident. Apparently cell growth at this depth is limited by light and only balances 
Figure 4. Relationship between attenuation cross section (measured with a transmissometer) and forward scattering cross section for cultures of Nannochloris and Synechococcus measured over the light:dark cycle. Data are from the same laboratory experiments as in Fig. 3, plus values from the natural light $(1500 \mu \mathrm{mol}$ photons $\mathrm{m}^{-2} \mathrm{~s}^{-1}$ ) experiment on Nannochloris. 


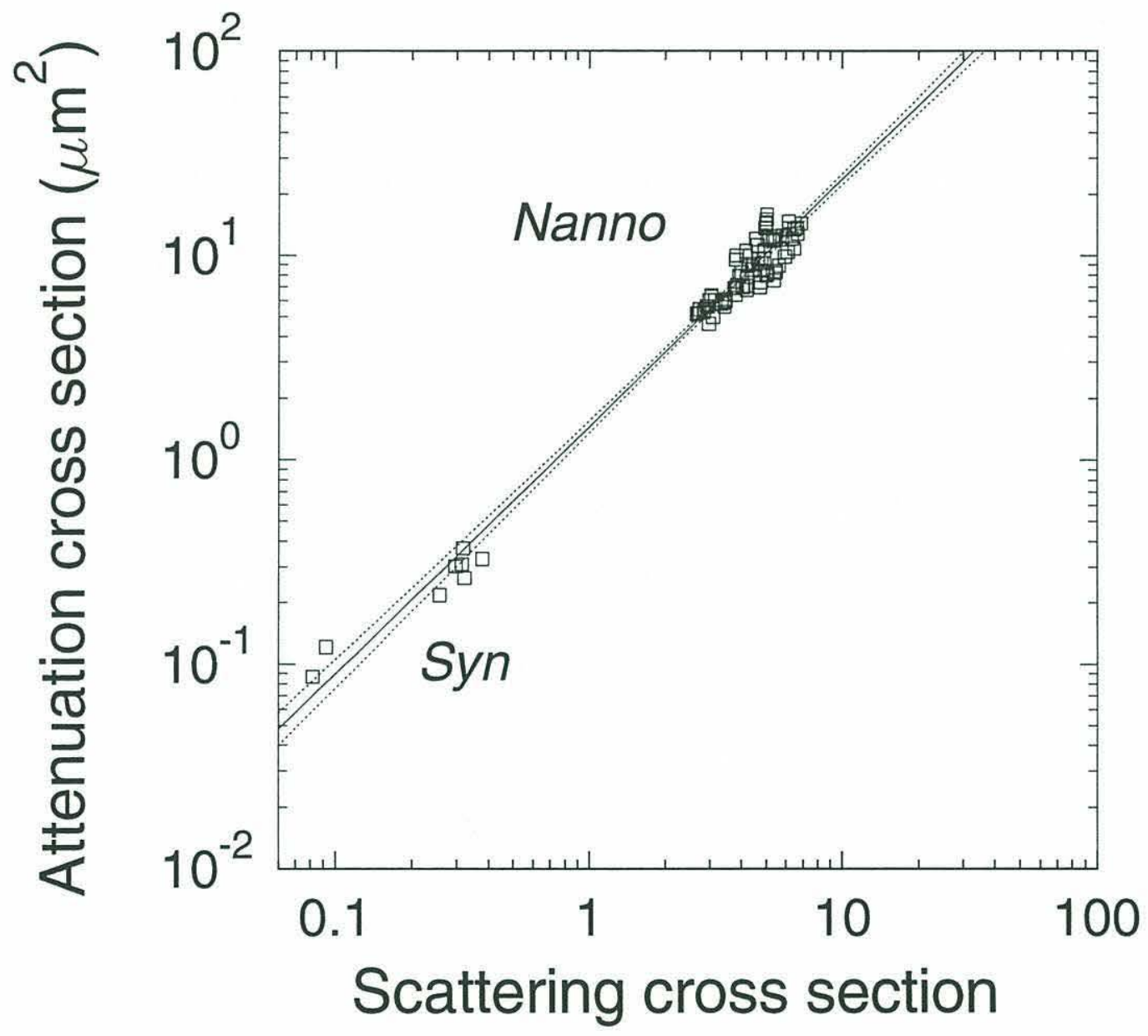

$\left(3^{\circ}-19^{\circ}, \mu m^{2}\right)$ 
Figure 5. Comparison between empirical and theoretical relationships between the attenuation cross section (at the wavelength of the transmissometer, $665 \mathrm{~nm}$ ) and the scattering cross section $\left(3^{\circ}-19^{\circ}\right.$; at the wavelength of the flow cytometer, $\left.488 \mathrm{~nm}\right)$. The dotted line shows the linear regression calculated from empirical data on Synechococcus and Nannochloris cells (shown in gray circles; data as in Fig. 4). The solid line shows the results of Mie theory calculations over a range of particle diameters $(0.5$ to $8 \mu \mathrm{m})$, assuming a constant refractive index of 1.05 and a constant absorption of cellular material $\left(\mathrm{a}_{\mathrm{cm}}\right)$ of $0.1 \mu \mathrm{m}^{-1}$ (and assuming the same $\mathrm{a}_{\mathrm{cm}}$ for 488 and $665 \mathrm{~nm}$ ). The dashed line shows similar calculations, except the $\mathrm{a}_{\mathrm{cm}}$ is constant at $0.2 \mu \mathrm{m}^{-1}$. The letters superimposed on the theory line mark the ranges of mean scattering cross section for specific types of cells observed in the field $(\mathrm{P}=$ Prochlorococcus, $\mathrm{S}=$ Synechococcus, $\mathrm{U}=$ ultraphytoplankton, and $\mathrm{N}=$ nanophytoplankton). 


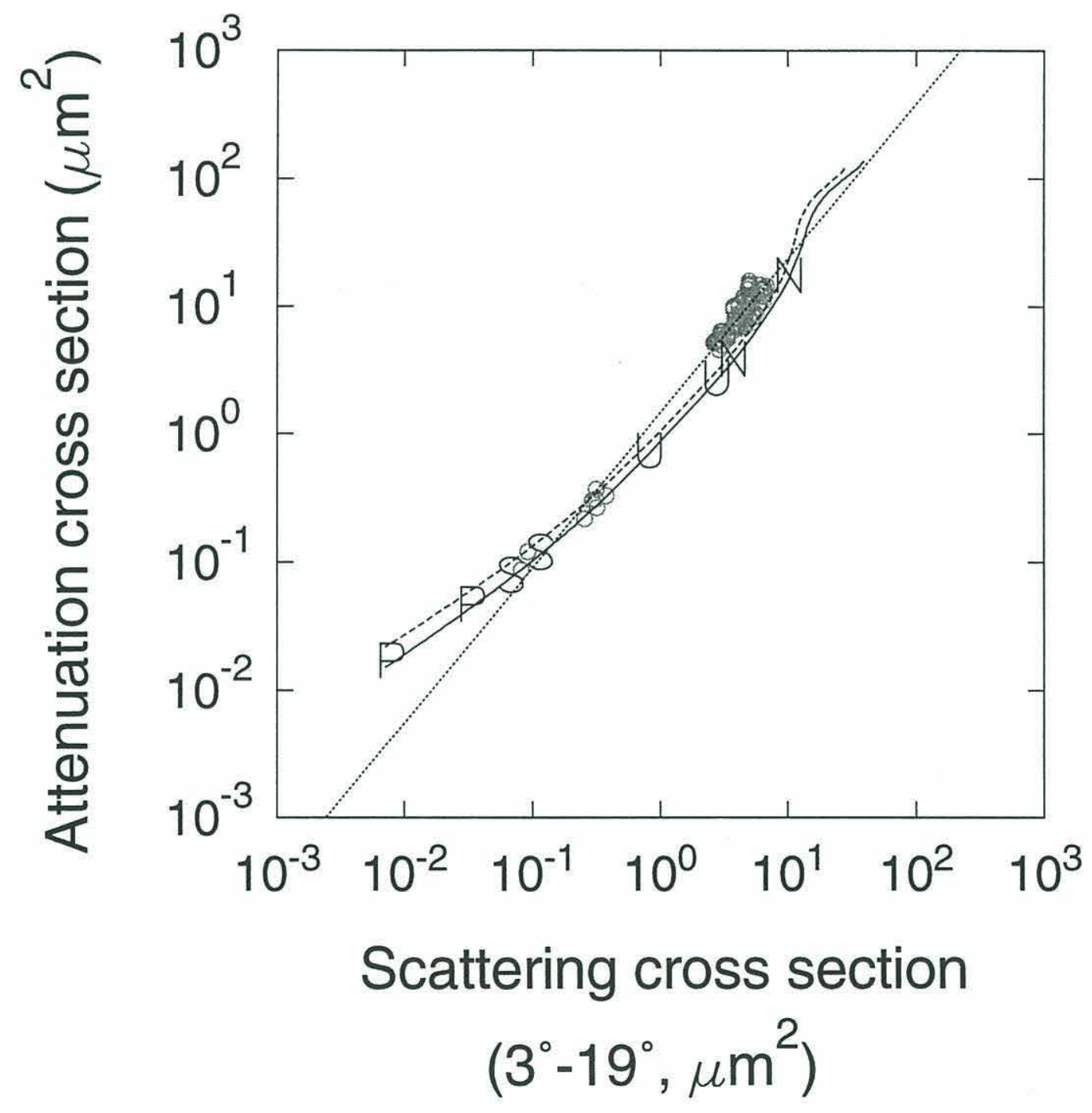


Figure 6. Time series of bulk beam attenuation due to particles (A) and calculated beam attenuation due to nanophytoplankton (B), ultraphytoplankton (C), Synechococcus (D), and Prochlorococcus (E) for TT12D2. Note that each plot is scaled independently in order to show the trends. Selected depths of $0 \mathrm{~m}(0), 30 \mathrm{~m}$ (O), and $60 \mathrm{~m}(\nabla)$ are plotted here. Results from TT8D1 and TT12D1 were similar to those shown here. 


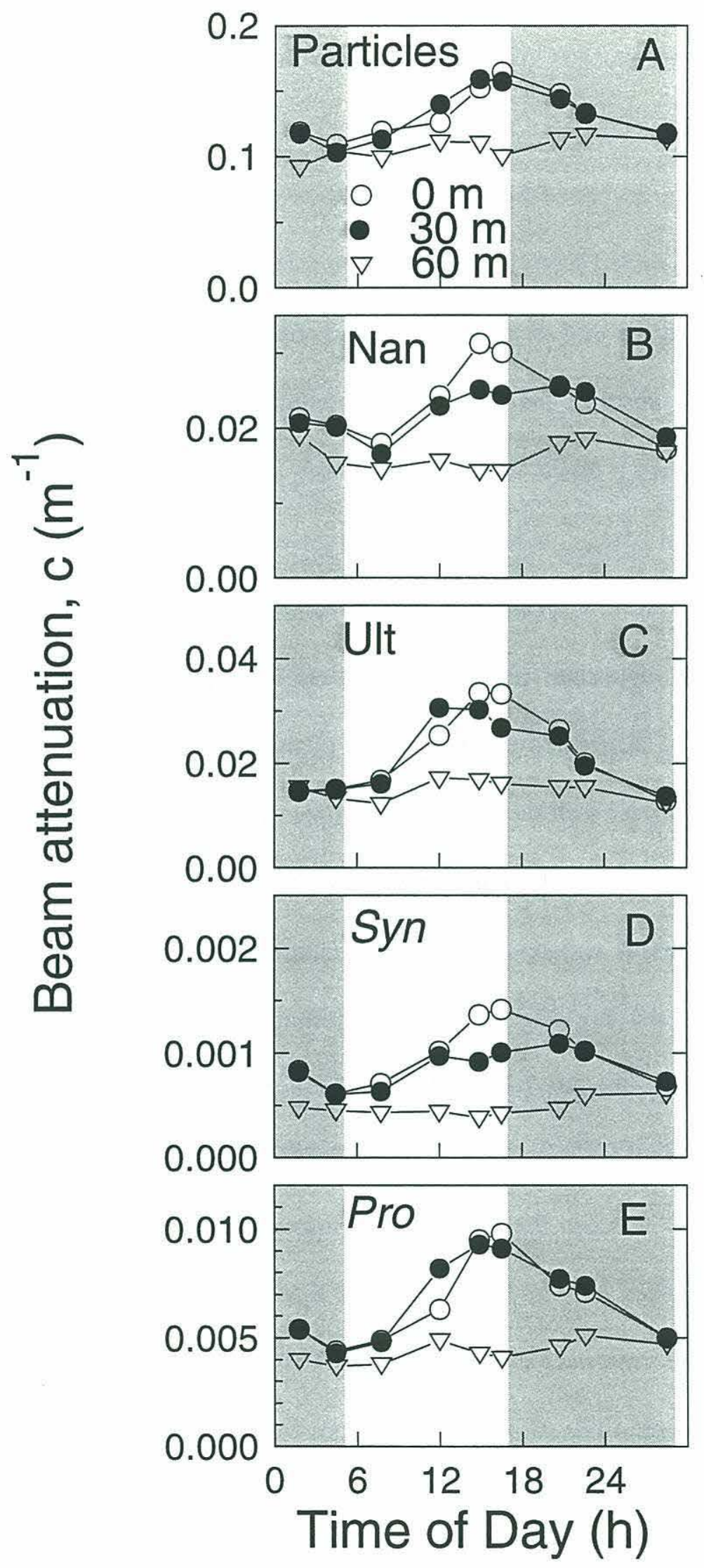


grazing losses during the day (in contrast to shallower depths where the increase in cell material during the day exceeds grazing). The increase in cell concentration at this depth during the night is caused not only by cell division, but by mixing of cells from above as a result of a deepened mixed layer (GARDNER et al., 1995). We see evidence of this deepened mixed layer in the homogenization of all the phytoplankton properties at the end of the night (Fig. 2, 6).

Examination of the absolute magnitudes of the contributions of each phytoplankton group to beam c reveal several noteworthy features (Fig. 7). The most important is that most of $\mathrm{c}_{\text {phyto }}$ was due to the nano- and ultraphytoplankton, with a smaller proportion due to Prochlorococcus; Synechococcus was always less than $5 \%$ of the total. The "off-scale" phytoplankton were low in number but had large scattering, thus $\mathrm{c}_{\text {off-scale }}$ accounted for about $10 \%$ of the total $\mathrm{c}_{\text {phyto }}$ (data not shown). Although the nanoplankton were in most samples the largest contributor to beam c, ultraphytoplankton often had greater changes in c during the diel cycle. In TT12D2, for example, this was apparently due to a greater relative increase in scatter of the smaller cells during the day (Fig. 2B, D), and perhaps also to a greater loss rate of the larger cells during the day (Fig. 2C, E). These data also show that there were differences in phytoplankton community composition (as expressed in terms of contribution to attenuation) between the two cruises: ultra-, and to a lesser degree nanophytoplankton, were more important during TT12 than TT8, while Prochlorococcus was more important during TT8 than TT12, especially at depth; similar trends in cell concentrations were also seen from flow cytometric analyses of daily samples from the two cruises (BINDER et al., submitted). 
Comparison of $c_{\text {particles }}$ and $c_{\text {phyto }}$

Since the pattern in $\mathrm{c}$ for each phytoplankton group matched that of $\mathrm{c}_{\text {particles}}$, we wished to see if the changes in $\mathrm{c}_{\text {particles }}$ could be quantitatively accounted for by the changes in $\mathrm{c}_{\text {phyto }} \quad\left(\mathrm{c}_{\text {phyto }}=\mathrm{c}_{P r o}+\mathrm{c}_{S y n}+\mathrm{c}_{\text {ult }}+\mathrm{c}_{\text {nan }}+\mathrm{c}_{\text {off-scale }}\right)$. To do this, we examined the changes between successive samples in $\mathrm{c}_{\text {particles }}\left(\Delta \mathrm{c}_{\text {particles }}\right)$ and $\mathrm{c}_{\text {phyto }}(\Delta$ $\left.\mathrm{c}_{\text {phyto }}\right)$. Thus, positive values were obtained when c's were increasing and negative values when decreasing. $\Delta \mathrm{c}_{\text {particles }}$ and $\Delta \mathrm{c}_{\text {phyto }}$ were strongly correlated $\left(\mathrm{r}^{2}=0.67\right)$ for all three diel experiments combined (Fig. 8). The intercept of the linear regression is negligible, and the slope (1.07) is not significantly different from 1 (t-test, $\mathrm{p}<0.05$ ). More detailed examination of the data in Fig. 8 reveals no trend with depth (data not shown). These results are important in that they suggest that the changes in $c_{\text {particles }}$ can be completely accounted for by the changes in $\mathrm{c}_{\text {phyto }}$. They also imply that our flow cytometer is measuring nearly all of the particles contributing to the diel pattern in beam c. This is expected since the sampling volume of the transmissometer (44 $\mathrm{ml})$ is close to that typically analyzed with our flow cytometer $(50 \mathrm{ml})$.

\section{Non-phytoplankton beam attenuation}

Once we have estimated the beam attenuation due to phytoplankton, then we can by difference also estimate the non-phytoplankton contribution $\left(\mathrm{c}_{\text {non-phyto }}\right)$ which could include bacteria, microzooplankton, and detritus. $\mathrm{C}_{\text {non-phyto }}$ is approximately $50 \%$ of the beam attenuation signal near the surface (Fig. 9); its contribution increases with depth as both the concentration and diel variations of 
Figure 7. Time series of calculated beam attenuation due to each group of phytoplankton $\left(\mathrm{c}_{\text {nan }}(\square), \mathrm{c}_{\mathrm{ult}}(\nabla), \mathrm{c}_{\text {syn }}(0)\right.$, and $\left.\mathrm{c}_{\text {pro }}(\Delta)\right)$ plotted together to show their relative contributions. Selected depths of 0,30 , and $60 \mathrm{~m}$ are plotted for each of the diel samplings (TT8D1, TT12D1, and TT12D2). 
TT8D1

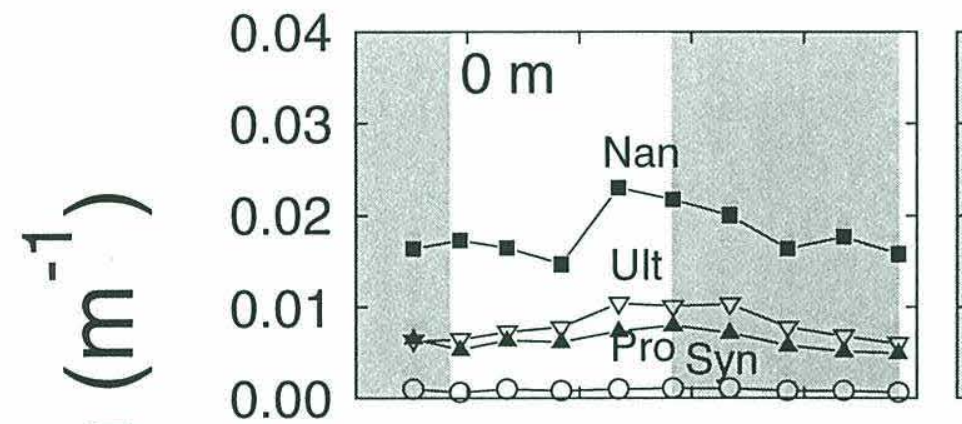

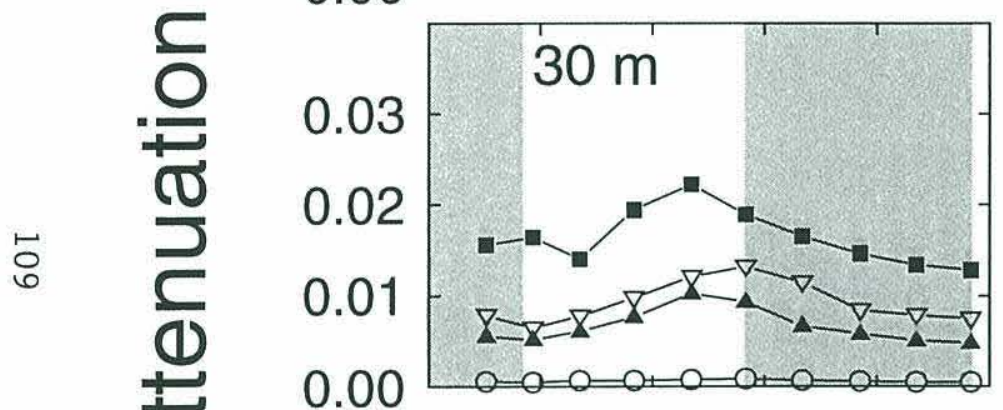

ฮ
TT12D1
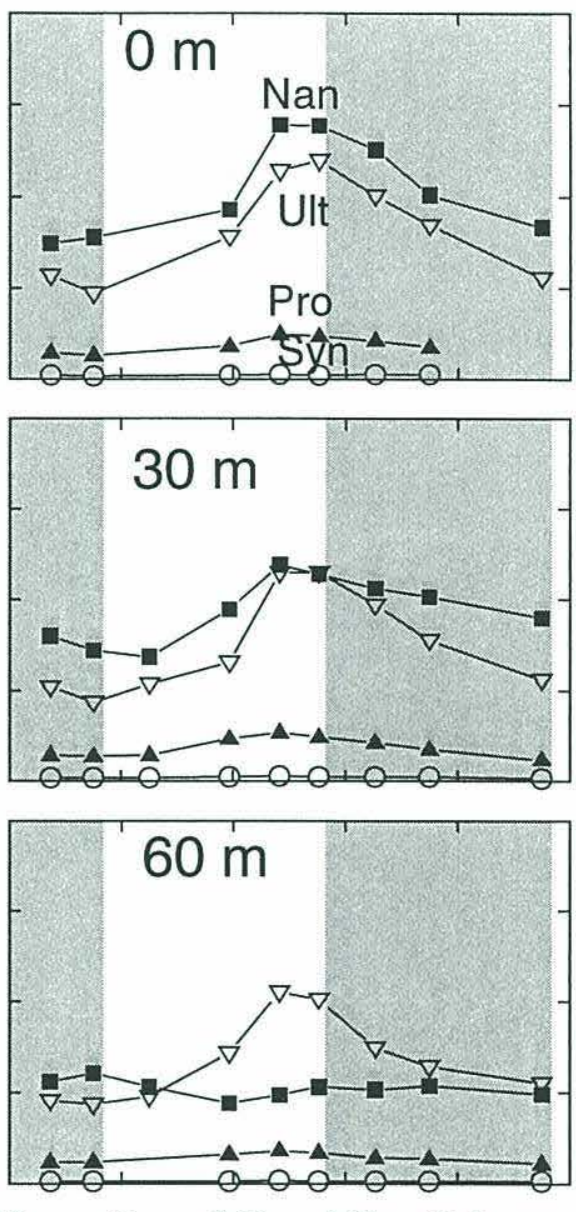

$\begin{array}{lllll}0 & 6 & 12 & 18 & 24\end{array}$
TT12D2
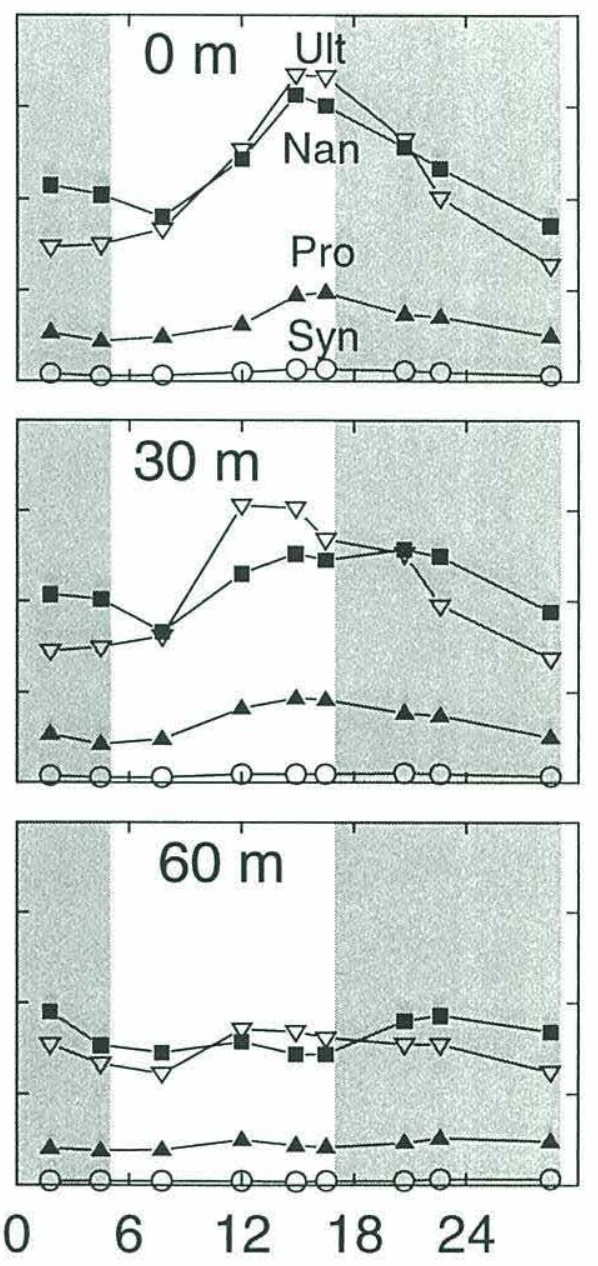

Time of Day (h) 
Figure 8. Relationship between $\Delta \mathrm{c}_{\text {particles }}$ and $\Delta \mathrm{c}_{\text {phyto }}$ for TT8D1 (0-100 m), TT12D1 $(0-100 \mathrm{~m})$, and TT12D2 $(0-75 \mathrm{~m})$. Solid line is linear regression $\left(\mathrm{r}^{2}=0.67\right.$, $\mathrm{n}=149)$. 


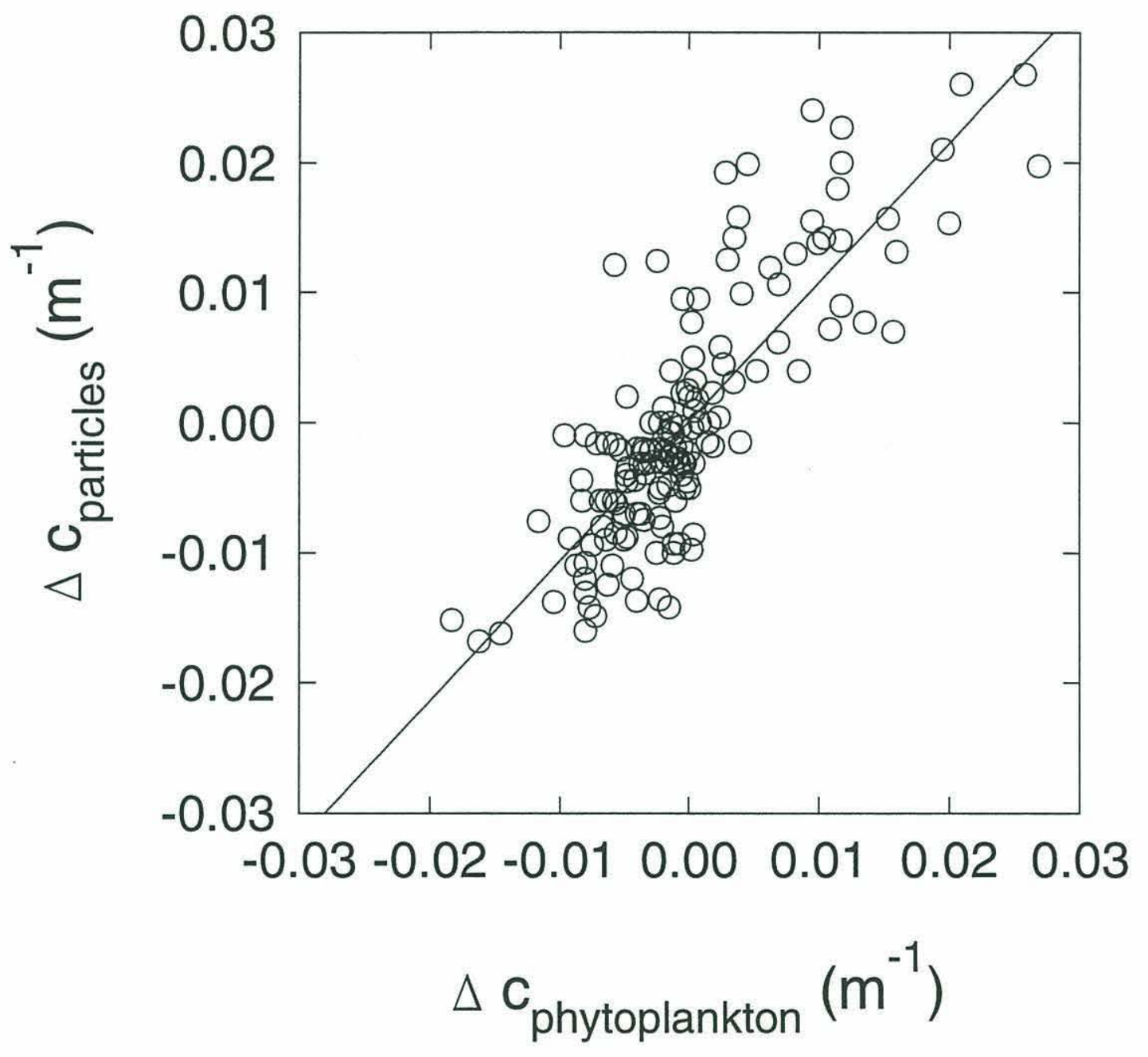


Figure 9. Depth profile for TT12D1 showing $\mathrm{c}_{\text {particles }}(\square)$ and $\mathrm{c}_{\text {non-phyto }}(\boldsymbol{\Delta}$, the difference between $c_{\text {particles }}$ and $c_{\text {phyto }}$ ). At each depth, the time series of data are plotted. Data from TT8D1 and TT12D2 showed similar though noisier trends. 


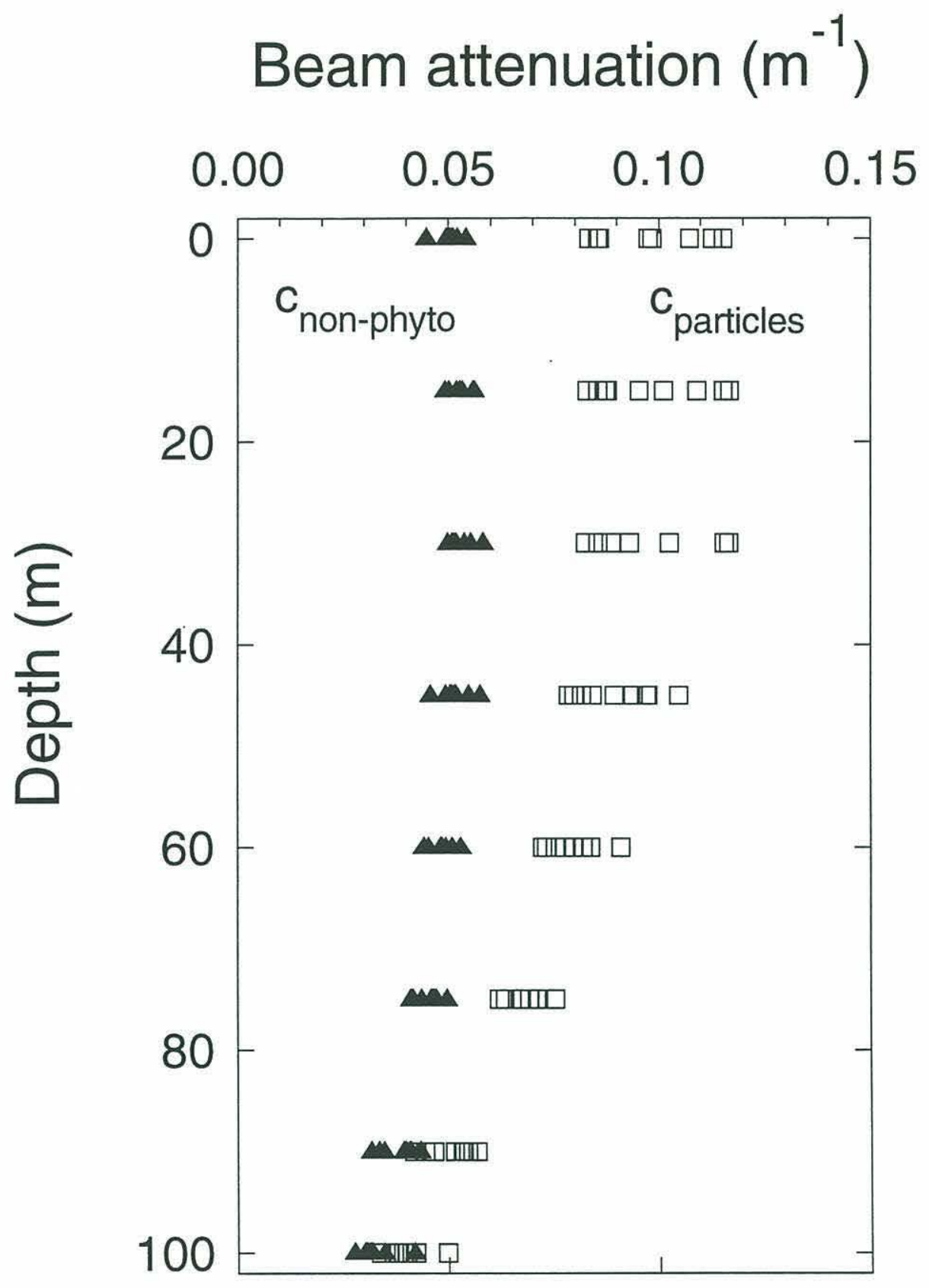


the phytoplankton scatter signal decrease. The variation in $\mathrm{c}_{\text {non-phyto }}$ over time (the presumed cause of the spread in the data at each depth) is quite small compared to the variation in $\mathrm{c}_{\text {particles }}$, as expected. An estimate of the bacterial contribution to $\mathrm{c}_{\text {non- }}$ ${ }_{\text {phyto }}$ can be made from bacterial abundance and volume data (DUCKLOW et al., 1995). They determined bacterial abundance (from acridine orange direct counts) from a near noon Go-Flo rosette cast. We compared this data to our Prochlorococcus concentrations from the near noon CTD/Niskin rosette cast during each diel sampling and found that bacteria were 3-5 times more abundant in the upper $60 \mathrm{~m}$ during TT8D1, 5-8 times more during TT12D1, and 7-9 times more during TT12D2. Since the estimated bacterial cell volume $\left(0.03-0.04 \mu \mathrm{m}^{3}\right.$, DUCKLOW et al., 1995) is 3-9 times smaller than the estimated volume of Prochlorococcus (based on a diameter of 0.6-0.8 $\mu \mathrm{m}$ ), the bacterial contribution to $\mathrm{c}_{\text {non-phyto }}$ would be expected to be similar to that of Prochlorococcus (assuming the same relationship between size and attenuation for the two groups), though it could be three times greater or three times smaller. Prochlorococcus contribution to $\mathrm{c}_{\mathrm{p}}$ in the upper $60 \mathrm{~m}$ at the near noon sampling was 9-12\% during TT8D1 and 4-6\% during TT12D1 and TT12D2. Note that these estimates of bacterial contribution to $c_{p}$ may be high since the bacterial abundances from acridine orange counts probably included Prochlorococcus (which were also detected by flow cytometry) as well as heterotrophic bacteria. 
Interpretation of diel patterns in c as production

Some investigators have used diel variations in beam attenuation to estimate community production, by relating the daily change in $\mathrm{c}$ to suspended particulate material and assuming that a given proportion (25\%-40\%) of it is particulate organic carbon (SIEGEL et al., 1989; CULLEN et al., 1992; WALSH et al., in press). The effect is to use a constant conversion factor between beam $\mathrm{c}$ and carbon $\left(\mathrm{c}_{\mathrm{c}}{ }_{\mathrm{c}}\right.$, the carbon specific beam attenuation) to estimate carbon production from the diel variations in c. SiEGEL et al. and CULLEN et al. used a $\mathrm{c}_{\mathrm{c}}{ }^{*}$ of $3.92 \mathrm{~m}^{2}(\mathrm{gC})^{-1}$, and obtained reasonable estimates of carbon production compared to carbon uptake production determinations. For the JGOFS Time Series cruises in the equatorial Pacific, WALSH et al. used a $\mathrm{c}_{\mathrm{c}}{ }^{*}$ of 5.5 for TT8 and 3.9 for TT12; the resulting estimates were approximately one-third of the ${ }^{14} \mathrm{C}$-derived production estimates of BARBER et al. (1994). WALSH et al. explain this discrepancy as being the result of mixing, grazing, aggregation, and respiration which can affect the beam attenuation measurements but not the bottle incubations. However, if the $\mathrm{c}_{\mathrm{c}}{ }^{*}$ differs among species or over the course of the day (as indicated by STRAMSKI and REYNOLDS, 1993, and STRAMSKI et al., 1995), analysis using a constant c $_{\mathrm{c}}{ }^{*}$ may not be valid. STRAMSKI and REYNOLDS measured an average $\mathrm{c}_{\mathrm{c}}{ }^{*}$ of 3.81 for Thalassiosira pseudonana, which was relatively constant over the day:night cycle. For Synechococcus, STRAMSKI et al. measured an average $\mathrm{c}_{\mathrm{c}}{ }^{*}$ of 2.48 , though it tended to be higher at dusk than at dawn. Our laboratory calibrations with Nannochloris and Synechococcus also indicate inter-species differences in $\mathrm{c}_{\mathrm{c}}{ }^{*}$ (see Fig. 3; for 
Nannochloris, mean $\mathrm{c}_{\mathrm{c}}{ }^{*}=3.38, \mathrm{sd}=0.34, \mathrm{n}=49$; for Synechococcus, , ean $\mathrm{c}_{\mathrm{c}}{ }^{*}=$ 1.52, $\mathrm{sd}=0.26, \mathrm{n}=8$ ). Using a lower estimate of $\mathrm{c}_{\mathrm{c}}{ }^{*}$ ( such as that determined for Nannochloris) leads to a higher estimate of production than WALSH et al. obtained, but still considerably lower than estimates from carbon uptake. Applying a variable $\mathrm{c}_{\mathrm{c}}{ }^{*}$ which is higher at dusk than at dawn, reduces the estimate even more. However, applying a $\mathrm{c}_{\mathrm{c}}{ }^{*}$ typical for Synechococcus to the portion of the change in beam c for which the picoplankton were responsible does lead to slightly higher estimates of production (though still not as high as carbon uptake determinations). These considerations illustrate the necessity of knowing the phytoplankton community composition for interpreting diel variations in beam c. The beam c approach appears to underestimate production; one reason for this is illustrated by the $60 \mathrm{~m}$ data in Fig. 2. The bulk beam c pattern changes very little from dawn to dusk, yet variations in scattering cross section, presumably related to carbon growth, of all the different phytoplankton groups are evident. These increases during the day are, in effect, cancelled out by the decreasing cell concentrations (presumably due to grazing) to produce a nearly constant beam $\mathrm{c}$ due to the phytoplankton groups during the day (Fig. 6), and thus an unchanging $\mathrm{c}_{\text {particles. }}$ This implies that grazed particles are removed from the beam attenuation signal (as suggested by CULLEN et al., 1992) and supports the contention that using diel variations in beam $\mathrm{c}$ to estimate production includes the effects of grazing (WALSH et al., 1995). 


\section{CONCLUSIONS}

We have shown that, over three intensive diel samplings and several pairs of dawn-dusk samplings during two cruises in the equatorial Pacific, diel variations in the bulk water optical property of beam attenuation (minimum near dawn and maximum near dusk) correspond to diel variations in the forward light scattering of phytoplankton populations, and not to cell concentration, which often exhibits the inverse diel pattern. These diel variations in light scattering of phytoplankton appear to be due primarily to cell growth as the cells photosynthesize and add carbon during the day, and then divide at night. The decrease in the bulk beam attenuation during the night is due to a combination of repackaging of cell material via cell division, aggregation, and grazing, as well as losses of material due to respiration and, mixing. By using laboratory and theoretically derived calibrations to analyze diel variations in phytoplankton populations at sea, we were able to account for essentially all of the

diel variation in $\mathrm{c}_{\text {particles. }}$. The majority of the $\mathrm{c}_{\text {phyto }}$ signal was from eukaryotic phytoplankton (the nano- and ultra- phytoplankton), with a smaller portion from the most abundant cell, Prochlorococcus, and a negligible amount from Synechococcus in these waters. In most cases, the largest contributor to the diel variation in $\mathrm{c}_{\text {phyto }}$ was the ultraphytoplankton group. These findings emphasize the need to characterize the composition of the phytoplankton community in order to use beam attenuation as a tool for monitoring productivity. 


\section{Acknowledgements}

We thank E. Zettler for technical support on both cruises and in the laboratory, B.

Binder for technical support on one cruise, W. Gardner for the beam attenuation data,

D. Siegel, H. Sosik and A. Solow for helpful discussions, and the captains and crew

of the R.V. Thomas Thompson. We also thank S. Ackleson and W. Gardner for

critical review. This work is part of the JGOFS Equatorial Pacific Process Study and was supported by NSF grant OCE-9024380 (to RJO) and a WHOI Ocean Ventures

Award (to MDD). 


\section{REFERENCES}

ACKLESON, S.G., J.J. Cullen, J. BROWN and M. LesSER. (1993) Irradiance-induced variability in light scatter from marine phytoplankton in culture. Journal of Plankton Research, 15, 737-759.

ACKLESON, S.G. and R.W. SPINRAD. (1988) Size and refractive index of individual marine particulates: a flow cytometric approach. Applied Optics, 27, 1270-1277.

BAKeR, E.T. and J.W. LAVELLE. (1984) The effect of particle size on the light attenuation coefficient of natural suspensions. Journal of Geophysical Research, 89, 8197-8203.

BARBER, R.T., J.W. MURRAY and J.J. MCCARTHY. (1994) Biogeochemical interactions in the equatorial Pacific. Ambio, 23, 62-66.

BARTZ, R., J.R.V. ZANEVELD and H. PAK. (1978) A transmissometer for profiling and moored observations in water. SPIE: Ocean Optics V, 160, 102-108.

BINDER, B.J., S.W. CHISHOLM, R.J. OLSON, S.L. FRANKEL and A.Z. WORDEN. (submitted) Dynamics of heterotrophic and autotrophic picoplankton and ultra-phytoplankton populations in the equatorial Pacific at $140^{\circ} \mathrm{W}$. Deep-Sea Research.

BOHREN, C.F. and D.R. HUFFMAN. (1983) Absorption and scattering of light by small particles. John Wiley and Sons, New York, 530 pp.

BRICAUd, A., A.-L. BEDHOMme and A. Morel. (1988) Optical properties of diverse phytoplanktonic species: experimental results and theoretical interpretation. Journal of Plankton Research, 10, 851-873.

Cullen, J.J., M.R. Lewis, C.O. DAvis and R.T. BARBer. (1992) Photosynthetic characteristics and estimated growth rates indicate grazing is the proximate control of primary production in the equatorial Pacific. Journal of Geophysical Research, 97, 639-654.

DUCKLOW, H.W., H.L. QUINBY and C.A. CARLSON (1995) Bacterioplankton dynamics in the equatorial Pacific during the 1992 El Niño. Deep-Sea Research.

GARDNER, W.D., S.P. CHUNG, M.J. Richardson and I.D. WALSH. (1995) The oceanic mixed-layer pump. Deep-Sea Research. 
GARDNER, W.D., M.J. RICHARDSON, I.D. WALSH and B.L. BERGLUND. (1990) In-situ optical sensing of particles for determination of oceanic processes. Oceanography, 3, 11-17.

GARDNER, W.D., I.D. WALSH and M.J. RICHARDSON. (1993) Biophysical forcing of particle production and distribution during a spring bloom in the North Atlantic. Deep-Sea Research, 40, 171-195.

GORDON, H.R., R.C. SMITH and J.R.V. ZANEVELD. (1984) Introduction to ocean optics. SPIE: Ocean Optics VII, 489, 2-41.

Hamilton, M., T.C. Granata, T.D. Dickey, J.D. Wiggert, D.A. Siegel, J. MarRa and C. LANGDON. (1990) Diel variations of bio-optical properties in the Sargasso Sea. SPIE: Ocean Optics X, 1302, 214-224.

Jerlov, N.G. (1976) Marine Optics. Elsevier Scientific Publishing Company, Amsterdam, $231 \mathrm{pp}$.

MOREL, A. and A. BRICAUD. (1986) Inherent optical properties of algal cells including picoplankton: Theoretical and experimental results, pp. 521-559 in T. Platt and W.K.W. Li (eds.), Photosynthetic Picoplankton. Canadian Bulletin of Fisheries and Aquatic Sciences 214, .

Olson, R.J., E.R. ZETTLER, S.W. CHISHOLM and J.A. DuSENBERRY. (1991) Advances in oceanography through flow cytometry, pp. 351-399 in S. Demers (ed.), Particle Analysis in Oceanography, NATO ASI Series G 27, Springer-Verlag, Berlin.

Olson, R.J., E.R. ZETTLER and M.D. DuRAND. (1993) Phytoplankton analysis using flow cytometry, pp. 175-186 in P.F. Kemp, B.F. Sherr, E.B. Sherr and J.J. Cole (eds.), Handbook of Methods in Aquatic Microbial Ecology, Lewis Publishers, Boca Raton.

PAK, H., D.A. KIEFER and J.C. KITCHEN. (1988) Meridional variations in the concentration of chlorophyll and microparticles in the North Pacific Ocean. Deep-Sea Research, 35, 1151-1171.

ShIBATA, K (1958) Spectrophotometry of intact biological materials. Journal of Biochemistry, 45, 599-623.

SiEgEL, D.A., T.D. DickeY, L. WAshbuRn, M.K. HAMilton and B.G. MitChell. (1989) Optical determination of particulate abundance and production variations in the oligotrophic ocean. Deep-Sea Research, 36, 211-222. 
STRAMSKA, M. and T.D. DiCKEY. (1992) Variability of bio-optical properties of the upper ocean associated with diel cycles in phytoplankton populations. Journal of Geophysical Research, 97, 17,873-17,887.

STRAMSKI, D. and R.A. REYNOLDS. (1993) Diel variations in the optical properties of a marine diatom. Limnology and Oceanography, 38, 1347-1364.

StRAMSKI, D., A. ShalAPYONOK and R.A. ReYNOLDS. (1995) Optical characterization of the oceanic unicellular cyanobacterium Synechococcus grown under a day-night cycle in natural irradiance. Journal of Geophysical Research.

VAN DE Hulst, H.C. (1957) Light Scattering by Small Particles. John Wiley \& Sons, Inc., New York, 470 pp.

Vaulot, D., C. Courties and F. Partensky. (1989) A simple method to preserve oceanic phytoplankton for flow cytometric analyses. Cytometry, 10, 629-635.

VAulot, D., D. Marie, R.J. Olson and S.W. Chisholm. (1995) Growth of Prochlorococcus, a photosynthetic prokaryote, in the equatorial Pacific Ocean. Science, 268, 1480-1482.

WALsh, I.D., S.P. Chung, M.J. RICHARDSON and W.D. GARDNER. (in press) The diel cycle in the integrated particle load in the equatorial Pacific: A comparison with primary production. Deep-Sea Research. 


\section{Chapter 4}

Contributions of phytoplankton light scattering and cell concentration changes to diel variations in beam attenuation in the Sargasso Sea 


\begin{abstract}
The mean forward light scatter of a mixed population of nanophytoplankton and the picophytoplankton, Prochlorococcus and Synechococcus, measured on individual cells by flow cytometry, increased during the day and decreased during the night in the Sargasso Sea. This pattern was similar to that of bulk beam attenuation due to particles. In contrast, cell concentrations changes did not generally correspond to the patterns in beam attenuation.

Using a combination of empirical calibrations relating beam attenuation to flow cytometric measurements of pure cultures of phytoplankton in the laboratory, and Mie theory, we estimated the contributions of phytoplankton to the diel variations in beam attenuation observed during diel samplings in January 1992, July 1993, and May 1994. The bulk beam attenuation due to particles was strongly correlated with calculated beam attenuation due to phytoplankton. During the July 1993 diel sampling, when pico- and nanophytoplankton populations were analyzed, in most instances the nanophytoplankton were the largest contributor to total beam attenuation due to phytoplankton, but Prochlorococcus were equally important at 70 $\mathrm{m}$ for some time points over the diel cycle. In the upper $40 \mathrm{~m}$, Prochlorococcus were a smaller contributor to beam attenuation changes than the nanophytoplankton, and Synechococcus were even less important. These findings emphasize the need to characterize the composition of the phytoplankton community in order to use beam attenuation as a tool for monitoring productivity.
\end{abstract}




\section{INTRODUCTION}

Diel variations in beam attenuation, with a minimum near dawn and a maximum near dusk, have been used to estimate primary productivity in the North Pacific (Siegel et al. 1989) and the equatorial Pacific (Cullen et al. 1992). In order to elucidate the relationship between phytoplankton and beam attenuation, we have related direct measurements of changes in the light scattered by the phytoplankton to changes in beam attenuation over the diel cycle in the Sargasso Sea in January 1992, July 1993, and May 1994. We observed diel variations in mean forward light scatter for populations of eukaryotic and prokaryotic phytoplankton that are minimum near dawn and maximum near dusk, the same patterns seen for bulk beam attenuation. In contrast, phytoplankton cell concentrations generally do not have the same diel patterns; instead, they usually have the opposite pattern. Using laboratory calibrations on phytoplankton combined with theoretical calculations, we estimated the contribution that each phytoplankton population made to the diel variations in beam attenuation in the Sargasso Sea. The complete explanation of the motivation behind the work and the calibrations used can be found in DuRand and Olson (in press [Chapter 3]), which uses the same method to analyze data from diel cycles in the equatorial Pacific. 


\section{MATERIALS AND METHODS}

\section{Field Studies}

Diel samplings were performed on four occasions during three cruises in the Sargasso Sea. During R.V. Endeavor 232 in January 1992, two diel samplings were performed (EnD1 for $48-\mathrm{h}$ at $27^{\circ} \mathrm{N} 68^{\circ} \mathrm{W}$ and EnD2 for $28-\mathrm{h}$ at $35^{\circ} \mathrm{N} 68^{\circ} \mathrm{W}$ ).

During R.V. Columbus Iselin 93-06 (July 1993), one 40-h sampling was performed (Iselin at $35^{\circ} \mathrm{N} 69^{\circ} \mathrm{W}$ ). During R.V. Cape Hatteras 0694 (May 1994), one 48-h sampling was performed (Hat at $35^{\circ} \mathrm{N} 71^{\circ} \mathrm{W}$ ). For each sampling, a holey-sock drogue set at $25 \mathrm{~m}$ was launched and tracked in order to follow the same water mass during the sampling. CTD-transmissometer casts were made every two hours and samples for flow cytometric analyses were taken with Niskin bottles at four to six depths.

The eukaryotic phytoplankton were analyzed on board the ship within two hours of collection, using an EPICS V flow cytometer modified to analyze $50 \mathrm{ml}$ seawater samples at 5-10 ml min ${ }^{-1}$ (Olson et al. 1991, 1993). Samples were kept at room temperature in the dark until analysis. Fluorescent microspheres $(3.79 \mu \mathrm{m}$, Polysciences) were added to each sample as an internal standard. Eukaryotic phytoplankton from 1-20 $\mu \mathrm{m}$ in diameter were counted and, for each particle, forward light scatter (FLS, $3^{\circ}-19^{\circ}$ at $488 \mathrm{~nm}$ ), side scatter, red (chlorophyll, 660-700 nm) fluorescence, and orange (phycoerythrin, 530-630) fluorescence were collected. Phytoplankton populations were discriminated on plots of forward light scatter vs. 
chlorophyll fluorescence using CytoPC software (D. Vaulot, Station Biologique, Roscoff, France). The population referred to here as the nanophytoplankton primarily consisted of $2-5 \mu \mathrm{m}$ diameter coccoid cells, but also included cells as large as $20 \mu \mathrm{m}$.

For the Iselin diel sampling, the picoplankton Synechococcus and Prochlorococcus were also analyzed on board the ship within two hours of collection using a high sensitivity configuration of an EPICS 753 flow cytometer (Olson et al., 1993), and $0.57 \mu \mathrm{m}$ beads (Polysciences) as an internal standard. Synechococcus were distinguished by their high phycoerythrin fluorescence and Prochlorococcus by their low FLS and chlorophyll fluorescence.

\section{Laboratory Studies}

Laboratory experiments were performed on the chlorophyte Nannochloris sp. grown on a $14 \mathrm{~h}$ light:10 h dark cycle and sampled every two hours for 24 hours. These experiments are described fully elsewhere (Chapter 2). Briefly, diel sampling experiments were performed at 250 (Nan250) and $500 \mu \mathrm{mol}$ photons $\mathrm{m}^{-2} \mathrm{~s}^{-1}$ (Nan500) in batch cultures in an incubator and at $1500 \mu \mathrm{mol}$ photons $\mathrm{m}^{-2} \mathrm{~s}^{-1}$ (Nan1500) outdoors under natural sunlight. Briefly, measurements were made of mean forward light scatter and cell concentration (flow cytometric analysis), beam attenuation (SeaTech 25-cm transmissometer), absorption (opal glass method, Shibata 1958, in a spectrophotometer), cell size (Coulter Multisizer), and carbon content (Perkin-Elmer 2400 CHN Analyzer). 
A similar experiment was performed on Synechococcus, with 4 strains

(WH8012, 8015, 8018, and 8103) grown at $75 \mu \mathrm{mol}$ photons $\mathrm{m}^{-2} \mathrm{~s}^{-1}$ on a $14: 10 \mathrm{~L}: \mathrm{D}$ cycle and sampled at "dawn" and "dusk." Measurements were made of FLS and cell concentration, beam attenuation, cell size, and carbon content.

\section{Conversion of forward light scatter to scattering cross section}

Our measurements of forward light scatter $\left(3^{\circ}-19^{\circ}\right)$ are expressed relative to light scattered by standard beads. To compare our results to theory, we need to express them in more meaningful units. We therefore calculated the scattering cross section $\left(\sigma_{\mathrm{b}}\right.$ in $\left.\mu \mathrm{m}^{2}\right)$ of the cells by reference to the calculated scattering cross section $\left(3^{\circ}-19^{\circ}\right)$ of the beads, for which the size, refractive index, and absorption are known (Bohren and Huffman, 1983; Ackleson and Spinrad, 1988). This procedure is fully described in DuRand and Olson (in press).

\section{RESULTS AND DISCUSSION}

\section{Diel Patterns in Phytoplankton and Beam Attenuation}

The mean scattering cross section (calculated from flow cytometric forward light scatter) of nanophytoplankton, Synechococcus, and Prochlorococcus cells was consistently at a minimum near dawn and maximum near dusk at all depths sampled during EnD1, Hat, and Iselin and at 0 and $20 \mathrm{~m}$ during EnD2 (Figs. 1B-3B, 4B, D, F). The patterns in beam attenuation due to particles $\left(\mathrm{c}_{\text {particles }}\right)$ were similar to those 
Figure 1. Time series data for each depth sampled during a 48-hour diel sampling experiment in January 1992 at $27^{\circ} \mathrm{N} 68^{\circ} \mathrm{W}$ (R.V. Endeavor, EnD1). A) Beam attenuation due to particles $\left.\left(\mathrm{c}_{\text {particles }}, \mathrm{m}^{-1}\right), \mathrm{B}\right)$ Forward light scattering cross section $\left(\sigma_{b}, \mu \mathrm{m}^{2}\right)$, and C) cell concentration (cells $\mathrm{ml}^{-1}$ ) for nanophytoplankton. 


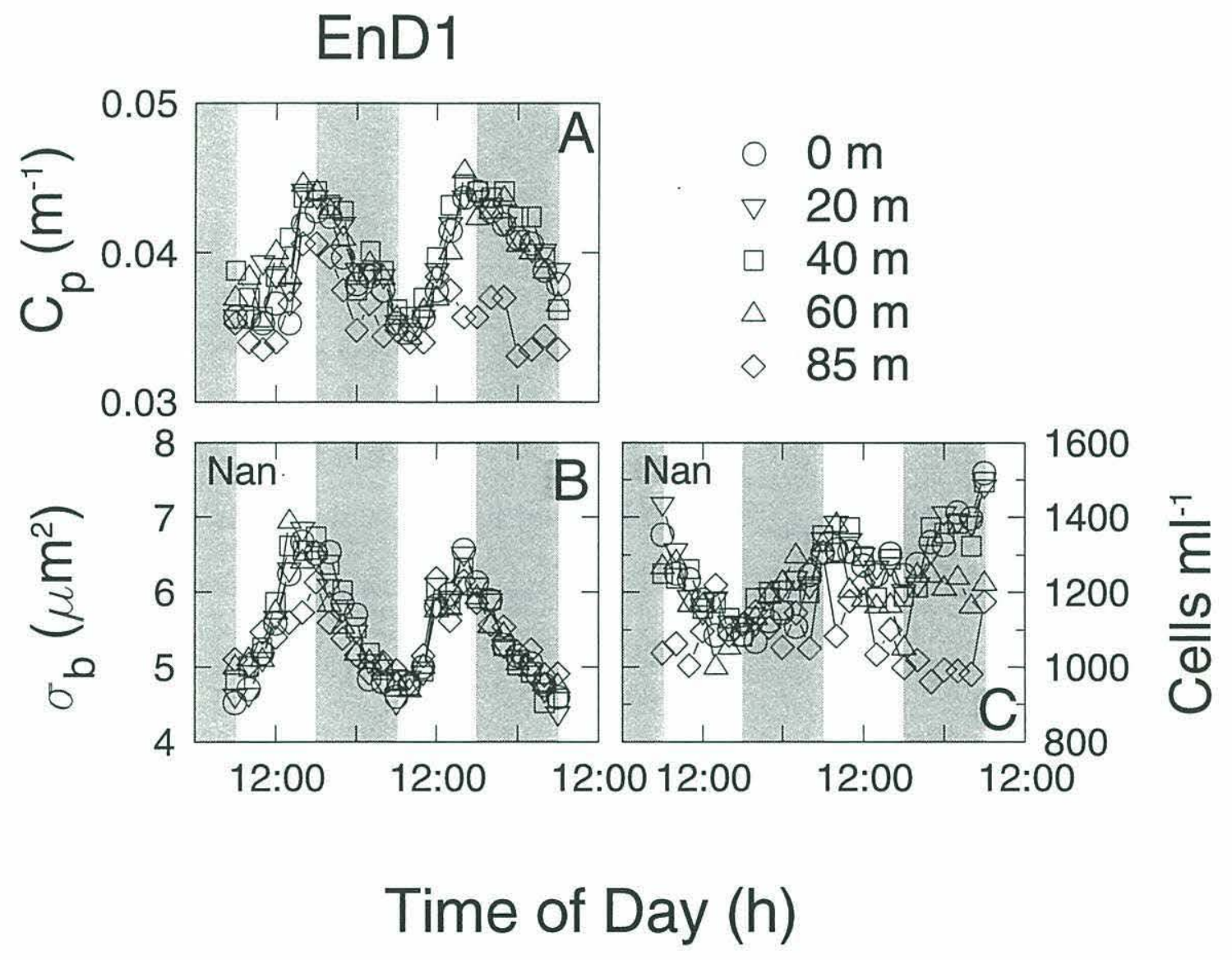


Figure 2. Time series data for depths to $100 \mathrm{~m}$ during a 28-hour diel sampling experiment in January 1992 at $35^{\circ} \mathrm{N} 68^{\circ} \mathrm{W}$ (R.V. Endeavor, EnD2). A) Beam attenuation due to particles $\left.\left(\mathrm{c}_{\text {particles }}, \mathrm{m}^{-1}\right), \mathrm{B}\right)$ Forward light scattering cross section $\left(\sigma_{\mathrm{b}}, \mu \mathrm{m}^{2}\right)$, and $\mathrm{C}$ ) cell concentration (cells $\mathrm{ml}^{-1}$ ) for nanophytoplankton. 


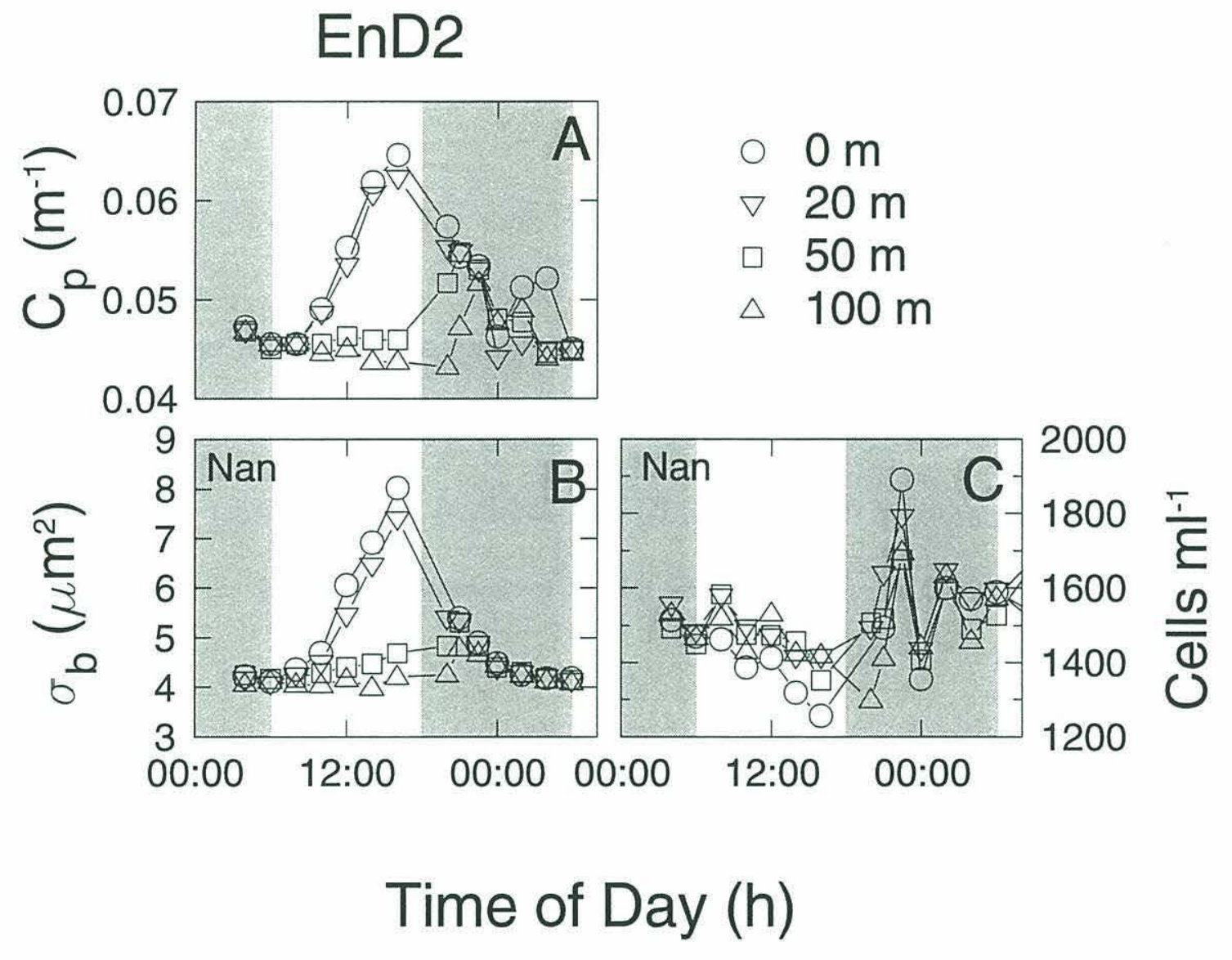


Figure 3. Time series data for all depths sampled during a 48-hour diel sampling experiment in May 1994 at $35^{\circ} \mathrm{N} 71^{\circ} \mathrm{W}$ (R.V. Cape Hatteras, Hat). A) Beam attenuation due to particles $\left.\left(\mathrm{c}_{\text {particles }}, \mathrm{m}^{-1}\right), \mathrm{B}\right)$ Forward light scattering cross section $\left(\sigma_{\mathrm{b}}, \mu \mathrm{m}^{2}\right)$, and C) cell concentration (cells $\mathrm{ml}^{-1}$ ) for nanophytoplankton. 
Hat

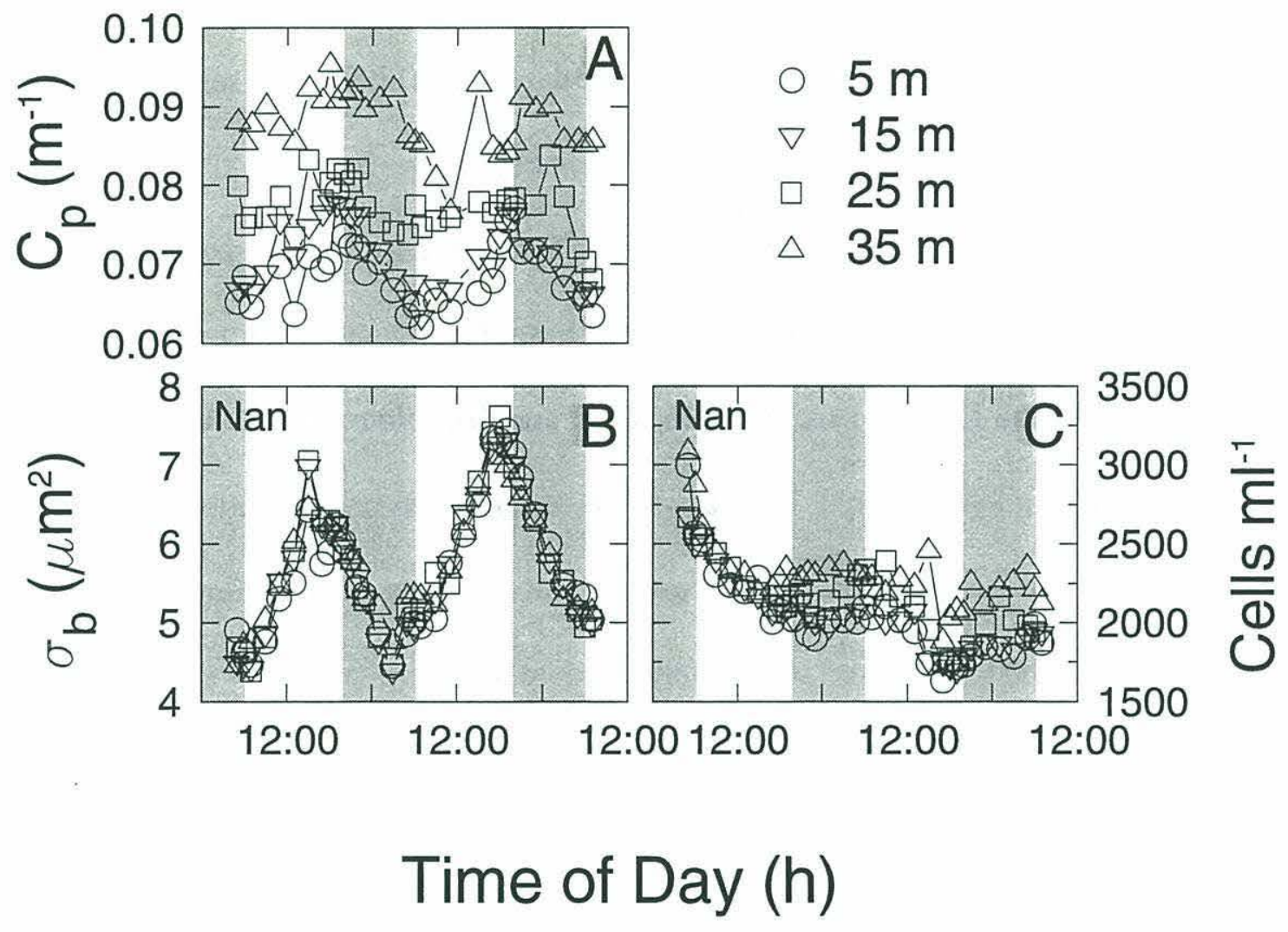


Figure 4. Time series data for all depths sampled during a 40-hour diel sampling experiment in July 1993 at $35^{\circ} \mathrm{N} 69^{\circ} \mathrm{W}$ (R.V. Columbus Iselin, Iselin). A) Beam attenuation due to particles $\left(\mathrm{c}_{\text {paricles }}, \mathrm{m}^{-1}\right)$. Forward light scattering cross section $\left(\mu \mathrm{m}^{2}\right)$, and cell concentration (cells $\mathrm{ml}^{-1}$ ) for nanophytoplankton (B and C), Synechococcus (D and E), and Prochlorococcus (F and G). Note that the y-axis for each plot is scaled independently. The nanophytoplankton cell concentrations and the Prochlorococcus scattering cross sections are both off-scale at $70 \mathrm{~m}$ for the last few data points in the time series, presumably because we were no longer sampling the same water mass at that depth (the drogue was set at $25 \mathrm{~m}$ ). 
Iselin

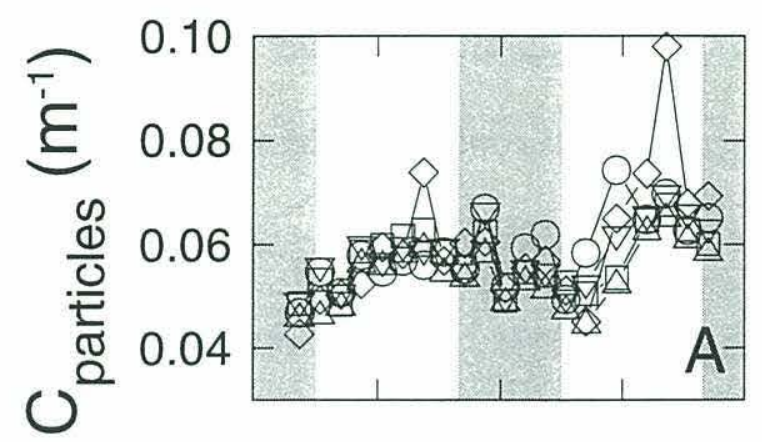

$\triangle 5 \mathrm{~m}$
$\nabla \quad 15 \mathrm{~m}$
$\square \quad 25 \mathrm{~m}$
$\triangle 40 \mathrm{~m}$
$\diamond 70 \mathrm{~m}$

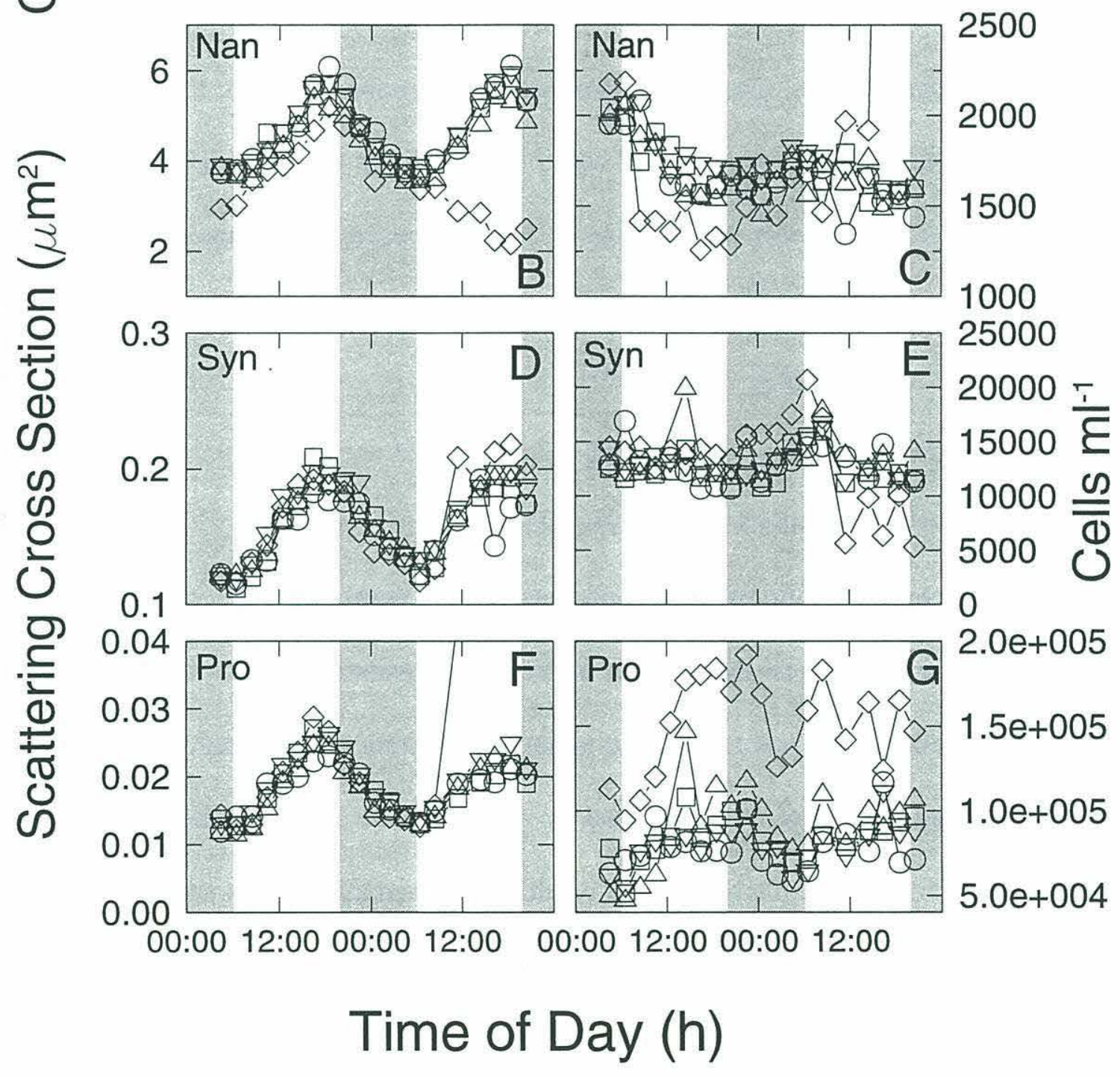


of FLS, with a minimum near dawn and a maximum near dusk (Figs. 1A-4A). Cell concentrations for the nanophytoplankton generally decreased during the day and increased during the night (Figs. 1C-3C, 4C, E, G). During the Iselin diel sampling, for which picoplankton were analyzed, Synechococcus cell concentrations were steady during the first day, increased during the night, and decreased the second day. Prochlorococcus cell concentrations exhibited a pattern never before observed in numerous diel sampling experiments in the Sargasso Sea and the equatorial Pacific (DuRand and Olson in press, Chapter 5, Appendix B; Dusenberry 1995); they increased during the day and decreased at night. However, Dusenberry did observe similar trends during laboratory experiments on Prochlorococcus in a mixostat. At the highest mixing rates (and thus the highest growth rates) tested, the cell concentrations increased during the day, either just before or concurrent with the increase in FLS during the day. Dusenberry suggested that nutrient limitation in these mixostats prevented cells from dividing until the light period.

It is clear that the patterns in the bulk property of beam attenuation are similar to the patterns in mean light scatter of different populations of phytoplankton, and they are generally different from those in cell concentration. The increase in light scatter during the day can be explained by growth of the phytoplankton cells as they photosynthesize and fix carbon. As a result of the increase in light scatter, the total beam c increases, despite the fact that cell concentrations are generally decreasing during the day (presumably due to grazing). The maximum in cell light scatter almost always occurs at the same time as the minimum in cell concentration, 
near dusk. The implication is that the cells begin to divide at this time, so that the average cell size decreases, with a corresponding increase in the cell concentration (newly divided cells). A number of factors can contribute to the decrease in beam c during the night; these include cell division, respiration, mixing, cell aggregation, and grazing. These are discussed in detail in DuRand and Olson (in press [Chapter 3]).

\section{Calculation of beam attenuation due to phytoplankton}

To obtain estimates of beam c from field measurements of scattering cross sections and cell concentrations of phytoplankton populations, we began with an empirical calibration using Nannochloris and Synechococcus cultures. The calibrations used are fully described in DuRand and Olson (in press). Briefly, we determined a relationship between the attenuation cross section $\left(\sigma_{\mathrm{c}}\right.$, beam $\mathrm{c}$ normalized to cell concentration) and scattering cross section $\left(\sigma_{b}\right.$, from flow cytometric FLS) from Nannochloris and Synechococcus cultures and found that it compared well to calculations based on Mie scattering theory. For Prochlorococcus, we obtained a relationship analogous to that used for the other populations by using theoretically-derived attenuation cross sections.

The appropriate calibration was applied to the field data of mean scattering cross section $\left(\sigma_{\mathrm{b}}\right)$ for different phytoplankton populations to obtain beam $\mathrm{c}$ per cell $\mathrm{ml}^{-1}$ (i.e., $\sigma_{\mathrm{c}}$, attenuation cross section) for each population. This was multiplied by the cell concentration to obtain an estimate of beam attenuation $\left(\mathrm{c}, \mathrm{m}^{-1}\right)$ due to each specific group of phytoplankton. The diel patterns in beam c due to the phytoplankton are qualitatively quite similar to that of $\mathrm{c}_{\text {particles }}$ (Figs. 5-8). 
Figure 5. Time series of bulk beam attenuation due to particles (A) and calculated beam attenuation due to nanophytoplankton (B) during a 48-hour diel sampling experiment in January 1992 at $27^{\circ} \mathrm{N} 68^{\circ} \mathrm{W}$ (R.V. Endeavor, EnD1). 
EnD1

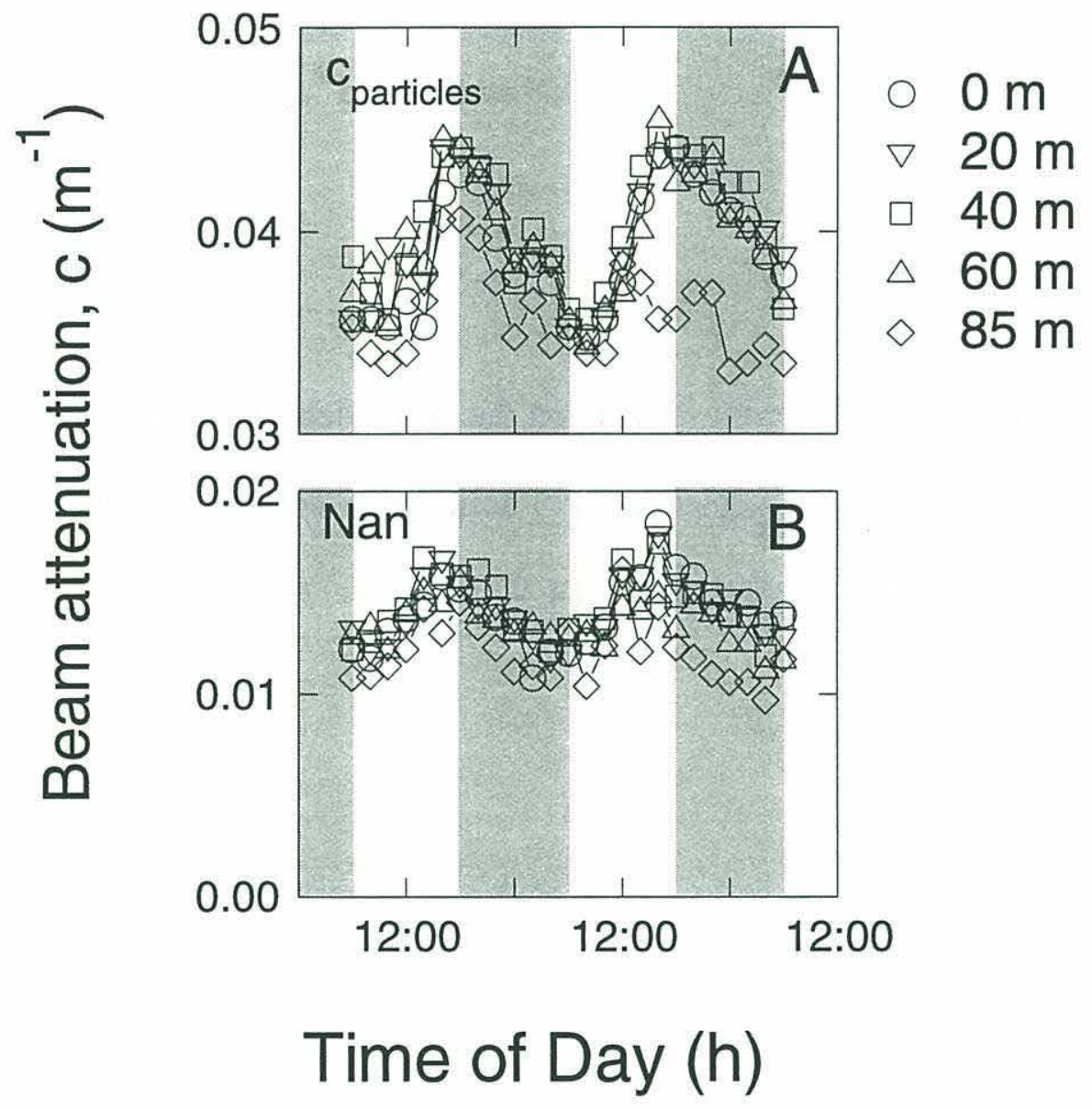


Figure 6. Time series of bulk beam attenuation due to particles (A) and calculated beam attenuation due to nanophytoplankton (B) during a 28-hour diel sampling experiment in January 1992 at $35^{\circ} \mathrm{N} 68^{\circ} \mathrm{W}$ (R.V. Endeavor, EnD2). 
EnD2

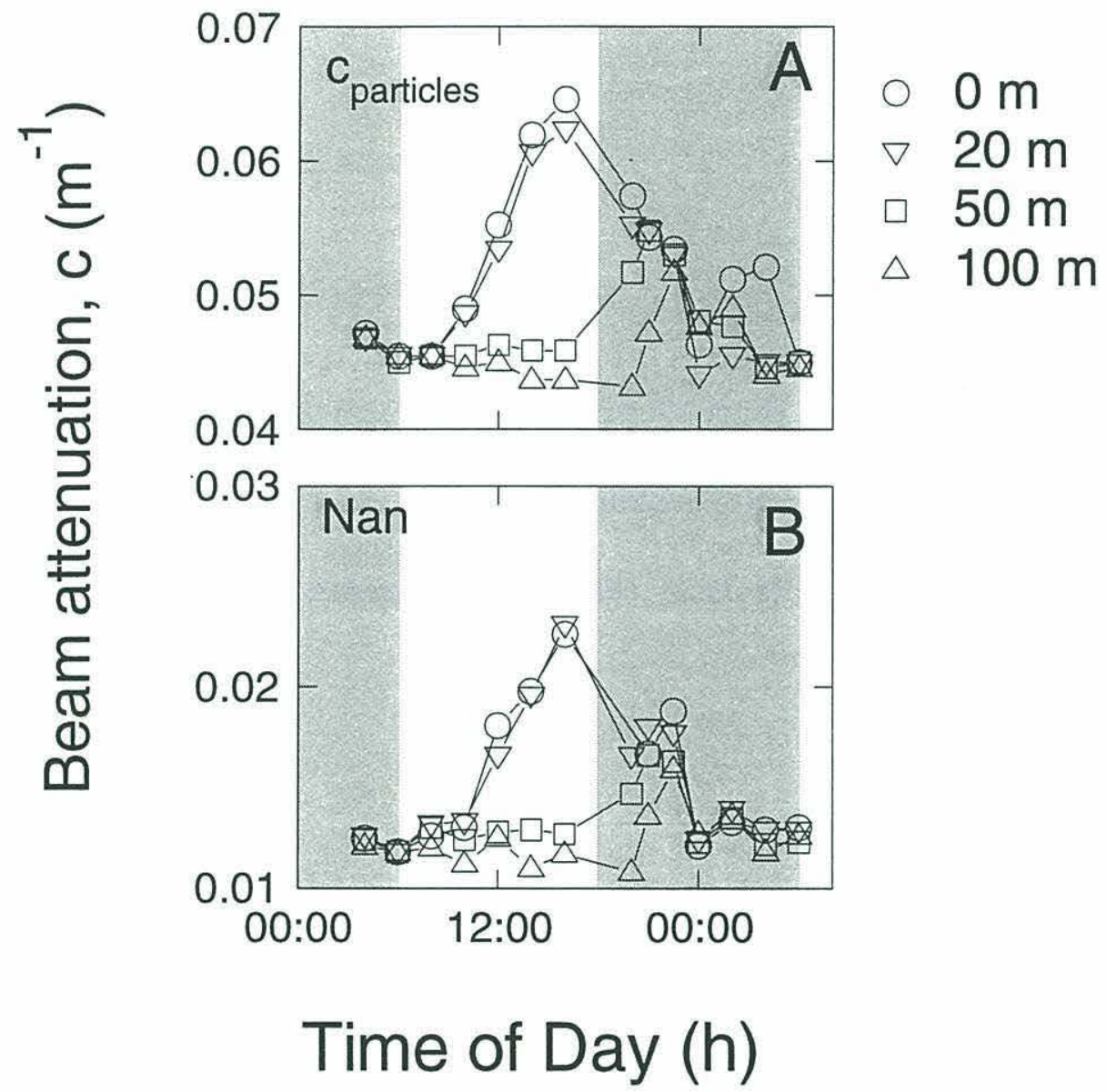


Figure 7. Time series of bulk beam attenuation due to particles (A) and calculated beam attenuation due to nanophytoplankton (B) during a 48-hour diel sampling experiment in May 1994 at $35^{\circ} \mathrm{N} 71^{\circ} \mathrm{W}$ (R.V. Cape Hatteras, Hat). 
Hat

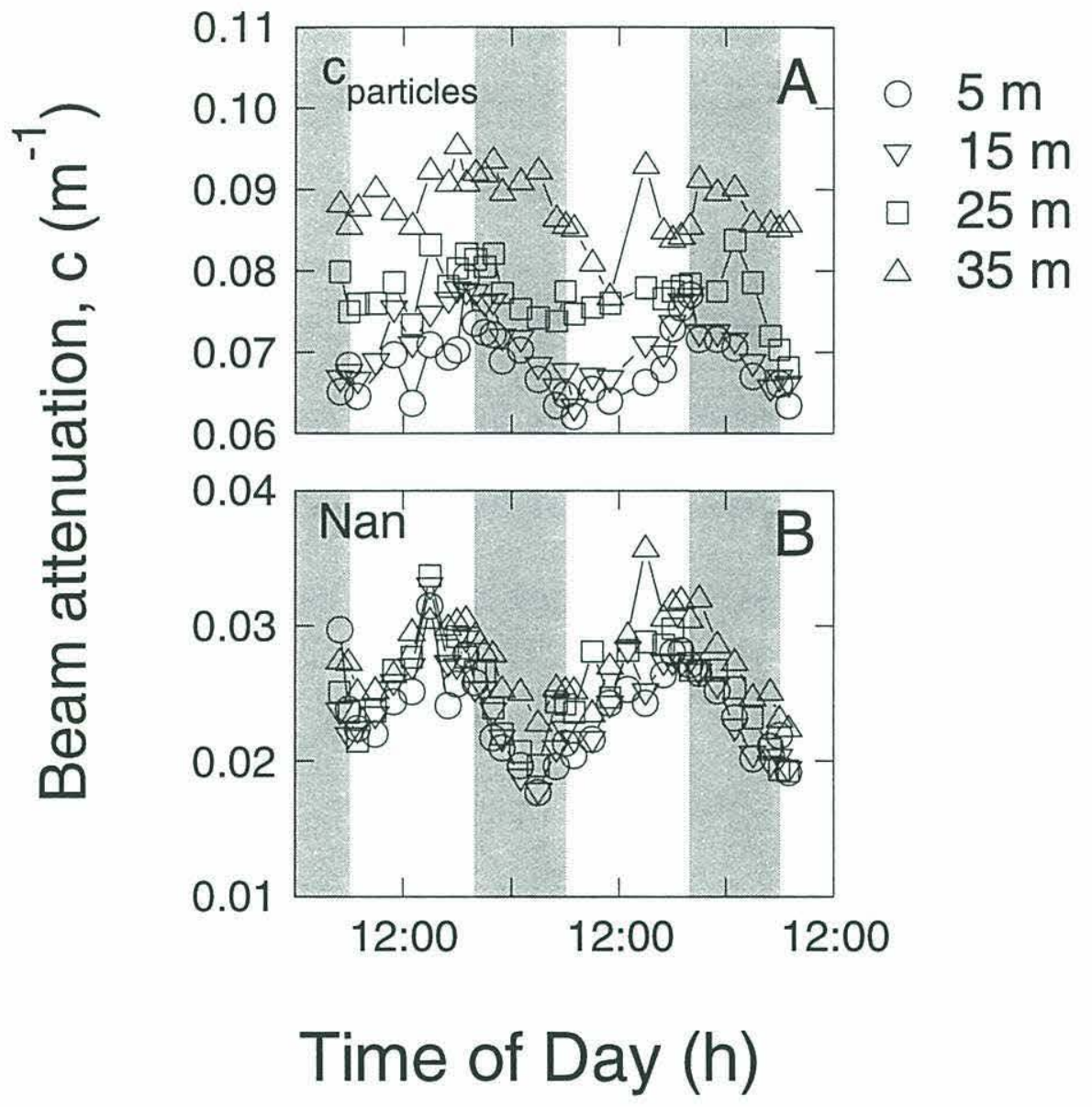


Figure 8. Time series of bulk beam attenuation due to particles (A) and calculated beam attenuation due to nanophytoplankton (B), Synechococcus (C), and Prochlorococcus (D) during a 40-hour diel sampling experiment in July 1993 at $35^{\circ} \mathrm{N} 69^{\circ} \mathrm{W}$ (R.V. Columbus Iselin, Iselin). Note that each plot is scaled independently in order to show the trends. 


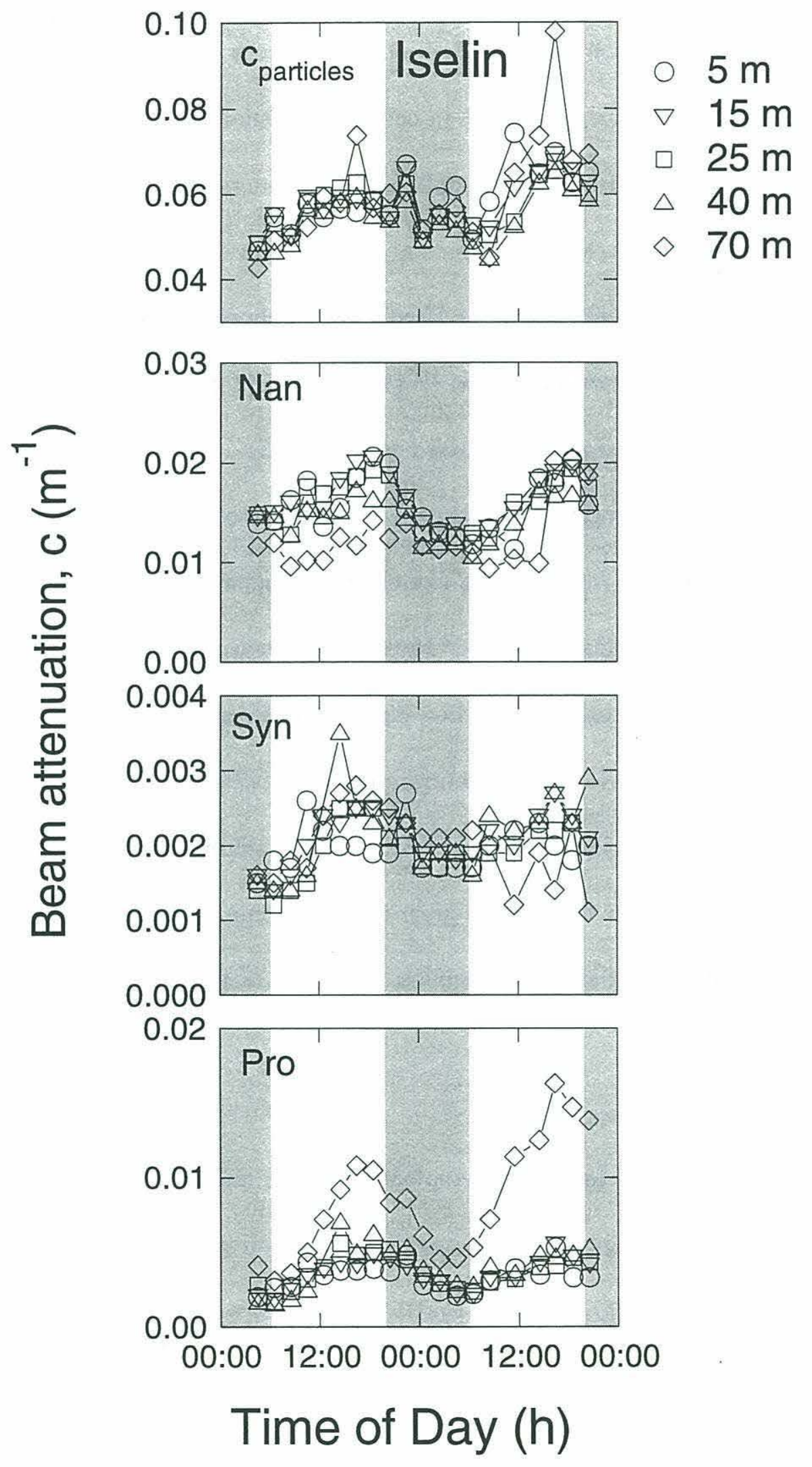


All tend to increase during the day and decrease during the night. For the most part, the variations in phytoplankton beam attenuation reflect those of the scattering cross section, dampened by the opposing trends in cell concentration. However, for Prochlorococcus during the Iselin diel sampling, the $\sigma_{\mathrm{b}}$ patterns are augmented by the cell concentration pattern, leading to greater variations in $\mathrm{c}_{\mathrm{pro}}$ (Figs. 4, 8). For $\mathrm{EnD} 2$, the increase in $\mathrm{c}_{\mathrm{nan}}$ which occurs at 50 and $100 \mathrm{~m}$ shortly after dark, is clearly caused by an increase in cell concentration (Figs. 2,6). This increase in cell concentration was due to mixing, as discussed in Chapter 5.

For the Iselin diel sampling, the absolute magnitudes of the contributions of each phytoplankton group to beam c were examined to emphasize their relative contributions (Fig. 9, same data as Fig. 8). Most of $\mathrm{c}_{\text {phyto }}$ was due to the nanophytoplankton, with a smaller proportion due to Prochlorococcus and Synechococcus. At $70 \mathrm{~m}$, however, the contribution of Prochlorococcus equals that of the nanophytoplankton at some time points during the sampling. Also, the diel variations in Prochlorococcus beam c are great and contribute more to the diel variation in $c_{p}$ than does the nanophytoplankton beam $c$ at that depth.

Comparison of $c_{\text {particles }}$ and $c_{\text {phyto }}$

Since the pattern in $\mathrm{c}$ for each phytoplankton group matched that of $\mathrm{c}_{\text {particles }}$, we wished to see if the changes in $c_{\text {particles }}$ could be quantitatively accounted for by the changes in $\mathrm{c}_{\text {phyto }}\left(\mathrm{c}_{\text {phyto }}=\mathrm{c}_{\text {nan }}\left[+\mathrm{c}_{P r o}+\mathrm{c}_{S y n}\right]\right)$. To do this, we examined the changes between successive samples in $\mathrm{c}_{\text {particles }}\left(\Delta \mathrm{c}_{\text {particles }}\right)$ and $\mathrm{c}_{\text {phyto }}\left(\Delta \mathrm{c}_{\text {phyto }}\right)$. Thus, 
positive values were obtained when c's were increasing and negative values when decreasing. For EnD2, there was a strong correlation between $\Delta \mathrm{c}_{\text {particles }}$ and $\Delta \mathrm{c}_{\text {phyto }}$ $\left(=\Delta c_{\operatorname{man}}\right.$, in this case; $r^{2}=0.69 ;$ Fig. 10$)$. The slope of the relationship is 1.3 , thus $\Delta$ $\mathrm{c}_{\text {nan }}$ accounts for $78 \%\left(1 / 1.3\right.$, expressed as a percentage) of $\Delta \mathrm{c}_{\text {particles. }}$. For diel studies in the equatorial Pacific, we accounted for virtually all of the $\Delta \mathrm{c}_{\text {particles }}$ with our calculated $\Delta \mathrm{c}_{\text {phyto }}$ (DuRand and Olson in press). However, the picoplankton, as well as the eukaryotic phytoplankton, were analyzed for those experiments. Here, we account for nearly $80 \%$ with the nanophytoplankton alone.

Though the general patterns in $\mathrm{c}_{\text {phyto }}$ are clearly similar to those in $\mathrm{c}_{\text {particles }}$, for EnD1, Hat, and Iselin, there is enough variability in the data, that the trends do not match exactly. Thus $\Delta \mathrm{c}_{\text {particles }}$ and $\Delta \mathrm{c}_{\text {phyto }}$ are not strongly correlated, as they are for EnD2, above. In order to reduce the jumpiness in the beam $\mathrm{c}$ data for these diel samplings, we smoothed the time series data with a three-point moving average.

There is some indication, at least during EnD1 and Hat, that $\mathrm{c}_{\text {phyto }}$ leads $\mathrm{c}_{\text {particles }}$ by one or two time points, or about two hours (Fig. 11). It is possible that this is because the water samples were not analyzed at the exact same time the transmissometer data was taken. The Niskin bottles must be sampled and each sample analyzed with the flow cytometer. All samples are completed within two hours, however, if the cells, which are in bottles in the dark, continue to progress through the cell cycle, then this could account for the apparent time shift, since the data are plotted using the sampling (CTD) time and not the time of analysis. However, it is not clear why this would affect some diel samplings and not others (EnD2, for example). For EnD1, 
Figure 9. Time series of calculated beam attenuation due to each group of phytoplankton $\left(\mathrm{c}_{\text {nan }}(O), \mathrm{c}_{\text {syn }}(\square)\right.$, and $\left.\mathrm{c}_{\text {pro }}(\nabla)\right)$ plotted together to show their relative contributions during the Iselin diel sampling. Note that this is the same data as in the previous figure. 


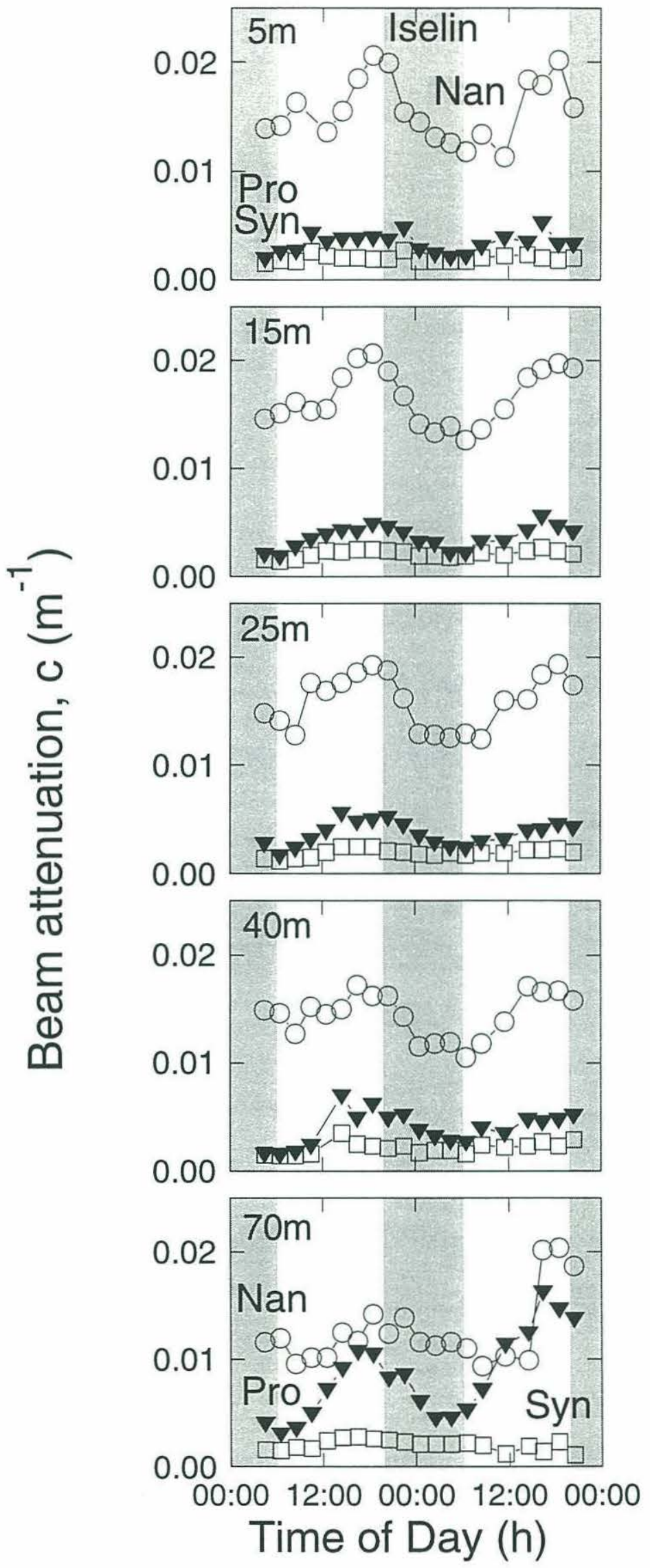


Figure 10. Relationship between $\Delta \mathrm{c}_{\text {particles }}$ and $\Delta \mathrm{c}_{\text {nanophytoplankton }}$ during a diel sampling experiment in January 1992 at $35^{\circ} \mathrm{N} 68^{\circ} \mathrm{W}$ (EnD2). Data are from 0-100 m. Solid line is linear regression $\left(r^{2}=0.69, n=50\right)$. 


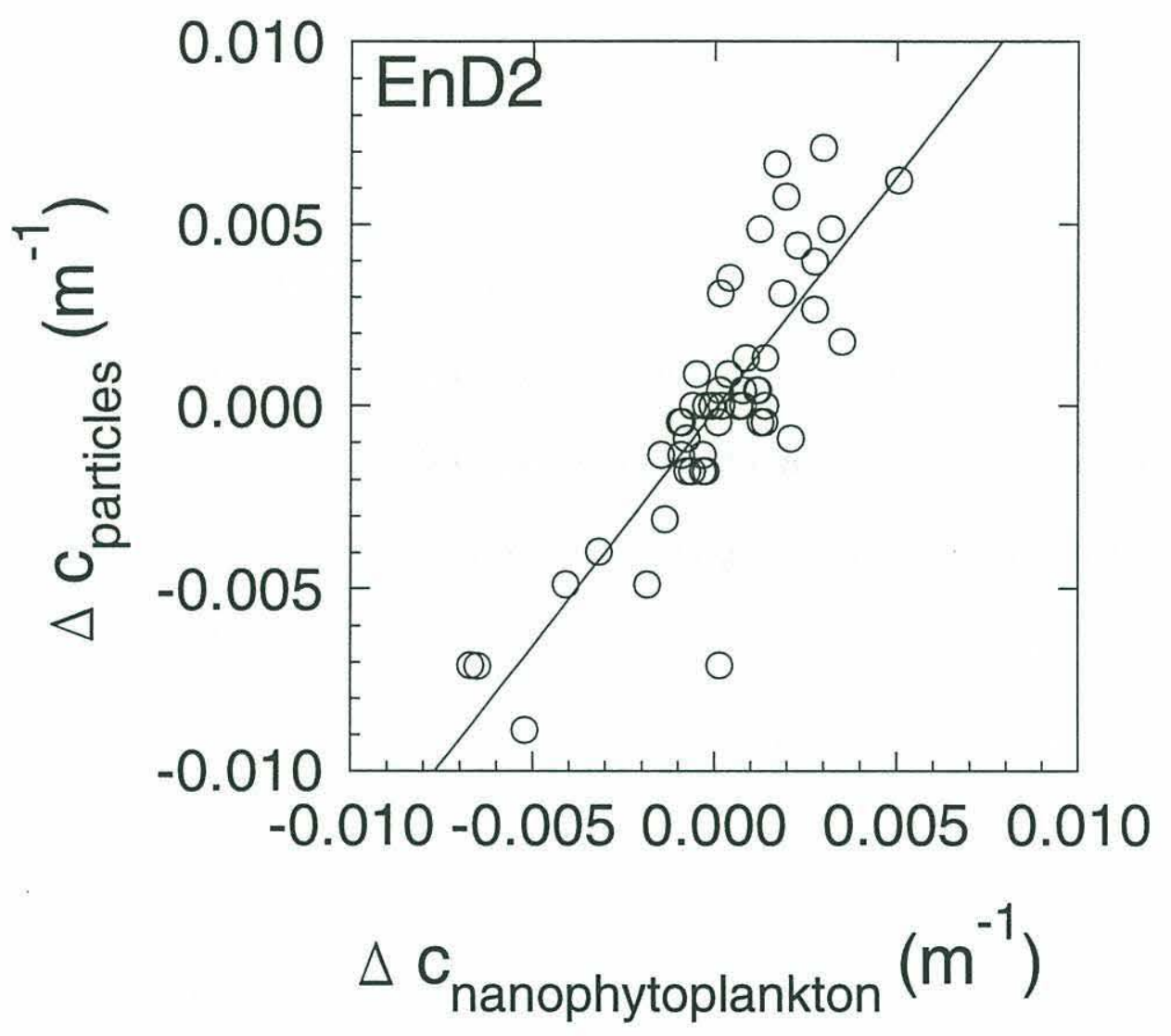


Figure 11. Comparison between $\mathrm{c}_{\text {particles }}(\bullet)$ and $\mathrm{c}_{\text {phyto }}(\mathrm{O})$ for A) EnD2 at $20 \mathrm{~m}, \mathrm{~B}$ ) EnD1 at $20 \mathrm{~m}, \mathrm{C}$ ) Hat at $15 \mathrm{~m}$, and D) Iselin at $15 \mathrm{~m}$. Each axis is scaled independently in order to compare the trends. Data for EnD1, Hat, and Iselin have been smoothed with a three-point moving average. For EnD2, the patterns match well on a point-by-point basis. While the general trends match for EnD1, Hat, and Iselin, there are differences which can be seen. 

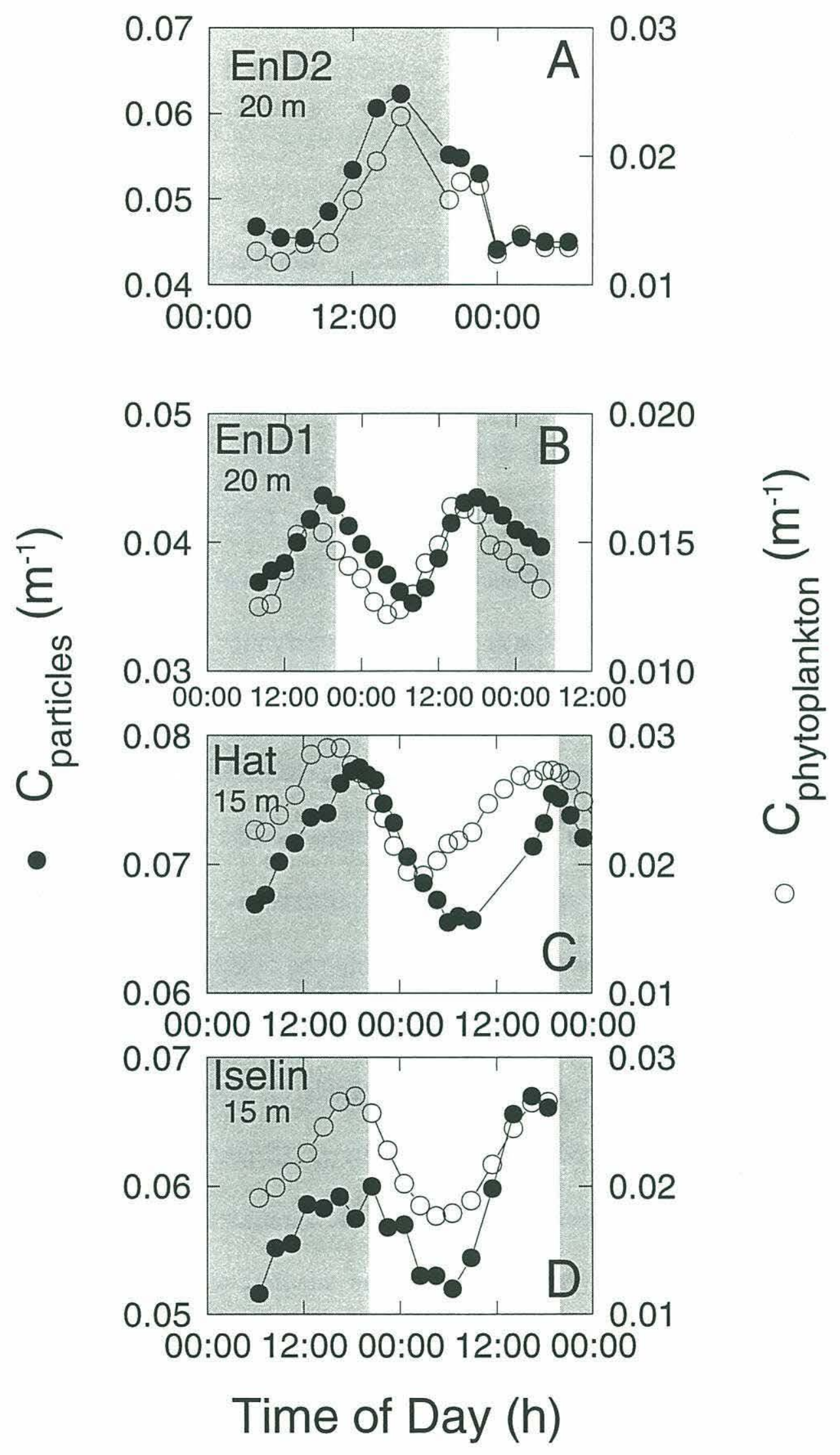
the fit of $\Delta c_{\text {particles }}$ regressed on $\Delta c_{\text {phyto }}$ is better if the $\Delta c_{\text {phyto }}$ values are shifted by one time point $\left(r^{2}=0.62\right.$ after shifting, instead of $\left.r^{2}=0.45\right)$. The slope of the regression is 1.53 , indicating that $65 \%(1 / 1.53$, expressed as a percentage $)$ of the variability in $\mathrm{c}_{\text {particles }}$ can be attributed to variations in $\mathrm{c}_{\text {phyto }}$.

A regression of all the $c_{\text {particles }}$ data on all the $c_{\text {phyto }}$ data results in a strong correlation $\left(r^{2}=0.82\right.$; Fig. 12). It is clear, though, that each diel sampling forms a distinct group of points. The Endeavor diel samplings in January have the lowest $c_{p}$ and the lowest $\mathrm{c}_{\text {phyto }}$. For these two diel samplings, the $\mathrm{c}_{\text {phyto }}$ values are in the same range, though $\mathrm{c}_{\text {particles }}$ is higher for EnD2 than for EnD1. The Hatteras diel sampling in May has the highest $\mathrm{c}_{\text {particles }}$ and the highest $\mathrm{c}_{\text {phyto }}$. The Iselin diel sampling in July, for which we measured the picoplankton as well as the eukaryotic nanophytoplankton, falls in the middle.

If we limit the data points to the upper waters ( $\leq 60 \mathrm{~m},<50 \mathrm{~m}$ for EnD2) where there are diel variations in $c_{p}$, then variation that we see (the range of the data on the plot) is due to changes over the day (and not to differences with depth). If we are accounting for all of the diel variations in $c_{p}$ with our calculated $c_{\text {phyto }}$, then the slope should be equal to one. For Iselin, where we analyzed the eukaryotic nanoplankton and the picoplankton, the slope is 1.06 (Table 1); thus our calculated $\mathrm{c}_{\text {phyto }}$ accounts for nearly all of the observed variation in $\mathrm{c}_{\mathrm{p}}$. (If just $\mathrm{C}_{\mathrm{nan}}$ is included, this raises the slope to 1.42 , so approximately $70 \%$ of the variation is accounted for by the nanophytoplankton alone.) The average $c_{\text {phyto }}$ for this data set is $37 \%$ of the average $c_{p}$; thus the average $c_{\text {non-phyto }}\left(c_{p}-c_{\text {phyto }}\right)$ is $63 \%$ of $c_{p}$. For the other diel 
samplings, where only the nanophytoplankton were analyzed, the slopes are higher

(Table 1), and indicate that about $65 \%$ of the diel variations in $\mathrm{c}_{\mathrm{p}}$ are accounted for by the nanophytoplankton. The average $\mathrm{c}_{\mathrm{p}}$ can be partitioned into approximately $30 \% \mathrm{c}_{\text {phyto }}$ and $70 \% \mathrm{c}_{\text {non-phyto }}$; however, for these samplings (EnD1, EnD2, and Hat), $\mathrm{c}_{\text {non-phyo }}$ is a misnomer, since it includes the picophytoplankton (Synechococcus and Prochlorococcus) which were not analyzed.

It is interesting that EnD1 and EnD2 are well separated on the plot of $c_{p}$ and $\mathrm{c}_{\text {phyto }}$. EnD2 has a higher percent contribution of $\mathrm{c}_{\text {non-phyto }}$ than does EnD1, indicating that there are more (or larger) non-phytoplankton particles (including bacteria, detritus, and microzooplankton) or picoplankton (since they were not analyzed for this sampling). Both diel samplings were performed in January, but EnD2 was north of Bermuda where there was a deep mixed layer $(200 \mathrm{~m})$ and $1 \mu \mathrm{M}$ nitrate at the surface, whereas EnD1 was south of Bermuda where there was a $20-40$ m surface mixed layer.

The calculations of beam attenuation due to phytoplankton presented here for diel sampling experiments in the Sargasso Sea can be compared to those for the equatorial Pacific (DuRand and Olson in press). The average beam attenuation due to particles tends to be higher in the equatorial Pacific than in the Sargasso Sea, except for the May 1994 (Hat) sampling (Table 1). The average contribution of beam attenuation due to phytoplankton to total $\mathrm{c}_{\mathrm{p}}$ ranges from $37-58 \%$ for diel samplings where both pico- and nanophytoplankton were analyzed, with the lowest for the Sargasso Sea sampling (Iselin). 
Figure 12. Relationship between beam attenuation due to particles $\left(\mathrm{c}_{\text {particles }}\right)$ and beam attenuation due to phytoplankton ( $\mathrm{c}_{\text {phyto }}$ ) for four diel samplings in the Sargasso Sea: EnD2 in January (०), EnD1 in January $(\nabla)$, Hat in May $(\Delta)$, and Iselin in July $(\diamond)$. A linear regression through all the data has an $r^{2}$ of 0.82 . 


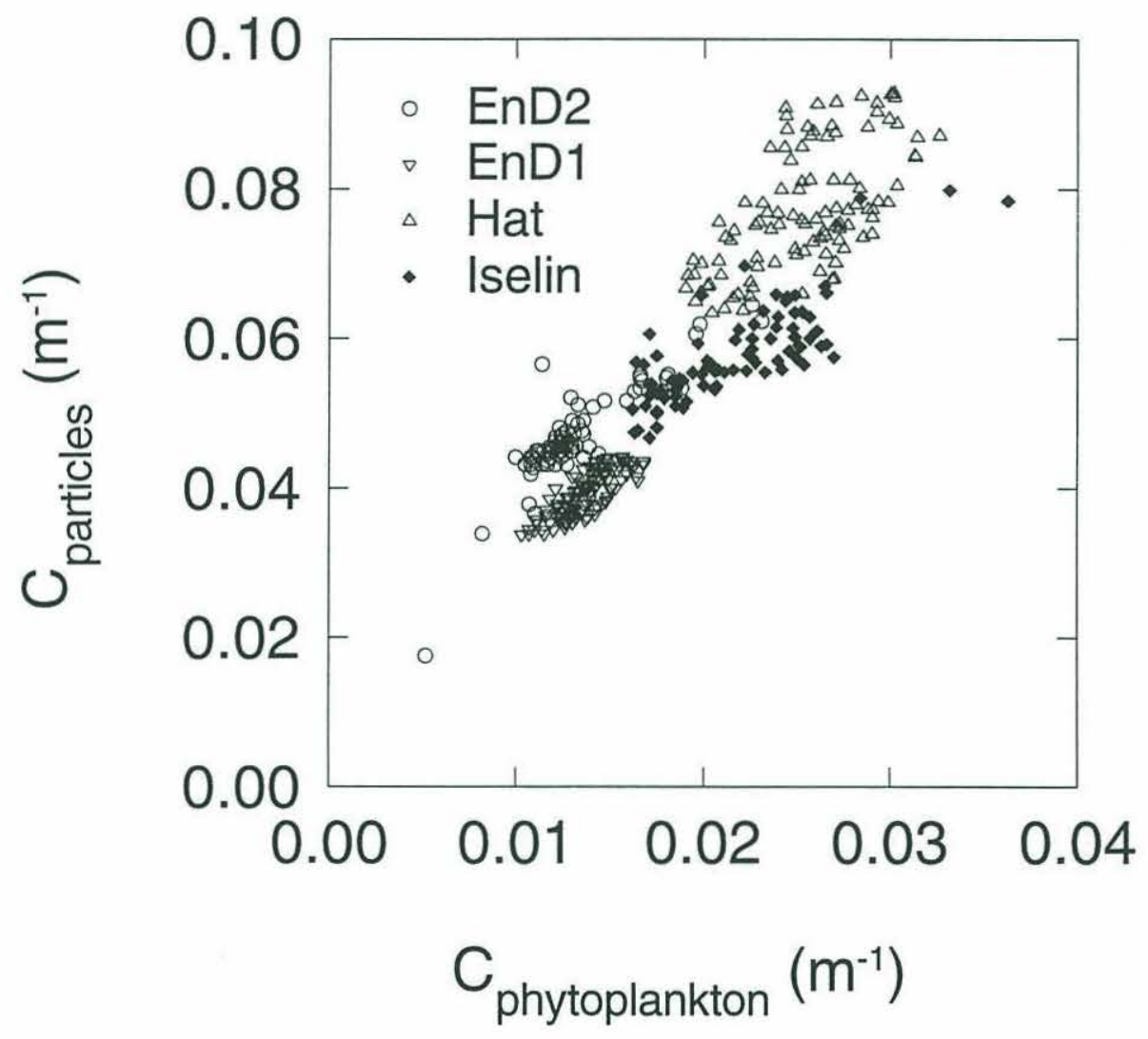


Table 1. Results of regressions of beam attenuation due to particles on the calculated beam attenuation due to the phytoplankton measured using flow cytometry (Fig. 12). For each diel sampling experiment, the following are listed: the phytoplankton populations measured with flow cytometry, the slope and fit of the regression, the average beam attenuation due to particles $\left(\mathrm{m}^{-1}\right)$, the average beam attenuation due to phytoplankton (expressed as percentage of $c_{p}$ ), and the average beam attenuation due to non-phytoplankton (expressed as percentage of $c_{p}$ ). Data for the Sargasso Sea sampling experiments, discussed in this chapter, and the equatorial Pacific sampling experiments (TT8D1, TT12D1, TT12D2; DuRand and Olson, in press) are compared. Asterisks indicate sampling experiments where the entire phytoplankton assemblage $(<20 \mu \mathrm{m}$ diameter) was measured.

\begin{tabular}{||l|l|l|l|l|l|l||}
\hline \hline Diel & Phyto & Slope & $\mathrm{r}^{2}$ & Avg $\mathrm{c}_{\mathrm{p}}$ & $\%$ Avg $\mathrm{c}_{\text {phyto }}$ & $\%$ Avg c $\mathrm{c}_{\text {non-phyto }}$ \\
\hline \hline Iselin & NanSynPro & 1.06 & 0.48 & 0.057 & $37 \% *$ & $63 \% *$ \\
\hline Iselin & Nan only & 1.42 & 0.43 & & & \\
\hline EnD1 & Nan & 1.51 & 0.52 & 0.040 & 35 & 65 \\
\hline EnD2 & Nan & 1.52 & 0.74 & 0.051 & 29 & 71 \\
\hline Hat & Nan & 1.54 & 0.38 & 0.077 & 32 & 68 \\
\hline \hline TT8D1 & NanUltSynPro & 1.09 & 0.62 & 0.066 & $58 *$ & $42 *$ \\
\hline TT12D1 & NanUltSynPro & 1.10 & 0.95 & 0.092 & $45 *$ & $55 *$ \\
\hline TT12D2 & NanUltSynPro & 1.19 & 0.82 & 0.125 & $42 *$ & $58 *$ \\
\hline
\end{tabular}




\section{CONCLUSIONS}

We have shown that, during a number of diel samplings in the Sargasso Sea, diel variations in the bulk water optical property of beam attenuation (minimum near dawn and maximum near dusk) correspond to diel variations in the forward light scattering of phytoplankton populations, and not to cell concentration, which often exhibits the inverse diel pattern. These diel variations in light scattering of phytoplankton appear to be due primarily to cell growth as the cells photosynthesize and add carbon during the day, and then divide at night. The decrease in the bulk beam attenuation during the night is due to a combination of repackaging of cell material via cell division, aggregation, and grazing, as well as losses of material due to respiration and mixing. By using laboratory and theoretically derived calibrations to analyze diel variations in phytoplankton populations at sea, we were able to determine the phytoplankton contribution to beam attenuation. Beam attenuation due to particles was strongly correlated with calculated beam attenuation due to phytoplankton. During a diel sampling in July 1993, when multiple phytoplankton populations were analyzed, the majority of the $\mathrm{c}_{\text {phyto }}$ signal was from nanophytoplankton, with a smaller portion from the most abundant cell, Prochlorococcus, and even less from Synechococcus. At the deepest depth analyzed . (70m), the Prochlorococcus contribution was equal to that of the nanophytoplankton at some times during the diel cycle; the Prochlorococcus contribution to the variations in beam attenuation was greater at that depth. Generally, the largest 
contributor to the diel variation in $\mathrm{c}_{\text {phyto }}$ was the nanophytoplankton group. These findings emphasize the need to characterize the composition of the phytoplankton community in order to use beam attenuation as a tool for monitoring productivity.

\section{Acknowledgements}

I thank Rob Olson and Erik Zettler for technical support on the cruises and in the laboratory, Jeff Dusenberry for assistance at sea, chief scientists Rob Olson and John Waterbury, and the captains and crews of the R.V. Endeavor, Columbus Iselin, and Cape Hatteras. This work was supported by NSF grant OCE-9012147 (to R. Olson) and a WHOI Ocean Ventures Award (to M. DuRand). 


\section{REFERENCES}

Ackleson, S.G. and R.W. Spinrad. 1988. Size and refractive index of individual marine particulates: a flow cytometric approach. Appl. Opt. 27: 1270-1277.

Bohren, C.F. and D.R. Huffman. 1983. Absorption and scattering of light by small particles. John Wiley and Sons, New York.

Cullen, J.J., M.R. Lewis, C.O. Davis and R.T. Barber. 1992. Photosynthetic characteristics and estimated growth rates indicate grazing is the proximate control of primary production in the equatorial Pacific. J. Geophys. Res. 97: $639-654$.

DuRand, M.D. and R.J. Olson. in press. Contributions of phytoplankton light scattering and cell concentration changes to diel variations in beam attenuation in the equatorial Pacific from flow cytometric measurements of pico-, ultra-, and nanoplankton. Deep-Sea Res.

Dusenberry, J.A. 1995. Picophytoplankton photoacclimation and mixing in the surface oceans. Massachusetts Institute of Technology/Woods Hole Oceanographic Institution, $\mathrm{PhD}$ thesis, $301 \mathrm{pp}$.

Olson, R.J., E.R. Zettler, S.W. Chisholm and J.A. Dusenberry. 1991. Advances in oceanography through flow cytometry, pp. 351-399. In S. Demers [ed.], Particle Analysis in Oceanography. NATO ASI Series G 27. Springer-Verlag.

Olson, R.J., E.R. Zettler and M.D. DuRand. 1993. Phytoplankton analysis using flow cytometry, pp. 175-186. In P.F. Kemp, B.F. Sherr, E.B. Sherr and J.J. Cole [ed.], Handbook of Methods in Aquatic Microbial Ecology. Lewis Publishers.

Shibata, K. 1958. Spectrophotometry of intact biological materials. Journal of Biochemistry 45: 599-623.

Siegel, D.A., T.D. Dickey, L. Washburn, M.K. Hamilton and B.G. Mitchell. 1989. Optical determination of particulate abundance and production variations in the oligotrophic ocean. Deep-Sea Res. 36: 211-222. 


\section{Chapter 5}

Analysis of phytoplankton growth in the equatorial Pacific and the Sargasso Sea by flow cytometric measurements of light scatter over diel cycles 


\begin{abstract}
Flow cytometric measurements of phytoplankton light scattering and cell concentration over the diel light cycle were used to estimate in situ phytoplankton group-specific growth and loss rates in the equatorial Pacific and the Sargasso Sea. Measurements of forward light scatter were converted to cell volume and carbon using laboratory and theoretically derived calibration factors for specific groups of phytoplankton, including Prochlorococcus, Synechococcus, ultraphytoplankton, nanophytoplankton, and coccolithophores. Assuming that division was phased, specific growth rates were estimated based on volume and carbon changes between minimum and maximum values over the day. Phytoplankton group-specific loss rates, and also separate day and night loss rates, were estimated from the calculated growth rates and measured cell concentrations over time. The method used to estimate growth rates works well for Prochlorococcus and appears to work for small eukaryotic phytoplankton, but leads to underestimates for Synechococcus and larger eukaryotes. Estimated growth rates for Prochlorococcus reached one division per day in the upper waters of the equatorial Pacific, but were about half that in the Sargasso Sea. For the eukaryotic phytoplankton, growth rates in the equatorial Pacific were near one division per day in the upper waters; in the Sargasso Sea, the growth rates approached that, but were more often lower. In general, phytoplankton growth rates were closely matched by in situ loss rates over the course of a day.
\end{abstract}




\section{INTRODUCTION}

It has long been a goal in biological oceanography to measure in situ phytoplankton growth rates as a measure of primary productivity. Approaches to this problem include cell cycle markers, biochemical rate measurements, and cage and bottle incubations (reviewed by Furnas 1990). Some work has been done to make growth rate measurements for specific groups of phytoplankton such as Prochlorococcus (Goericke and Welschmeyer 1993, Vaulot et al. 1995, Liu et al. 1995), Synechococcus (Campbell and Carpenter 1986, Iturriaga and Marra 1988, Liu et al. 1995), and the dinoflagellate Ceratium (Weiler 1980).

It is particularly interesting to study high-nutrient, low-chlorophyll (HNLC) areas of the ocean, such as the equatorial Pacific, where a number of mechanisms have been invoked to explain the maintenance of an area with low phytoplankton biomass, yet excess nitrate. Hypotheses include control by grazing (Frost 1991), limitation by iron (Martin et al. 1989, 1991), and a combination of the two (the ecumenical hypothesis, Morel et al. 1991). HNLC areas can be compared with the oligotrophic Sargasso Sea, where phytoplankton biomass and nutrient levels are generally low and a seasonal cycle exists.

The equatorial Pacific is dominated by small, solitary phytoplankton less than 5- $\mu \mathrm{m}$ in diameter (Chavez 1989) consisting of Synechococcus, red fluorescing picoplankton (including prochlorophytes and eukaryotes such as Micromonas, Chlorella, and Nannochloris), prymnesiophytes, and pennate diatoms (Chavez et al. 
1990). Cullen et al. (1992) estimated phytoplankton growth rates in the equatorial Pacific to be $0.6 \mathrm{~d}^{-1}$ or higher and concluded that phytoplankton population levels were closely controlled by grazing. In another study, growth rates estimated by both phytoplankton carbon from microscopy and ${ }^{14} \mathrm{C}$ uptake were close to $0.7 \mathrm{~d}^{-1}$, or one doubling per day, and grazing rates estimated from dilution experiments were about $0.5 \mathrm{~d}^{-1}$ (Chavez et al. 1991). Vaulot et al. (1995) calculated Prochlorococcus growth rates from cell cycle analysis of DNA distributions and found them to be growing at a rate close to one doubling per day.

The Sargasso Sea north of Bermuda undergoes a seasonal variation in the phytoplankton communities, primarily due to the seasonal cycle which brings nutrients to the euphotic zone from deep mixing in the winter followed by restratification in the early spring (Siegel et al. 1990, Michaels et al. 1994). Prochlorococcus and Synechococcus distributions have been examined (Olson et al. 1990a, b) and growth rate estimates for Prochlorococcus in the surface waters of 0.3 $\mathrm{d}^{-1}$ (Goericke and Welschmeyer 1993) and for Synechococcus of 0.42-0.86 $\mathrm{d}^{-1}$ (Campbell and Carpenter 1986) and 0.5-1.2 $\mathrm{d}^{-1}$ (Iturriaga and Marra 1988) reported.

From analysis of light scattering by individual phytoplankton cells in a variety of marine environments, we have seen dramatic diel patterns, which are presumably the results of cell growth during the day followed by division at night (Olson et al. 1990, 1991; DuRand and Olson in press). With calibrations using pure cultures in the laboratory, we can convert the diel variations in forward light scatter to cell volume and to cell carbon and thus estimate in situ growth rates of specific groups 
within the phytoplankton. With data on cell concentrations over time, we can also estimate phytoplankton loss rates over the course of the diel experiments. Here we estimate in situ growth and loss rates in the equatorial Pacific and the Sargasso Sea for phytoplankton populations which can be distinguished using flow cytometry, including Prochlorococcus, Synechococcus, ultraphytoplankton, nanophytoplankton, and coccolithophores. This method is particularly attractive because it does not require incubation or manipulation (such as labeling) of cells, and could thus be performed using an in situ flow cytometer.

\section{MATERIALS AND METHODS}

\section{Field Studies}

Equatorial Pacific - Diel sampling was performed on three occasions during the two JGOFS Time Series cruises in the equatorial Pacific in 1992 (at $0^{\circ} \mathrm{N}, 140^{\circ}$ W; Table 1). During R.V. Thomas Thompson 008, one diel sampling was performed (TT8D1 on 1 April) and during cruise 012, two diel samplings were performed (TT12D1 on 5 October and TT12D2 on 11 October). In each case, CTD casts were made every three hours for 24 hours and samples for flow cytometric analysis were taken with Niskin bottles at $0,15,30,45,60,75,90$, and $100 \mathrm{~m}$.

Sargasso Sea - Diel samplings were performed on four occasions during three cruises in the Sargasso Sea (Table 1). During R.V. Endeavor 232 in January 1992, two diel samplings were performed (EnD1 for 48 -h at $27^{\circ} \mathrm{N} 68^{\circ} \mathrm{W}$ and EnD2 for 
Table 1. Summary of diel sampling experiments in the equatorial Pacific and the Sargasso Sea.

\begin{tabular}{|c|c|c|c|c|}
\hline Expt. & Cruise & Date & Location & Sampling \\
\hline TT8D1 & Thomas Thompson 008 & 1 April 92 & $0^{\circ} \mathrm{N} 140^{\circ} \mathrm{W}$ & $\begin{array}{l}\text { Diel } 1 \\
24 \text { hours }\end{array}$ \\
\hline TT12D1 & Thomas Thompson 008 & 5 Oct. 92 & $0^{\circ} \mathrm{N} 140^{\circ} \mathrm{W}$ & $\begin{array}{l}\text { Diel } 1 \\
24 \text { hours }\end{array}$ \\
\hline TT12D2 & Thomas Thompson 012 & 11 Oct. 92 & $0^{\circ} \mathrm{N} 140^{\circ} \mathrm{W}$ & $\begin{array}{l}\text { Diel } 2 \\
24 \text { hours }\end{array}$ \\
\hline EnD1 & Endeavor 232 & 20-21 Jan. 92 & $\begin{array}{l}27^{\circ} \mathrm{N} 68^{\circ} \mathrm{W} \\
\text { (drogue) }\end{array}$ & $\begin{array}{l}\text { Diel } 1 \\
48 \text { hours }\end{array}$ \\
\hline EnD2 & Endeavor 232 & 29 Jan. 92 & $\begin{array}{l}35^{\circ} \mathrm{N} 68^{\circ} \mathrm{W} \\
\text { (drogue) }\end{array}$ & $\begin{array}{l}\text { Diel } 2 \\
28 \text { hours }\end{array}$ \\
\hline Iselin & Iselin 93-06 & 6-7 July 93 & $\begin{array}{l}35^{\circ} \mathrm{N} 69^{\circ} \mathrm{W} \\
\text { (drogue) }\end{array}$ & 40 hours \\
\hline Hat & Hatteras 0694 & 24-25 May 94 & $\begin{array}{l}35^{\circ} \mathrm{N} 71^{\circ} \mathrm{W} \\
\text { (drogue) }\end{array}$ & 48 hours \\
\hline
\end{tabular}

28-h at $35^{\circ} \mathrm{N} 68^{\circ} \mathrm{W}$ ). During R.V. Columbus Iselin 93-06 (July 1993), one 40-h sampling was performed (Iselin at $35^{\circ} \mathrm{N} 69^{\circ} \mathrm{W}$ ). During R.V. Cape Hatteras 0694 (May 1994), one 48-h sampling was performed (Hat at $35^{\circ} \mathrm{N} 71^{\circ} \mathrm{W}$ ). For each sampling, a holey-sock drogue set at $25 \mathrm{~m}$ was launched and tracked in order to follow the same water mass during the sampling. CTD casts were made every two hours and samples for flow cytometric analyses were taken with Niskin bottles at four to six depths. 
Flow cytometry

Eukaryotic phytoplankton - An EPICS flow cytometer modified to run 5-10 $\mathrm{ml} \mathrm{min}{ }^{-1}$ (Olson et al. 1991, 1993) was used to analyze $50 \mathrm{ml}$ seawater samples live during the cruises. Eukaryotic phytoplankton from 1-20 $\mu \mathrm{m}$ in diameter were counted and, for each particle, forward light scatter (FLS, $3^{\circ}-19^{\circ}$ ), side scatter (LS90, $\left.73^{\circ}-107^{\circ}\right)$, red or chlorophyll fluorescence $(660-700 \mathrm{~nm})$, and orange or phycoerythrin fluorescence $(530-630 \mathrm{~nm})$ were collected. For the equatorial Pacific diel samplings (TT8D1, TT12D1, and TT12D2), two populations of eukaryotic phytoplankton were discriminated: ultraphytoplankton (1-2 $\mu \mathrm{m}$ cells), and nanophytoplankton (mostly 2-3 $\mu$ m cells, but including cells up to $20 \mu$ m; DuRand and Olson in press, Fig. 1). For EnD1 and Iselin diel samplings, only one population of eukaryotic phytoplankton could be discriminated (nanophytoplankton). For EnD2, a population of coccolithophores was also distinguished (Olson et al. 1989).

Prokaryotic phytoplankton - The prokaryotic picoplankton, Synechococcus and Prochlorococcus, were analyzed for TT8D1, TT12D1, and TT12D2 and for Iselin diel samplings using an EPICS flow cytometer configured for high-sensitivity operation (Olson et al. 1993). On the TT cruises, the samples were preserved and stored until analysis on the flow cytometer in the laboratory on shore (Vaulot et al. 1989, Olson et al. 1993). For the Iselin cruise, the samples were analyzed live on the ship. 


\section{Laboratory experiments}

Laboratory experiments were performed on the chlorophyte Nannochloris sp. grown on a $14 \mathrm{~h}$ light:10 h dark cycle and sampled every two hours for 24 hours. These experiments are described fully elsewhere (Chapter 2). Briefly, diel sampling experiments were performed at a range of light levels: at 250 (Nan250) and 500 $\mu \mathrm{mol}$ photons $\mathrm{m}^{-2} \mathrm{~s}^{-1}$ (Nan500) in batch cultures in an incubator, at 60, 120, and 330 $\mu \mathrm{mol}$ photons $\mathrm{m}^{-2} \mathrm{~s}^{-1}$ (Nan60, 120, and 330) in cyclostats in an incubator, and at 1500

$\mu \mathrm{mol}$ photons $\mathrm{m}^{-2} \mathrm{~s}^{-1}$ (Nan1500) outdoors under natural sunlight. Measurements were made of cell size and concentration, light attenuation and absorption, flow cytometric light scattering (in forward and side directions), and carbon content (for Nan60, 120, and 330 only cell size, concentration, and light scattering were determined). In addition, the refractive index was calculated for Nan250, 500, and 1500 .

\section{Calculation of growth and loss rates}

Mean forward light scatter for populations of phytoplankton in the field was converted to cell volume or carbon using laboratory calibrations (for eukaryotic phytoplankton) and theory (for prokaryotic picoplankton). To calculate growth rates, the model used here assumes that, for a given cell, volume or carbon doubles before division takes place, and that cell division is phased to the light:dark cycle. Thus an observation of a doubling of mean cell volume during the day would indicate that all the cells were dividing (a specific growth rate, $\mu$, of $0.69 \mathrm{~d}^{-1}$, and a division rate, $\mathrm{k}$, of one doubling per day). However, if the phytoplankton cells of interest are only 
partially phased, then the model used here would lead to underestimates of growth rate. If there is a fraction of cells which are not phased in their division, then the minimum near dawn would contain a number of doublet cells. There could still be a peak in FLS during the diel cycle if only a portion of the population is phased; however, we would underestimate the true growth rate using the method described here. This method would also not be expected to work for diatoms, which divide at all times during the diel light cycle (Chisholm 1981).

The calculated mean cell volume and carbon over the diel cycle were used to estimate specific growth rates $(\mu)$ from the increase in volume or carbon during the day (from the minimum near dawn to the maximum near dusk) and from the decrease in volume or carbon during the night (from the maximum near dawn to the minimum near the following dawn). Thus the equation used to determine specific growth rate $\left(\mathrm{d}^{-1}\right)$ is: $\quad \mu=\ln \frac{\text { maximum volume or carbon }}{\text { minimum volume or carbon }}$

From the cell number changes from dawn of one day to dawn of the next day, we calculated net growth rate $\left(\mathrm{d}^{-1}\right)$. Phytoplankton loss rates over the day were calculated from the difference between this net growth rate and the specific growth rate. Separate day and night loss rates were also calculated. To calculate the daytime loss rates, we assumed that no cell division occurs during the daytime hours, thus the decrease in cell concentration is a true estimate of cell losses. The increase in cell concentration during the night is the result of cell division offset by cell losses. The number of cells expected in the absence of cell losses was calculated 
from the growth rate. The difference between the expected number of cells at the end of cell division (near dawn) and the actual number of cells at that time point gives the number of cells lost during the night, which is then expressed as a loss rate $\left(h^{-1}\right)$.

\section{RESULTS AND DISCUSSION}

Diel variations in cell light scatter and concentration

In the field, the mean forward light scatter (FLS) of the distinguishable phytoplankton populations consistently was minimal near dawn and maximal near dusk (often two hours before dusk; data from TT8D1 and Iselin in Figs. 1-3, see Appendix B for data from other diel samplings). The cell concentrations generally decreased during the day and increased at night (except for Prochlorococcus during the Iselin diel, which increased during the day and decreased at night; Figs. 1-3; Appendix B). We interpret the increase in scatter during the day as cell growth and the decrease during the night as the result of cell division. The maximum in cell light scatter generally occurred at the same time point as the minimum in cell concentration. The cell concentrations decrease during the day due to grazing and other cell losses, and then begin to increase when the cells divide at night. The increase seen in cell concentration during the night is dampened by cell losses from grazing, mixing, and aggregation (if aggregates are formed which are larger than the cells measured by the flow cytometer). We have generally seen that the magnitude of the forward light scatter increase is dampened with depth. 
Figure 1. Time series of Prochlorococcus A) forward light scatter (relative to 3.79 $\mu \mathrm{m}$ bead) and B) cell concentration, and Synechococcus C) forward light scatter and D) cell concentration in the equatorial Pacific in April 1992 (TT8D1). 
TT8D1

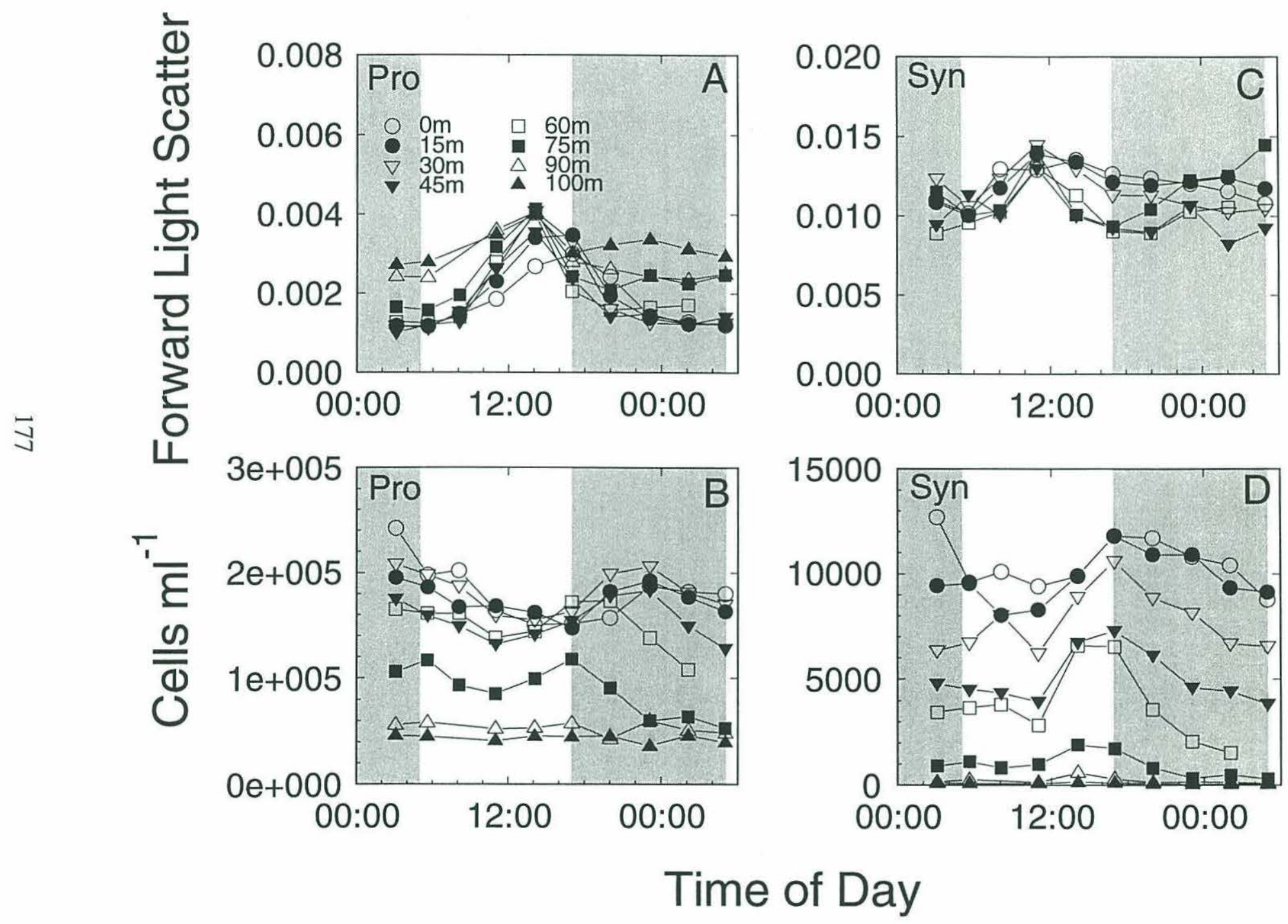


Figure 2. Time series of ultraphytoplankton A) forward light scatter (relative to 3.79 $\mu \mathrm{m}$ bead) and B) cell concentration, and nanophytoplankton C) forward light scatter and D) cell concentration in the equatorial Pacific in April 1992 (TT8D1). 


\section{TT8D1}
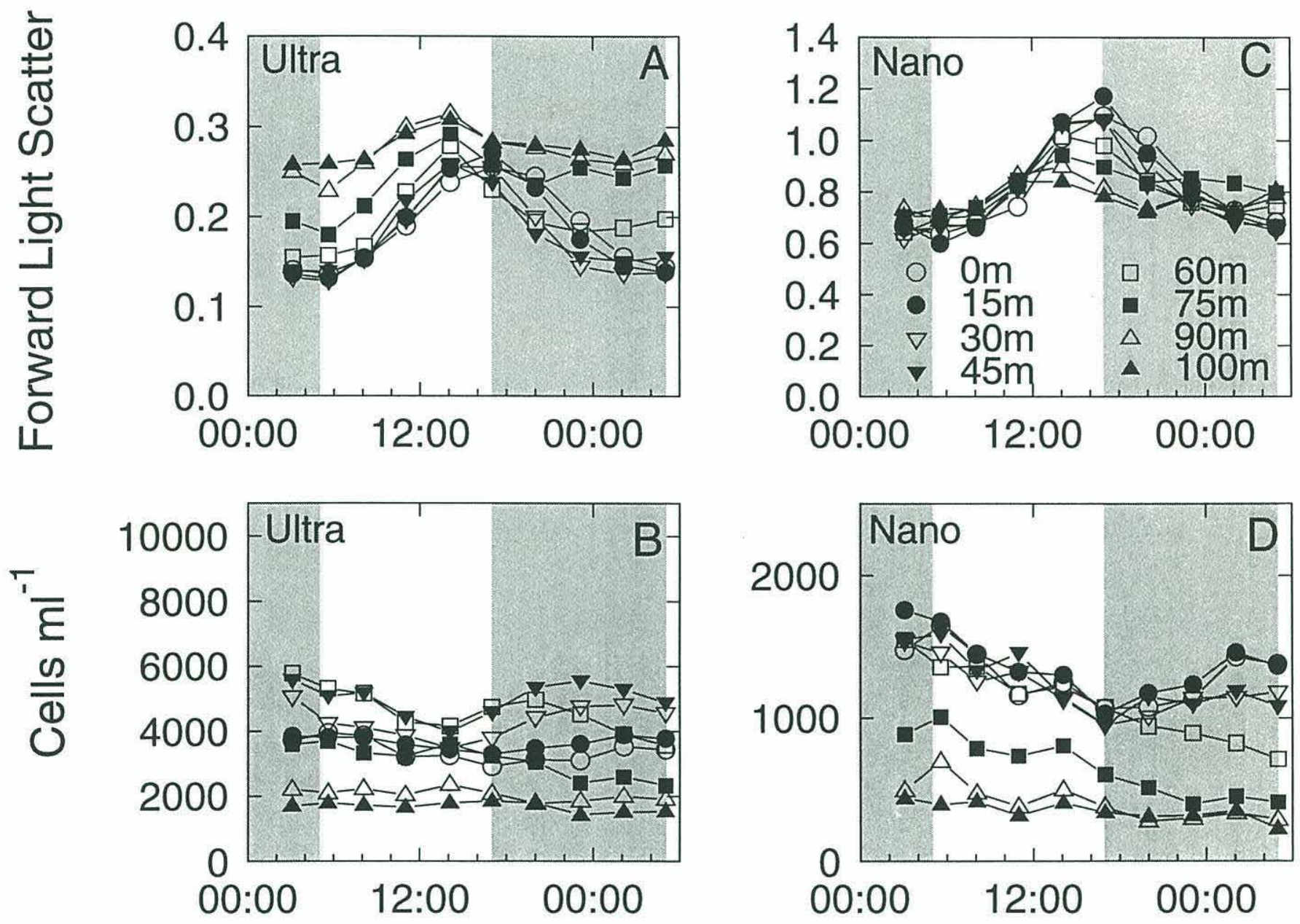

Time of Day 
Figure 3. Time series of Prochlorococcus A) forward light scatter (relative to 3.79 $\mu \mathrm{m}$ bead) and B) cell concentration, Synechococcus C) forward light scatter and D) cell concentration, and nanophytoplankton E) forward light scatter and F) cell concentration during a 40-hour diel sampling experiment in July 1993 at $35^{\circ} \mathrm{N} 69^{\circ} \mathrm{W}$ (R.V. Columbus Iselin, Iselin). 


\section{Iselin}
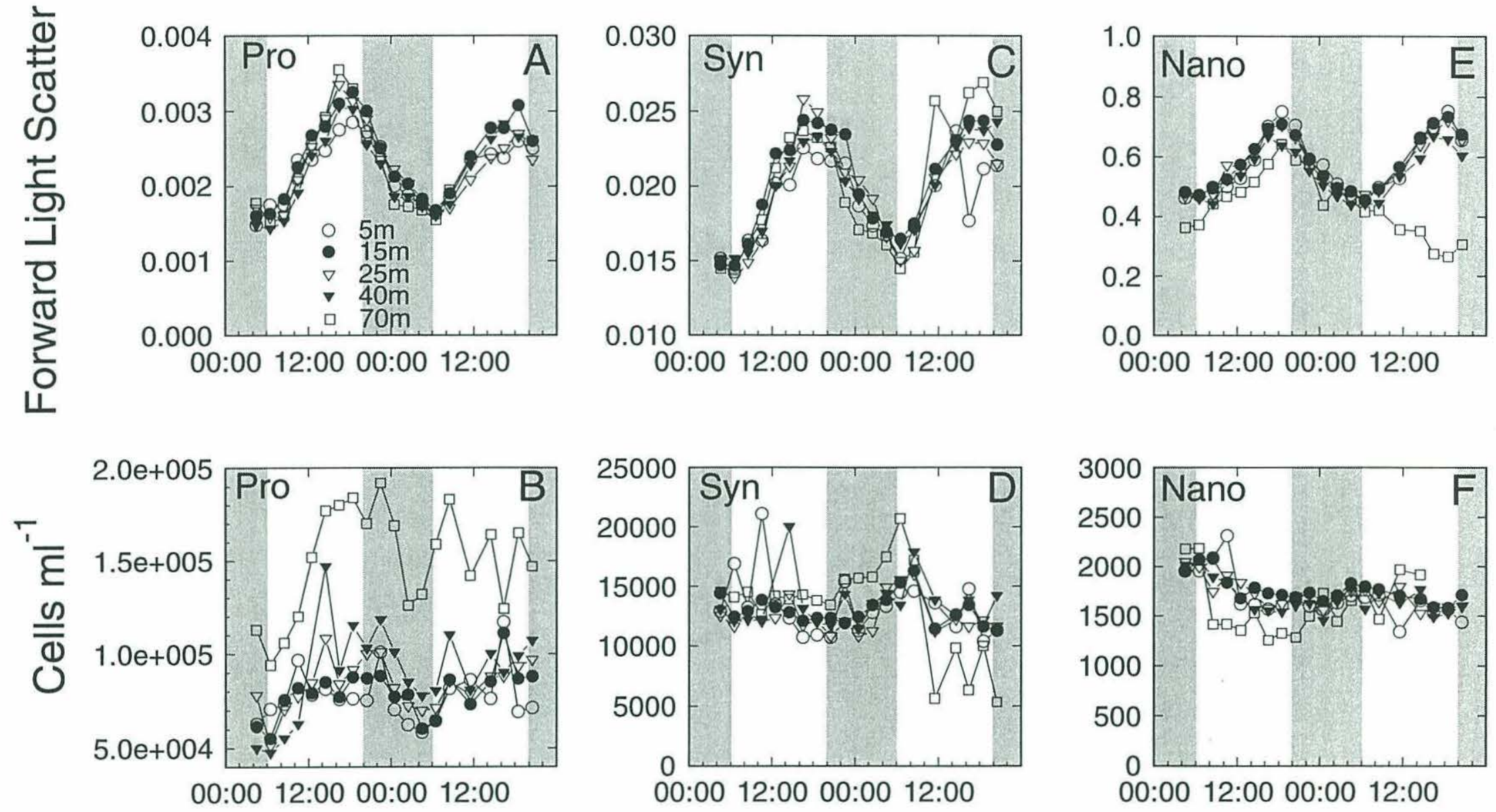

Time of Day 
During the equatorial Pacific cruises, we saw that the maximum forward light scatter (FLS) for Prochlorococcus occurred at the time point closest to dusk (near $1700 \mathrm{~h}$ ) in the surface waters (Fig. 1A; 0 and $15 \mathrm{~m}$ for TT8D1; 0, 15, and $30 \mathrm{~m}$ for TT12D1; $0 \mathrm{~m}$ for TT12D2), but at the preceding time point $(1400-1500 \mathrm{~h})$ for the deeper depths (down to $100 \mathrm{~m}$ for all three diel samplings, with the exception of 60 and $75 \mathrm{~m}$ for TT12D2, where the peak was at noon). This is similar to the results of Vaulot et al. (1995) who analyzed samples from the same diel experiments for cell cycle analysis of DNA. Near $1400 \mathrm{~h}$, they saw a population of cells entering the DNA synthesis (S) phase at $30 \mathrm{~m}$ and below, while the cells in the surface layer (0 and $15 \mathrm{~m}$ ) did not enter $\mathrm{S}$ phase until $1700 \mathrm{~h}$ (dusk). Then, by $2300 \mathrm{~h}$, they saw that the cells had divided; this corresponds to the time when we see that FLS is again near minimum (and remains there until dawn of the next day). Thus the peak that we see in Prochlorococcus FLS appears to correspond with the time when the cells are in the S phase, and the minimum in FLS corresponds with the time when division is complete.

The maximum forward light scatter for Synechococcus in the equatorial Pacific occurs earlier in the day than for the other phytoplankton groups examined (Fig. 1C). The maximum usually occurs near noon (and occasionally, 3 out of 17 times, at the following sampling point). The Synechococcus concentration is at a minimum near the same time point and then increases dramatically shortly thereafter. 


\section{Laboratory calibrations}

In order to convert FLS measurements made on field populations to cell size and carbon, we made measurements on Nannochloris cultures over the diel cycle (see Chapter 2). According to Mie theory, the forward light scatter for cells in the size range of Nannochloris and refractive indices typical of phytoplankton should be proportional to diameter to the power of three (FLS $\propto$ diameter $^{3} ;$ FLS determined using Mie scattering program of Ackleson and Spinrad 1988). We first determined a simple linear regression of FLS vs. cell size for each laboratory diel experiment on Nannochloris separately (see Chapter 2) and performed an analysis of covariance: the hypothesis that all slopes $(\beta)$ are equal was rejected $(\mathrm{p}<0.0005)$. A multiple comparison testing of the slopes (Tukey test) revealed that they came from two separate populations, where $\beta_{\mathrm{Nan120}}=\beta_{\mathrm{Nan60}}=\beta_{\mathrm{Nan500}}=\beta_{\mathrm{Nan330}} \neq \beta_{\mathrm{Nan1500}}$ (we cannot conclude how $\beta_{\mathrm{Nan250}}$ is related to the other population slopes). The implication is that Nan 1500 , the natural light experiment, is different from the others and so we will consider it separately. Since extending a linear regression between mean forward light scatter and mean cell diameter to cells of much different sizes is not appropriate, the data were then fitted with a power relationship $\left(\mathrm{FLS} \propto\right.$ Diameter $\left.^{\mathrm{a}}\right)$ which was used to convert forward light scatter measured in the field to cell diameter (Fig. 4; for Nan1500: FLS $=0.0388 *$ Diameter $^{2.74}, \mathrm{n}=28, \mathrm{r}^{2}=0.98$; for Nan60,120,330,500: FLS $=0.0463 *$ Diameter $^{2.30}, \mathrm{n}=77, \mathrm{r}^{2}=0.80$ ).

For picoplankton, the predicted relationship is that forward light scatter varies with diameter to the sixth power (Morel and Bricaud 1986). For measurements of 
Figure 4. Relationship between forward light scatter (FLS in $3.79 \mu \mathrm{m}$ bead units) and cell diameter $(\mu \mathrm{m})$ for Nannochloris cells measured over the diel cycle in the laboratory. Data for cultures grown at $1500 \mu \mathrm{mol}$ photons $\mathrm{m}^{-2} \mathrm{~s}^{-1}$ (Nan1500) outdoors under natural sunlight were fitted with a power relationship (FLS $=0.0388$ * Diameter ${ }^{2.74}, \mathrm{n}=28, \mathrm{r}^{2}=0.98$ ). Data for cultures grown at $60,120,330$, and 500 $\mu \mathrm{mol}$ photons $\mathrm{m}^{-2} \mathrm{~s}^{-1}(\mathrm{Nan} 60,120,330,500)$ in an incubator were fitted separately $\left(\right.$ FLS $=0.0463 *$ Diameter $\left.{ }^{2.30}, \mathrm{n}=77, \mathrm{r}^{2}=0.80\right)$. 


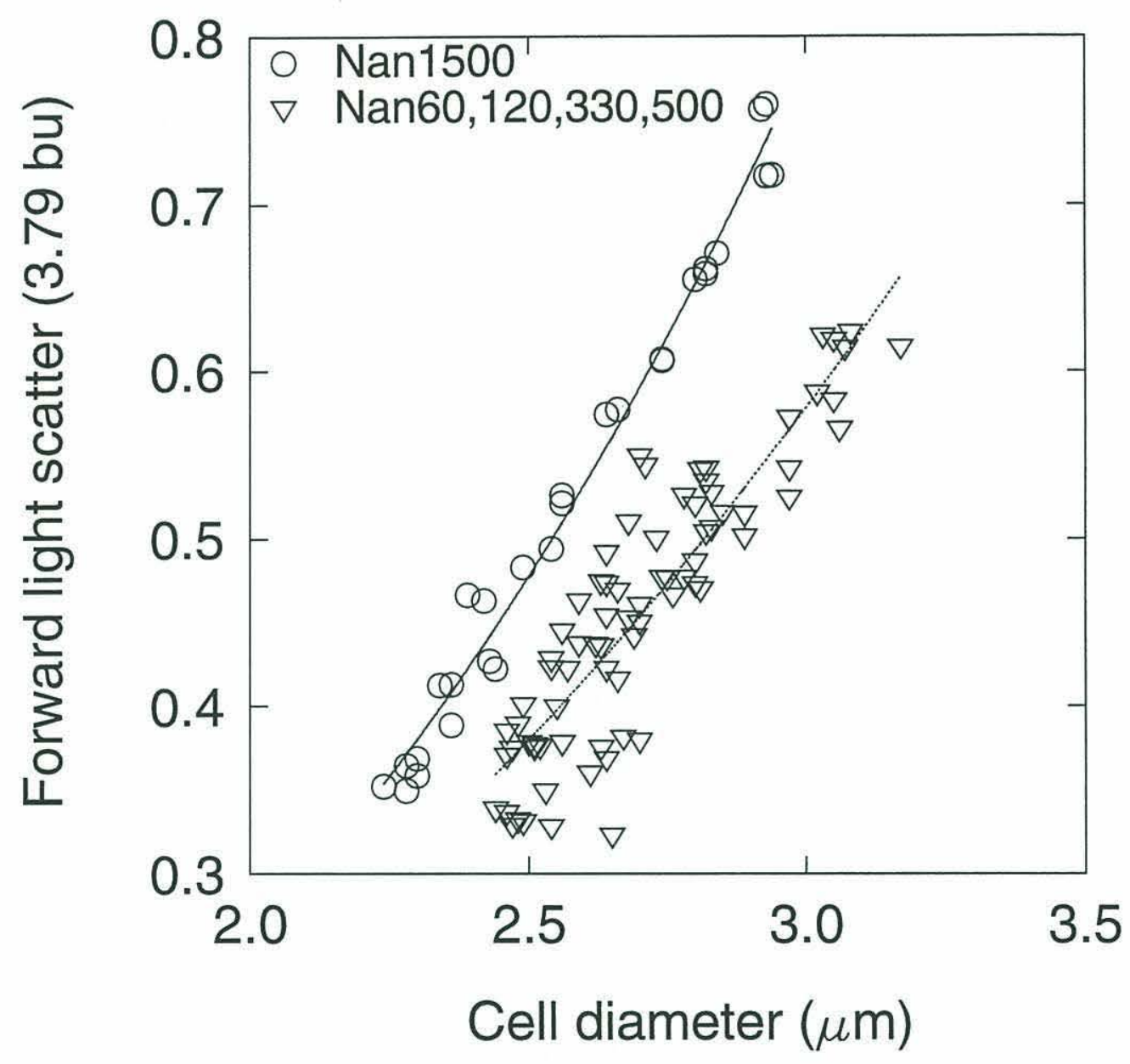


Synechococcus in the laboratory, we determined by best fit that FLS $\propto$ Diameter ${ }^{5.4}$; $\left.n=8, r^{2}=0.90\right)$. We do not have an experimentally determined fit for Prochlorococcus. To convert Synechococcus and Prochlorococcus FLS to cell size, we will assume a power relationship of either 5.4 or 6 and compare the results.

From laboratory relationships between forward light scatter and carbon per cell, we have determined a conversion to use for field data for the eukaryotic phytoplankton. Data for cultures grown at $1500 \mu \mathrm{mol}$ photons $\mathrm{m}^{-2} \mathrm{~s}^{-1}$ (Nan1500) outdoors under natural sunlight were fitted with a power relationship (FLS $=3.53 \mathrm{e}-4$ * Carbon ${ }^{0.928}, \mathrm{n}=28, \mathrm{r}^{2}=0.94$; Fig. 5). Data for cultures grown at $500 \mu \mathrm{mol}$ photons $\mathrm{m}^{-2} \mathrm{~s}^{-1}$ (Nan500) in an incubator were fitted separately (FLS $=3.30 \mathrm{e}-3 *$ Carbon ${ }^{0.6350}, \mathrm{n}=25, \mathrm{r}^{2}=0.89$ ). These two data sets were considered independently since an analysis of covariance with the hypothesis that the slopes of a linear regression for $\mathrm{Nan} 250,500$, and $1500(\beta)$ are equal was rejected $(\mathrm{p}<0.001)$. A multiple comparison testing of the slopes (Tukey test) revealed that they came from two separate populations, where $\beta_{\mathrm{Nan500}} \neq \beta_{\mathrm{Nan1500}}$ (we cannot conclude how $\beta_{\mathrm{Nan250}}$ is related to the other population slopes).

\section{Growth rates}

Estimates of growth rates were calculated by converting FLS to volume or carbon using the above equations and then applying the equation $\mu=\ln (\mathrm{Max} / \mathrm{Min})$ to the calculated volume or carbon data, as described in the methods. The results from using the Nan1500 FLS and diameter relationship (FLS $\propto \mathrm{d}^{2.74}$, or Volume ${ }^{0.913}$ ) 
were very close (within $2 \%$ ) to those from using the Nan1500 FLS and carbon relationship (FLS $\propto$ carbon $^{0.928}$ ). Using the Nan60,120,330,500 FLS and diameter relationship $\left(\mathrm{FLS} \propto \mathrm{d}^{2.3}\right.$, or Volume $\mathrm{e}^{0.767}$ ) or the Nan500 FLS and carbon relationship led to estimates of $\mu 19 \%$ or $44 \%$ higher, respectively, than using the Nan 1500 FLS and diameter relationship. The growth rate estimates presented here were calculated using the Nan 1500 FLS and diameter relationship. For the picoplankton, estimates of growth rates using FLS $\propto d^{5.4}$ were $11 \%$ higher than those using FLS $\propto d^{6}$. The results presented here use FLS $\propto \mathrm{d}^{6}$ for the calculations.

\section{Equatorial Pacific growth rates}

For the equatorial Pacific diel samplings, the specific growth rates of Prochlorococcus calculated from flow cytometric forward light scatter changes over the day compare well to those of Vaulot et al. (1995), which were determined from cell cycle analysis of DNA distributions from the same diel samplings (Fig. 6A, B, C). For each of the three diel samplings (TT8D1, TT12D1, and TT12D2), the specific growth rate is maximum at $30 \mathrm{~m}$, decreases slightly toward the surface, and decreases more with depth to $100 \mathrm{~m}$. The maximum growth rate is approximately equal to one doubling per day. It is encouraging that the growth rates calculated here show the same general trend as those of Vaulot et al. Linear regressions of $\mu$ calculated from FLS (separate estimates from the day increase due to cell growth and night decrease due to cell division) and growth rates from DNA measurements show strong correlations $\left(r^{2}=0.82\right.$ for day, $r^{2}=0.91$ for night; Fig. 7). The estimates 
Figure 5. Relationship between forward light scatter (FLS in $3.79 \mu \mathrm{m}$ bead units) and cell carbon (fg) for Nannochloris cells measured over the diel cycle in the laboratory. Data for cultures grown at $1500 \mu \mathrm{mol}$ photons $\mathrm{m}^{-2} \mathrm{~s}^{-1}$ (Nan1500) outdoors under natural sunlight were fitted with a power relationship (FLS $=3.53 \mathrm{e}-4$ * Carbon $\left.{ }^{0.928}, \mathrm{n}=28, \mathrm{r}^{2}=0.94\right)$. Data for cultures grown at $500 \mu$ mol photons $\mathrm{m}^{-2}$ $\mathrm{s}^{-1}(\mathrm{Nan} 500)$ in an incubator were fitted separately (FLS $=3.30 \mathrm{e}-3 *$ Carbon ${ }^{0.6350}, \mathrm{n}$ $=25, r^{2}=0.89$ ). 


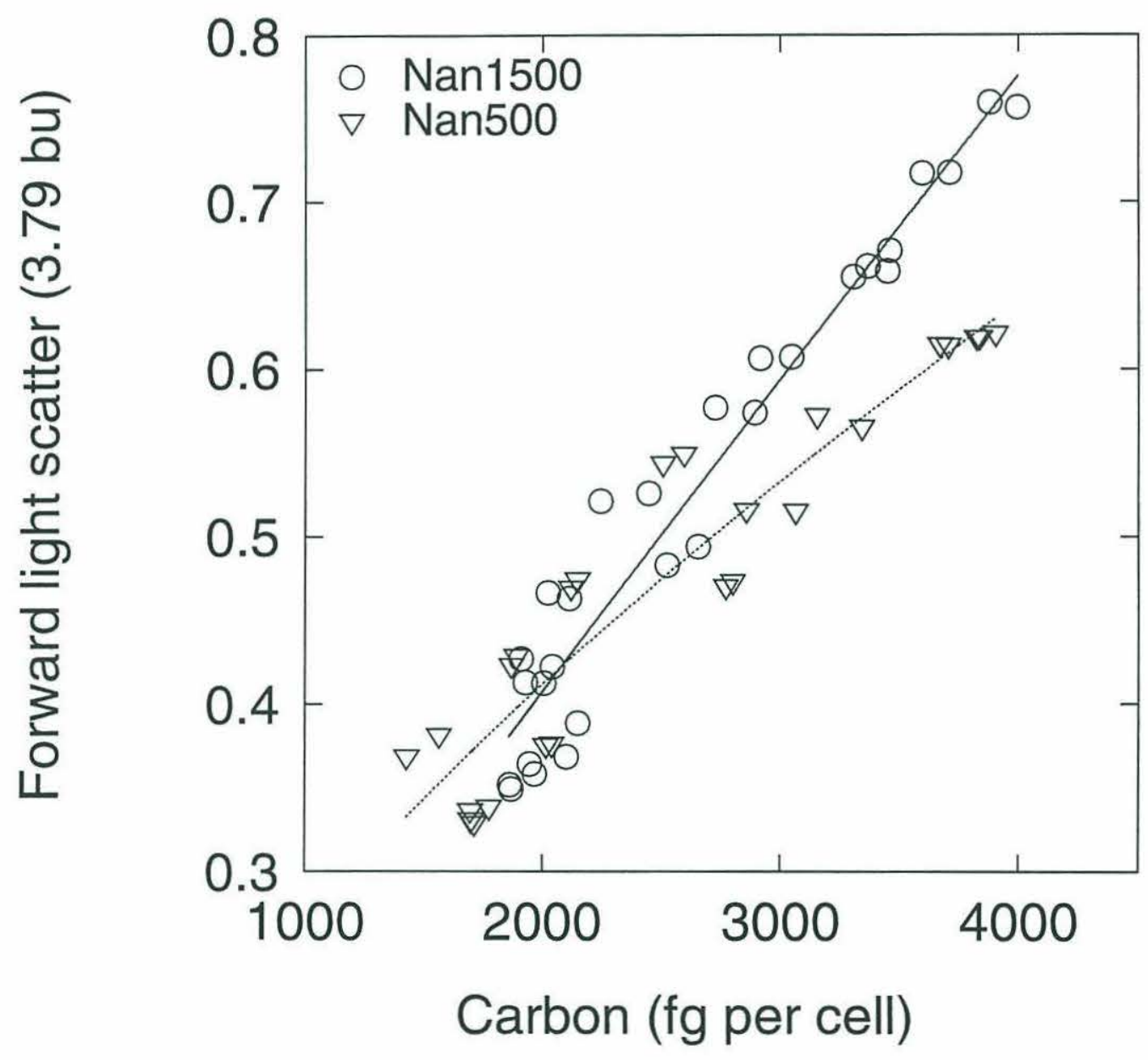


Figure 6. Depth profiles of specific growth rates $\left(\mu, \mathrm{d}^{-1}\right)$ for Prochlorococcus (A, B, C) and Synechococcus (D, E, F) in the equatorial Pacific during one diel sampling in April (TT8D1) and two in October 1992 (TT12D1 and TT12D2). Growth rates calculated from the daytime increase in forward light scatter FLS, the nighttime decrease in FLS, or the DNA distributions (for Prochlorococcus, $\mu$ from DNA from Vaulot et al. 1995). Surface light intensity data from R.T. Barber (http://www1.whoi.edu). 
Specific Growth Rate $\left(\mu, \mathrm{d}^{-1}\right)$

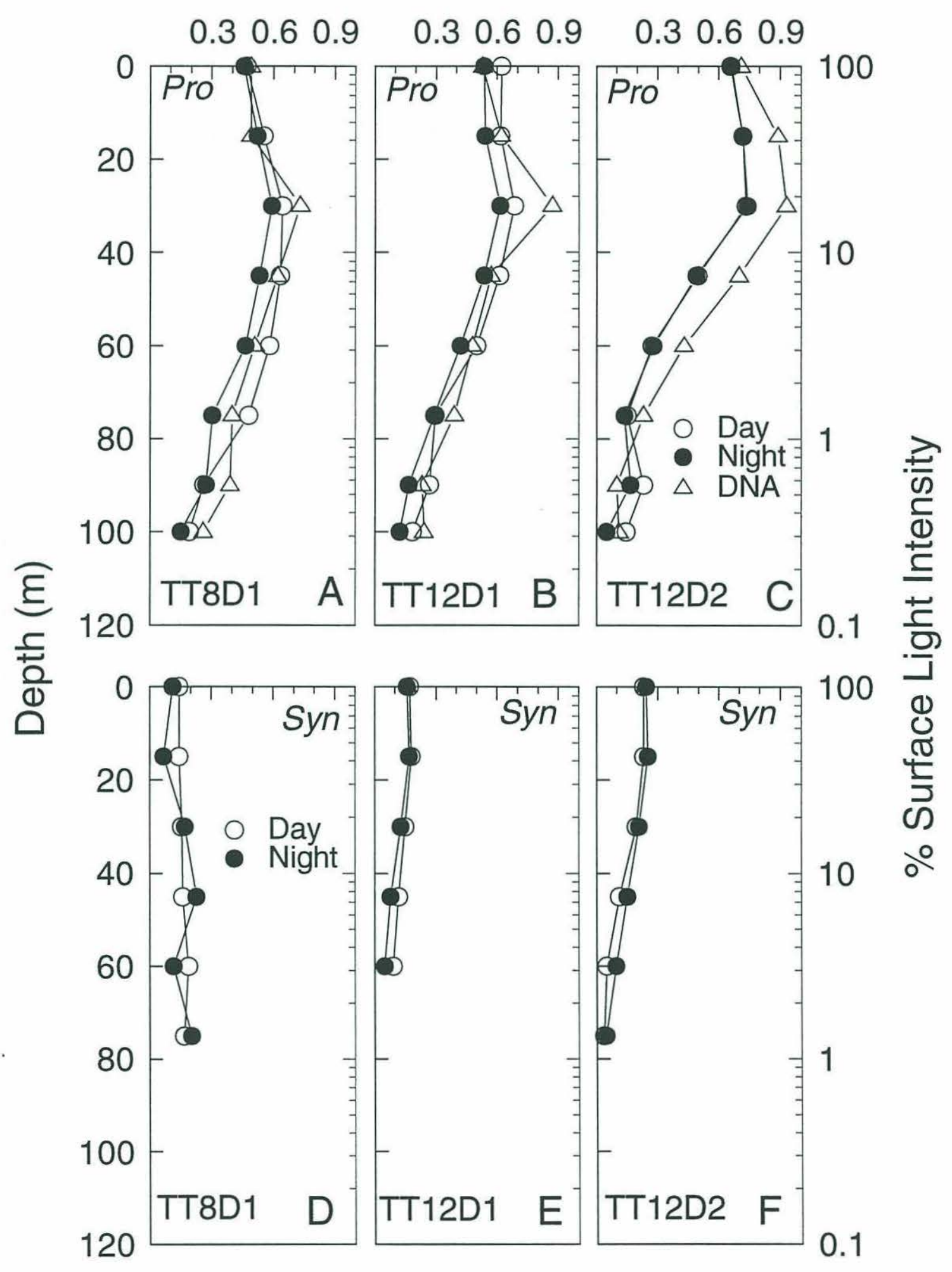


Figure 7. Comparison of Prochlorococcus growth rates estimated from FLS

(daytime increase or nighttime decrease) and DNA distributions (Vaulot et al. 1995).

The dotted line shows a 1:1 relationship. 


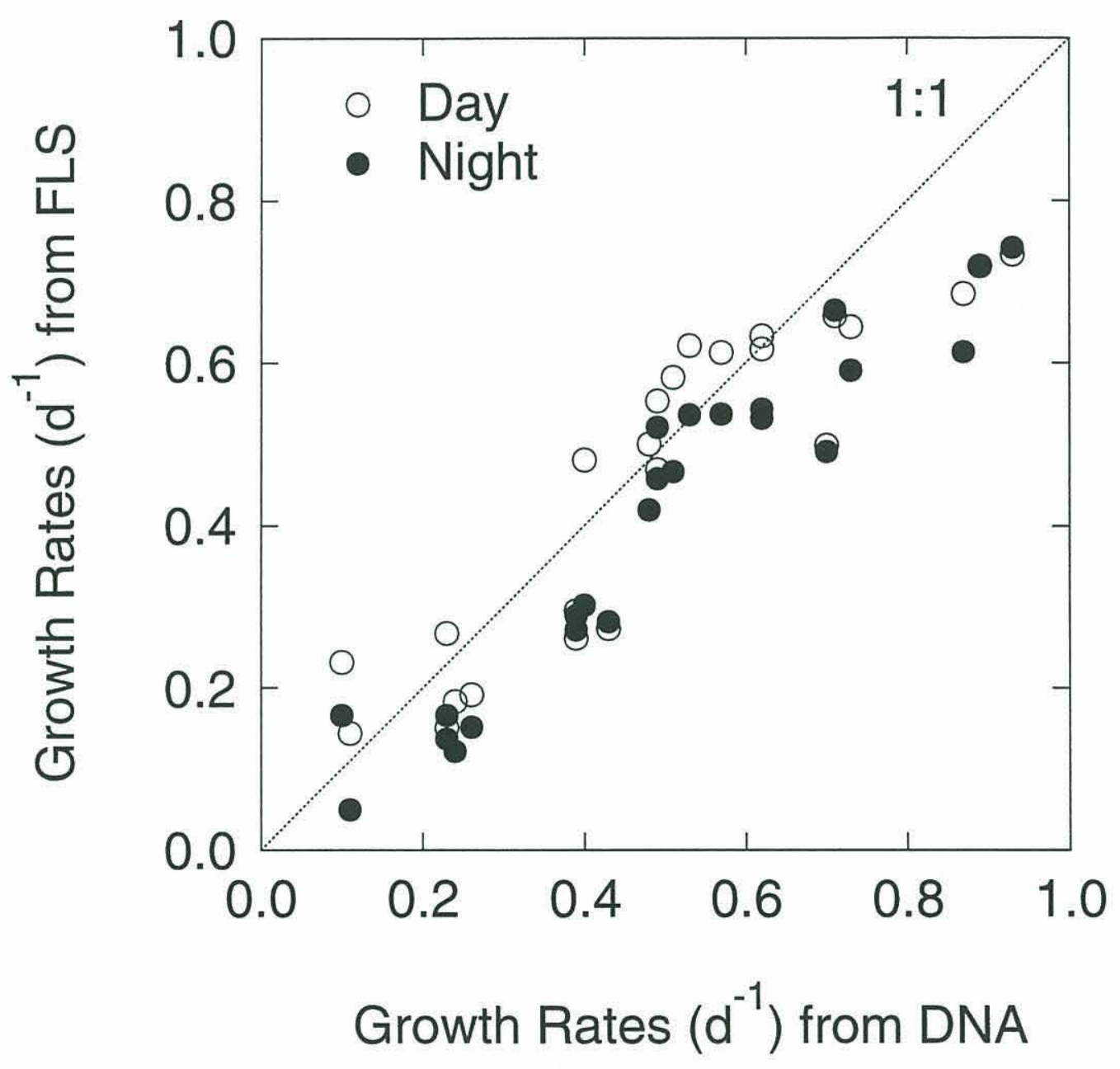


from FLS tend to be lower than those from DNA at the highest growth rates. However, Vaulot et al. state that their highest measurements (up to $0.93 \mathrm{~d}^{-1}$ ) are overestimates of a doubling time of one day $\left(\mu=0.69 \mathrm{~d}^{-1}\right)$; since there was tight synchrony and only one maximum in the synthesis phase cells, the maximum must have been one division per day. Our highest estimate is $0.74 \mathrm{~d}^{-1}$, close to the maximum expected rate of $0.69 \mathrm{~d}^{-1}$.

Estimated growth rates for Synechococcus in the equatorial Pacific reach only $0.25 \mathrm{~d}^{-1}$ (doubling time of once every $\sim 3$ days; Fig. 6D, E, F). For TT8D1, $\mu$ is about the same down to $75 \mathrm{~m}$; for TT12D1 and TT12D2, $\mu$ is maximum at the surface and $15 \mathrm{~m}$ and decreases slightly with depth. Growth rates calculated from cell concentrations measured in the field (thus a minimum growth rate; i.e., growth minus grazing) were three-fold higher (on average in the upper $60 \mathrm{~m}$ ) than growth rates estimated from FLS. Thus the growth rates for Synechococcus using the FLS method are almost certainly underestimates. We believe this underestimation is due to incomplete phasing of cell division to the light:dark cycle. This interpretation is supported by previous observations of patterns in the frequency of dividing cells (FDC) in Synechococcus, which would be expected to be similar to patterns in FLS. Waterbury et al. (1986) saw the frequency of dividing cells increase from $8 \%$ to only $32 \%$ in a culture with a growth rate of $0.85 \mathrm{~d}^{-1}$. Campbell and Carpenter (1986), in studies of cultures at different light levels and temperatures, determined growth rates from 0.10 to $1.02 \mathrm{~d}^{-1}$, yet the FDC at the highest growth rate only reached $22 \%$. At the fastest growth rates, they observed that FDC was high all day and after the light 
period ended; for growth rates less than $0.69 \mathrm{~d}^{-1}$, the peak in FDC was sharper, occurring over only 2 to 4 hours. Armbrust et al. (1989) found that Synechococcus has two light-dependent gaps in DNA synthesis, thus cells can become blocked in the doublet stage during the night and not released until the light period. The model used here to estimate growth rates from FLS, assumes tight phasing and a maximum of one division per day; thus it does not appear that Synechococcus populations are amenable to growth rate analysis based on FLS patterns.

For the eukaryotic phytoplankton (subdivided into two distinguishable populations: ultra- and nanoplankton) in the equatorial Pacific, the specific growth rate was maximum in the upper waters and decreased with depth (Fig. 8). Growth rates for the ultraphytoplankton were higher during TT12 than TT8. The nanophytoplankton reached a maximum $\mu$ of about one doubling per day. According to these estimates, the ultraphytoplankton were growing faster than one doubling per day, which is impossible given the assumptions of the model. The assumptions are that a single peak in FLS during the day can, at the most, translate into each cell doubling in size before division. Thus the maximal detectable growth rate should be one doubling per day $\left(\mu=0.69 \mathrm{~d}^{-1}\right)$. Since the ultraphytoplankton cells are considerably smaller than the Nannochloris cells used in the laboratory, it is quite possible that our lab calibration is inappropriate for these smaller cells. If we assume that FLS varies with diameter to the fourth power rather than to the 2.74 power, then we obtain estimates of a maximum $\mu$ of 0.73 , close to one doubling per day. 
Figure 8. Depth profiles of specific growth rates $\left(\mu, d^{-1}\right)$ for ultraphytoplankton (A, B, C) and nanophytoplankton (D, E, F) in the equatorial Pacific during one diel sampling in April (TT8D1) and two in October 1992 (TT12D1 and TT12D2). Growth rates calculated from the daytime increase in forward light scatter FLS or the nighttime decrease in FLS. Surface light intensity data from R.T. Barber (http://www1.whoi.edu). 


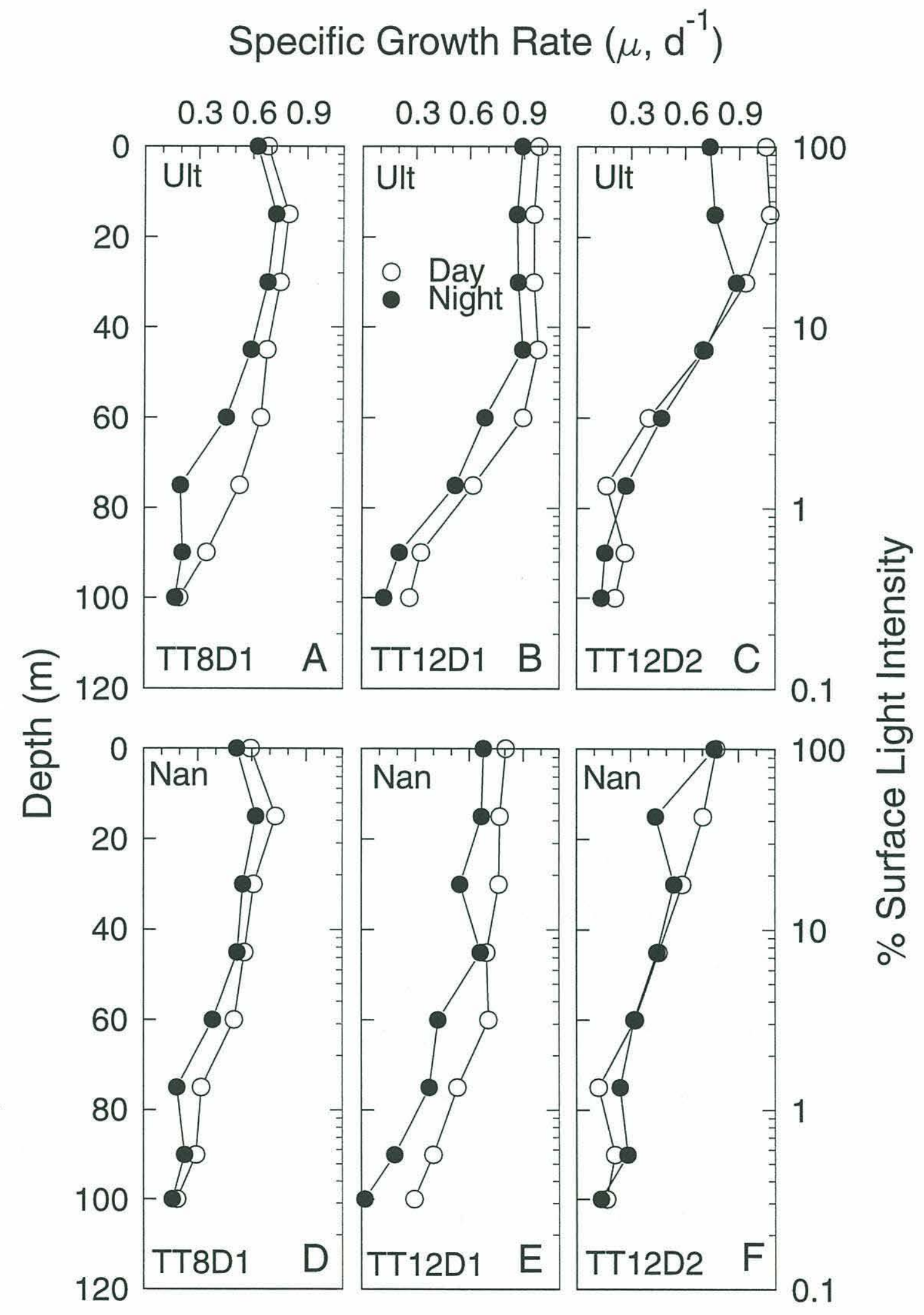


Sargasso Sea growth rates

During a January 1992 cruise to the Sargasso Sea, two diel sampling experiments were performed. The first diel (EnD1) was about 350 nautical miles SSW of Bermuda, where there was a surface mixed layer of $20-40 \mathrm{~m}$. The estimated growth rates of the nanophytoplankton population were maximum in the upper water (0.4-0.45 $\mathrm{d}^{-1}$ at 0 and $20 \mathrm{~m}$ ) and decreased with depth (Fig. 9A, B). They were roughly the same for the first and second days of the sampling. The second diel (EnD2) was about 200 nautical miles NW of Bermuda, where the water column was mixed down to $200 \mathrm{~m}$ and there was $1 \mu \mathrm{M}$ nitrate at the surface. The day was cloudy (about $100 \mu \mathrm{mol}$ photons $\mathrm{m}^{-2} \mathrm{~s}^{-1}$ just below the surface at noon) and it rained heavily in the morning. The nanophytoplankton were growing at a rate of about one doubling per day near the surface, slightly lower at $20 \mathrm{~m}$, then dramatically lower at $50 \mathrm{~m}\left(\sim 0.1 \mathrm{~d}^{-1}\right)$, and near zero down to $200 \mathrm{~m}$ (Fig. 9C). Growth rates of the coccolithophore population, which was distinguishable during this diel, had the same trend with depth (Fig. 9D). However, the values calculated are likely to be underestimates, since the coccolithophore cells are considerably larger than the Nannochloris in the laboratory which were used for the calibration.

During a July 1993 cruise to the Sargasso Sea, a diel sampling (Iselin) was performed about 200 nautical miles N-NW of Bermuda where the mixed layer was about $20 \mathrm{~m}$ deep. Prochlorococcus growth rates were about $0.3 \mathrm{~d}^{-1}$ in the upper 40 $\mathrm{m}$ and increased with depth (Fig. 10A, B). These rates in the upper water are similar to those determined by Goericke and Welschmeyer (1993) for Prochlorococcus in the 
Sargasso Sea from measuring the incorporation of ${ }^{14} \mathrm{C}$ into divinyl-chlorophyll $a$. The pattern seen here with depth (increasing growth rate) was only seen during the March 1985 sampling (out of 9 growth rate profiles from March 1985 - September 1986) by Goericke and Welschmeyer. It is possible, however, that we were not tracking the same water mass at the deepest depths (the drogue was set at $25 \mathrm{~m}$ ). Our estimated growth rates for Synechococcus were at a maximum of $0.2-0.3 \mathrm{~d}^{-1}$ at $25 \mathrm{~m}$ and decreased both toward the surface and with depth, though these rates are most likely an underestimate due to incomplete phasing, as discussed above (Fig. 9C, D). For both Prochlorococcus and Synechococcus, the growth rates the second day of the diel were slightly lower than the first day. Growth rates of the eukaryotic nanophytoplankton were $0.5-0.6 \mathrm{~d}^{-1}$ in the upper waters and decreased only slightly with depth during both days of the sampling (Fig. 10E, F).

During a May 1994 cruise to the NW Sargasso Sea, a diel sampling experiment (Hat) was performed about 350 nautical miles NW of Bermuda, where the upper 20-30 m was mixed. The 48-h sampling was performed the day after a storm with 40 knot winds. For this diel, only the eukaryotic nanophytoplankton were analyzed. Their growth rates were maximum (near $0.5 \mathrm{~d}^{-1}$ ) at 15 and $25 \mathrm{~m}$ and decreased slightly at the surface and $35 \mathrm{~m}$ (the deepest depth analyzed; Fig. 11). The second day of the sampling showed nearly constant rates in the upper $25 \mathrm{~m}$, with a slight decrease at $35 \mathrm{~m}$. It is interesting to note that, for the first day, the estimates based on the daytime increase in FLS or the nighttime decrease in FLS match quite well, indicating that the FLS at the first dawn and the second dawn are 
Figure 9. Depth profiles of specific growth rates $\left(\mu, d^{-1}\right)$ for nanophytoplankton in the Sargasso Sea during a 48-hour diel sampling experiment in January 1992 at $27^{\circ} \mathrm{N}$ $68^{\circ} \mathrm{W}$ (A and B: R.V. Endeavor, EnD1, Day1 and Day2) and for nanophytoplankton and coccolithophores during a 28-hour diel sampling experiment in January 1992 at $35^{\circ} \mathrm{N} 68^{\circ} \mathrm{W}$ (C and D: EnD2). Growth rates calculated from the daytime increase in forward light scatter FLS or the nighttime decrease in FLS. Surface light intensity from a noon light cast using a Biospherical Instruments Inc. QSP-200 $4 \pi$ sensor. 
Specific Growth Rate $\left(\mu, \mathrm{d}^{-1}\right)$

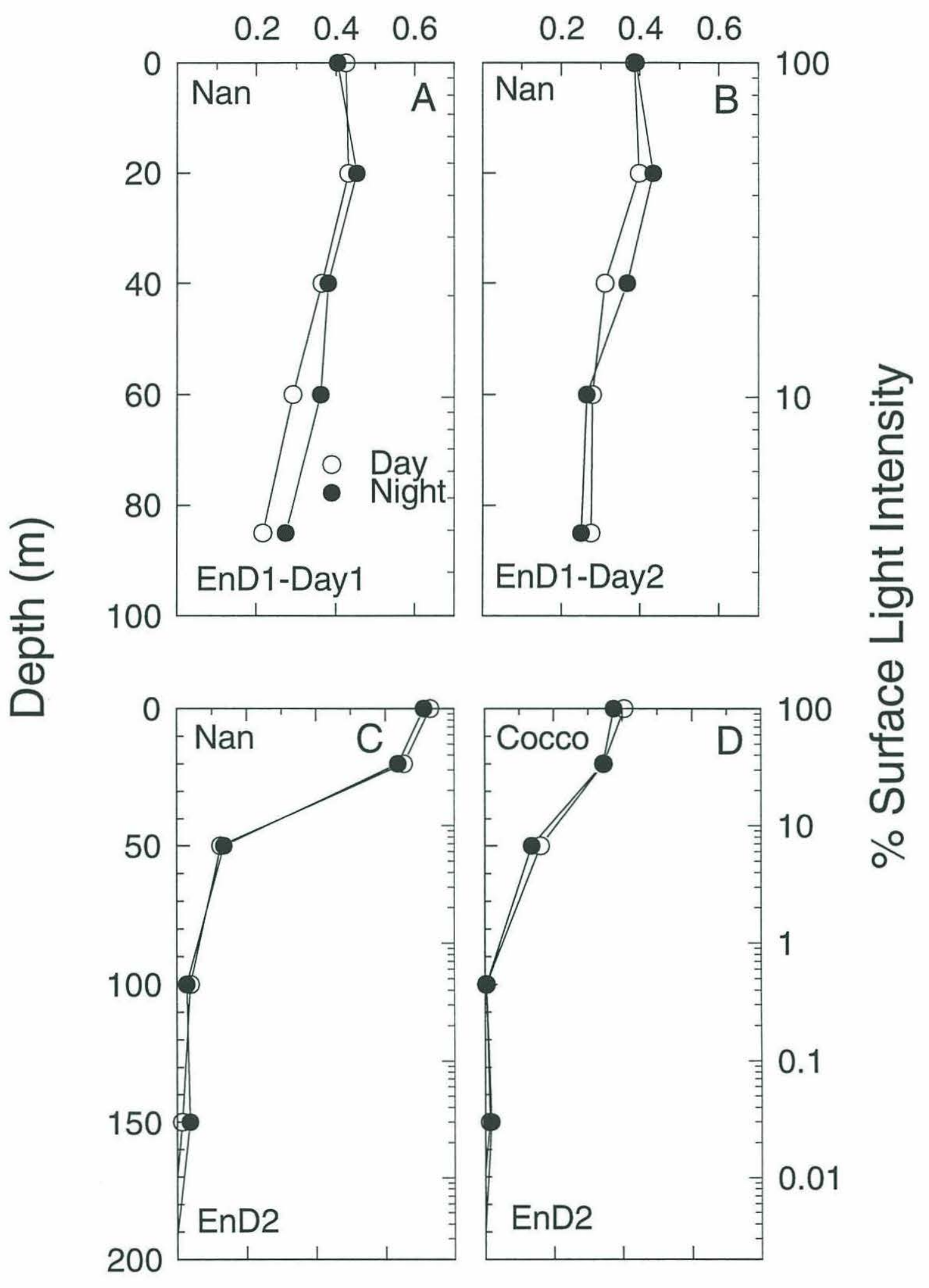


Figure 10. Depth profiles of specific growth rates $\left(\mu, \mathrm{d}^{-1}\right)$ for Prochlorococcus (A, B), Synechococcus (C, D), and nanophytoplankton (E, F) in the Sargasso Sea during a 40-hour diel sampling experiment in July 1993 at $35^{\circ} \mathrm{N} 69^{\circ} \mathrm{W}$ (R.V. Columbus Iselin, Iselin, Day1 and Day2). Growth rates calculated from the daytime increase in forward light scatter FLS or the nighttime decrease in FLS. Surface light intensity from measurements of Secchi depth. 
Specific Growth Rate $\left(\mu, \mathrm{d}^{-1}\right)$

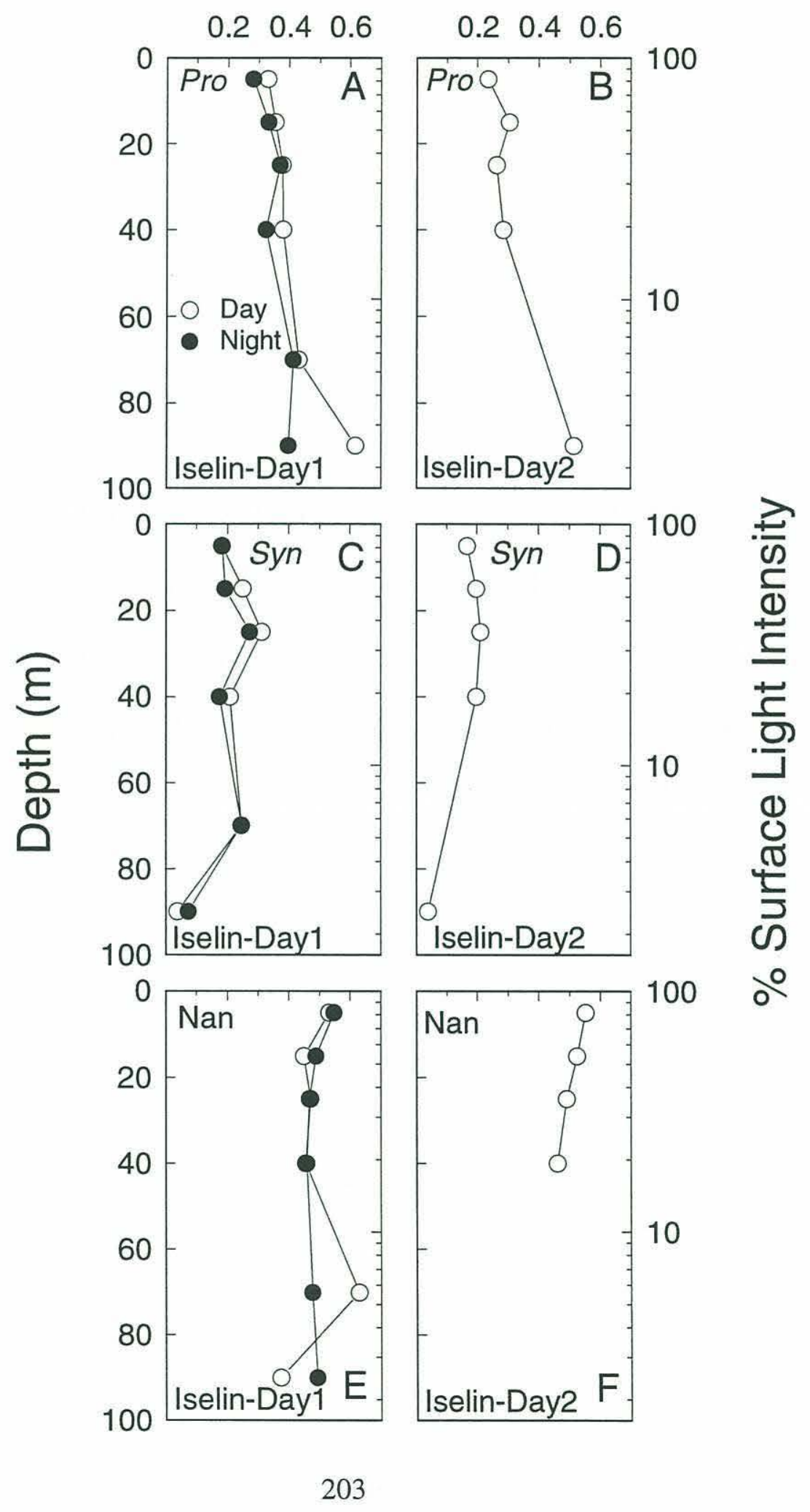


Figure 11. Depth profiles of specific growth rates $\left(\mu, d^{-1}\right)$ for nanophytoplankton in the Sargasso Sea during a 48-hour diel sampling experiment in May 1994 at $35^{\circ} \mathrm{N}$ $71^{\circ} \mathrm{W}$ (R.V. Cape Hatteras, Hat, Day1 and Day2). Growth rates calculated from the daytime increase in forward light scatter FLS or the nighttime decrease in FLS. Surface light intensity from measurements of Secchi depth. 
Specific Growth Rate $\left(\mu, \mathrm{d}^{-1}\right)$
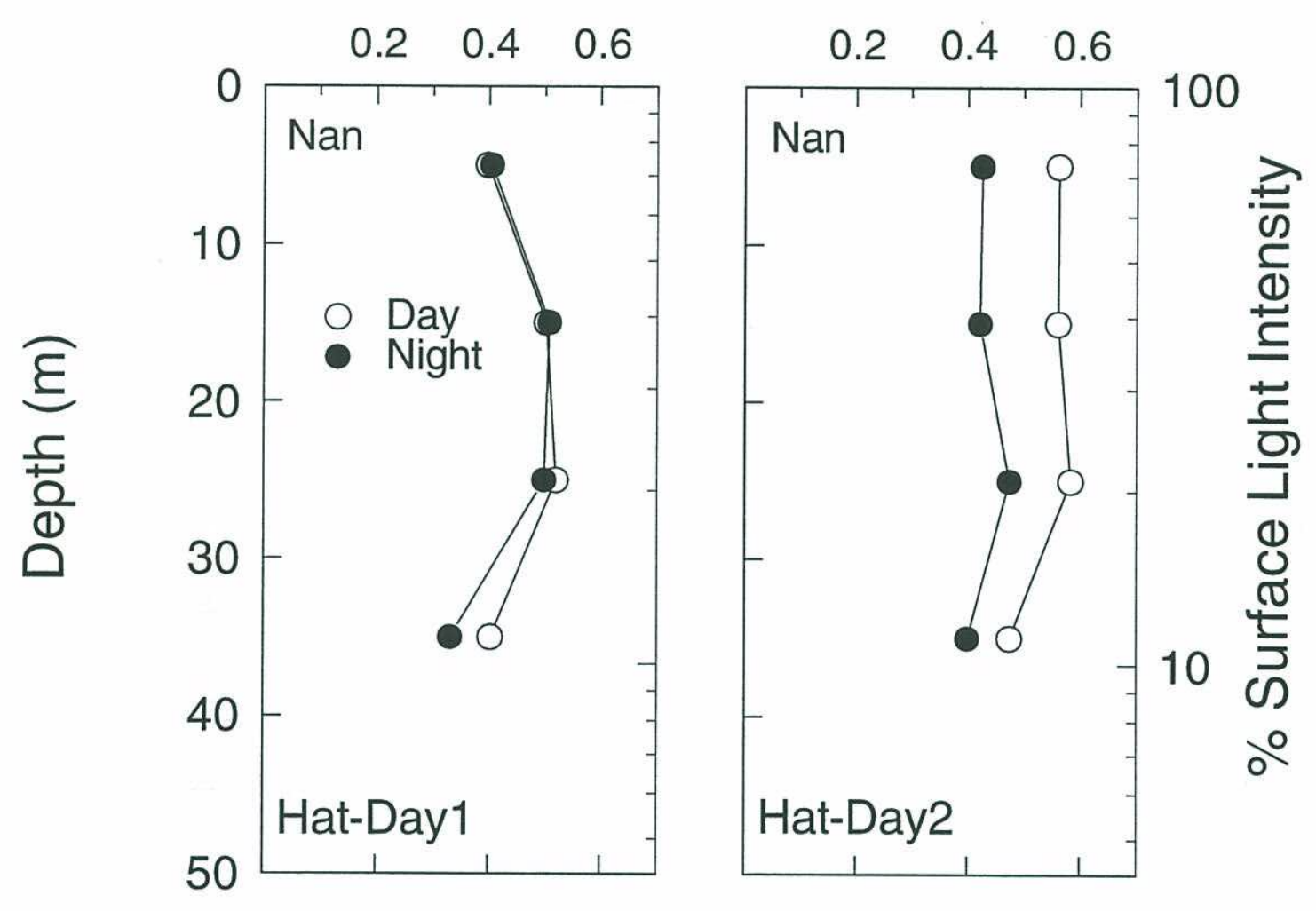
the same. For the second day, however, these separate estimates do not match as well, since the FLS was lower for the second dawn than the third dawn, indicating that the phytoplankton were not at steady state.

Despite the uncertainties in the absolute magnitude of some of the growth rate estimates (discussed above), the overall patterns seen are encouraging. An additional problem, however, would be if the phytoplankton cells in the field are significantly changing refractive index during the day, or if cells at different depths have different refractive indices. Changes in refractive index were not taken into account for the calculations presented here. For the laboratory studies on Nannochloris, we saw a strong relationship between cell volume and cell carbon, and only small changes in refractive index over the course of the day; the scattering was primarily due to changes in cell size and not changes in refractive index (Chapter 2). However, we could not make measurements of refractive index in the field on specific populations of phytoplankton, thus we are assuming that the relationship seen in the lab applies. If the cells in the field are changing refractive index during the course of the day, and changes in FLS do not reflect changes in cell carbon, then the laboratory calibration may not be appropriate for these cells in the field. Others have seen changing refractive indices during laboratory studies on cultured phytoplankton (Ackleson et al. 1993, Stramski and Reynolds 1993, Stramski et al. 1995). 
Loss rates

Usually, the cell concentrations at dawn of one day are about the same as the cell concentrations at dawn of the next day. This means that growth rates and loss rates approximately balance over the day for the diel samplings in the equatorial Pacific and the Sargasso Sea (Figs. 12-15). The loss rates calculated here are in situ loss rates, thus they may be the result of grazing, mixing, and other processes such as aggregation that could repackage cells so that they are no longer present at concentrations that would be sampled in $50 \mathrm{ml}$. In some cases, the loss rates are greater than the growth rates; this appears to occur more frequently at depth than in the upper waters. However, during Hat Day1 and 2, the loss rates exceeded the growth rates for the nanophytoplankton in the upper waters $(5-35 \mathrm{~m})$. The only times that the growth rates exceeded the loss rates were for Prochlorococcus during TT12D2, for nanophytoplankton during EnD1 Day2 (which were approximately balanced during Day1), and for Synechococcus during the Iselin diel sampling.

Phytoplankton growth and microzooplankton grazing rates were determined from dilution experiments during the same cruises to the equatorial Pacific (though not on the same days; Verity et al. 1994). They found that growth and grazing rates were higher in the fall (TT12) than the spring (TT8) at 15 and $60 \mathrm{~m}$. In the spring, grazing exceeded growth and in the fall, growth and grazing approximately balanced. These results are similar to the ones presented here (Fig. 12). 
Figure 12. Depth profiles of specific growth rates ( $\mu$ from daytime increase in FLS, $\left.\mathrm{d}^{-1}\right)$ and loss rates $\left(\mathrm{d}^{-1}\right)$ for Prochlorococcus $(\mathrm{A}, \mathrm{B}, \mathrm{C})$, ultraphytoplankton (D, E, F), and nanophytoplankton $(\mathrm{G}, \mathrm{H}, \mathrm{I})$ in the equatorial Pacific during one diel sampling in April (TT8D1) and two in October 1992 (TT12D1 and TT12D2). 
Specific growth rate ( 0 ) or Loss rate ( $\quad$ ) $\mathrm{d}^{-1}$

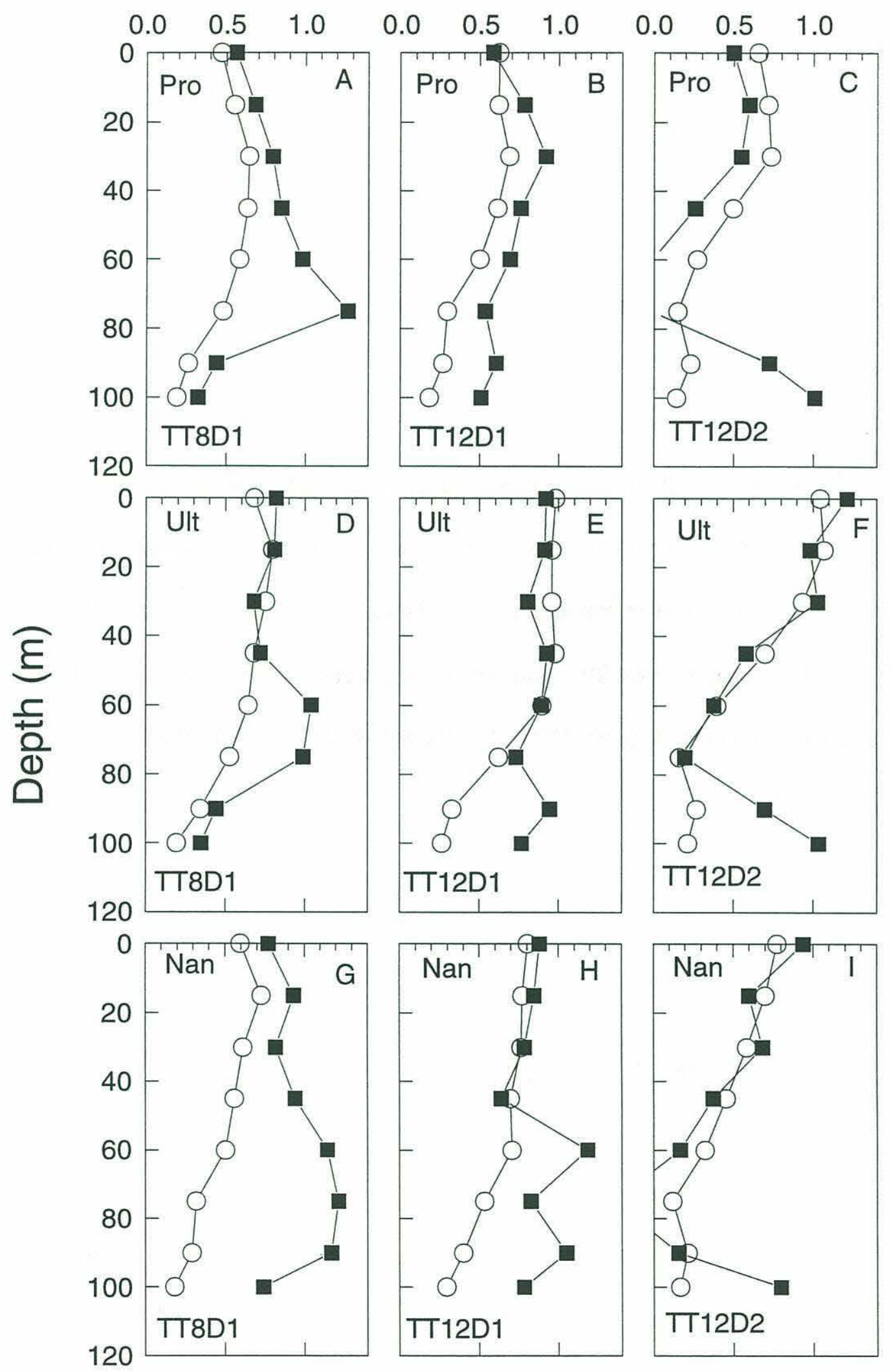


Figure 13. Depth profiles of specific growth rates ( $\mu$ from daytime increase in FLS, $\left.\mathrm{d}^{-1}\right)$ and loss rates $\left(\mathrm{d}^{-1}\right)$ for nanophytoplankton in the Sargasso Sea during a 48-hour diel sampling experiment in January 1992 at $27^{\circ} \mathrm{N} 68^{\circ} \mathrm{W}$ (A and B: EnD1, Day1 and Day2) and for nanophytoplankton and coccolithophores during a 28-hour diel sampling experiment in January 1992 at $35^{\circ} \mathrm{N} 68^{\circ} \mathrm{W}$ (C and D: EnD2). 
Specific growth rate ( 0 ) or Loss rate ( $\quad$ ) d $\mathrm{d}^{-1}$
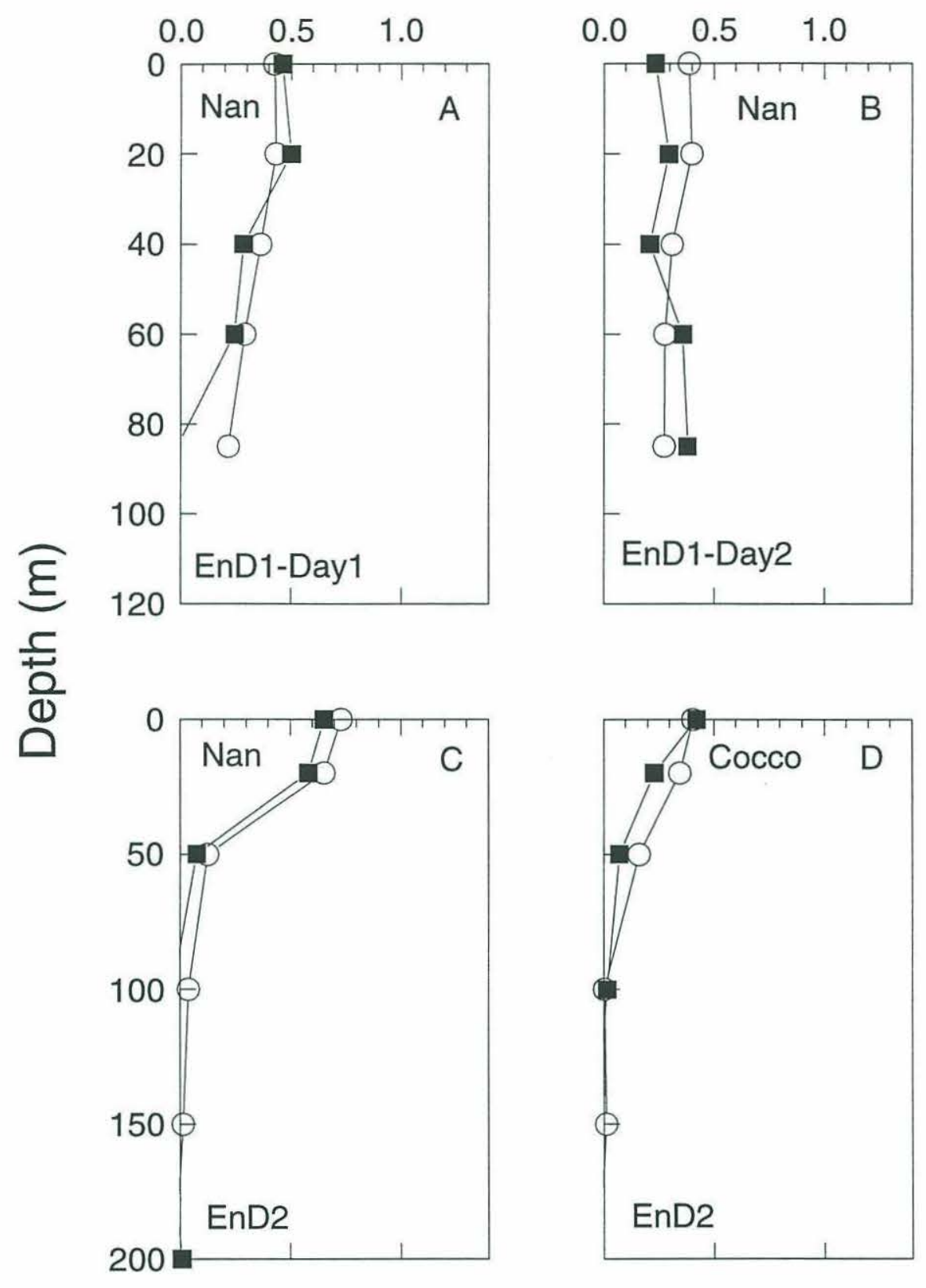
Figure 14. Depth profiles of specific growth rates ( $\mu$ from daytime increase in FLS, $\left.\mathrm{d}^{-1}\right)$ and loss rates $\left(\mathrm{d}^{-1}\right)$ for Synechococcus (A), and nanophytoplankton (B) in the Sargasso Sea during a 40-hour diel sampling experiment in July 1993 at $35^{\circ} \mathrm{N} 69^{\circ} \mathrm{W}$ (R.V. Columbus Iselin, Iselin). 


\section{Specific growth rate ( $\circ)$ ) or Loss rate $(\square) d^{-1}$}
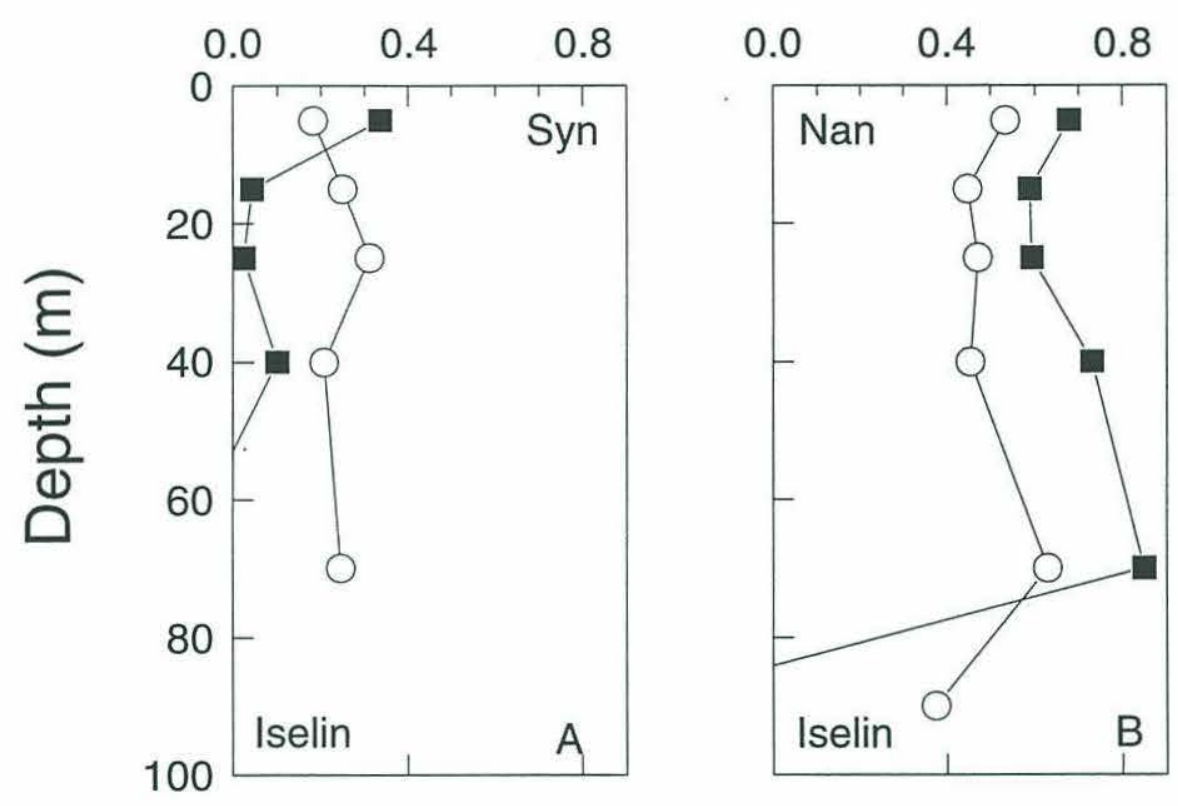
Figure 15. Depth profiles of specific growth rates $(\mu$ from daytime increase in FLS, $\left.\mathrm{d}^{-1}\right)$ and loss rates $\left(\mathrm{d}^{-1}\right)$ for nanophytoplankton in the Sargasso Sea during a 48-hour diel sampling experiment in May 1994 at $35^{\circ} \mathrm{N} 71^{\circ} \mathrm{W}$ (Hat, Day1 and Day2). 


\section{Specific growth rate $(\circ)$ or Loss rate $(\square) d^{-1}$}
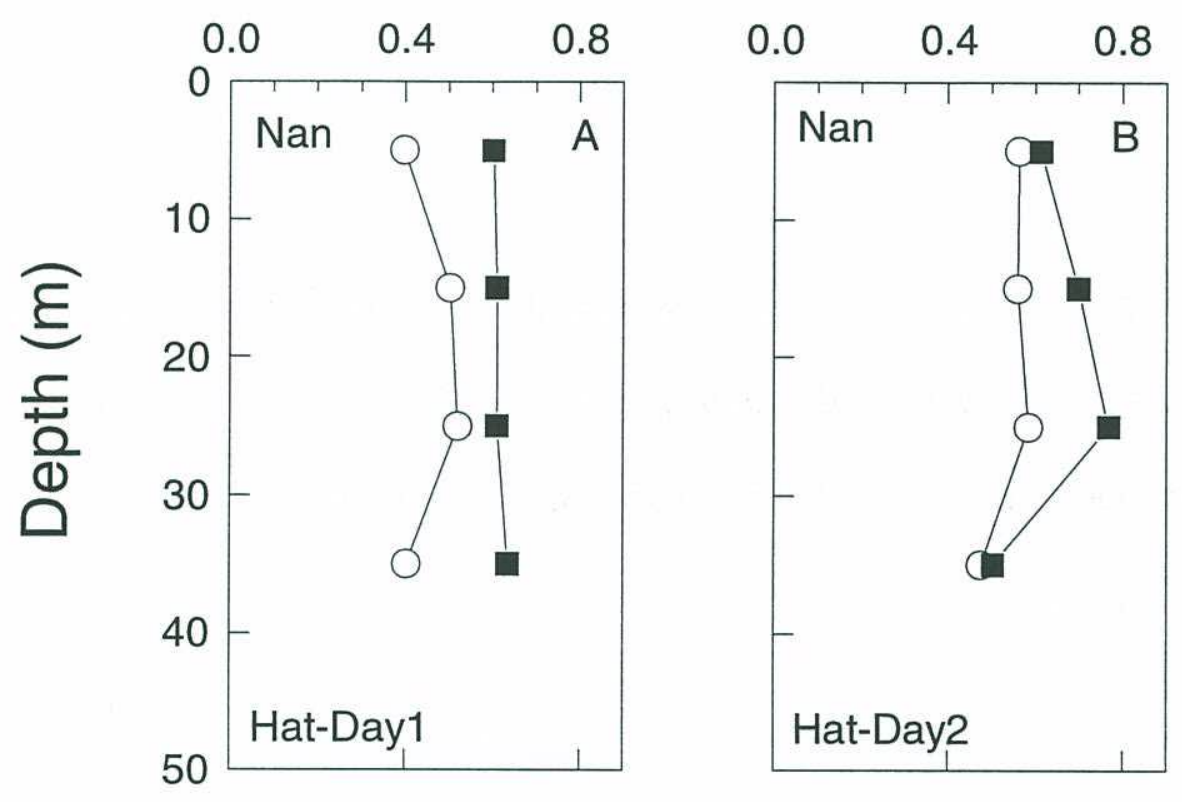
Figure 16. Depth profiles of day or night loss rates $\left(\mathrm{h}^{-1}\right)$ for Prochlorococcus (A, B, C), ultraphytoplankton (D, E, F), and nanophytoplankton (G, H, I) in the equatorial Pacific during one diel sampling in April (TT8D1) and two in October 1992 (TT12D1 and TT12D2). 


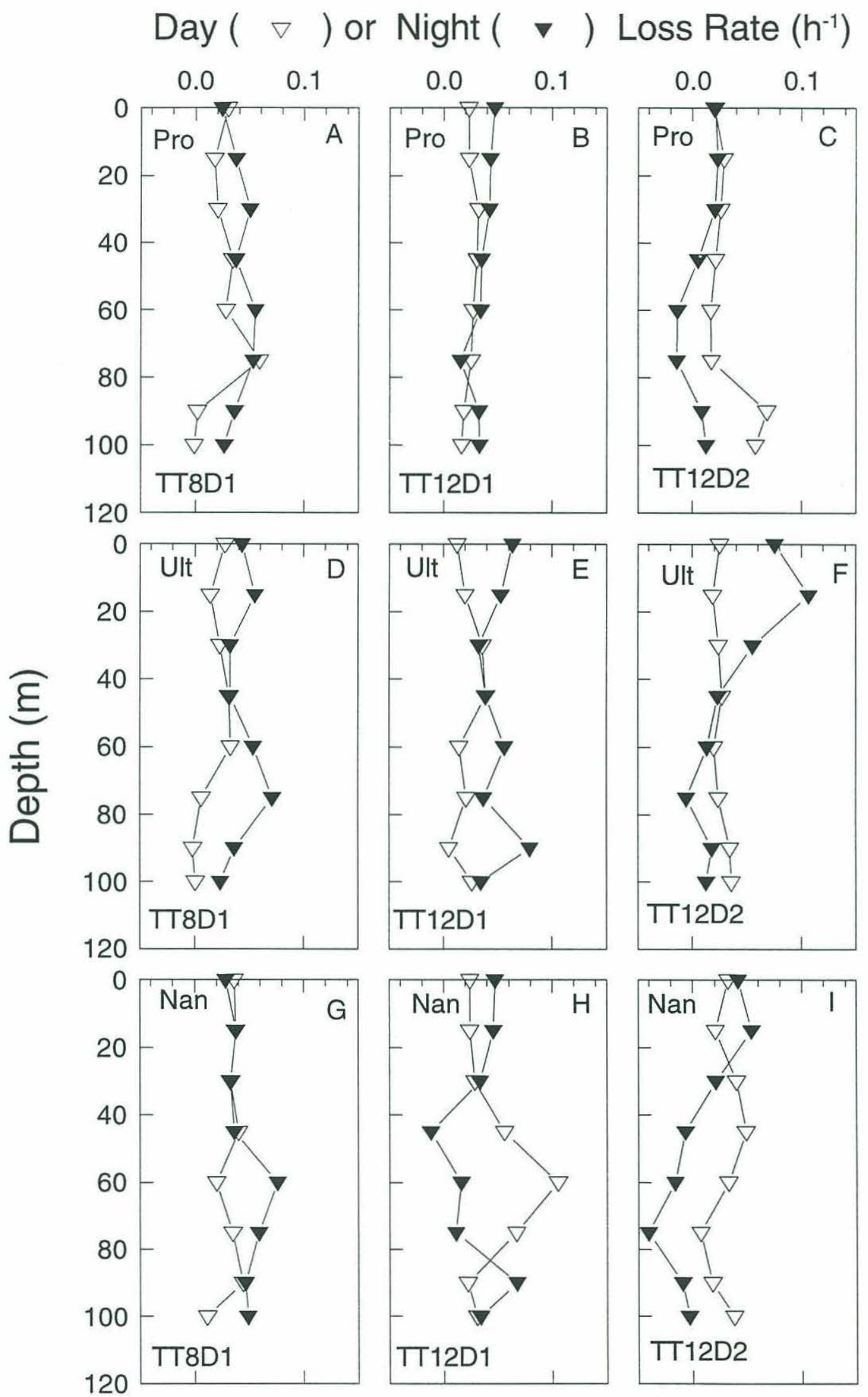


Figure 17. Depth profiles of day or night loss rates $\left(\mathrm{h}^{-1}\right)$ for nanophytoplankton in the Sargasso Sea during a 48-hour diel sampling experiment in January 1992 at $27^{\circ} \mathrm{N}$ $68^{\circ} \mathrm{W}$ (A and B: EnD1, Day1 and Day2) and for nanophytoplankton and coccolithophores during a 28 -hour diel sampling experiment in January 1992 at $35^{\circ} \mathrm{N}$ $68^{\circ} \mathrm{W}(\mathrm{C}$ and $\mathrm{D}: \mathrm{EnD} 2)$. 


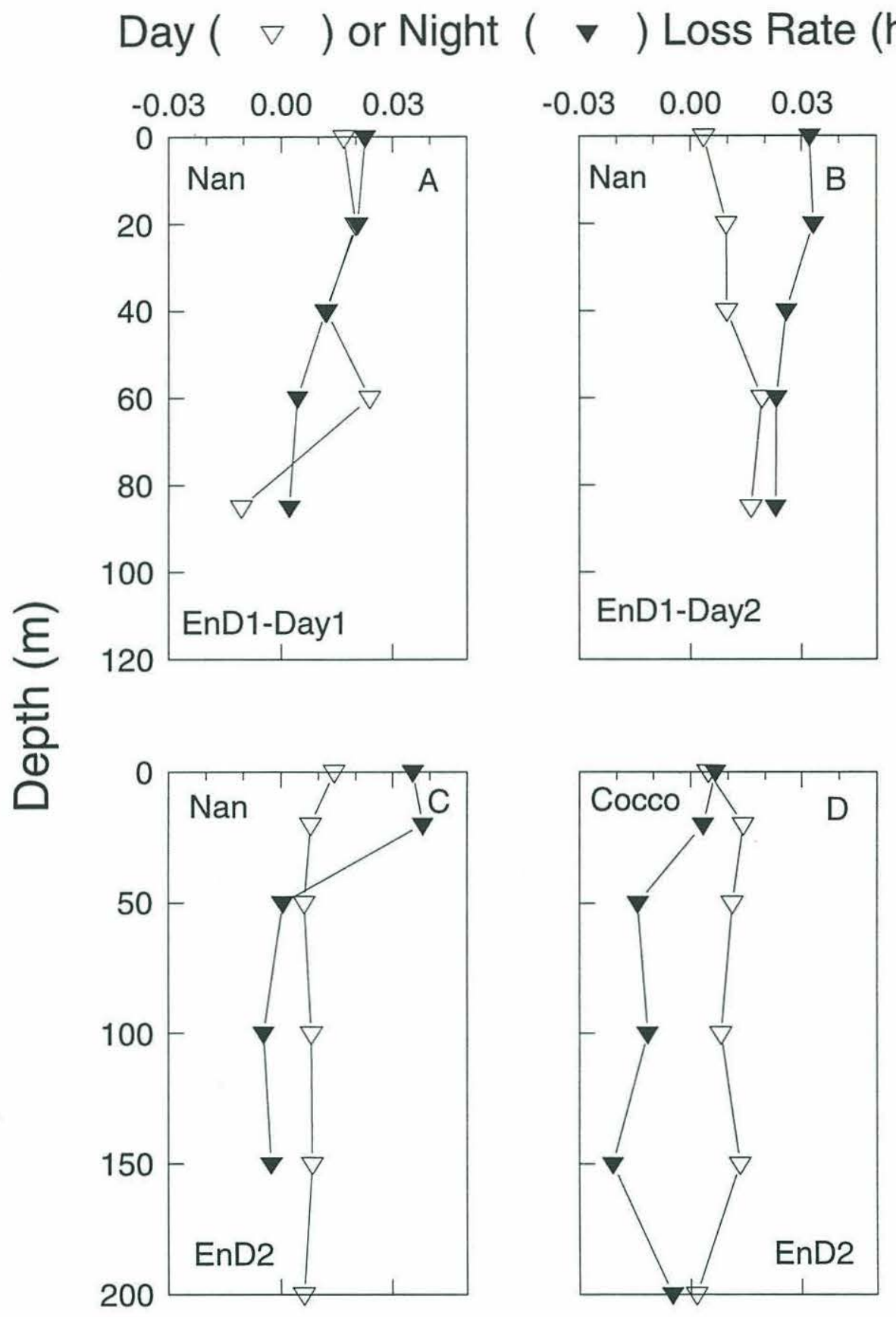


Figure 18. Depth profiles of day or night loss rates $\left(\mathrm{h}^{-1}\right)$ for Synechococcus (A), and nanophytoplankton (B) in the Sargasso Sea during a 40-hour diel sampling experiment in July 1993 at $35^{\circ} \mathrm{N} 69^{\circ} \mathrm{W}$ (R.V. Columbus Iselin, Iselin). 


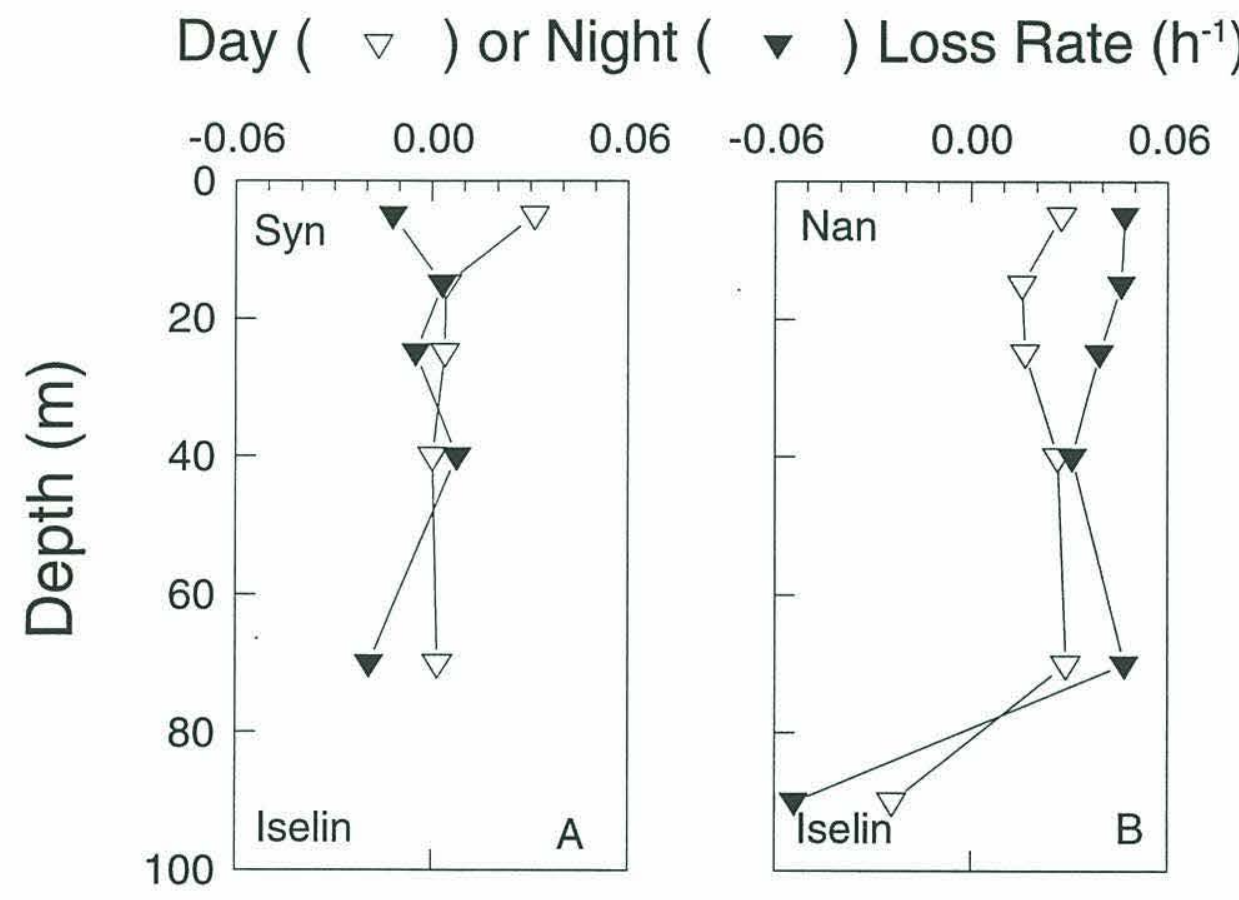


Figure 19. Depth profiles of day or night loss rates $\left(\mathrm{h}^{-1}\right)$ for nanophytoplankton in the Sargasso Sea during a 48-hour diel sampling experiment in May 1994 at $35^{\circ} \mathrm{N}$ $71^{\circ} \mathrm{W}$ (Hat, Day1 and Day2). 


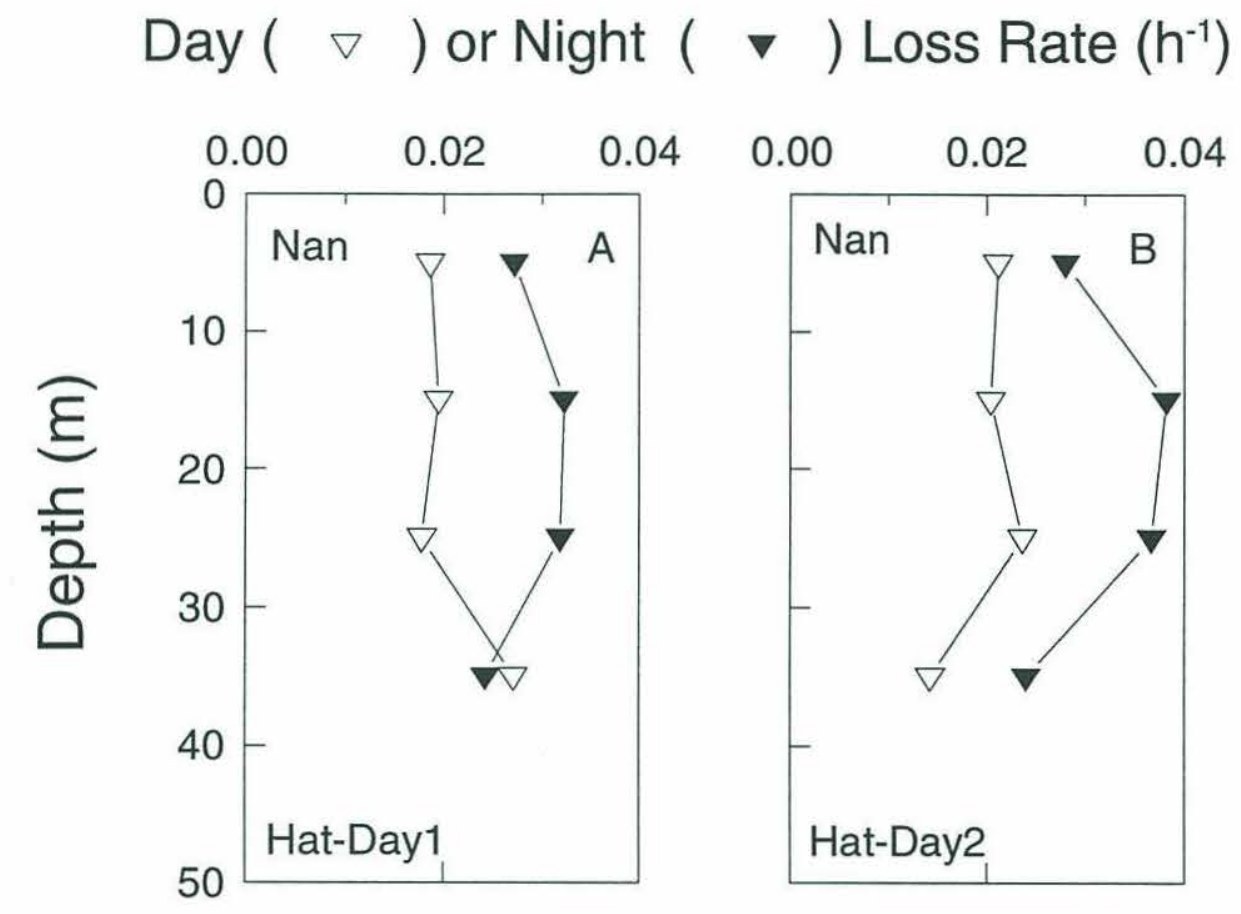


Figure 20. Depth profile of density $\left(\sigma_{t}\right)$ during a 28 -hour diel sampling experiment in January 1992 at $35^{\circ} \mathrm{N} 68^{\circ} \mathrm{W}$ (R.V. Endeavor, EnD2) at selected times (0600, 1400,1600 , and $2000 \mathrm{~h}$ ). At $0600 \mathrm{~h}$, the water column was deeply mixed. There was a rainstorm in the morning (heaviest around $1000 \mathrm{~h}$ ), which produces less dense water near the surface in the $1400 \mathrm{~h}$ profile. At $1600 \mathrm{~h}$, this less dense water had begun to mix downward. By $2000 \mathrm{~h}$ the water column again appeared to be deeply mixed. 


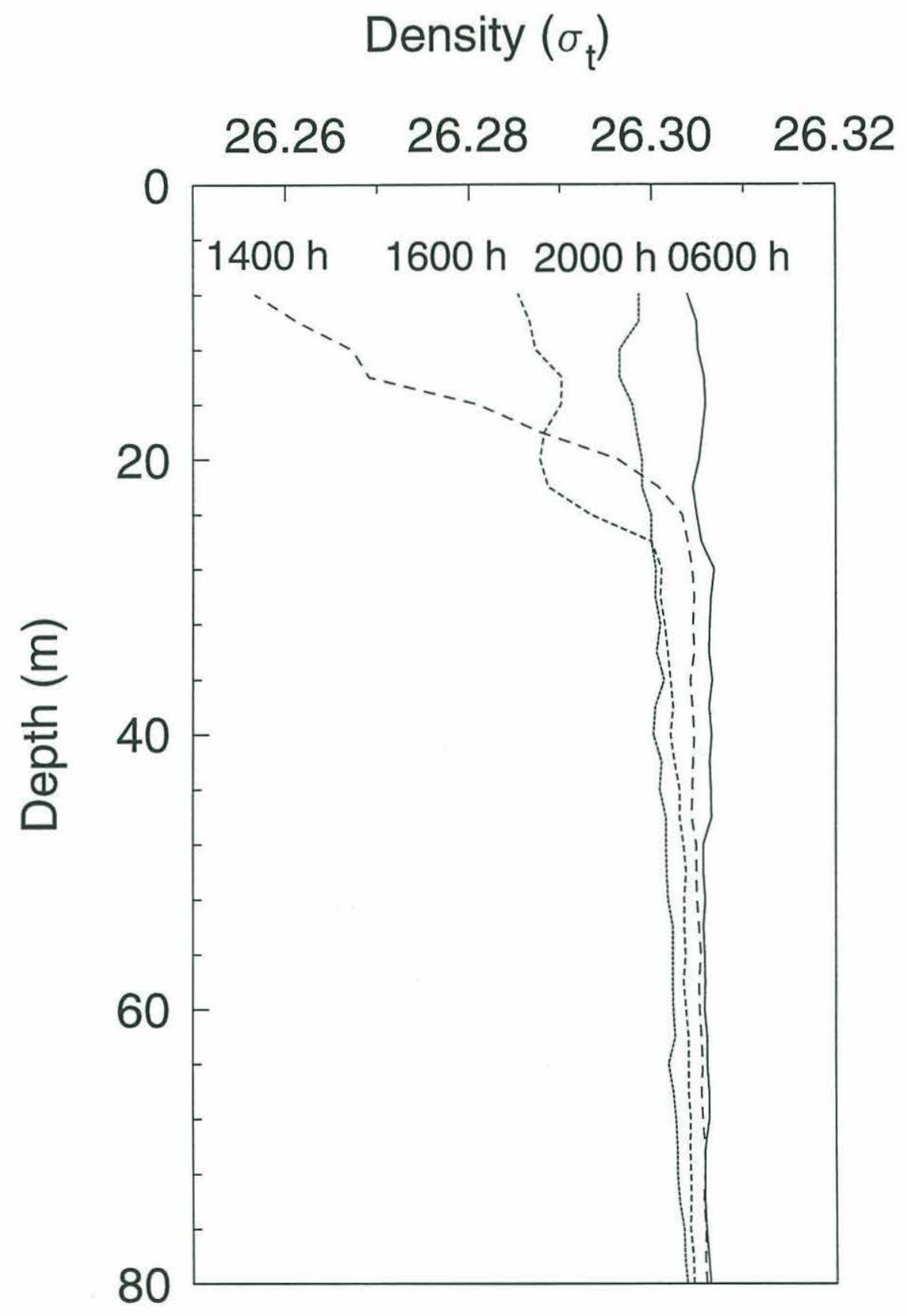


Separate day and night loss rates were calculated as described in the methods. In general, night loss rates tend to be higher than day loss rates (with a few exceptions; Figs. 16-19). It is interesting to note that the high night loss rates for the nanophytoplankton at 0 and $20 \mathrm{~m}$ during EnD2 (Fig. 17C) can be attributed primarily to mixing. This is evident from an examination of depth profiles of density (Fig. 20). There was a nocturnal deepening of the surface layer, with cells from the surface waters being mixed downward after dark. Less dense water (from a heavy rainstorm in the morning) was trapped near the surface during the day and appears to have first mixed to $50 \mathrm{~m}$ (and deeper) sometime between $1600 \mathrm{~h}$ and $2000 \mathrm{~h}$. Thus cells that were produced in the upper $20 \mathrm{~m}$ (see growth rates, Fig. 13C) were mixed deeper in the evening, causing the high nighttime loss rates in the upper waters. Since daytime shoaling followed by nocturnal deepening of the mixed layer is not uncommon and was seen during the equatorial Pacific cruises (Gardner et al. 1995), the nighttime loss rates are more likely to be a combination of losses due to grazing and to mixing in the upper waters. The nighttime loss rate in the deeper waters is sometimes less than zero (thus a gain rate) since the cells in the upper, more productive waters are mixed downward (Figs. 16C, I; 17C, D). 


\section{CONCLUSIONS}

Phytoplankton group-specific growth rate estimates from diel variations in flow cytometric light scattering are comparable to more conventional determinations of growth rates for Prochlorococcus and small eukaryotes. Prochlorococcus had a higher growth rate in the equatorial Pacific than in the Sargasso Sea during these cruises. Synechococcus growth rates were similar between the two areas, though the rates presented here are most likely underestimates due to incomplete phasing.

Growth rates for the eukaryotic phytoplankton (ultra and nano) in the equatorial Pacific were near one doubling per day in the upper waters. In the Sargasso Sea, the nanophytoplankton rates approached one doubling per day, but were more often lower than that. Generally, phytoplankton growth rates were closely matched by in situ loss rates over the course of a day. Nighttime loss rates were more likely to be higher than daytime loss rates, at least in part due to increased mixing due to nocturnal deepening of the mixed layer.

\section{Acknowledgements}

I thank Brian Binder, Jeff Dusenberry, Rob Olson, and Erik Zettler for assistance at sea; chief scientists Rob Olson, John Waterbury, Michael Roman, and Michael Bacon; and the captains and crew of the RV Thomas Thompson, Endeavor, Columbus Iselin, and Cape Hatteras. This work was supported by NSF grants OCE-9012147 and OCE-9024380 (to RJO) and a WHOI Ocean Ventures Award (to MDD). 


\section{REFERENCES}

Ackleson, S.G. and R.W. Spinrad. 1988. Size and refractive index of individual marine particulates: a flow cytometric approach. Appl. Opt. 27: 1270-1277.

Ackleson, S.G., J.J. Cullen, J. Brown and M. Lesser. 1993. Irradiance-induced variability in light scatter from marine phytoplankton in culture. J. Plankton Res. 15: 737-759.

Armbrust, E.V., J.D. Bowen, R.J. Olson and S.W. Chisholm. 1989. Effect of light on the cell cycle of a marine Synechococcus strain. Appl. Environ. Microbiol. 55: 425-432.

Campbell, L. and E.J. Carpenter. 1986. Diel patterns of cell division in marine Synechococcus spp. (Cyanobacteria): use of the frequency of dividing cells technique to measure growth rate. Mar. Ecol. Prog. Ser. 32: 139-148.

Chavez, F.P. 1989. Size distribution of phytoplankton in the central and eastern tropical Pacific. Global Biogeochemical Cycles 3: 27-35.

Chavez, F.P., K.R. Buck and R.T. Barber. 1990. Phytoplankton taxa in relation to primary production in the equatorial Pacific. Deep-Sea Res. 37: 1733-1752.

Chavez, F.P., K.R. Buck, K.H. Coale, J.H. Martin, G.R. DiTullio, N.A. Welschmeyer, A.C. Jacobson and R.T. Barber. 1991. Growth rates, grazing, sinking, and iron limitation of equatorial Pacific phytoplankton. Limnol. Oceanogr. 36: 1816-1833.

Chisholm, S.W. 1981. Temporal patterns of cell division in unicellular algae, pp. 150-181. In T. Platt [ed.], Physiological Bases of Phytoplankton Ecology. Canadian Bulletin of Fisheries and Aquatic Sciences 210.

Cullen, J.J., M.R. Lewis, C.O. Davis and R.T. Barber. 1992. Photosynthetic characteristics and estimated growth rates indicate grazing is the proximate control of primary production in the equatorial Pacific. J. Geophys. Res. 97: 639-654.

DuRand, M.D. and R.J. Olson. in press. Contributions of phytoplankton light scattering and cell concentration changes to diel variations in beam attenuation in the equatorial Pacific from flow cytometric measurements of pico-, ultra-, and nanoplankton. Deep-Sea Res.

Frost, B.W. 1991. The role of grazing in nutrient-rich areas of the open sea. Limnol. Oceanogr. 36: 1616-1630. 
Furnas, M.J. 1990. In situ growth rates of marine phytoplankton: approaches to measurement, community and species growth rates. J. Plankton Res. 12: 1117-1151.

Gardner, W.D., S.P. Chung, M.J. Richardson and I.D. Walsh. 1995. The oceanic mixed-layer pump. Deep-Sea Res. in press.

Goericke, R. and N.A. Welschmeyer. 1993. The marine prochlorophyte Prochlorococcus contributes significantly to phytoplankton biomass and primary production in the Sargasso Sea. Deep-Sea Res. 40: 2283-2294.

Iturriaga, R. and J. Marra. 1988. Temporal and spatial variability of chroococcoid cyanobacteria Synechococcus spp. specific growth rates and their contribution to primary production in the Sargasso Sea. Mar. Ecol. Prog. Ser. 44: 175-181.

Liu, H., L. Campbell and M.R. Landry. 1995. Growth and mortality of Prochlorococcus and Synechococcus measured with a selective inhibitor technique. Mar. Ecol. Prog. Ser. 116: 277-287.

Martin, J.H., R.M. Gordon and S.E. Fitzwater. 1991. The case for iron. Limnol. Oceanogr. 36: 1793-1802.

Martin, J.H., R.M. Gordon, S.E. Fitzwater and W.W. Broenkow. 1989. VERTEX: phytoplankton/iron studies in the Gulf of Alaska. Deep-Sea Res. 36: 649-680.

Michaels, A.F., et al. 1994. Seasonal patterns of ocean biogeochemistry at the U.S. JGOFS Bermuda Atlantic Time-series Study site. Deep-Sea Res. 41: 1013-1038.

Morel, A. and A. Bricaud. 1986. Inherent optical properties of algal cells including picoplankton: Theoretical and experimental results, pp. 521-559. In T. Platt and W.K.W. Li [eds.], Photosynthetic Picoplankton. Canadian Bulletin of Fisheries and Aquatic Sciences 214.

Morel, F.M.M., J.G. Rueter and N.M. Price. 1991. Iron nutrition of phytoplankton and its possible importance in the ecology of ocean regions with high nutrient and low biomass. Oceanography 4: 56-61.

Olson, R.J., S.W. Chisholm, E.R. Zettler, M.A. Altabet and J.A. Dusenberry. 1990a. Spatial and temporal distributions of prochlorophyte picoplankton in the North Atlantic Ocean. Deep-Sea Res. 37: 1033-1051.

Olson, R.J., S.W. Chisholm, E.R. Zettler and E.V. Armbrust. 1990b. Pigments, size, and distribution of Synechococcus in the North Atlantic and Pacific Oceans. 
Limnol. Oceanogr. 35: 45-58.

Olson, R.J., E.R. Zettler and O.K. Anderson. 1989. Discrimination of eukaryotic phytoplankton cell types from light scatter and autofluorescence properties measured by flow cytometry. Cytometry 10: 636-643.

Olson, R.J., E.R. Zettler, S.W. Chisholm and J.A. Dusenberry. 1991. Advances in oceanography through flow cytometry, pp. 351-399. In S. Demers [ed.], Particle Analysis in Oceanography. NATO ASI Series G 27. Springer-Verlag.

Olson, R.J., E.R. Zettler and M.D. DuRand. 1993. Phytoplankton analysis using flow cytometry, pp. 175-186. In P.F. Kemp, B.F. Sherr, E.B. Sherr and J.J. Cole [eds.], Handbook of Methods in Aquatic Microbial Ecology. Lewis Publishers.

Siegel, D.A., R. Itturiaga, R.R. Bidigare, R.C. Smith, H. Pak, T.D. Dickey, J. Marra and K.S. Baker. 1990. Meridional variations of the springtime phytoplankton community in the Sargasso Sea. J. Mar. Res. 48: 379-412.

Stramski, D. and R.A. Reynolds. 1993. Diel variations in the optical properties of a marine diatom. Limnol. Oceanogr. 38: 1347-1364.

Stramski, D., A. Shalapyonok and R.A. Reynolds. 1995. Optical characterization of the oceanic unicellular cyanobacterium Synechococcus grown under a day-night cycle in natural irradiance. J. Geophys. Res.

Vaulot, D., C. Courties and F. Partensky. 1989. A simple method to preserve oceanic phytoplankton for flow cytometric analyses. Cytometry 10: 629-635.

Vaulot, D., D. Marie, R.J. Olson and S.W. Chisholm. 1995. Growth of Prochlorococcus, a photosynthetic prokaryote, in the equatorial Pacific Ocean. Science 268: 1480-1482.

Verity, P.G., D.K. Stoecker and M.E. Sieracki. 1994. Microzooplankton grazing of primary production in the equatorial Pacific. EOS, Transactions, American Geophysical Union 75: 84.

Waterbury, J.B., F.W. Valois and D.G. Franks. 1986. Biological and ecological characterization of the marine unicellular cyanobacterium Synechococcus, pp. 71-120. In T. Platt and W.K.W. Li [eds.], Photosynthetic Picoplankton. Canadian Bulletin of Fisheries and Aquatic Sciences 214.

Weiler, C.S. 1980. Population structure and in situ division rates of Ceratium in oligotrophic waters of the North Pacific central gyre. Limnol. Oceanogr. 25: 610-619. 
Chapter 6

Conclusions 
In this thesis, I utilize flow cytometric measurements of phytoplankton light scattering and cell concentrations made over the diel cycle in the field in two ways. The first is to relate them to the bulk water optical property beam attenuation in order to explain the diel variations observed. The second is to relate them to growth processes of phytoplankton groups and thus estimate in situ phytoplankton groupspecific growth and loss rates in the oceans. In order to accomplish these intents, I have collected field data from three diel sampling experiments in the equatorial Pacific and four in the Sargasso Sea. In addition, I have performed laboratory experiments to investigate the variations over the diel cycle in optical properties of a cultured marine nanophytoplankton, Nannochloris sp. Calibrations from the laboratory experiments, along with theoretical calculations, are then applied to the field data to interpret the patterns seen.

The laboratory experiments on Nannochloris, grown at a range of light levels and under both artificial and natural light, showed pronounced diel patterns, with a minimum near dawn and a maximum near dusk, in cell size and cell-specific attenuation, absorption, flow cytometric light scatter, and carbon. The diel variations in the attenuation cross section were found to be primarily influenced by the changes in cell size due to growth and division, while changes in refractive index had only a small effect. These results are important, since, though systematic studies on variability in optical properties over the diel cycle have been performed on a marine diatom (Stramski and Reynolds 1993) and Synechococcus (Stramski et al. 1995), 
these two groups have division patterns unlike those of most other phytoplankton. This is the first diel study on the optical properties of a more typically dividing marine phytoplankton which is of a size expected to be an important contributor to optical properties in the oceans.

Field observations of diel variations in bulk beam attenuation, with a minimum near dawn and a maximum near dusk, have been presumed to reflect particle concentration changes over the course of the day and thus used to estimate particle production rates (Siegel et al. 1989). From flow cytometric measurements of individual phytoplankton cells in the field, it is clear that the diel variations in mean forward light scatter for phytoplankton populations are similar to those in beam attenuation, whereas cell concentrations generally have the opposite pattern. From laboratory studies, it has been suggested that a portion of diel variations in cell optical properties may be carbon-independent (increases in cell size without increases in cell carbon, Ackleson et al. 1993). Diel sampling experiments on cultures of Nannochloris have revealed increasing cell size during the day accompanied by increasing cell carbon as the cells photosynthesize and add carbon (grow) during the day, followed by division (and corresponding decreases in cell size and carbon) during the night. Using a combination of empirical calibrations relating beam attenuation to flow cytometric measurements of pure cultures of phytoplankton in the laboratory, and Mie theory, the contributions of different groups of phytoplankton to the diel variations in beam attenuation in the field were estimated. The results indicate that the phytoplankton assemblage measured by flow cytometry can account 
for essentially all of the diel variation in the beam attenuation signal. These diel variations are equated with growth processes of the cells over the diel cycle.

Diel variations in beam attenuation have been used to estimate primary production by applying a constant value for carbon-specific beam attenuation (Siegel et al. 1989, Cullen et al. 1992). However, if the carbon-specific beam attenuation $\left(c_{c}{ }^{*}\right)$ is different for different species (Ackleson et al. 1993, Stramski et al. 1995) or is not constant over the diel cycle (Stramski et al 1995), then this approach may not be appropriate. In addition, the $\mathrm{c}_{\mathrm{c}}{ }^{*}$ utilized was obtained from previous studies relating beam attenuation to suspended particulate material (SPM) and assuming that $25 \%$ of SPM is due to particulate organic carbon (POC). This $\mathrm{c}_{\mathrm{c}}{ }^{*}$ was then applied to the diel variation seen in beam attenuation $(\Delta \mathrm{c})$. The results presented in this thesis indicate that $37-58 \%$ of the total beam attenuation due to particles is due to the phytoplankton. However, I found that nearly all of the diel variation in beam attenuation can be accounted for by phytoplankton. Thus $\Delta \mathrm{c}$ should be directly converted to production using a $\mathrm{c}_{\mathrm{c}}{ }^{*}$ determined for phytoplankton. However, there are indications that $\mathrm{c}_{\mathrm{c}}{ }_{\mathrm{c}}$ is not constant over the diel cycle; it increased by up to $25 \%$ from dawn to dusk for cultures of Nannochloris. In addition, Synechococcus appears to have a lower $\mathrm{c}_{\mathrm{c}}{ }^{*}$ than Nannochloris, which could be important. If different phytoplankton groups are not contributing to production in the same manner that they are contributing to changes in optical properties, then estimates of primary production cannot be made from bulk measurements of beam attenuation without knowing the composition of the phytoplankton community. 
Since diel variations in mean light scattering of phytoplankton populations were equated with growth processes, flow cytometric measurements of phytoplankton light scattering over the diel light cycle were used to estimate in situ phytoplankton group-specific growth rates in the equatorial Pacific and the Sargasso Sea. Though there are a number of assumptions inherent in this approach, it yielded promising results for some groups. The method used to estimate growth rates works well for Prochlorococcus and appears to work for small eukaryotic phytoplankton, but leads to underestimates for Synechococcus and larger eukaryotes. Estimated growth rates for Prochlorococcus reached one division per day in the upper waters of the equatorial Pacific, but were about half that in the Sargasso Sea, consistent with other methods (Vaulot et al. 1995, Goericke and Welschmeyer 1993). For the eukaryotic phytoplankton, growth rates in the equatorial Pacific were near one division per day in the upper waters; in the Sargasso Sea, the growth rates approached that, but were more often lower. From the concomitant measurements of cell concentrations in the field, loss rates were also estimated. In general, phytoplankton growth rates were closely matched by in situ loss rates over the course of a day in both the equatorial Pacific and the Sargasso Sea. Estimating growth rates from flow cytometric measurements of phytoplankton light scatter over the diel cycle is a particularly attractive method since in situ processes are sampled without disturbance from incubations or manipulation, different phytoplankton groups can be distinguished, and the method could potentially be used with an in situ flow cytometer. 


\section{REFERENCES}

Ackleson, S.G., J.J. Cullen, J. Brown and M. Lesser. 1993. Irradiance-induced variability in light scatter from marine phytoplankton in culture. J. Plankton Res. 15: 737-759.

Cullen, J.J., M.R. Lewis, C.O. Davis and R.T. Barber. 1992. Photosynthetic characteristics and estimated growth rates indicate grazing is the proximate control of primary production in the equatorial Pacific. J. Geophys. Res. 97: 639-654.

Goericke, R. and N.A. Welschmeyer. 1993. The marine prochlorophyte Prochlorococcus contributes significantly to phytoplankton biomass and primary production in the Sargasso Sea. Deep-Sea Res. 40: 2283-2294.

Siegel, D.A., T.D. Dickey, L. Washburn, M.K. Hamilton and B.G. Mitchell. 1989. Optical determination of particulate abundance and production variations in the oligotrophic ocean. Deep-Sea Res. 36: 211-222.

Stramski, D. and R.A. Reynolds. 1993. Diel variations in the optical properties of a marine diatom. Limnol. Oceanogr. 38: 1347-1364.

Stramski, D., A. Shalapyonok and R.A. Reynolds. in press. Optical characterization of the oceanic unicellular cyanobacterium Synechococcus grown under a day-night cycle in natural irradiance. J. Geophys. Res.

Vaulot, D., D. Marie, R.J. Olson and S.W. Chisholm. 1995. Growth of Prochlorococcus, a photosynthetic prokaryote, in the equatorial Pacific Ocean. Science 268: 1480-1482. 
Appendix A

Calibration of forward light scatter and cell volume 
A laboratory calibration experiment was performed to determine the relationship between cell volume and flow cytometric forward light scatter (FLS) for a range of phytoplankton sizes. This calibration may be useful for conversion of flow cytometric light scatter to cell volume, which can then be converted to cell carbon (Strathman 1967, Chisholm 1992), to estimate oceanic distributions of phytoplankton volume or biomass.

Culturing - Each of the thirteen phytoplankton cultures (listed in Table 1) was grown in $\mathrm{f} / 2$ medium at $22^{\circ} \mathrm{C}$ in a continuous light incubator at approximately 90 $\mu \mathrm{mol}$ photons $\mathrm{m}^{-2} \mathrm{~s}^{-1}$. When the cells were expected to be in exponential phase, each tube was sampled and the following measurements were made.

Coulter Multisizer - Each culture was diluted with $0.22 \mu \mathrm{m}$ filtered seawater to obtain a coincidence rate $<5 \%$ when analyzed on a Coulter Multisizer. The orifice size used depended on the cell size $(30 \mu \mathrm{m}$ orifice for the smallest two, $50 \mu \mathrm{m}$ orifice for the next smallest three, and $70 \mu \mathrm{m}$ orifice for the largest eight; see Table 1). Volumes are averages of at least three replicate samples analyzed for each culture.

Flow cytometer - Each culture was analyzed at approximately the same time using two different flow cytometers. In each case, replicate samples were analyzed live (after dilution with $0.22 \mu \mathrm{m}$ filtered seawater), and then replicate preserved and frozen samples were analyzed (see below for preservation protocol). Both the flow cytometers were modified to analyze $50 \mathrm{ml}$ seawater samples at $5-10 \mathrm{ml} \mathrm{min}^{-1}$ (Olson et al. 1991, 1993) and had a Profile flow cell (Coulter, EPICS) instead of a jet-in-air 
Table 1. Phytoplankton cultures used, arranged in order of increasing cell volume. Listed are the culture name (identifying information or abbreviation used in the Olson stock culture collection), average Coulter volume $\left(\mu \mathrm{m}^{3}\right)$, and average forward light scatter (FLS) for the culture analyzed live on Epics \#1, preserved on Epics \#1, live on Epics \#2, and preserved on Epics \#2. All FLS data are expressed relative to $3.79 \mu \mathrm{m}$ beads.

\begin{tabular}{|c|c|c|c|c|c|}
\hline Culture & $\begin{array}{l}\text { Vol. } \\
\mu \mathrm{m}^{3}\end{array}$ & $\begin{array}{l}\text { FLS } \\
\text { (E\#1 } \\
\text { Live) }\end{array}$ & $\begin{array}{l}\text { FLS } \\
\text { (E\#1 } \\
\text { Pres) }\end{array}$ & $\begin{array}{l}\text { FLS } \\
\text { (E\#2 } \\
\text { Live) }\end{array}$ & $\begin{array}{l}\text { FLS } \\
\text { (E\#2 } \\
\text { Pres) }\end{array}$ \\
\hline Pycnococcus provasoli $(\Omega$ 48-23) & 9 & 0.637 & 0.627 & 0.612 & 0.603 \\
\hline Nannochloris sp. (Nanno) & 10 & 0.626 & 0.523 & 0.629 & 0.513 \\
\hline Minutocellus polymorphus (Hudson sort) & 20 & 0.697 & 0.738 & 0.680 & 0.627 \\
\hline Emiliania huxleyi (Eh 12-1) & 35 & 1.042 & 0.869 & 0.927 & 0.783 \\
\hline Phaeodactylum tricornutum (Phaeo) & 38 & 0.311 & 0.235 & 0.384 & 0.281 \\
\hline Cryptomonas sp. (Eel Pond) & 113 & 1.055 & 1.060 & 1.301 & 1.390 \\
\hline Cylindrotheca fusiformis (Cf) & 172 & 0.816 & 0.828 & 0.579 & 0.668 \\
\hline Dunaliella tertiolecta (Dun) & 200 & 1.811 & 1.528 & 1.356 & 1.259 \\
\hline Hymenomonas carterae (NCO) & 356 & 2.891 & 2.251 & 2.258 & 1.990 \\
\hline Amphidinium carteri (Amphi) & 380 & 3.524 & 3.233 & 2.311 & 2.494 \\
\hline Hymenomonas carterae (COII) & 442 & 4.802 & 3.814 & 3.175 & 2.990 \\
\hline Thalassiosira weissflogii (Tw) & 915 & 3.826 & 4.042 & 2.703 & 3.223 \\
\hline Syracosphaera elongata (SE62) & 2095 & 5.015 & 4.076 & 4.061 & 3.804 \\
\hline
\end{tabular}

as used for a previous calibration (Olson et al. 1989). One flow cytometer (referred to as E\#1) was an Epics V with a standard photodiode (with wide obscuration bar) used to collect the forward light scatter signal. The second flow cytometer (E\#2) was an EPICS 753 with a PMT to collect the forward light scatter signal. The window of the PMT was positioned $192 \mathrm{~mm}$ from the center of the flow cell. Part of the PMT was covered with black tape so that only a portion of the light reaching 
the PMT was collected (a rectangle $7.5 \mathrm{~mm}$ high and $11 \mathrm{~mm}$ wide was unmasked). The estimated angles of collection are $3^{\circ}-19^{\circ}$.

Preservation - For each phytoplankton culture, 14 1-ml aliquots were dispensed into cryovials, $5 \mu \mathrm{L} 25 \%$ glutaraldehyde (final concentration $0.125 \%$ ) was added, the vials were mixed and left in the dark for 10 minutes before being frozen in liquid nitrogen. One set of these preserved samples were analyzed on the flow cytometers (as described above) and the rest remain in liquid nitrogen for calibrating future configurations.

The relationship between flow cytometric forward light scatter and cell volume (Fig. 1) is strongly correlated for the phytoplankton cultures tested (excluding the pennate diatoms, Phaeodactylum tricornutum and Cylindrotheca fusiformis, which have lower FLS than would be expected from their cell volume, Olson et al. 1989). The regression equations are as follows (FLS is relative to $3.79 \mu \mathrm{m}$ beads and volume is in $\mu \mathrm{m}^{3}$ ):

$$
\begin{array}{ll}
\log (\text { FLS }, \text { E\#1 Live })=0.43 * \log (\text { volume })-0.66 & r^{2}=0.92 \\
\log (\text { FLS, E\#1 Pres })=0.41 * \log (\text { volume })-0.67 & r^{2}=0.93 \\
\log (\text { FLS, E\#2 Live })=0.36 * \log (\text { volume })-0.59 & r^{2}=0.96 \\
\log (\text { FLS, E\#2 Pres })=0.39 * \log (\text { volume })-0.67 & r^{2}=0.96
\end{array}
$$

Statistical analysis to compare the slopes and elevations of the equations for E\#1 Live and E\#2 Live indicate that the lines are not significantly different. Data from these two different configurations for FLS, each of which was used in the laboratory and field experiments described in this thesis, are considered to be comparable. 
Figure 1. Relationship between flow cytometric forward light scatter (FLS expressed relative to $3.79 \mu \mathrm{m}$ beads) and cell volume $\left(\mu \mathrm{m}^{3}\right)$ for Epics\#1 analyzed live (E\#1 Live) or preserved (E\#1 Pres) and Epics\#2 analyzed live (E\#2 Live) or preserved (E\#2 Pres). The thirteen phytoplankton cultures used are listed in Table 1. 


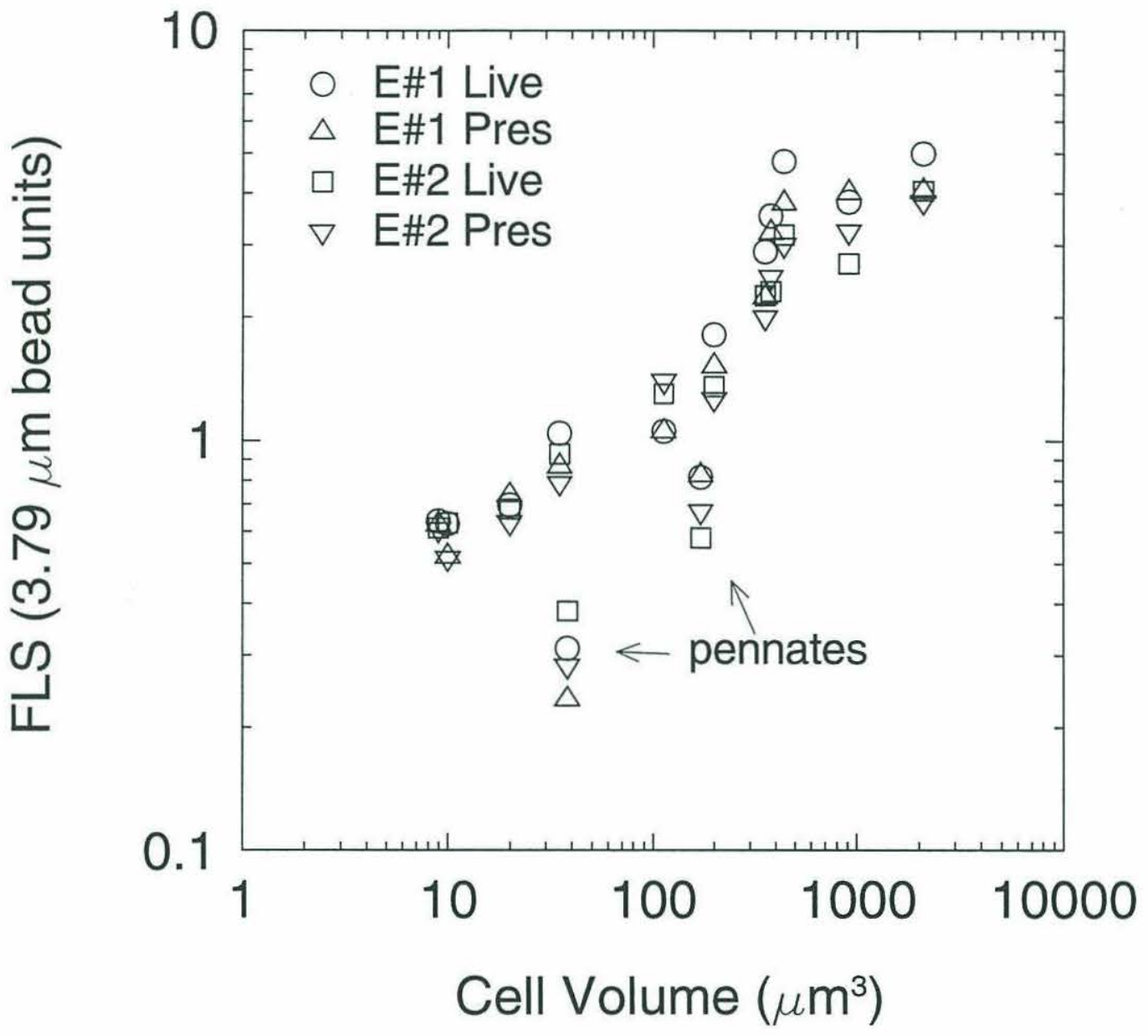




\section{REFERENCES}

Chisholm, S.W. 1992. Phytoplankton size, pp. 213-237. In P.G. Falkowski and A.D. Woodhead [eds.], Primary Productivity and Biogeochemical Cycles in the Sea. Environmental Science Research 43. Plenum Press.

Olșon, R.J., E.R. Zettler and O.K. Anderson. 1989. Discrimination of eukaryotic phytoplankton cell types from light scatter and autofluorescence properties measured by flow cytometry. Cytometry 10: 636-643.

Olson, R.J., E.R. Zettler, S.W. Chisholm and J.A. Dusenberry. 1991. Advances in oceanography through flow cytometry, pp. 351-399. In S. Demers [ed.], Particle Analysis in Oceanography. NATO ASI Series G 27. Springer-Verlag.

Olson, R.J., E.R. Zettler and M.D. DuRand. 1993. Phytoplankton analysis using flow cytometry, pp. 175-186. In P.F. Kemp, B.F. Sherr, E.B. Sherr and J.J. Cole [eds.], Handbook of Methods in Aquatic Microbial Ecology. Lewis Publishers.

Strathmann, R.R. 1967. Estimating the organic carbon content of phytoplankton from cell volume or plasma volume. Limnol. Oceanogr. 12: 411-418. 


\section{Appendix B}

Ancillary data for Chapter 5 
Presented here are time series data of forward light scatter and cell concentrations from diel sampling experiments in the equatorial Pacific and the Sargasso Sea (described below). Data from two selected experiments (TT8D1 in the equatorial Pacific and Iselin in the Sargasso Sea) are included in Chapter 5 (Figs. 1-3). The rest of the data (which are used to estimate the growth and loss rates presented in Chapter 5) are included in this appendix.

\section{Field Studies}

Equatorial Pacific - Diel sampling was performed on three occasions during the two JGOFS Time Series cruises in the equatorial Pacific in 1992 (at $0^{\circ} \mathrm{N}, 140^{\circ} \mathrm{W}$ ). During R.V. Thomas Thompson 008, one diel sampling was performed (TT8D1 on 1 April, see Chapter 5, Figs. 1,2) and during cruise 012, two diel samplings were performed (TT12D1 on 5 October and TT12D2 on 11 October; Figs. 1-4). In each case, CTD casts were made every three hours for 24 hours and samples for flow cytometric analysis were taken with Niskin bottles at $0,15,30,45,60,75,90$, and $100 \mathrm{~m}$.

Sargasso Sea - Diel samplings were performed on four occasions during three cruises in the Sargasso Sea. During R.V. Endeavor 232 in January 1992, two diel samplings were performed (EnD1 for $48-\mathrm{h}$ at $27^{\circ} \mathrm{N} 68^{\circ} \mathrm{W}$ and $\mathrm{EnD} 2$ for 28 -h at $35^{\circ} \mathrm{N}$ 68 W; Figs. 5, 6). During R.V. Columbus Iselin 93-06 (July 1993), one 40-h 
sampling was performed (Iselin at $35^{\circ} \mathrm{N} 69^{\circ} \mathrm{W}$; see Chapter 5, Fig. 3). During R.V. Cape Hatteras 0694 (May 1994), one 48-h sampling was performed (Hat at $35^{\circ} \mathrm{N}$ $71^{\circ} \mathrm{W}$; Fig. 7). For each sampling, a holey-sock drogue set at $25 \mathrm{~m}$ was launched and tracked in order to follow the same water mass during the sampling. CTD casts were made every two hours and samples for flow cytometric analyses were taken with Niskin bottles at four to six depths (depths varied with each sampling). 
Fig. 1. Time series of Prochlorococcus A) forward light scatter (relative to $3.79 \mu \mathrm{m}$ bead) and B) cell concentration, and Synechococcus C) forward light scatter and D) cell concentration in the equatorial Pacific in October 1992 (TT12D1). 


\section{TT12D1}
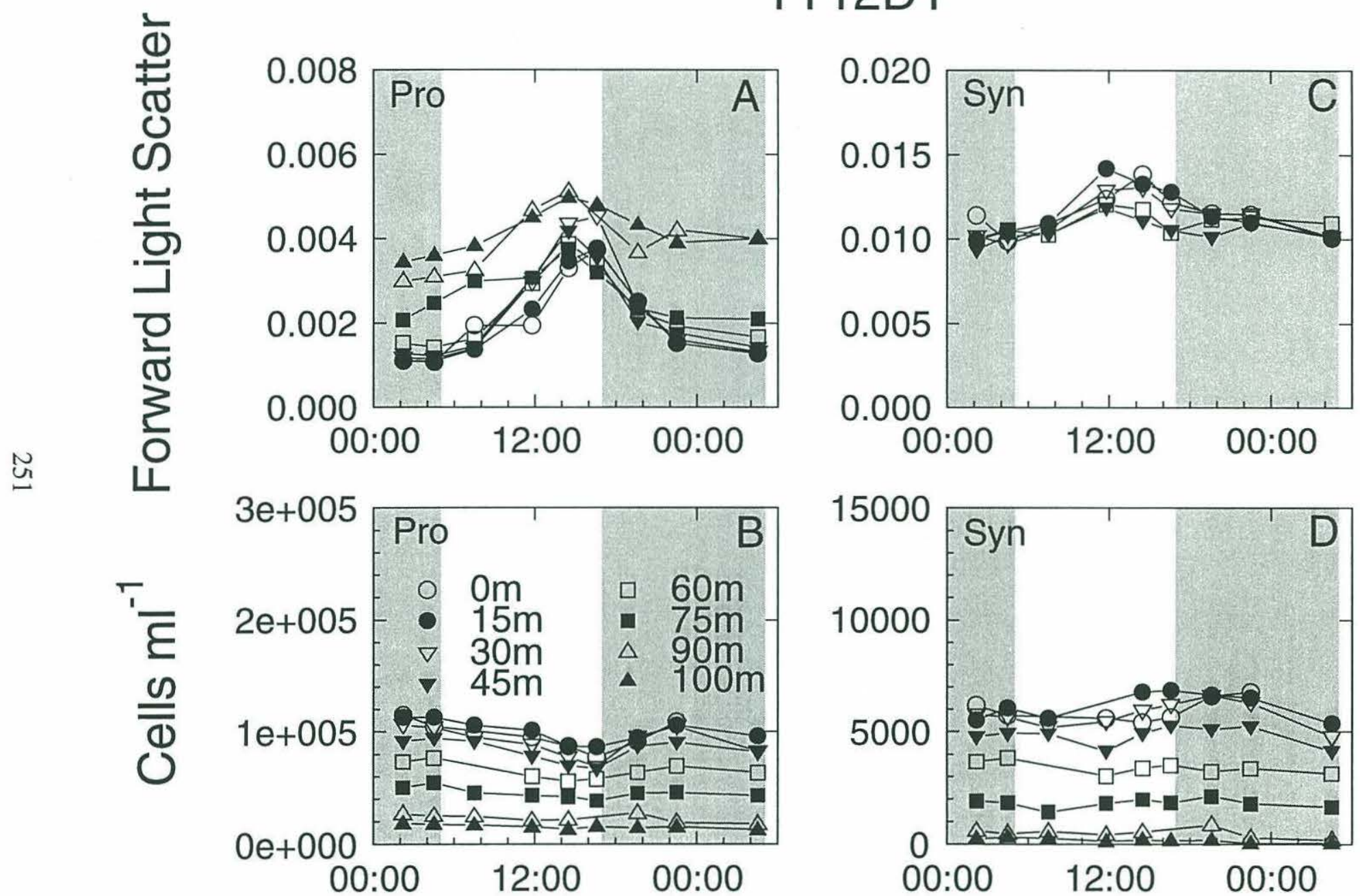

Time of Day 
Fig. 2. Time series of ultraphytoplankton A) forward light scatter (relative to $3.79 \mu \mathrm{m}$ bead) and B) cell concentration, and nanophytoplankton C) forward light scatter and D) cell concentration in the equatorial Pacific in October 1992 (TT12D1). 
TT12D1

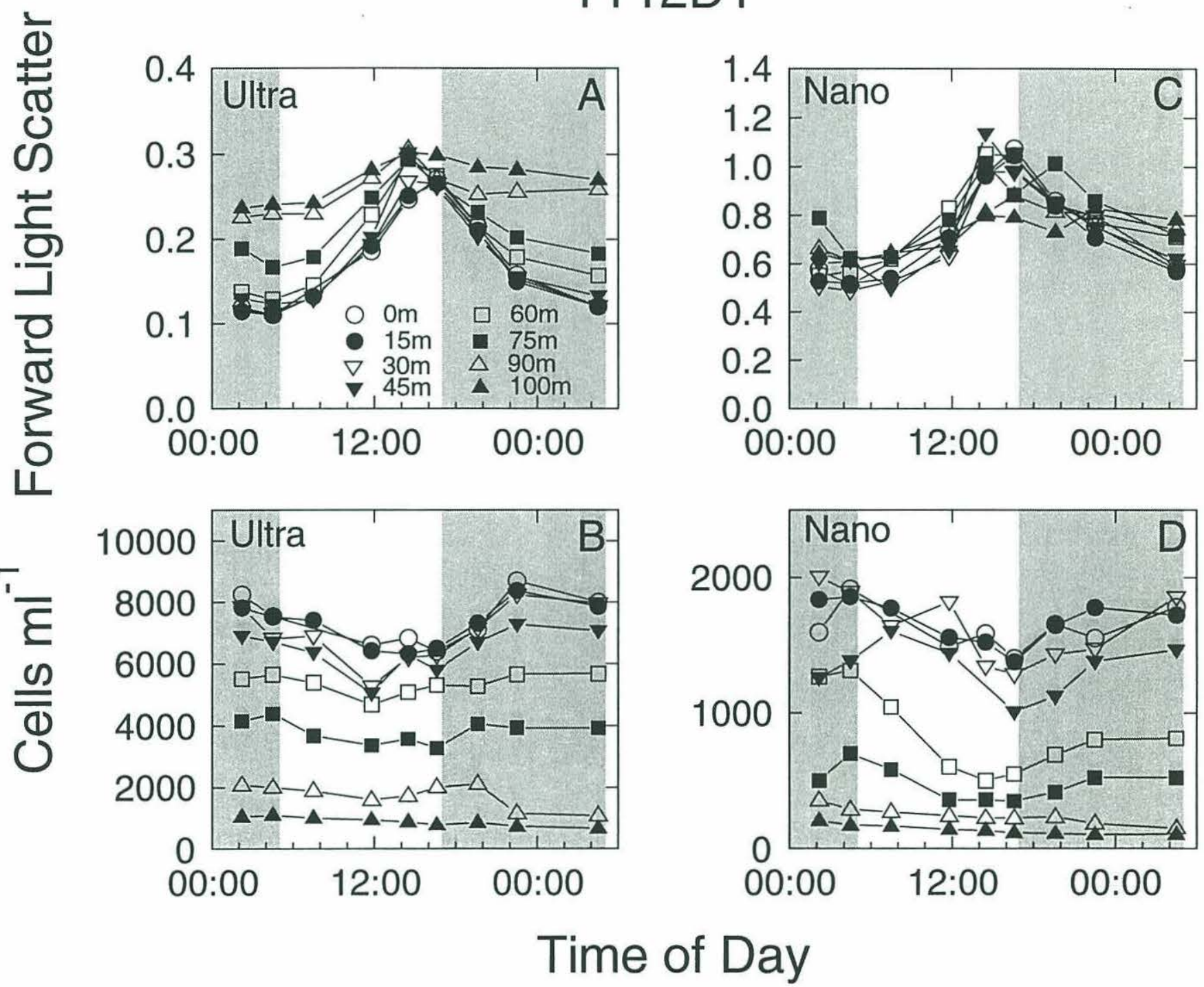


Fig. 3. Time series of Prochlorococcus A) forward light scatter (relative to $3.79 \mu \mathrm{m}$ bead) and B) cell concentration, and Synechococcus C) forward light scatter and D) cell concentration in the equatorial Pacific in October 1992 (TT12D2). 
TT12D2

ü

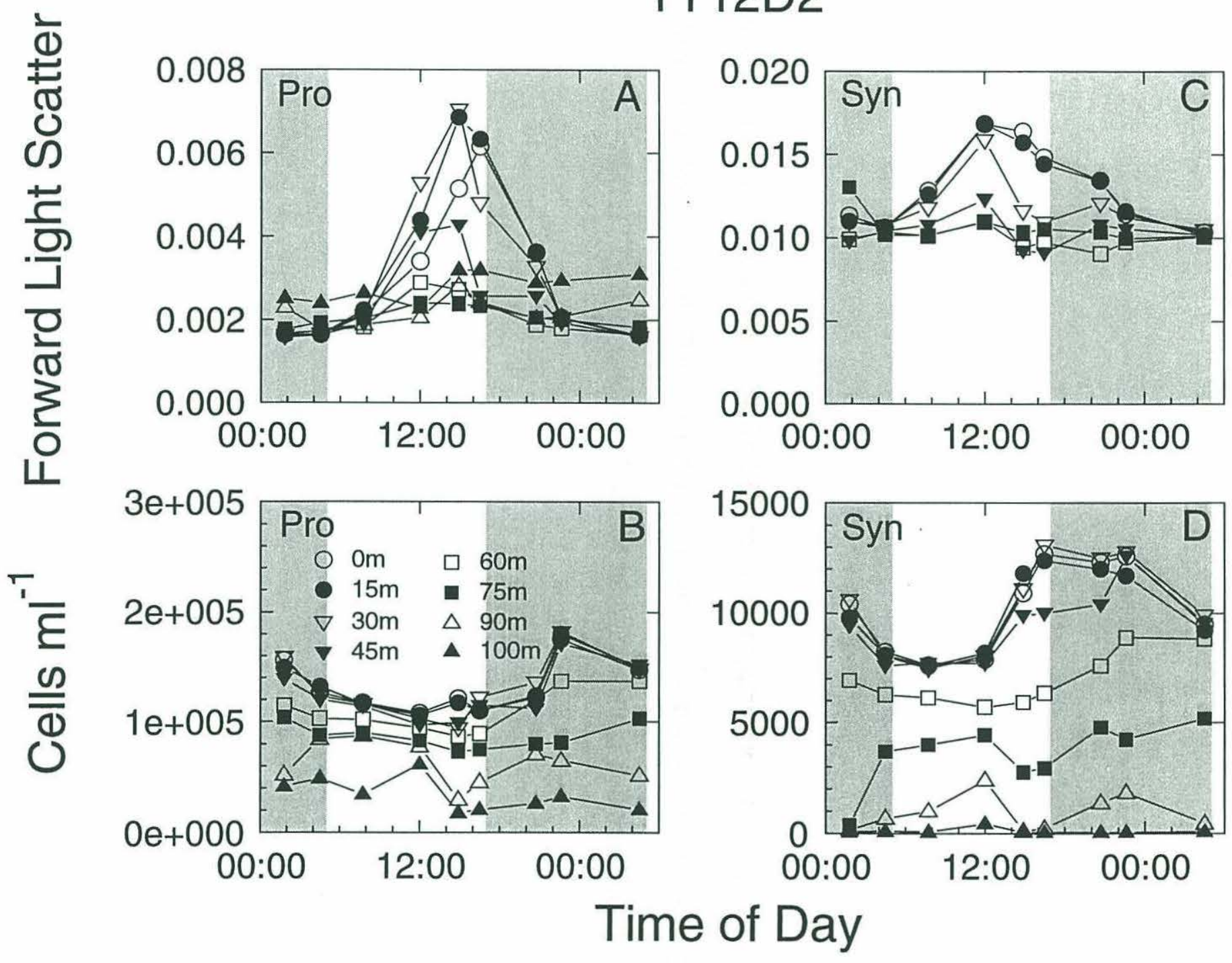


Fig. 4. Time series of ultraphytoplankton A) forward light scatter (relative to $3.79 \mu \mathrm{m}$ bead) and B) cell concentration, and nanophytoplankton C) forward light scatter and D) cell concentration in the equatorial Pacific in October 1992 (TT12D2). 


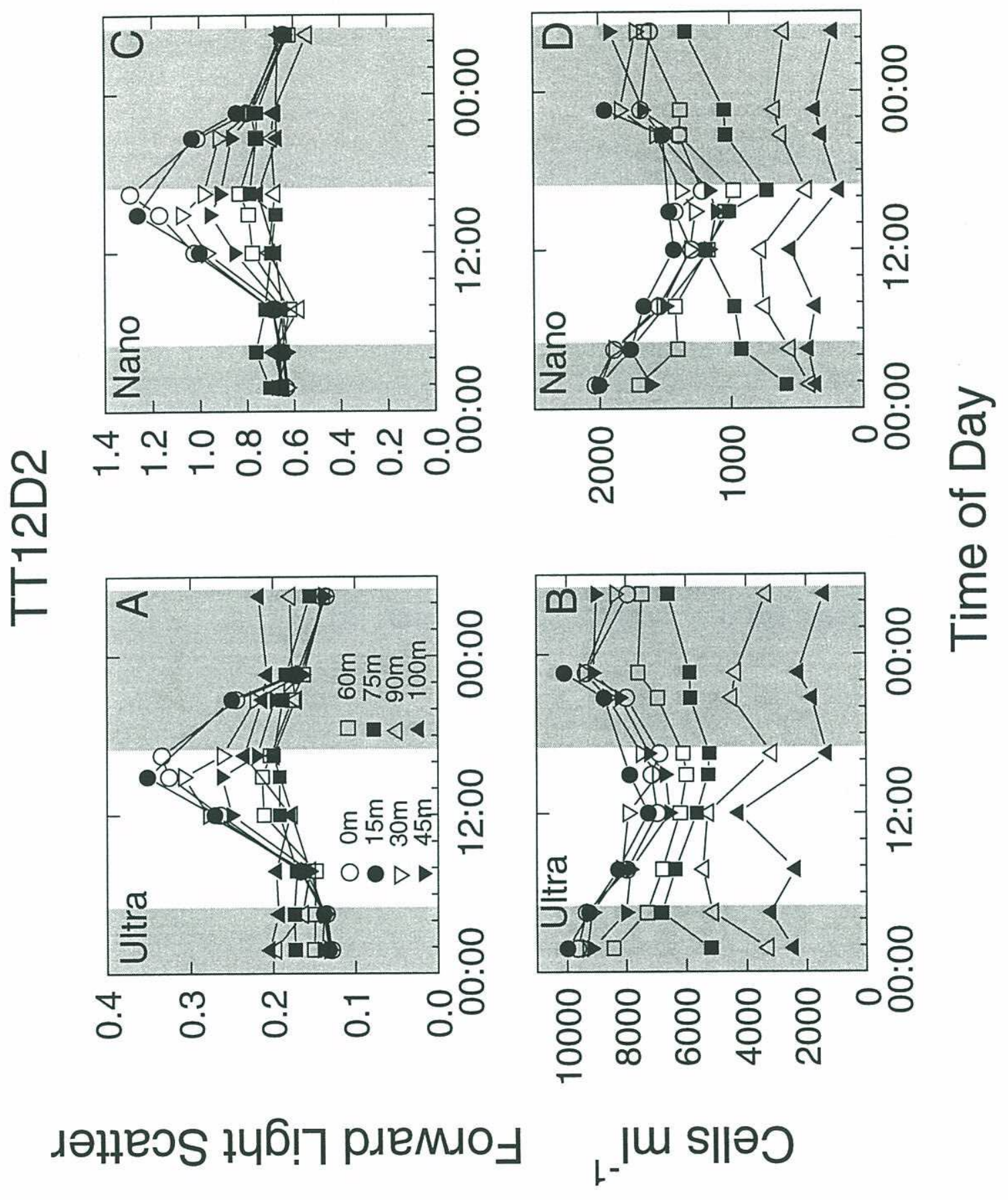


Fig. 5. Time series of nanophytoplankton A) forward light scatter (relative to $3.79 \mu \mathrm{m}$ beads) and B) cell concentration during a 48-hour diel sampling experiment in January 1992 in the Sargasso Sea at $27^{\circ} \mathrm{N} 68^{\circ} \mathrm{W}$ (R.V. Endeavor, EnD1). 

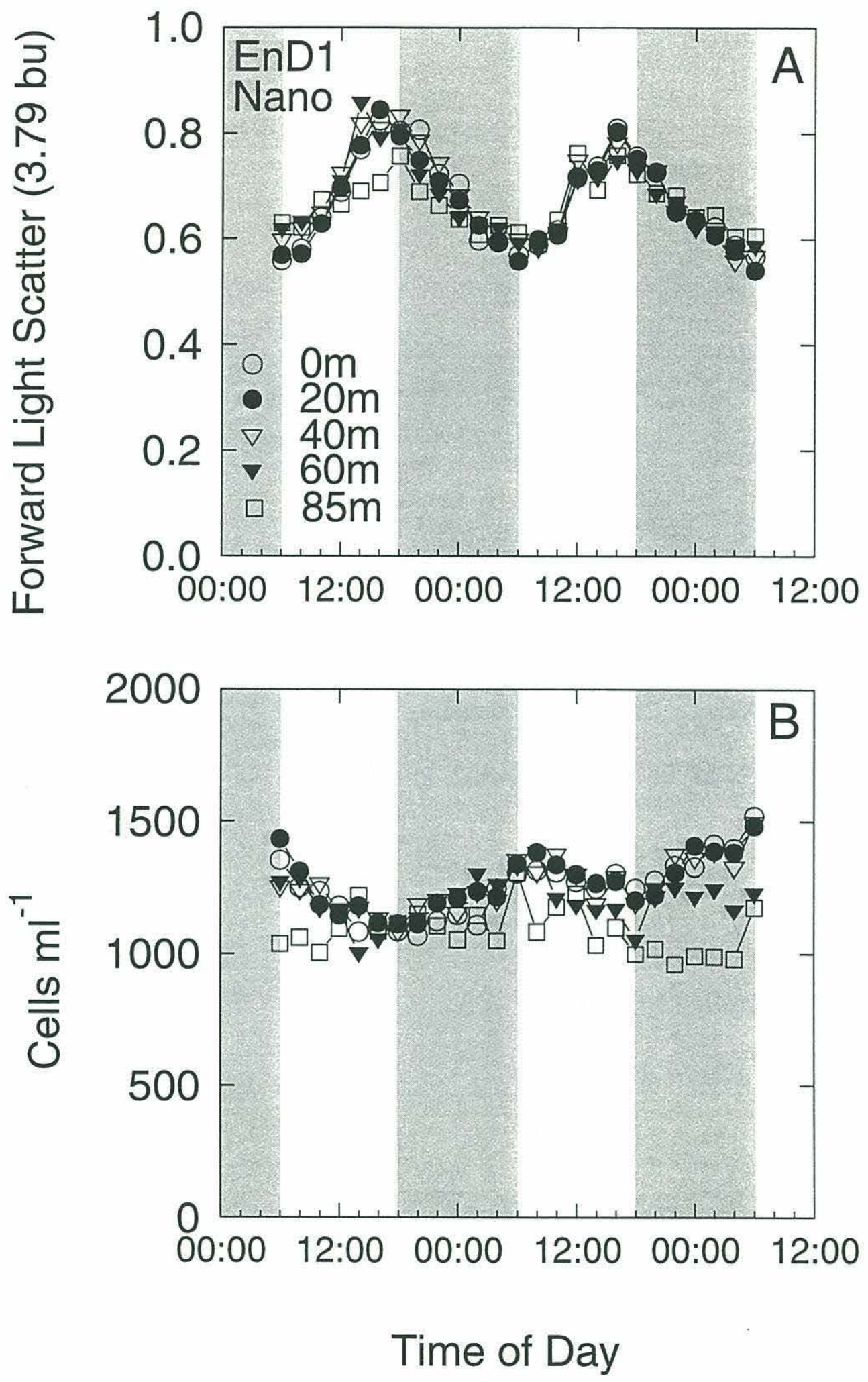
Fig. 6. Time series of nanophytoplankton A) forward light scatter (relative to $3.79 \mu \mathrm{m}$ bead) and B) cell concentration, and coccolithophore C) forward light scatter and D) cell concentration during a 28-hour diel sampling experiment in January 1992 in the Sargasso Sea at $35^{\circ} \mathrm{N} 68^{\circ} \mathrm{W}$ (R.V. Endeavor, EnD2). 


\section{EnD2}

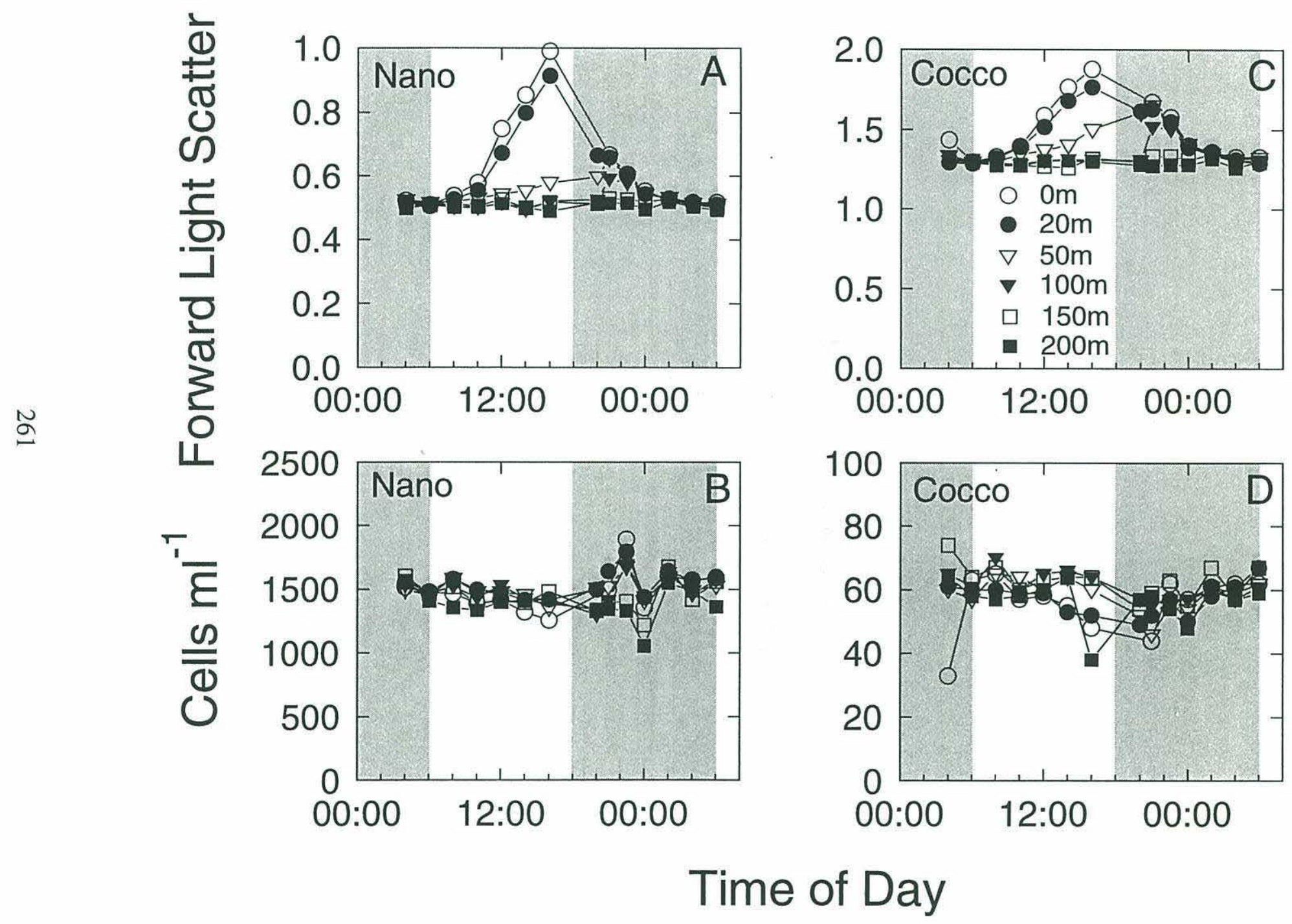


Fig. 7. Time series of nanophytoplankton A) forward light scatter (relative to $3.79 \mu \mathrm{m}$ bead) and B) cell concentration during a 48-hour diel sampling experiment in May 1994 in the Sargasso Sea at $35^{\circ} \mathrm{N} 71^{\circ} \mathrm{W}$ (R.V. Cape Hatteras, Hat). 

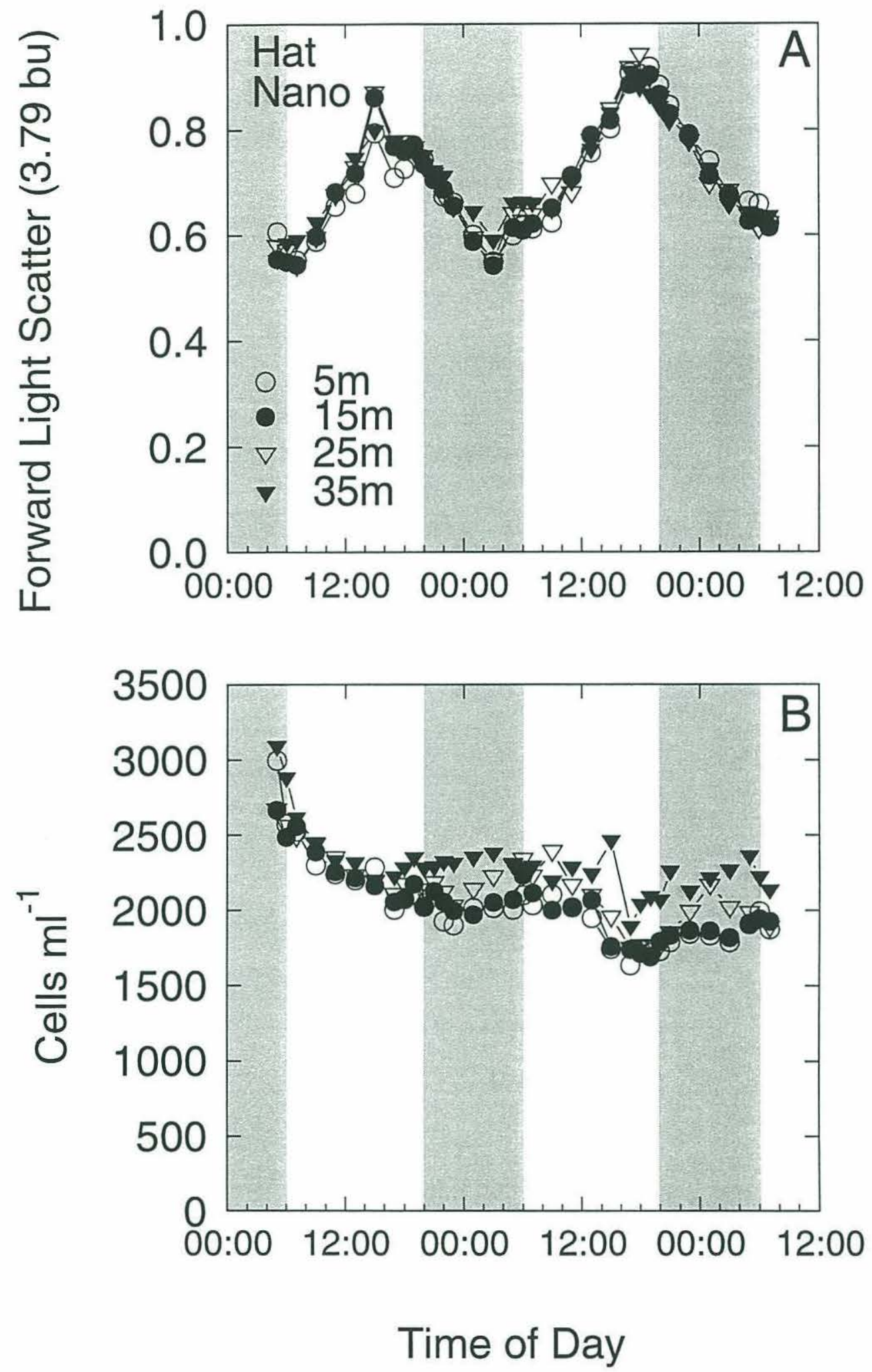